Reiner Anselm, Jan Hermelink ( $\mathrm{Hg}$.)

\title{
Der Dritte Weg auf dem Prüfstand
}

Theologische, rechtliche und ethische

Perspektiven des Ideals der Dienstgemeinschaft

in der Diakonie

6. Kästorfer Management-Symposium

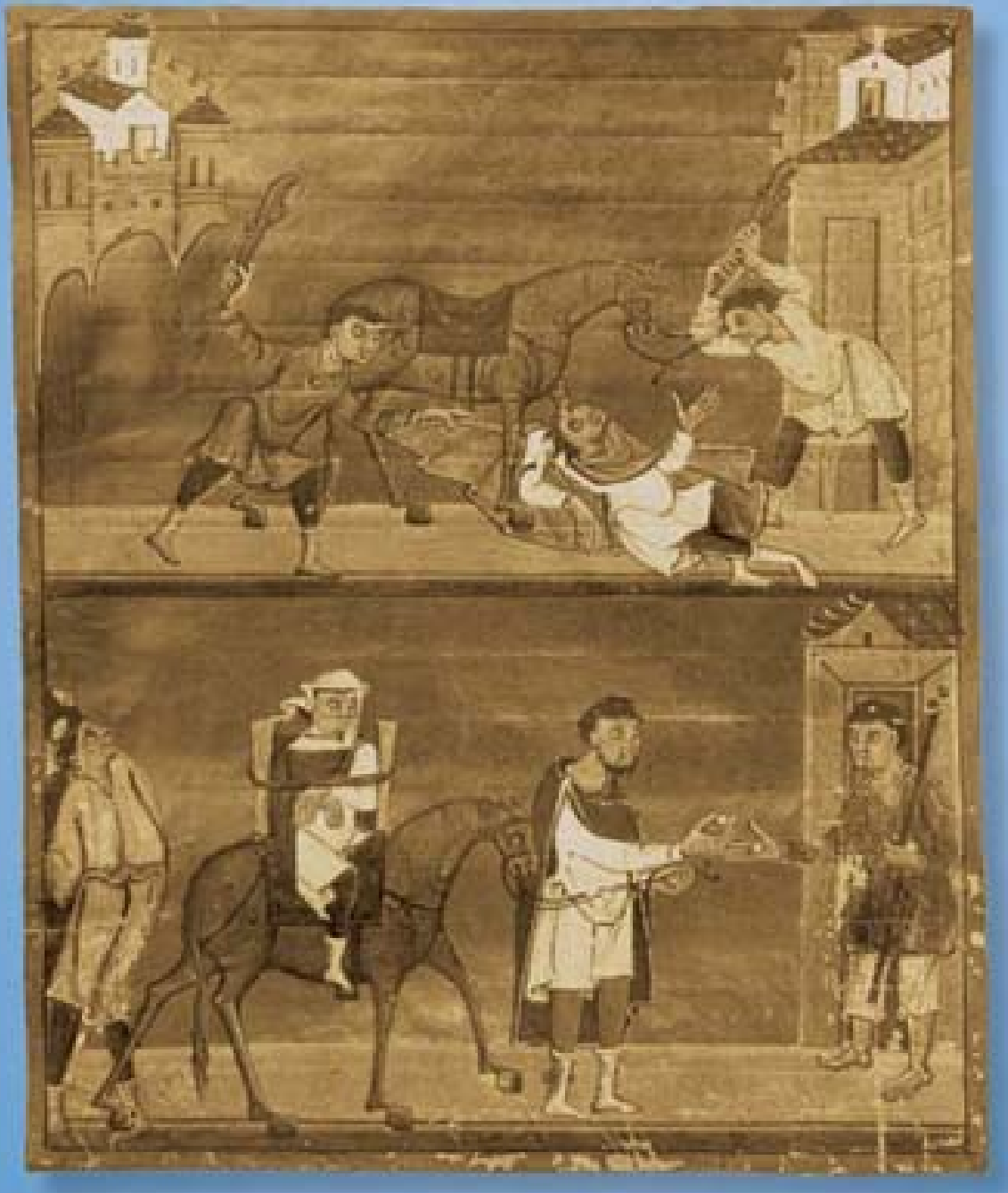



Reiner Anselm, Jan Hermelink (Hg.)

Der Dritte Weg auf dem Prüfstand

This work is licensed under the Creative Commons License 2.0 "by-nd", allowing you to download, distribute and print the document in a few copies for private or educational use, given that the document stays unchanged and the creator is mentioned.

You are not allowed to sell copies of the free version.

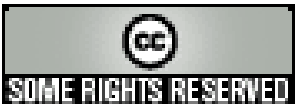


erschienen im Universitätsverlag Göttingen 2006 
Reiner Anselm, Jan Hermelink (Hg.)

\section{Der Dritte Weg auf dem Prüfstand}

Theologische, rechtliche und ethische Perspektiven des Ideals der Dienstgemeinschaft in der Diakonie

6. Kästorfer ManagementSymposium

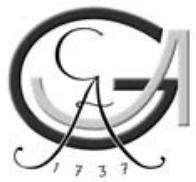

Universitätsverlag Göttingen 2006 
Bibliographische Information der Deutschen Nationalbibliothek

Die Deutsche Nationalbibliothek verzeichnet diese Publikation in der

Deutschen Nationalbibliographie; detaillierte bibliographische Daten sind im Internet über < http://dnb.ddb.de> abrufbar

Mit freundlicher Förderung von:

\section{क्षKästorf}

DIAKONISCHE HEIME IN KÄSTORF E.V.

Dieses Buch ist auch als freie Onlineversion über die Homepage des Verlags sowie über den OPAC der Niedersächsischen Staats- und Universitätsbibliothek (http://www.sub.uni-goettingen.de) erreichbar und darf gelesen, heruntergeladen sowie als Privatkopie ausgedruckt werden. Es ist nicht gestattet, Kopien oder gedruckte Fassungen der freien Onlineversion zu veräußern.

Umschlagabbildung: Gleichnis vom barmherzigen Samariter, Perikopenbuch, um 10201040, Reichenau, München, Bayerische Staatsbibliothek, Cod.lat. 23338. Bildarchiv Foto Marburg, Biegenstraße 11, D-35037 Marburg

Umschlaggestaltung: Kilian Klapp

(C) Universitätsverlag Göttingen 2006

http:/ / univerlag.sub.uni-goettingen.de

ISBN-10: 3-938616-56-3

ISBN-13: 978-3-938616-56-7 


\section{Inhalt}

HANS-PETER HOPPE

Geleitwort.

REINER ANSELM, JAN HERMELINK, STEPHAN SCHLEISSING

Zur Einführung. . .9

\section{Der kirchliche Dienst in der Kirchentheorie}

JAN HERMELINK

Kirche als Diakonie - Diakonie als Kirche... .17

HANS-RICHARD REUTER

Kirchenspezifische Anforderungen an die privatrechtliche berufliche

Mitarbeit in der Evangelischen Kirche und ihrer Diakonie. .33

\section{Der „Dritte Weg“ im Arbeitsrecht}

\section{REINHARD RICHARDI}

Arbeitsrecht in der Diakonie.

ULRICH HAMMER

Dritter Weg und Tarifvertrag - Gegensatz oder notwendige Ergänzung?. .79 


\section{Was heißt Solidarität in der „Dienstgemeinschaft“?}

MANFred Freyermuth, Peter FÜNDELING, LOTHAR STEMPIN

Perspektiven aus der Praxis

KLAUS TANNER

Wem diene ich, wenn ich diene?

Zum Verhältnis von Individualismus und Dienstgemeinschaft 117

IV. Unternehmenskultur und Ethik in der Diakonie

GÜNTHER SCHANZ

Unternehmen als Wertegemeinschaften

REINER ANSELM

Konflikt und Konsens.

Ethische Aspekte zur Auseinandersetzung um den „Dritten Weg““ .143

Hinweise zu den Autoren 
Hans-Peter Hoppe

\section{Geleitwort}

Die Symposien in den Diakonischen Heimen Kästorf haben in der Vergangenheit immer wieder versucht, theologische Fragestellungen der Diakonie mit Erkenntnissen der Wirtschaftswissenschaften zu konfrontieren. Ausgewiesene Fachleute aus Theorie und Praxis haben dabei nicht den Vorrang der einen Wissenschaft gegenüber der anderen festgestellt, sondern das in der Wissenschaftsgeschichte so oft erfolgreiche Ineinandergreifen der aus den unterschiedlichen Perspektiven gewonnenen Erkenntnisse dargestellt. Dabei stand für alle Beteiligten immer das Interesse der Menschen im Mittelpunkt, die sich der Hilfe einer diakonischen Einrichtung versichern wollen.

Die Ergebnisse des 6. Kästorfer Management-Symposiums, die in diesem Band vorgestellt werden, weisen auf eine neue Perspektive hin. Etwa eine halbe Million Menschen arbeiten in mehr als 27.000 Einrichtungen in der Diakonie in Deutschland. Wesentliche Maschen unseres sozialen Netzes werden von Ihnen geknüpft, der Beitrag der Diakonie für den Sozialstaat Deutschland ist unersetzlich. Die für die Diakonie unentbehrliche Ressource „Menschlichkeit“ wird gespeist durch die Menschen, die sich dem besonderen christlichen Anspruch in der Diakonie verpflichtet fühlen.

Daraus abgeleitet ergibt sich auch ein besonderer arbeitsrechtlicher Rahmen - in der Vergangenheit manchmal undifferenziert mit dem Begriff „Dienstgemeinschaft“ bezeichnet -, den es neu zu füllen gilt. Der so genannte „Dritte Weg“, der in der Verfassung der Kirche garantierte Weg der Arbeitsrechtsgestaltung der Kirchen, und eben die Zugehörigkeit zur 
Kirche erfordert ein besonderes Verhältnis zwischen Arbeitgebern und Arbeitnehmern. Denn nach diakonischem Verständnis ist der Auftraggeber jeder diakonischen Dienstleistung Jesus Christus selbst, dessen Gegenwart sich in dem Hilfebedürftigen manifestiert. Alle Mitarbeiter und Mitarbeiterinnen, alle Hierarchieebenen sind gleichermaßen beteiligt, diesen Auftrag zu erfüllen.

Diesem besonderen Umstand Rechnung zu tragen, ohne in die dienstherrlichen Verhaltensweisen der Vergangenheit zurückzufallen, ist eine Herausforderung, der sich diakonische Arbeitgeber genauso wie die diakonischen Arbeitnehmer zu stellen haben. Wie sie mit dieser Herausforderung umgehen, wird durchaus misstrauisch von den Repräsentanten des „Zweiten Weges“ - hier besonders von den Gewerkschaften - beobachtet.

Die Besonderheiten und Fallgruben in der Verfolgung des „dritten Weges“ zu erkennen und zu benennen, war die Aufgabe des Symposiums. Die hier gesammelten Beiträge geben aus unterschiedlichen Perspektiven Hilfestellung für alle, die sich mit dem Thema auseinandersetzen wollen und geben Erläuterungen denen, die bisher aus kritischer Distanz sich kein fundiertes Urteil bilden konnten. 
Reiner Anselm, Jan Hermelink, Stephan Schleissing

\section{Zur Einführung}

Seit Mitte der 1970er Jahre gehen die Evangelischen Kirchen und die Diakonie in Deutschland bei der Gestaltung ihres Arbeitsrechtes einen eigenen, immer wieder diskutierten und kritisierten Weg. Die Arbeitsverhältnisse der Mitarbeiterinnen und Mitarbeiter werden seither nicht mehr einseitig, durch Beschlüsse kirchlicher oder diakonischer Leitungsorgane geregelt, sie folgen aber auch nicht dem allgemeinen Tarifrecht, sondern realisieren einen sog. „Dritten Weg“. Die Landeskirchen wie auch die meisten diakonischen Einrichtungen greifen dabei auf einen seitens der Evangelischen Kirche in Deutschland (EKD) 1976 vorgelegten Musterentwurf eines Arbeitsrechts-Regelungsgesetzes (ARRG) zurück. Kernstück dieses Gesetzes ist die Bildung von sog. Arbeitsrechtlichen Kommissionen, die paritätisch aus Vertretern der Mitarbeitenden im Kirchlichen Dienst einerseits und Vertretern kirchlicher und diakonischer Anstellungsträger andererseits gebildet werden.

Dieser „Dritte Weg“ ist juristisch durch das verfassungsmäßig verbriefte kirchliche Selbstbestimmungsrecht ermöglicht; theologisch wird er begründet durch das Leitbild einer Kirche, die sich als christliche Dienstgemeinschaft versteht: Aufgaben und Interessenvertretung aller kirchlichen Mitarbeitenden sind so zu gestalten, dass ein Konsens unabhängig von der jeweiligen arbeitsrechtlichen Stellung des Einzelnen als Folge des christlichen Dienstgedankens möglich ist. Im Hintergrund 
steht ein theologisches Konzept, das seinen maßgeblichen Ausdruck in der 1934 verfassten Barmer Theologischen Erklärung gefunden hat. Dort heißt es in der vierten These: „'Ihr wisset, daß die weltlichen Fürsten herrschen, und die Oberherren haben Gewalt. So soll es nicht sein unter euch; sondern so jemand will unter euch gewaltig sein, der sei eurer Diener' (Mt 20, 25.26). Die verschiedenen Ämter in der Kirche begründen keine Herrschaft der einen über die anderen, sondern die Ausübung des der ganzen Gemeinde anvertrauten und befohlenen Dienstes."

Die Frage, wieweit dieses Leitbild einer „Dienstgemeinschaft“ heute noch tragfähig für die Gestaltung kirchlicher Arbeitsverhältnisse zu sein vermag, wird gegenwärtig wieder besonders kontrovers diskutiert. Unmittelbarer Anlass für die neuerliche Debatten um den „Dritten Weg“, insbesondere innerhalb der Diakonie, sind vor allem veränderte ökonomische Rahmenbedingungen, dazu die erhöhten Erwartungen der Mitarbeitenden an das Management von Sozialunternehmen bzw. die Gestaltung einer zukunftsgerechten Personalentwicklung. Seit der Entstehung eines Pflege- und Gesundheitsmarktes steigt der Kostendruck in der Diakonie. In dieser Situation stehen sich kirchliche Mitarbeitende als Arbeitnehmer und als Arbeitgeber gegenüber. Beide Seiten sehen sich aufgefordert, bei der Verteilung von knapper werdenden Finanzmitteln und Beschäftigungschancen gerecht und effizient zugleich zu handeln. Dabei gerät das Leitbild der „Dienstgemeinschaft“ zunehmend unter Praxisdruck: Kann das Paritätsprinzip im kirchlichen Arbeitsrecht auch dann für Akzeptanz sorgen, wenn Interessensgegensätze nicht vollständig ausgeglichen werden können? Kann man Personalkosten im Konsens senken - oder benötigt der Dritte Weg ein gewisses $\mathrm{Maß}$ an Prosperität?

Mit dem „Dritten Weg“ stehen auch die Kirchen selbst als Arbeitgeber auf dem Prüfstand. Damit geraten die arbeitsrechtlichen Regelungen in einen erweiterten Horizont. In der Diskussion zu kurz gekommen ist nämlich bisher eine theologische Klärung der Frage, wie das Leitbild der „Dienstgemeinschaft“ in einer modernen, pluralistischen Gesellschaft überhaupt auf Organisationen zu übertragen ist. Angesichts ökonomischer Verteilungskonflikte, Veränderungen des diakonischen Berufsethos und nachhaltigen Betreuungserfordernissen hilfesuchender Menschen stellt sich die Frage, wie Diakonie nicht nur organisierbar, sondern im christlichen Sinne auch lebbar ist.

Diesen Aspekten eines kirchlich-theologischen Selbstverständnisses der Diakonie widmet sich der vorliegende Sammelband, der auf eine gemeinsam verantwortete Tagung der Lehrstühle für Praktische Theologie und Ethik der Universität Göttingen und der Diakonischen Heime in Kästorf e.V. zurückgeht: Zahlreiche hier versammelte Beiträge standen vom 29. bis 30. September 2005 auf dem 6. Kästorfer Management-Symposium zur Diskussion; im vorliegenden Sammelband werden sie durch 
aktuelle Einzelstudien weiterer Autoren ergänzt.* Alle Beiträge widmen sich, aus unterschiedlichen Perspektiven, dem zentralen Problem der empirischen Transformation eines theologischen Leitgedankens in die Wirklichkeit gelebter Arbeitsverhältnisse.

In einem ersten Abschnitt wird dieser Aspekt zunächst in kirchentheoretischer Hinsicht zum Thema. Jan Hermelink, Praktischer Theologe in Göttingen, widmet sich in seinem Eingangsbeitrag der Frage, inwieweit gegenwärtige Einsichten über den Zusammenhang von Theologie und empirischer Wirklichkeit der verfassten Kirche auch für die Diakonie von Bedeutung sind. Er interpretiert die aktuell vor allem als Krise akzentuierte Selbstbeschreibung der Kirche zugleich als Chance einer theologischen Selbstklärung ihres institutionellen Profils. Das betrifft sowohl den Umgang mit den Mitarbeitenden in der Diakonie als auch mit den von ihnen betreuten Menschen. Wenn Kirche mehr sein will als eine bloße Organisation sozialer Arbeit, dann stellt sich hier vor allem die Frage, wie im Umgang mit Personen erfahrbar wird, dass der Sinn der Kirche in der Darstellung des Glaubens besteht. In dieser Perspektive plädiert Hermelink für ein Leitungsverständnis, das die theologisch zu beschreibende Differenz von Glaubens- und Handlungsgemeinschaft so in die diakonische Praxis übersetzt, dass damit den Erwartungen persönlich hilfreicher Zuwendung sowohl in der Qualität sozialen Engagements als auch in einprägsamen liturgischen und homiletischen Vollzügen entsprochen werden kann. Dann kann sich diakonische Leitungskompetenz aber nicht in Managementfähigkeiten erschöpfen, sondern ist angewiesen auf eine theologische Reflexion, die die Darstellung des Glaubens im Handeln am Ort individueller Praxis erkennbar macht: „Auch in der organisierten Diakonie sind Mitarbeitende und Betreute zuerst und zuletzt wahrzunehmen als Mitglieder der Kirche: als potenziell Hörende, selbständig Fragende und so auch als unverfügbar - Glaubende."

Inwiefern aus der Zugehörigkeit von beruflich Mitarbeitenden in Kirche und Diakonie spezifische Loyalitätserfordernisse erwachsen, ist das Thema eines theologischen Gutachtens zu einer „Loyalitätsrichtlinie“, das der Münsteraner Sozialethiker Hans-Richard Reuter im Auftrag des Rates der EKD im Frühjahr 2005 vorgelegt hat. Seine hier dokumentierten Überlegungen und Änderungsvorschläge zum bis dato bestehenden EKD-Entwurf sind im Wesentlichen in die LoyalitätsRichtlinie eingegangen, die der Rat der EKD dann am 1. Juli 2005 verabschiedet hat. Thema seines Beitrags sind vor allem Aspekte persönlicher oder verhal-

\footnotetext{
* Die Veranstaltung fand im Rahmen des neuen Master-Weiterbildungsstudiengangs „Führungskompetenz in theologischer Sicht" der Göttinger Theologischen Fakultät statt und wurde von dessen wissenschaftlichem Koordinator, Stephan Schleissing, organisiert. Das theologische Profil dieses neuen Qualifizierungsangebots für leitende Mitarbeiterinnen und Mitarbeiter in Diakonie und Kirche wird durch die hier abgedruckten Beiträge der verantwortlichen Initiatoren, Reiner Anselm und Jan Hermelink, markiert. Ausführliche Informationen zum Master-Weiterbildungsstudiengang „Führungskompetenz in theologischer Sicht" finden sich im Internet unter www.theologie.unigoettingen.de/weiterbildung.
} 
tensbezogener Erwartungen wie etwa die Kirchenmitgliedschaft, die Identifikation mit dem kirchlichen Auftrag oder die Anerkennung konfessioneller Prägung kirchlicher Arbeit als Bestandteil eines privatrechtlichen Arbeitsverhältnisses in der evangelischen Kirche und den ihr zugeordneten Einrichtungen und Werken. Im Mittelpunkt seiner Studien steht die Frage, wie der theologische Begriff der „Dienstgemeinschaft“ so auf die Realität von Arbeitsverhältnissen bezogen werden kann, dass er der Vielfalt sowohl der Professionalisierungsanforderungen, als auch der Konfessionen von Mitarbeitenden gerecht wird. In theologischer Sicht kommt es hier vor allem darauf an, das Verständnis von „Zeugnis“ und „Dienst“ in der protestantischen Dialektik von Freiheit und Bekenntnis erkennbar werden zu lassen. Reuter macht deutlich, dass die Initiative zu einer Vereinheitlichung der kirchenspezifischen Berufsanforderungen vor allem durch die deutsche und europäische Rechtsentwicklung gegeben ist. Will man Kirche als Institution innerhalb einer arbeitsteiligen und pluralistischen Gesellschaft (und nicht gegen sie) weiterentwickeln, dann muss diese sich als „offene Kirche“ auch für Nicht-Christen verstehen. Dem entsprechen aber am besten kirchliche Arbeits- und Dienstvertragsordnungen, die an einem mitgliedschaftsbezogenen Regel-Ausnahme-Modell orientiert sind und erforderliche Loyalitätsobliegenheiten nach einem konfessionellen Abstufungsmodell gestalten, das die jeweilige Tätigkeitsart stärker in Rechnung stellt. Nicht nur aus pragmatischen, sondern auch aus theologischen Gründen wäre eine Orientierung diakonischen Handelns allein an der Verkündigung als Zentrum jeder Mitarbeit in Kirche und Diakonie eine Engführung. Wie schon Hermelink hebt auch Reuter die strikt theologische Bestimmung der Idee der Dienstgemeinschaft als Konsequenz des Kirche konstituierende Grundsatzes des allgemeinen Priestertums der Gläubigen hervor. Dieser Differenz von Glauben und Handeln haben Kirche und Diakonie als Organisationen so zu entsprechen, dass sie kirchliche Gemeinschaft am Ort des Mitarbeiters als „Dienst der Freiheit“ aktualisieren.

Die folgenden beiden Beiträge fokussieren, gleichsam im Gegenüber, auf primär juristische Fragen zur Rolle des „Dritten Wegs“ im Arbeitsrecht der Diakonie. Der Regensburger Arbeitsrechtler Reinhard Richardi konstatiert, dass die Entgegensetzung zwischen einem kirchlichem und einem „weltlichen“ Arbeitsrecht eine Scheinalternative ist. Denn ,bei einer Zuordnung zur Kirche ergibt sich aus dem ,weltlichen Arbeitsrecht', dass kirchliches Recht anzuwenden ist." Freilich kommt das verfassungsrechtlich verbürgte Selbstbestimmungsrecht nicht direkt der diakonischen Einrichtung zu, sondern ist ein Recht der Religionsgesellschaft. Darum führen auch Ausgründungen einzelner Servicebereiche in GmbHs, wie dies aus Wettbewerbsgründen als lohnend erscheinen mag, nicht zu der Einschränkung der rechtlichen Folgen, wie sie das Arbeitsrecht des „Dritten Wegs“" vorsieht. Richardi hebt hervor, dass die aktuellen Probleme in der Diakonie, wie sie vor allem anhand einer Revision der Lohnfestsetzung diskutiert werden, im Kern kein Problem des „Dritten Wegs“, sondern der ökonomisch- 
sozialen Vernunft in den jeweiligen Arbeitsrechtlichen Kommissionen sind, deren Partizipationsprinzip sich angesichts der ökonomischen Lage zu bewähren hat.

Dass der „Dritte Weg“ nicht notwendig in einer Abkehr vom allgemeinen Tarifvertragsrecht ausgestaltet werden muss, ist die Kernaussage von Ulrich Hammers Beitrag, der in Hildesheim Verfassungs-, Arbeits- und Sozialrecht lehrt. Nach seiner Darstellung stellt das Beharren auf einem eigenen kirchlichen Arbeitsrecht ein „permanentes Paradoxon“ dar, das beide großen Kirchen in Deutschland angesichts der gesellschaftlichen Verhältnisse nicht nur in Erklärungsnot bringt, sondern aufgrund aktueller Wettbewerbserfordernisse auch dazu führt, das Qualitätsniveau kirchlicher Einrichtungen dauerhaft abzusenken. In seiner Kritik am „Dritten Weg“ hebt Hammer hervor, dass dessen Charakter als Einzelvertragsrecht einseitig die Arbeitnehmerrechte schwächt, zumal in den Arbeitsrechtlichen Kommissionen höchstens von einer numerischen, nicht aber von einer materialen Parität die Rede sein kann. Deshalb stellt nach Hammer die Annäherung kirchlicher Arbeitsvertragsverordnungen an das Tarifvertragsrecht „eine unabdingbare betriebwirtschaftliche Notwendigkeit dar.“ Aber auch die das kirchliche Arbeitsrecht konstituierende Gemeinschaftsidee könne auf dem Weg tarifvertraglicher Interessensregelung wirklichkeitsgerechter gestaltet werden als über eine alleinige Orientierung am Verfahrensmodus Arbeitsrechtlicher Kommissionen. Weil Hammer in der Trennung von kirchlichem und staatlichem Rechtskreis keine Bereichs-, sondern lediglich eine Funktionstrennung erblickt, erscheint deshalb ein integriertes Tarif- und Kommissionsmodell, dessen Grundlagen Hammer abschließend skizziert, sehr wohl möglich. Seine Umsetzung durch die Kirchen würde dokumentieren, „dass die Kirchen die Anerkennung der Gewerkschaften als unverzichtbare gesellschaftliche Kraft" nicht nur im Gemeinsamen Sozialwort der Kirchen (1997) für die Allgemeinheit fordern, sondern auch für ihre eigene arbeitsrechtliche Praxis anerkennen.

Der Begriff der „Dienstgemeinschaft“ ist mehr als ein arbeitsrechtlicher Terminus - eben darum kann er die Brücke schlagen zwischen einem theologischen und einem rechtlich-institutionellen Verständnis von Kirche. Weil „Dienstgemeinschaft" jedoch primär ein Begriff sozialer Verhältnisse ist, hängt seine Plausibilität vornehmlich an einer Wirklichkeit kirchlich-diakonischer Arbeitsbeziehungen, deren christlicher Gemeinschaftscharakter auch erfahrbar sein muss. Aus der Sicht unterschiedlicher Praxisperspektiven in kirchlichen Leitungsorganen und Einrichtungen in Niedersachsen diskutieren Manfred Freyermuth, Peter Fündeling und Lothar Stempin die Frage, inwiefern die Rede von einer „Dienstgemeinschaft“ als Ausdruck des kirchlichen Propriums diakonischer Arbeit noch geeignet ist, aktuelle Konflikte bei der Gestaltung von Arbeitsverhältnissen zu moderieren. Dabei zeigt sich u.a., dass die Frage nach der Ersetzung des Begriffs der „Dienstgemeinschaft" durch die gesellschaftlich eingeübte Formel der „Solidarität“ nicht einfach nur ein Streit um Worte ist, sondern in das Zentrum des Problems christlicher Identität diakonischen Handelns führt. Konkret: Ist 
jener Rechtsbegriff durch die tatsächliche Gestaltung der Arbeitsverhältnisse in einem inhaltlichen Sinn noch gefüllt? Oder verschleiert der Begriff die realen Konflikte, weil die unterschiedlichen Interessen nicht mehr als Ausdruck eines christlichen Dienstes der Gemeinschaft oder an der Gemeinschaft verstanden werden können?

Dass der Schlüsselbegriff „Dienst“ im Christentum der Neuzeit eine durchaus ambivalente Tradition hat, macht der Hallenser Systematiker Klaus Tanner deutlich, wenn er an die Diskrepanz zwischen einer hohen normativen Aufladung von „Dienstgemeinschaft“ einerseits und ihrer gelebten institutionell-rechtlichen Gestalt andererseits erinnert. In der Realität sozialer Beziehungen kann das christliche Ideal nicht romantisierend von den vorfindlichen Machtbeziehungen abstrahieren, soll der Begriff nicht zur Hohlformel degenerieren. Darum formuliert Tanner es als zentrale theologische Aufgabe eines „christlichen Ethos des Dienens“, die beiden Seiten des lutherischen Freiheitsverständnisses - Freiheit und Dienen - unter veränderten Arbeits- und Sozialbeziehungen heute wieder in ihrem Zusammenhang zur Geltung zu bringen. Die Bereitschaft zum Dienst als Gestaltung von Freiheit hat darauf zu achten, dass die individuelle Selbstbindung, wie sie im christlichen Dienstgedanken ihren Ausdruck findet, als freiwillige Zustimmung möglich wird. Das erfordert in der Diakonie ein rechtes Maß zwischen der Schaffung von Wettbewerbschancen und der institutionellen Förderung von Vertrauen als Voraussetzung freiwilliger Dienstbereitschaft.

Dieser Zusammenhang von effektiven Strukturen und einer Kultur des Vertrauens wird auch in den betriebswirtschaftlichen Überlegungen deutlich, die der Göttinger Betriebswirtschaftler Günther Schanz zur Frage anstellt, ob Unternehmen als Wertegemeinschaften verstanden werden können. Schanz nimmt seinen Ausgangspunkt nicht bei der Diakonie, sondern bei profitorientierten Unternehmen und zeigt, dass Werten innerhalb der Unternehmensorganisation eine nicht $\mathrm{zu}$ unterschätzende Koordinationsfunktion zukommt. Dabei unterscheiden sich „starke“ von „schwachen“ Kulturen durch eine deutlichere Prägnanz und Homogenität ihrer Unternehmenskultur, wobei die Folgen dieser „Stärke“ durchaus auch desintegrierende Wirkungen zeitigen können. Überträgt man seine Kategorien auf die Frage der Gestaltbarkeit einer Unternehmenskultur in diakonischen Organisationen, dann stellt sich im Anschluss an die vorangegangenen Beiträge z.B. die Frage, wieviel individuelle Meinungs- und Glaubensvielfalt mit der derzeit wieder verstärkt geforderten Homogenisierung von Werthaltungen in der Diakonie vereinbar ist.

Aus der Sicht protestantischer Ethik und ihrer Geschichte läßt sich zumindest ein entscheidender Vorteil „schwacher“ Kulturen deutlich machen: ihre Fähigkeit, zwischen Ideal und Wirklichkeit, christlichem Liebesgedanken und seiner rechtlich-sozialen Gestaltung einen Kompromiss finden zu können. In seinem Schlussbeitrag führt der Göttinger Sozialethiker Reiner Anselm aus, dass diese Fähigkeit zur Kompromissbildung des christlichen Ethos als Voraussetzung jeder 
erstrebten Konsensfindung anzusehen ist, weil sie diese als begrenzten und darum immer wieder aushandelbaren Konsens anerkennungsfähig macht. Zugleich stellt er heraus, dass das Fortbestehen einer derartigen christlichen Kompromisskultur auf Leiterzählungen angewiesen bleibt, deren Vitalität davon abhängt, dass sie immer wieder erneuert und so durch ihre Mitglieder weitergeschrieben werden. In dieser Perspektive schlägt Anselm vor, die Dienst-Metaphorik nicht in Abgrenzung zum ökonomischen Sprachgebrauch zu profilieren, sondern nach gemeinsamen Sinnebenen zu fragen, wie sie z.B. im Begriff der „Dienstleistung“ auch sprachlich vorliegen und einer christlichen Reinterpretation offenstehen. Insofern käme es darauf an, einen gegenüber profitorientierten Unternehmen einzuschlagenden „Dritten Weg“ nicht nur auf der Ebene des Arbeitsrechts, sondern in der gesamten Organisationskultur von Kirche und Diakonie als Wesensmerkmal des Protestantismus weiterzuentwickeln.

Die Herausgeber danken allen Autoren, dass sie ihre Beiträge für den vorliegenden Sammelband bereitwillig zur Verfügung gestellt haben. Besonders hervorheben möchten wir die gute Zusammenarbeit mit dem Kästorfer Management-Symposium, das unter der Regie des Vorstandes der Diakonischen Heime in Kästorf e.V., Herrn Hans-Peter Hoppe, ein exzellentes Forum für eine qualifizierte und durchaus kontroverse Diskussion der hier versammelten Positionen darstellte. Danken möchten wir auch Frau stud. theol. Anne-Kathrin Lück, die zusammen mit Herrn Stephan Schleissing die Redaktion der Beiträge höchst zuverlässig betreut hat. Schließlich sei Frau Margo Bargheer und Frau Dr. Birgit Schmidt vom Göttinger Universitätsverlag für die gute Zusammenarbeit bei der Drucklegung dieses Bandes gedankt. 

Jan Hermelink

\title{
Diakonie als Kirche - Kirche als Diakonie Kirchentheoretische Fragen an die diakonische Führungskompetenz ${ }^{*}$
}

\begin{abstract}
„Diakonie als Kirche - Kirche als Diakonie“ - der Titel des Eingangsreferats markiert Hoffnungen, aber auch Enttäuschungen der diakonischen Arbeit in den letzten Jahrzehnten, auch und erst recht in der Gegenwart. Ich konzentriere mich auf die aktuelle Situation.

„Wir sind Kirche“ - so betont das Leitbild des Diakonischen Werkes der EKD von 1997. ${ }^{1}$ Und weiter heißt es: „Diakonie heißt erkennen: Die Kirche lebt!“ was offenbar nicht selbstverständlich ist. Alfred Jäger propagiert seit Jahren die Formel „Diakonie ist eine eigenständige Gestalt der Kirche“ - nicht allein eine sekundäre „Lebensäußerung“ der verfassten kirchlichen Institution, sondern deren gleichrangiges, geschwisterliches Gegenüber. ${ }^{2}$ Diakonie ist Kirche: Das soll Emanzipation und Selbstbewusstsein signalisieren.
\end{abstract}

\footnotetext{
* Vortrag auf dem Symposion in Kästorf (29. September 2005) „Diakonie im Ausverkauf? Der Dritte Weg auf dem Prüfstand“.

1 Diakonisches Werk der EKD (Hg.), Leitbild Diakonie - damit Leben gelingt, Stuttgart 1997, Leitsatz 7, und Erläuterungen.

2 Alfred Jäger, Diakonie als eigenständige Gestalt von Kirche, in: WzM 49 (1997), 340-353.
} 
Diakonie ist Kirche: Damit wird, im Kontext der gegenwärtigen Umbrüche, zudem eine spezifische Ressource der diakonischen Arbeit betont: Kirchlich geprägte Unternehmen unterscheiden sich von anderen Anbietern auf dem Markt sozialer Dienstleistungen; die Unternehmen der Diakonie sind charakterisiert durch spezifische Werte, spezifische Sinngebungen, die sich mit dem Bild von Kirche verbinden, und die ihnen - so wird angenommen - einen Wettbewerbsoder Marktvorteil, genauer: einen Marken-Vorteil verschaffen könnten. Diakonie als Kirche - das könnte eine Ressource diakonischen Handelns sein.

Diakonie als Kirche: Das ist aber auch eine Quelle nachhaltigen Ressentiments. Die Betonung der Kirchlichkeit von Diakonie verbindet sich mit vielfältigen Erfahrungen von Misstrauen und Kontrolle: Sind die diakonischen Mitarbeiter auch in der Kirche? Oder müssen sie nicht wenigstens zum Eintritt aufgefordert werden? Gibt es eine Art geistlicher Aufsicht durch die „,verfasste Kirche“ - und was hat diese Aufsicht in der Diakonie bewirkt - oder verhindert? Muss das diakonische Unternehmen immer durch einen Pfarrer geleitet werden - auch wenn er ein ökonomischer Laie ist? Muss sich Diakonie kirchlich legitimieren - und wem gegenüber? Ihnen allen sind die vielen Enttäuschungen, die Blockaden, auch die Kränkungen vertraut, die sich mit diesem Thema verbinden.

Diakonie als Kirche: Damit verbindet sich heute nicht selten die Sorge, die Diakonie könnte sich damit an ein sinkendes Schiff gebunden haben. Die Kirche wird kleiner, sie verliert an Mitgliedern und an öffentlicher Aufmerksamkeit. Was wird dann aus einem sozialen Handeln, das sich ausdrücklich als eine „Gestalt von Kirche“ bezeichnet? Droht der Diakonie, wenn sie ausdrücklich als Kirche firmiert, allmähliche Randständigkeit, Irrelevanz, am Ende gar Spott?

Und noch konkreter: Droht nicht die ökonomische Lähmung, der Konkurs, wenn diakonische Unternehmen sich weiterhin an das Arbeitsrecht, speziell die Tarifgestaltung der Kirche binden? Diakonie ist Kirche - ist diese Devise noch bezahlbar? Oder wird aus der Ressource der kirchlichen Bindung ein unkalkulierbares Risiko?

Diakonie ist Kirche: In diesem Satz bündeln sich viele Probleme gegenwärtiger diakonischer Arbeit - aber auch, so möchte ich behaupten, nicht wenige Chancen. Einige dieser Chancen möchte ich im Folgenden aufzeigen - und zwar aus der Perspektive der praktisch-theologischen Kirchentheorie, der „Kybernetik“. Diese Disziplin ist in den letzten zwei Jahrzehnten neu aufgeblüht, weil sich die Kirche sehr gewandelt hat - zuletzt unter ökonomischem Druck, aber auch schon lange zuvor durch soziale und auch politische Kräfte. Wer praktisch-theologisch nach der Kirche fragt, wird daher heutzutage sehr vielfältige, auch überraschende Antworten bekommen - Antworten aus der unmittelbaren Erfahrung, aus der Theologie, aber auch aus den Sozialwissenschaften.

Diakonie ist Kirche. Das heißt dann auch, dass die neueren Einsichten der Kirchentheorie nicht nur die Institutionen der verfassten Kirche betreffen, von 
der Ortsgemeinde bis zum Landeskirchenamt. Vielmehr sind diese kybernetischen Einsichten auch bedeutsam für die diakonischen Institutionen, vom einzelnen Sozialdienst bis zum Großunternehmen. Da mir vertiefte Einblicke in die Praxis der diakonischen Unternehmen jedoch fehlen, will ich die Relevanz kirchentheoretischer Reflexion nicht einfach behaupten, sondern in Frageform formulieren: Könnte das, was sich gegenwärtig im Blick auf die verfasste Kirche theologisch und empirisch sagen lässt, auch für die Diakonie von Bedeutung sein? Vier Hinsichten sind es, in denen die neuere Theorie der Kirche mir für die Praxis diakonischer Leitung bedeutsam erscheint:

1. Die Krise der Kirche wird inzwischen auch als Chance, genauer als Chance der Selbstbesinnung begriffen - gilt dies auch für die Diakonie?

2. Der Sinn der Kirche ist die öffentliche Darstellung des Glaubens - ist das auch der Sinn der Diakonie?

3. Die Mitglieder haben von der Kirche offenbar das Bild, ein traditionell-religiöser Horizont je individueller Lebensdeutung zu sein - zeigen sich hier auch Erwartungen (und Dilemmata) der Diakonie in der Sicht ihrer „Kunden“ wie ihrer Mitarbeitenden?

4. Und schließlich: Wenn die Theologie sich in neuer Weise als Theorie der kirchlichen Leitung versteht - kann sie dann auch diakonische Leitungstätigkeit orientieren?

\section{Die Krise der Kirche als Chance der Selbstklärung - auch für die Diakonie?}

Kirche und Diakonie sind jedenfalls insofern gut vergleichbar, als sie sich gegenwärtig in einer krisenhafte Lage befinden. Hier wie dort vollziehen sich unter sozialem wie ökonomischen Druck - zahlreiche Suchbewegungen in der Mitarbeiterschaft, der jeweiligen Klientel bzw. Mitgliedschaft, auch auf den Leitungs-ebenen. Dass sich die Krise auch im Einzelnen recht ähnlich darstellt, weist auf Strukturanalogien, ja auf gemeinsame Wurzeln der Institutionen hin. Ich erinnere an einige Aspekte der kirchlichen Krisenwahrnehmung; die diakonischen Parallelen brauche ich allenfalls anzudeuten.

Nicht wenige kirchliche Körperschaften wären, wenn es keinen innerkirchlichen Solidarausgleich gäbe, inzwischen zahlungsunfähig. Hier werden die finanziellen Einbrüche weniger durch sinkende Tarife und Kassen-Leistungen, jedoch mindestens ebenso nachhaltig durch sinkende Mitgliederzahlen, vor allem aber durch demographische und steuerpolitische Veränderungen bewirkt.

Dieses Schwinden der Ressourcen ist, wie sich leicht erkennen lässt, vor allem durch das immer noch hochwirksame Erbe staatskirchlicher Strukturen verursacht. Das betrifft nicht nur die extreme Abhängigkeit von der - aus den genannten 
Gründen stetig sinkenden - Kirchensteuer, sondern auch die verbreiteten Erwartungsstrukturen: Kirchliche „Leistungen“, vor allem seelsorgliche und kasualgottesdienstliche Zuwendung, werden auch dort erwartet, wo man keine Verpflichtung zur Mitgliedschaft oder gar zum kirchlichen Engagement sieht.

Die organisierte Diakonie hat das Verblassen ihrer (wohlfahrts-)staatlichen Bindung früher zu spüren bekommen; spätestens seit Ende der 1970er Jahre sieht sie sich, in diversen Entwicklungsschüben, nolens volens als Akteur auf einem Markt sozialer Dienstleistungen. Inzwischen, eine Generation später, legt sich auch für die Kirchen die Marktmetaphorik immer häufiger nahe - weniger noch im Blick auf die rechtliche Bindung der Mitglieder, wohl aber im Blick auf deren Engagement, vor allem in finanzieller Hinsicht: Gemeinden konkurrieren um Spenden, Stiftungsgelder und Erbschaften.

Die erheblichen Umstrukturierungen, zu denen die Kirche genötigt ist, stellen sie nicht zuletzt vor die Frage nach ihrem institutionellen Selbstverständnis. Auch wenn die Kirche neuerdings ihre Ressourcen und ihre Personalstruktur bedenken muss, auch wenn sie nach einer „corporate identity“ und zunehmend auch nach einem „corporate design“ sucht - viele Mitglieder und Mitarbeiter wollen die Kirche doch nicht als (unternehmerische) religiöse Organisation, sondern als Gemeinschaft verstehen, die durch gemeinsame Überzeugungen zusammengehalten wird und sich in überschaubaren Sozialformen realisiert. Verbreitet wird daher nach neuen, zugleich offenen und verbindlichen Formen kirchlicher Zeugnis- und auch Dienstgemeinschaft gesucht, nach „Traditionslebensräumen“ (M. Nüchtern), die die Überlieferung lebendig halten und sozial darstellen. ${ }^{3}$

Ähnlich wird auch in der organisierten Diakonie gefragt, wie sich die Nötigung zu unternehmerischem Selbstverständnis verbinden lässt mit dem Begriff der „Dienstgemeinschaft“, der ja - lange vor seiner dienstrechtlichen Karriere - eine bestimmte soziale, ja ursprünglich eine religiöse Erfahrung markiert. Nachdem die klassischen diakonischen Gemeinschaften weitgehend verschwunden sind, wird auch hier nach neuen Gemeinschaftsformen gesucht; ich erinnere etwa an die „dritte Gemeinschaft" verbindlich, aber nicht gemeinschaftlich und auch nicht zölibatär lebender Christen, wie sie von Kaiserswerth aus erprobt wird.

Hinter den Krisen der Finanzen, der Strukturen und der sozialen Formen wird oft eine Krise der Überzengungen gesehen: Was ist dasjenige, wofür die Kirche - als Gemeinschaft wie als Großorganisation - steht, was sie vertritt und dann auch offensiv in die Öffentlichkeit zu bringen hat? Die evangelische Kirche versucht, in diesem Sinne das „evangelische Profil“ neu zu bestimmen, also zu fragen, worin in

\footnotetext{
${ }^{3}$ Michael Nüchtern, Lust auf die Komposition von Menüs, keine Rezepte. Was von der Auswertung $\mathrm{zu}$ erwarten ist und was nicht, in: Wolfgang Huber u.a. (Hg.), Kirche in der Vielfalt der Lebensbezüge. Die vierte EKD-Erhebung über Kirchenmitgliedschaft, Gütersloh 2006, (41-47) 45.
} 
ihrer Arbeit und in ihrem Leben das „unterscheidend Christliche“ zum Ausdruck kommt.

Auf dem Hintergrund solcher Diskussionsprozesse werden allmählich auch die Chancen der gegenwärtigen Umbrüche in der Kirche erkennbar: Die Umstellung von einem staatsanalogen auf ein eher unternehmerisches Selbstverständnis nötigt zur Selbstklärung, und zwar nicht nur organisatorisch, mit der Frage, was angesichts knapper Ressourcen unbedingt nötig erscheint, sondern auch inhaltlich: Was ist unser spezifisches Anliegen, wofür stehen wir als Kirche? Was ist denen, die von einer bestimmten Erfahrung des Glaubens herkommen, im gemeinsamen Arbeiten, vielleicht auch im gemeinsamen Leben wichtig?

Die Umstellung nötigt weiterhin zur Frage nach den einzelnen Mitgliedern: Was erwarten sie von der Kirche, der sie - trotz meist offenkundiger Distanz zu Gemeinde - weiterhin angehören, für die sie auch einiges aufwenden? Die Erwartungen der Mitglieder werden für eine Kirche in der Krise offenbar wichtiger, als eine wichtige Orientierung für Prioritätensetzung - wenn auch nicht als letzter Maßstab. Dazu soll im dritten Abschnitt noch einiges ausgeführt werden.

Die institutionelle Krise der Kirche bietet eine Chance zur Selbstklärung - vor allem durch die Wahrnehmung neuer Außenperspektiven, wie die der Mitgliedschaft und möglicher „Konkurrenten“. Auch und gerade dort, wo diese reflexive Selbstklärung nicht kurzschlüssig auf die Legitimation - oder den Ausschluss bestimmter Arbeitsfelder und Organisationsformen zielt, eröffnet sie die Einsicht in die spezifischen Ressourcen, die der Kirche eigen sind: die Überæengung des Glaubens, dass Gott - den Menschen zugute - gegenwärtig handelt; die Texte und Traditionen, auf die sich der christliche Glauben berufen kann; die spezifischen Vollzüge, in denen dies dargestellt wird - und nicht zuletzt: die Mitarbeitenden, die diese Überzeugungen und Traditionen, auch Liturgien verkörpern und weitertragen, sie plausibel machen. Und schließlich sind die Mitglieder zu nennen, die diese personale Präsentation von Tradition erwarten und ihr erstaunlich treu bleiben.

In der kirchlichen Umstellungskrise wird zunehmend deutlich, dass die Mitarbeitenden, und die Mitglieder überhaupt, der größte Schatz der Kirche sind. Der Ausbau der Fortbildung, Programme der Personalentwicklung, bis hin zu einem „Studium Ehrenamt“, wie die Hannoversche Landeskirche es eingerichtet hat - alle diese Maßnahmen sind (auch) Ausdruck der Wertschätzung der Personen, mit denen die erforderliche Umstellung vonstatten gehen kann.

An die diakonisch Leitungsverantwortlichen richtet sich dann meine Frage: Wenn Diakonie Kirche ist, auch Kirche in der Krise - lässt sich dann hier auch vom kirchlichen „Krisenmanagement“ etwas lernen? Bisher war es - aus guten Gründen - eher umgekehrt; die verfasste Kirche macht sich die Erfahrungen der Diakonie mit ökonomischen Sichtweisen und Methoden nun allmählich zu Eigen. 
Jan Hermelink

Aber vielleicht ist auch ein geistliches Lernen möglich. Kann also auch die diakonische Leitungsverantwortung gezielter nach den eigenen Ressourcen fragen, nach den Traditionen, den Texten, den Grundvollzügen, und vor allem: den Mitarbeitenden und den Mitgliedern? Können die Mitarbeitenden als der Schatz der Diakonie gesehen werden?

Noch brisanter erscheint mir die Ressourcenfrage im Blick auf das Gegenüber der diakonischen Arbeit. Reicht es aus, die Menschen, für die Diakonie „stark“ sein will, nicht mehr als Hilfe-Empfänger oder Betreute, sondern als Klienten oder Kunden zu bezeichnen? Oder sind sie als Menschen zu sehen, in deren Bedürftigkeit die conditio humana selbst aufleuchtet - und zugleich das Angesicht Gottes? In den neuesten Entwürfen einer Theologie der Diakonie erscheinen die Menschen, die diakonische Arbeit in Anspruch nehmen, nicht mehr als Ziel, sondern als Ausgangspunkt theologischer Reflexion, nicht mehr als Objekte christlicher Liebe, sondern als Subjekte christlicher Offenbarung. ${ }^{4}$

\section{Der Sinn der Kirche: Darstellung des Glaubens - auch der Sinn der Diakonie?}

Zur Krisenerfahrung der Kirche gehört, wie bereits angedeutet, nicht zuletzt ihre organisatorische Vielfalt: Kirche ist Gemeinde vor Ort - aber auch Landeskirche, auch Frauenwerk, auch ökumenische Kooperation und klösterliche Gemeinschaft; sie ist massenmedial präsent und äußert sich zugleich im Gemeindebrief; sie ist Kirche in der Schule und Kirche in der Großstadt ... Kirche, das ist in der Alltagserfahrung vieles zugleich, unübersichtlich, verwirrend, auch für Insider.

Ähnliches gilt für die Diakonie. Als Nicht-Insider frage ich mich nicht selten, was die Insider meinen, wenn sie von „Diakonie“ sprechen: die Kästorfer Anstalten und andere soziale Groß-Unternehmungen? Die Verbände und Spitzenverbände oder die Fachverbände? Das Hilfehandeln in einzelnen Gemeinden, in kreiskirchlichen Einrichtungen, in lokalen Initiativen? Wie gehört - unter dem Namen „Diakonie“ - eine Dimension allen christlichen Handelns zusammen mit bestimmten, ausgesprochen komplexen Organisationsformen?

Jedenfalls für die Kirche ist diese Frage nicht nur eine akademische, sondern inzwischen bekanntlich auch eine bedrängend praktische Frage: Was gehört so zur Kirche, dass es weiter unterstützt und gefördert werden soll? Dahinter verbirgt sich die theologische Frage, was Kirche ,ist“. Wofür steht dieser Begriff - und wofür stehen dann auch all die Sozialformen, Institutionen und Vereinigungen, die sich „Kirche“ nennen?

\footnotetext{
${ }^{4}$ Vgl. etwa Steffen Fleßa, Arme habt ihr allezeit! Ein Plädoyer für eine armutsorientierte Diakonie, Göttingen 2003, oder die kritischen Bemerkungen bei Johannes Degen, Diakonie als Unternehmen, in: Günter Ruddat u.a. (Hg.), Diakonisches Kompendium, Göttingen 2005, (228-240) 239f.
} 
Zur Klärung dieser Frage hat sich in den letzten Jahren eine Differenzierung zwischen drei Aspekten oder Dimensionen von „Kirche“ bewährt. Diese Unterscheidung wurde von Hans-Richard Reuter entwickelt, in etwas anderer Weise auch von Eilert Herms. ${ }^{5}$ Beide machen darauf aufmerksam, dass Kirche, theologisch gesprochen, auf bestimmten Erfahrungen beruht, die sich in bestimmte Handlungen umsetzen. Dazu - in aller Knappheit - einige Erinnerungen an die Einsichten der Reformation.

Bei Luther heißt es bekanntlich: „Es weiß gottlob ein Kind von sieben Jahren, was die Kirche sei, nämlich die heiligen Gläubigen und ,die Schafe, die ihres Hirten Stimme hören "“. 6 Kirche wird in der Reformation fundamental durch eine Erfahrung des Hörens bestimmt, genauer: durch die Erfahrung, Christus zu hören und damit zum Glauben an ihn zu kommen. Wenn Kirche „die heiligen Gläubigen, die Schafe, die ihres Hirten Stimme hören“ ist, dann erscheint sie als eine Gemeinschaft der hörend Glaubenden. Dementsprechend heißt es im Augsburger Bekenntnis, die Kirche sei „die Versammlung der Glaubenden, in der das Evangelium rein gepredigt (gelehrt) und die Sakramente dem göttlichen Wort gemäß gereicht werden“ (CA VII). Der Gemeinschaft der Glaubenden eignet also, in einem nächsten Schritt der Konkretion, eine bestimmte Sozialform: der Gottesdienst, der durch bestimmte Vermittlungsvollzïge, durch Predigt und Sakrament bestimmt ist. Aus der Erfahrung des Glaubens ergibt sich - um das Hören, das diesen Glauben bewirkte, auf Dauer zu stellen - die Konsequenz der Einrichtung bestimmter Handlungsvollzüge. Diese sind wesentlich inhaltlich bestimmt; sie haben dem göttlichen Wort, dem Evangelium zu entsprechen, oder, in den Formulierungen Luthers, der Einsicht in die Freiheit eines Christenmenschen und in seine Pflicht zum Nächstendienst.

Eilert Herms spricht daher davon, dass zur Kirche eine "Ordnung der Lehre“ gehört: Die - unverfügbare - Hörerfahrung des Glaubens muss gleichwohl systematisch festgehalten werden, damit die - so gelehrten - Glaubenden erkennen, dass sie tatsächlich die (befreiende) Stimme Christi in der Predigt hören. Dazu ist für die Kirche eine Ordnung des Gottesdienstes konstitutiv. Beide Ordnungen zielen darauf, dass der Grund des Glaubens hörbar, öffentlich laut wird, und dass der Glaube selbst sozialen Ausdruck, öffentliche Darstellung findet. Aus der Erfahrung des Glaubens entsteht, so formuliert Reuter, die Kirche als Glaubensgemeinschaft, und diese Glaubensgemeinschaft wird sichtbar in bestimmten Handlungen, sie stellt sich (und ihren Glauben) dar als eine Handlungsgemeinschaft. $\mathrm{Zu}$ diesen Handlungen gehört, von Anfang an, auch die gegenseitige Hilfe der Christen, die sich - wiederum aus Gründen des Glaubens - alsbald auch über den

\footnotetext{
5 Vgl. zum Folgenden Hans-Richard Reuter, Der Begriff der Kirche in theologischer Sicht, in: Gerhard Rau u.a. (Hg.), Das Recht der Kirche, Bd. I, Gütersloh, 23-75; Eilert Herms, Erfahrbare Kirche. Beiträge zur Ekklesiologie, Tübingen 1990, bes. 49ff, 102ff.

${ }^{6}$ Schmalkalische Artikel (1537), in: BSLK, $459 f$.
} 
Jan Hermelink

Raum der Gemeinde hinaus erstreckt: Die handelnde Kirche ist wesentlich auch Dienstgemeinschaft.

Ein dritter Reflexionsschritt ergibt: Diese - liturgische und zugleich diakonische Handlungsgemeinschaft muss sich, um soziale Dauer und gesellschaftliche Prägnanz zu erlangen, bestimmte organisatorische Regeln geben: Es entstehen Ämter, Berufe, Ausbildungsordnungen; dazu Finanzierungsformen, Mitgliedschaftsregeln, übergemeindliche Leitungsstrukturen u.a. - es entsteht die Kirche als Rechtsgemeinschaft, als dauerhafte Institution, in der Neuzeit auch als soziale Organisation.

Ein solcher dreifacher Kirchenbegriff vermag das kirchliche Handeln gerade unter den Bedingungen einer Umstellungskrise zu orientieren. Im Zusammenhang der Frage nach der kirchlichen Qualität der Diakonie markiere ich zwei Aspekte:

Zum einen kann deutlicher zwischen den Rechts- und Organisationsformen der Kirche einerseits und dem für sie konstitutiven Handeln andererseits unterschieden werden: Auch wenn eine bestimmte kirchliche Teil-Organisation, eine Beratungsstelle oder eine Kapellengemeinde, nicht mehr finanziert werden kann, so kann - und muss - doch das für Kirche konstitutive Handeln weiter geführt werden: die öffentliche Darstellung des Glaubens, vor allem im Gottesdienst. Dabei ist zu bedenken, dass „Gottesdienst“ zu keiner Zeit in der Kirchengeschichte nur den Sonntagsgottesdienst meinte. Auch der Weihnachtsgottesdienst, die kirchliche Trauung, der Schulgottesdienst, nicht zuletzt: die Morgenandacht und das Jahresfest einer diakonischen Einrichtung - dies alles sind gottesdienstliche Gelegenheiten, an denen die Inhalte des Glaubens so einladend wie einprägsam darzustellen und ihn gemeinschaftlich zu feiern sind.

Zum anderen unterstreicht diese kirchentheoretische Differenzierung, dass die zentralen Vollzüge der Kirche sich aus einer Erfahrung, genauer: einem Widerfahrnis, einer zunächst passiv empfangenen Überzeugung ergeben. Die Kirche begründet sich nicht daraus, was sie für die Gesellschaft oder für das Heil Einzelner leistet; sie kann ihre Arbeit, ihren Erfolg oder Misserfolg im Grunde nicht messen - sondern immer nur sekundär, mit geistlich begründeter Zurückhaltung an äußeren Zeichen ablesen. Das schließt kirchliches Qualitätsmanagement keineswegs aus, aber es kann immer nur um die Qualität der Darstellung gehen - nicht um die Qualität oder gar die Quantität des Dargestellten, eben des hörenden, vertrauenden Glaubens einzelner Menschen.

Wiederum seien die diakonischen Leitungskräfte gefragt: Ist eine solche kirchentheoretische Differenzierung auch für die Diakonie - die ja Kirche ist orientierungskräftig? Können diese Überlegungen unterscheiden helfen zwischen der Erfahrung der Diakonie - der Zuwendung Gottes zu bedürftigen Menschen und Gruppen -, den konstitutiven Vollzügen des diakonischen Handelns und seiner zweckmäßigen, möglichst qualitätsvollen Organisation? 
Zu fragen ist weiter, ob die organisierte Diakonie auch die in dieser Unterscheidung enthaltene Sinnzuschreibung der Kirche für sich übernehmen kann: Ist auch diakonisches Handeln im Kern die Darstellung einer Erfabrung des Glaubens ohne dass diese Grundschicht des Handelns das jeweilige konkrete Hilfehandeln entwertet oder instrumentalisiert? Kann im diakonischen Handeln - im einzelnen Dienst wie in der Leitung eines Unternehmens - die Erfahrung des Glaubens öffentlich zugänglich werden? Noch einmal zugespitzt: Wird auch im diakonischen Sektor der Kirche deutlich, dass das Evangelium zuerst und zuletzt ein Geschenk, eine Gabe - und dann erst ein Geben ist? Wird in der Diakonie die ja Kirche ist - auch öffentlich dargestellt (nochmals: im Handeln, in dessen Organisation, auch im Tarifrecht), dass wir unser Leben nicht in der Hand haben, sondern einem gnädigen und höchst geduldigen Gott verdanken?

\section{Das Bild der Kirche: Hilfreiche Tradition, einprägsame Liturgie und persönliche Zuwendung - auch ein Bild der Diakonie?}

Die Umstellungskrise der Kirche hat dazu geführt, dass nicht nur die theoretische, sondern auch die empirische Selbstklärung der Kirche sich intensiviert hat. Mitgliedschaftsbefragungen werden auch vor Ort häufiger, ${ }^{7}$ denn die Gemeinde muss sich dafür interessieren, warum und wie ihre Mitglieder sie (nicht oder nicht mehr) unterstützen wollen. Hier lauern natürlich viele Gefahren einer zu raschen Instrumentalisierung der Ergebnisse, aber höher einzuschätzen ist doch die Chance, ein klareres (Selbst-)Bild der eigenen Wirkung zu bekommen und dann auch - theologisch verantwortet - in veränderte Handlungs- und Organisationsstrukturen umzusetzen.

Im Frühjahr 2006 sind die Ergebnisse der IV. Kirchenmitgliedschaftsuntersuchung der EKD unter dem Titel „Kirche in der Vielfalt der Lebensbezüge" veröffentlicht worden. ${ }^{8}$ Nach dieser repräsentativen Untersuchung unter 1539 west- und 609 ostdeutschen Mitgliedern der evangelischen Kirche und dazu 880 Konfessionslosen ist und bleibt die Kirche eine bedeutsame Institution des gesellschaftlichen wie des individuellen Lebens - allerdings nicht als autoritative Vorgabe, sondern als eine Instanz, auf die man - mitunter nur ganz gelegentlich zurüickgreift, um das eigene Leben zu klären, zu orientieren, auch mit seinen Grenzen umzugehen. Ich skizziere vier Ergebnisse aus dieser neuen Repräsen-

\footnotetext{
${ }^{7}$ So werden etwa die Teilnehmenden an alternativen, missionarisch ausgerichteten Gottesdiensten regelmäßig nach ihren Erwartungen und Eindrücken befragt. Auch viele Qualitätssicherungsprogramme, etwa in der Kinder- und Jugendarbeit, setzen bei Bedarfserhebungen an.

${ }^{8}$ Vgl. Wolfgang Huber u.a. (Hg.), Kirche in der Vielfalt der Lebensbezüge. Vierte EKD-Erhebung über Kirchenmitgliedschaft, Gütersloh 2006. Die Erhebung fand 2002 statt. Solche Erhebungen werden seit 1972 im Zehnjahres-Abstand durchgeführt.
} 
Jan Hermelink

tativumfrage - und frage dann wiederum, ob sie auch für die Außenwahrnehmung der Diakonie bedeutsam sein könnten.

(a) Zunächst kann man feststellen: Es mag strittig sein, ob die Diakonie Kirche ist, sein will und theologisch sein darf - umgekehrt jedenfalls gilt: Die Kirche ist bedeutsam als Diakonie. Unter den Erwartungen an die Institution liegen - seit langem - ihre Zuwendung $\mathrm{zu}$,Menschen in sozialen Notlagen“, und die Betreuung von „Alten, Kranken und Behinderten“ an vorderster Stelle. ${ }^{9}$ Das gilt für die Mitglieder - sie begründen ihre Mitgliedschaft wesentlich damit, diese Arbeit unterstützen zu wollen; ${ }^{10}$ und das gilt auch für die von uns befragten Konfessionslosen: In der Umfrage wie in begleitenden Gruppengesprächen machen sie deutlich, dass die Kirche als diakonische Institution mit ihrem Wohlwollen, mit hoher Akzeptanz und durchaus auch mit punktueller Unterstützung rechnen kann. ${ }^{11}$ Insofern hat die Diakonie - auch und gerade aus der Außensicht der Mitglieder - allen Grund, selbstbewusst zu formulieren: „Wir sind Kirche“.

(b) Neben der Diakonie wird das Bild der Kirche von der Erwartung gottesdienstlicher Vollzüge bestimmt: Die Kirche soll „Menschen durch Taufe, Konfirmation, Hochzeit und Beerdigung an den Wendepunkten des Lebens begleiten"; sie soll Gottesdienste feiern und die christliche Botschaft verkünden. ${ }^{12}$ Wieder ist bemerkenswert, dass auch die Konfessionslosen diesem Bild von Kirche mit großer Mehrheit zustimmen. Die Kirche ist die Institution der öffentlichen Darstellung des Glaubens, und zwar vor allem im Bezug auf die Krisen- und Höhepunkte des je eigenen Lebens, in den Gottesdiensten zu Taufe, Trauung und Bestattung, und zu Heiligabend. Dieses allgemeingesellschaftliche Bild kirchlicher Arbeit stimmt mit dem oben skizzierten theologischen Selbstverständnis bemerkenswert klar überein.

(c) Bemerkenswert ist sodann, welche Erwartungen mit dem kirchlichen Gottesdienst im Detail verbunden werden - eine Frage, die 2002 neu gestellt wurde. ${ }^{13}$ Die höchste Zustimmung von je zwei Dritteln der Befragten erhielten die beiden Vorgaben: „Der Gottesdienst soll von einer zeitgemäßen Sprache geprägt sein“ und er soll „,vor allem eine gute Predigt enthalten“; in geringem Abstand $(63 \%)$ folgt die Erwartung, er solle ,durch eine fröhliche und zuversichtliche Stimmung gekennzeichnet sein" - also die Erwartung einer bestärkenden Erfahrung. Besonders wichtig ist den Befragten offenbar genau das, worauf sich auch das reformatorische Bekenntnis konzentriert: Sie erwarten eine gute Predigt

\footnotetext{
${ }^{9}$ Huber u.a., Kirche in der Vielfalt der Lebensbezüge, a.a.O., 58f, 457.

$10 \mathrm{Vgl}$. a.a.O., 60f, $449 \mathrm{f}$.

11 Vgl. a.a.O., $106 f, 457$.

12 Vgl. a.a.O., 58f, $106 \mathrm{f}$ (Konfessionslose), 457 (Daten zu Mitgliedern und Konfessionslosen).

$13 \mathrm{Vgl.} \mathrm{a.a.O.,} \mathrm{80f,} 454$.
} 
- das heißt eine Predigt, ${ }^{14}$ die die Hörenden erreicht, sie zeitgemäß anspricht, sie zuversichtlich stimmt, also - wie die CA formuliert - das Evangelium lehrt. Stimmung und Gehalt, emotionale und kognitive Dimensionen des Gottesdienstes stehen für die Befragten (wie für die lutherische Reformation) durchaus nicht im Widerspruch. Dem korrespondiert, dass die Mitgliedschaft in hohem Maße damit begründet wird, dass einem „der christliche Glauben etwas bedeutet“, und man „der christlichen Lehre zustimmt". .15

Das Bild der Kirche, so kann man zusammenfassen, erscheint - bei Mitgliedern wie bei Nichtmitgliedern - als ausgesprochen traditionell: Lebenshilfe, Amtshandlungen, gehaltvolle Predigt, auch christliche Lehre. Dieser letzte Punkt erscheint mir besonders bedeutsam: Dass die Kirche bestimmte Einsichten zu Gehör bringen soll, dass sie für eigentümliche Überzeugungen steht und diese plausibel und nachvollziehbar machen will - das ist den Menschen, weit über den Kreis der Mitglieder hinaus, offenbar durchaus selbstverständlich. Kirche soll eine lehrende, inhaltsbezogene, überzeugende Institution sein.

(d) Wie aber sollen diese Überzeugungen vermittelt werden? Im Gefolge früherer empirischer Untersuchungen hat man immer wieder von der „Schlüsselrolle der Pfarrer" gesprochen, man hat also den Personen, die für Kirche stehen, eine zentrale Vermittlungsfunktion zugeschrieben. ${ }^{16}$ Hier hält die neueste Untersuchung eine gewisse Überraschung bereit. ${ }^{17}$ Zwar haben über $90 \%$ der Befragten einen guten (54\%) oder sehr guten (39\%) Eindruck von ihren pastoralen Gesprächspartnern - aber auf die Frage, wie wichtig ein persönlicher Kontakt mit der/dem Gemeindepfarrer/in sei, meinen fast die Hälfte, dieser persönliche Kontakt sei ihnen weniger oder gar nicht wichtig; nur knapp über einem Viertel finden den pastoralen Besuch wichtig (18\%) oder gar sehr wichtig $(10 \%)$. Dazu passt, dass das je eigene Verhältnis zu Kirche und Glauben - nach Auskunft der Befragten - positiv vor allem von Eltern und Großeltern geprägt wurde; erst an dritter Stelle werden hier die Pastorinnen/Pastoren genannt. ${ }^{18}$

Pfarrer sollen gehaltvoll predigen, sie sollen ansprechende, ermutigende Gottesdienste leiten; aber im persönlichen Kontakt werden sie - so kann man vermuten - doch zunächst eben auch als lehrende, als belebrende Figuren gesehen und darum eher auf Abstand zum eigenen Leben gehalten.

Gleichwohl machen die Befragten an vielen Stellen deutlich, dass ihnen im Blick auf die Kirche an persönlicher Zuwendung, an der Wahrnehmung und Würdigung

\footnotetext{
${ }^{14}$ Man wird annehmen können, dass hier auch die Kasualpredigten mit im Blick sind.

${ }^{15}$ Huber, Kirche in der Vielfalt der Lebensbezüge, a.a.O., 60f, 449f.

${ }^{16}$ Vgl. Peter Krusche, Der Pfarrer in der Schlüsselrolle, in: Joachim Matthes (Hg.), Erneuerung der Kirche - Stabilität als Chance? Konsequenzen aus einer Umfrage, Gelnhausen/Berlin 1975, 161 188.

17 Vgl. zum Folgenden a.a.O., 78f, 450-452.

${ }^{18}$ Vgl. a.a.O., $67 f, 444 f$.
} 
Jan Hermelink

ihres je eigenen Lebens sehr gelegen ist. Die Kirche wird kritisiert, wenn sie nur noch als ferne Institution oder als rituelle Routine erscheint. Und positiv wird sie, werden auch die Personen, die für Kirche stehen, vor allem dann gesehen, wenn sie die Einzelnen in ihrer je eigenen religiösen Suchbewegung unterstützen. Stellen Pfarrer/innen und andere Christen die Fragen nach dem Tod, machen sie die Grenzen der Leistungsfähigkeit, das Unvollendete, aber auch das unverhofft Empfangene zum Thema, helfen sie nach dem Sinn des Leidens zu suchen, ohne fertige Antworten zu geben - dann erscheinen sie als bedeutsame Repräsentanten, als persönlich überzeugende Darsteller des Glaubens.

Das Bild der Kirche ist geprägt von der Erwartung persönlich hilfreicher Zuwendung, von liturgischen und auch homiletischen Vollzügen, von der Erwartung, dass letzte Fragen - nicht etwa beantwortet, sondern - gestellt werden. Kann dieses Bild auch Diakonie als Kirche charakterisieren? Kann und soll also auch das diakonische Handeln die verlässliche Tradition, und damit im Grunde die Verlässlichkeit Gottes zur Darstellung bringen? Und kann, ja soll Diakonie in der helfenden Zuwendung zu den Einzelnen auch auf die Liturgie des Glaubens Bezug nehmen - oder hat Johannes Degen recht, wenn er meint, für die „diakonische Markenidentität“ seien ausdrücklich „kirchliche Handlungen und formale Merkmale (z.B. Kirchenzugehörigkeit) sekundär"?19

Dass diakonisches Handeln einer „,theologischen Achse“ (Alfred Jäger), also einer expliziten inhaltlichen Reflexion bedarf, das wird in den neueren Konzepten der diakonischen Leitung regelmäßig betont. Aber gehört es auch zum Bild der Diakonie als Kirche, diese theologische, oder besser vielleicht: diese geistliche Mitte des Handelns auch im Vollzug selbst explizit zu machen, also ausdrücklich darzustellen, dass Diakonie sich christlichen Überzeugungen und je neuer Erfahrung des Glaubens verdankt? Überlastet diese Maßgabe das jeweilige Handeln bzw. die jeweilige Organisation - oder wird es, umgekehrt, von den Beteiligten durchaus erwartet, dass sie die Gründe (also nicht nur die Motive) ihres diakonischen Engagements argumentativ offen legen können?

Nochmals sei auf die Art und Weise hingewiesen, in der die befragten Kirchenmitglieder eine solche persönliche Vermittlung von Lehre erwarten: nicht als autoritative Belehrung, nicht als An-Predigen - sondern als gemeinsame Suche, als Anregung, Nachfrage. Könnte Diakonie also wesentlich darin Kirche sein, dass die diakonisch Handelnden der Frage nach den Grenzen, nach dem Sinn, nach der Würde auch am Ende des Lebens nicht ausweichen, sondern in ihr Handeln ausdrücklich mit hinein nehmen - und zwar als Frage?

Nicht nur die Partner des diakonischen Handelns, sondern auch die Mitarbeitenden erwarten - einschlägigen Untersuchungen zufolge - genau dies von ihrem Arbeitgeber: Die Kirchlichkeit der Diakonie „wird für Mitarbeitende

${ }_{19}$ Degen, Diakonie als Unternehmen, a.a.O. (s.o. Anm. 4), 235 mit Anm. 16. 
relevant als Unterstützung bei der Entfaltung des eigenen geistlichen Weges in der Auseinandersetzung mit der Arbeitssituation. [...] Fortbildung im [Fachlichkeit wie Religiosität] umfassenden Sinne, und das Arbeitsklima [sind] das wichtigste Desiderat, an dem faktische Kirchlichkeit von Mitarbeitenden [selbst] gemessen wird." 20 Wieder wird die Kirche - in der Diakonie - als hilfreicher Horizont je eigenen Fragens bedeutsam, als Rahmen und Thema selbst verantworteter, inhalts- wie personbezogener Fortbildung. Zugespitzt ist zu folgern: Auch in der organisierten Diakonie sind Mitarbeitende zuerst und zuletzt wahrzunehmen als Mitglieder der Kirche: als potenziell Hörende, selbständig Fragende und so auch als unverfügbar - Glaubende.

\section{Leitung in der Kirche durch persönlich angeeignete Theologie - auch als diakonische Leitungskompetenz?}

In den gegenwärtigen Umstellungskrisen wird das kirchliche Leitungshandeln schwieriger und anspruchsvoller, nicht nur auf der Ebene von Landeskirchen, sondern auch in Kirchenkreisen und Ortsgemeinden. Die Frage nach den Kompetenzen, die für das Leiten in der Kirche erforderlich sind, wird daher immer stärker gestellt ${ }^{21}$ - als Frage nach (Management-) Fähigkeiten, aber auch als Frage nach den theoretisch-theologischen Inhalten, mit denen dieses Leitungshandeln reflektiert und verantwortet werden kann.

Durch welches Wissen diese Kompetenzen ausgebildet werden können, das ist besonders nachdrücklich von Friedrich Schleiermacher entfaltet worden, der bekanntlich die ganze Theologie als eine Theorie der kirchlichen Leitung verstanden hat. Sämtliche philosophischen, historischen und empirischen Kenntnisse, die die zukünftigen Geistlichen sich im Studium aneignen, dienen dem Ziel einer reflektierten, „zusammenstimmenden Leitung der christlichen Kirche“.22 Diese Leitung selbst zielt darauf, wie Schleiermacher formuliert, „die Idee des Christentums nach der eigentümlichen Auffassung der evangelischen Kirche [...] immer reiner zur Darstellung zu bringen und immer mehr Kräfte für sie zu gewinnen“. ${ }^{23}$ Die Kirche ist eine Institution zur öffentlichen Darstellung des

\footnotetext{
${ }^{20}$ Eberhard Hauschildt, Kirchlichkeit als Markenzeichen im diakonischen Alltag, in: Institut für Diakoniewissenschaft (Hg.), Diakonie - quo vadis?, Bonn/Mülheim 1999, (44-67), 61, mit Verweis auf Hans-Ulrich Nübel, Die neue Diakonie: Teilhabe statt Preisgabe, Mitarbeiterinnen und Mitarbeiter kommen zu Wort, Freiburg 1994. Hervorhebungen im Zitat JH.

${ }^{21}$ Vgl. nur Hans-Jürgen Abromeit (Hg.), Spirituelles Gemeindemanagement, Göttingen 2002; Friederike/Peter Höher, Handbuch Führungspraxis Kirche. Entwickeln, Führen, Moderieren, Gütersloh 1999; Ulrich Müller-Weißner, Chef sein im Hause des Herrn. Führen und Leiten in der Kirche - eine Praxishilfe, Gütersloh 2003.

22 Vgl. Friedrich Schleiermacher, Kurze Darstellung des theologischen Studiums zum Beruf einleitender Vorlesungen, 1. Aufl. 1811, 2. Aufl. 1830, 3. krit. Ausgabe hg. v. Heinrich Scholz, Leipzig 1910, hier $\ 5$.

23 A.a.O., $₫ 313$.
} 
Jan Hermelink

christlichen Glaubens - das wird hier, unter den Bedingungen einer beginnenden Unterscheidung von Kirche, Staat und Gesellschaft bereits präzise zu Ausdruck gebracht, und mit einer neu geordneten wissenschaftlich-theologischen Ausbildung verbunden.

Dass die Kirche vor allem einer theologischen Reflexion ihrer Leitung bedarf, ist seither immer wieder betont worden. In der Gegenwart treten dabei besonders die folgenden Einsichten in den Vordergrund:

- Angesichts der immer komplexeren gesellschaftlichen, religiösen, kirchlichen und - nicht zuletzt - individuellen Lebensverhältnisse muss auch die theologische Ausbildung zur Kirchenleitung vielfältiger werden. Sie muss insbesondere Einsichten aus anderen wissenschaftlichen Disziplinen einbeziehen, von der historischen Philologie bis etwa zur Betriebswirtschaftslehre ${ }^{24}$ - und sie muss diese Einsichten zugleich in einen theologischen Theorierahmen stellen.

- Die klassische Abfolge der pastoralen Ausbildung - akademisches Studium, praktischer Vorbereitungsdienst und dann eigenverantwortliche Berufspraxis erscheint unzureichend, weil das Verhältnis von theoretischer Einsicht und praktischer Erfahrung wechselseitig gedacht werden muss. Daher sind Fort- und Weiterbildungsveranstaltungen, bis hin zu einem regelmäßigen „Kontaktstudium“ an der Universität, zu unverzichtbaren Elementen einer theologisch verantwortlichen Leitungspraxis geworden.

- Die Basis der theologischen Aus- und Fortbildung bleibt die Kenntnis der christlichen Überlieferung in Bibel und theologischer Lehrbildung. $\mathrm{Zu}$ diesen inhaltlichen, lehrhaften Einsichten kommt - seit den 1960er Jahren vermehrt wahrgenommen - die Fähigkeit ihrer kommunikativen Vermittlung. Seit den 1990er Jahren wird deutlicher gesehen, dass hier nicht nur soziologische und psychologische Einsichten bedeutsam sind, sondern auch ästhetische und kreative, ja inszenatorische Fähigkeiten: Theologie, oder jedenfalls Praktische Theologie kann nunmehr als Theorie der Darstellungskunst, als Wissenschaft von der öffentlichen Inszenierung des christlichen Glaubens verstanden werden.

- Deutlicher als noch vor zwanzig Jahren wird auch gesehen, dass die genannten Kenntnisse und Fähigkeiten persönlich angeeignet werden müssen, dass Aus- und Fortbildung also nicht zuletzt heißt, die theologische Einsicht und ihre Darstellung mit der je eigenen Lebensgeschichte und Lebensprägung zu vermitteln.

- Daher kann es in der theologischen Aus- und Fortbildung zur kirchlichen Leitung nicht um die Vermittlung bereits fertiger, immer schon feststehender Antworten gehen. Theologie erscheint vielmehr auch und wesentlich als die Fähigkeit, kritische Fragen an die Überlieferung wie an die gegenwärtige Situation zu stellen - und sich nicht zuletzt auch selbst befragen zu lassen. Damit wird im

${ }^{24}$ Vgl. zuletzt Antje-Silja Tetzlaff, Führung und Erfolg in Kirche und Gemeinde. Eine empirische Analyse in evangelischen Gemeinden, Gütersloh 2005. 
Übrigen auch den - geistlich wohl begründeten - Erwartungen an die kirchliche Institution entsprochen, wie sie institutionsnahe wie -ferne Menschen zum Ausdruck bringen.

- Schließlich gehört auch der (Wieder-)Aufstieg der Kybernetik, der praktischtheologischen Kirchentheorie zu den Charakteristika einer theologischen Ausund Fortbildung, die die pastorale Leitungskompetenz verbessern soll. Denn zu dieser Kompetenz gehört eine vertiefte Kenntnis der Institution selbst, die geleitet werden soll - und zwar eine Kenntnis, die wiederum theologisch verantwortet werden kann.

Auch im Blick auf diejenigen Formen kirchlichen Lebens, die sich primär als „Diakonie“ verstehen, kann und muss die Frage nach den spezifischen Leitungskompetenzen und nach ihrer angemessenen Aneignung gestellt werden. Dass zur Leitung diakonischer (Groß-) Institutionen juristische und ökonomische Kenntnisse unerlässlich sind, das erscheint inzwischen selbstverständlich. Gleichwohl wäre zu prüfen, ob solche Institutionen, wenn sie sich denn mit guten Gründen als „Kirche“ verstehen, nicht ebenfalls wesentlich mittels theologischer Kompetenzen zu leiten sind.

Der im Sommersemester 2006 erstmals angelaufene Studiengang „Führungskompetenz in theologischer Sicht" (MA) der Göttinger Theologischen Fakultät verfolgt dezidiert ein entsprechendes theologisches Weiterbildungsprogramm. Dazu gehört die wissenschaftliche Kenntnisnahme der Ursprungstraditionen des christlichen Glaubens, dazu gehört die Wahrnehmung der sozialen und religiösen Kontexte gegenwärtigen kirchlich-diakonischen Handelns, und dazu gehört nicht zuletzt die theologische Reflexion der je eigenen diakonischen Institution selbst mittels der Analyse konkreter ethischer wie konkreter kybernetischer Konflikte und Handlungsaufgaben. Dies alles zielt auf eine persönliche Aneignung, mittels derer die künftig Leitenden die Wahrheit des christlichen Glaubens auch im diakonischen Leitungsalltag überzeugend zur Darstellung bringen können.

Auf diese Weise - mittels einer profunden wissenschaftlich-theologischen Ausbildung - könnte deutlich werden, dass Diakonie auch in ihrer Leitungskultur von Einsichten und Überzeugungen lebt, die dem christlichen Glauben entstammen - und dass sie sich eben darum ganz zu Recht als integraler Teil von „Kirche“ versteht. 

Hans-Richard Reuter

\section{Kirchenspezifische Anforderungen an die privat- rechtliche berufliche Mitarbeit in der evangelischen Kirche und ihrer Diakonie*}

\section{Einleitung}

Gegenstand dieses Gutachtens ist die theologische - hier: ekklesiologische und (sozial-)ethische - Legitimität kirchenspezifischer Anforderungen an beruflich Mitarbeitende in privatrechtlichen Arbeitsverhältnissen der evangelischen Kirche und der ihr zugeordneten Einrichtungen und Werke, insbesondere diakonischer Art. Als solche für das individuelle Arbeitsrecht relevante kirchenspezifische Anforderungen kommen (in erster Annäherung) in Betracht: besondere persönliche oder verhaltensbezogene Erwartungen wie etwa die Kirchenmitgliedschaft, die Identifikation mit dem kirchlichen Auftrag, die Loyalität gegenüber der

\footnotetext{
* Die folgende Studie wurde im Auftrag des Rates der Evangelischen Kirche in Deutschland als Theologisches Gutachten zum Entwurf einer „Loyalitätsrichtlinie“ im März 2005 angefertigt. Die hier unter 7. formulierten Empfehlungen sind in die Richtlinie des Rates der Evangelischen Kirche in Deutschland nach Art. 9 Buchst. b Grundordnung über die Anforderungen der privatrechtlichen beruflichen Mitarbeit in der Evangelischen Kirche in Deutschland und des Diakonischen Werkes der EKD v. 1.7.2005, ABl. EKD S. 413, übernommen worden.
} 
Kirche, die Anerkennung der konfessionellen Prägung kirchlicher Arbeit sowie sonstige Erwartungen an das dienstliche und/oder außerdienstliche Verhalten.

Die damit angesprochene Problematik wird im Folgenden erörtert vor dem Hintergrund des Entwurfs einer diesbezüglichen Richtlinie des Rates der EKD in der Fassung vom Februar 2004. ${ }^{1}$ Dieser Entwurf stößt auf entschiedene Kritik seitens der Mitarbeitervertretungen und der Gewerkschaft ver.di. Hier wird eine Verschärfung bereits bestehender Regelungen kritisiert; als Kündigungsgründe kämen nicht nur Kirchenaustritt und ,grobe Missachtung der evangelischen Kirche und ihrer Ordnungen“" in Betracht, sondern auch mangelnde Bereitschaft, „das Evangelium in der Einrichtung zu bezeugen“; das allgemeine Arbeitsrecht reiche zur Begründung von Loyalitätspflichten aus; diese blieben im Richtlinienentwurf unbestimmt und öffneten rigider Auslegung wie im katholischen Bereich $^{2}$ sowie Misstrauen bis hin zum Denunziantentum Tür und Tor; sie widersprächen dem Leitbild einer einladenden, offenen Kirche. ${ }^{3}$ Das Regelerfordernis der Mitgliedschaft in der evangelischen Kirche gehe über das bisher im Bereich des Diakonischen Werks Geforderte hinaus, könne als Zwangsmission erlebt werden und fördere Heuchelei; drei Viertel der Mitarbeiter arbeiteten nicht aus Glaubensgründen, sondern zur Ausübung ihrer beruflichen Qualifikation in kirchlichen Einrichtungen. ${ }^{4}$

Beachtliche Einwände bringt auch ein im Auftrag von ver.di erstelltes wissenschaftliches Gutachten von Michael Haspel vor. ${ }^{5}$ Die im engeren Sinn theologische Kritik läuft im Kern auf drei Argumente hinaus: Erstens könne die Kirche besondere Verhaltensanforderungen, die über die Einhaltung der für alle Kirchenmitglieder geltenden und in den kirchlichen Lebensordnungen umschriebenen Pflichten hinausgehen, nur denjenigen Bediensteten auferlegen, die in spezifischer Weise an einem mit geistlicher Beauftragung versehenem Amt partizipieren. Zweitens stünde zur Sanktion bei Verstößen gegen Verhaltensanforderungen im Fall von Amtsträgern die Amtszucht, bei allen anderen nur die allgemeine Kirchenzucht zur Verfügung. Wenn jedoch die Kirche - wie weithin beobachtbar - das Instrument der Kirchenzucht gegenüber ihren Mitgliedern nicht mehr ernst nehme, sei es inakzeptabel, an dessen Stelle arbeitsrechtliche Maßnahmen gegen-

\footnotetext{
${ }^{1}$ Richtlinie des Rates der Evangelischen Kirche in Deutschland nach Art. 9 Buchst. b Grundordnung über die Anforderungen der privatrechtlichen beruflichen Mitarbeit in der Evangelischen Kirche in Deutschland und ihres Diakonischen Werkes (Entwurfsstand 18.2.2004; Az: 0340/1 und 2700/5.124-10); im Folgenden zit. als EKD-Richtlinienentwurf II.

2 Ahndung von offener Homosexualität und öffentlicher Bekundungen zur Abtreibungsfrage, die der kirchlichen Lehre widersprechen.

${ }^{3}$ Unterschriftenaktion der Gewerkschaft ver.di, epd-Dok 35/2004, 31.

${ }^{4}$ Unterschriftenaktion des Gesamtausschusses der Mitarbeitervertretungen der Ev.-Luth. Landeskirche Hannovers, http://www.gamav.de/archiv/2004/unterschriftloyal.htm.

5 Michael Haspel, Die kirchenrechtliche Regelung der Anforderungen an die privatrechtliche berufliche Mitarbeit in der EKD und ihres Diakonischen Werkes aus theologischer Perspektive, epdDok 35/2004, 4-26.
} 
über den Mitarbeitern treten zu lassen. Drittens sei ein strikt theologisches Verständnis des kirchlichen Dienstes in der Welt nicht mit dem für das kirchliche Arbeitsrecht zentralen Konzept der „Dienstgemeinschaft“ zur Deckung zu bringen; vielmehr sei im Bereich des Letzteren eine Differenzierung nach (Berufs-) Gruppen erforderlich, die mit abgestuften Loyalitätsanforderungen einhergeht.

Im Folgenden wird zunächst auf die unmittelbar einschlägigen verfassungsrechtlichen Vorgaben und auf die europäische Rechtsetzung hingewiesen (2.). Ich versuche dann einen Überblick über die hier interessierenden Normen des geltenden kirchlichen Arbeitsrechts im Vergleich zur EKD-Initiative zu geben (3.). Auf eine Skizze der ekklesiologischen und kirchentheoretischen Grundlagen (4.) folgen Überlegungen zum personellen Geltungsbereich kirchenspezifischer Anforde-rungen und zum Konzept der „Dienstgemeinschaft“ (5.). An die Ausführungen zur inhaltlichen Festlegung kirchenspezifischer Pflichten (6.) schließen sich Empfehlungen zur Überarbeitung des EKD-Richtlinienentwurfs an (7.).

\section{Vorgaben der externen Rechtsentwicklung}

Interpretiert man den EKD-Richtlinienentwurf II nicht vor dem Hintergrund

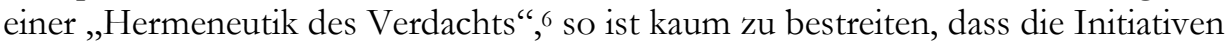
$\mathrm{zu}$ einer Vereinheitlichung der kirchenspezifischen Berufsanforderungen in den Gliedkirchen der EKD und ihrem Diakonischen Werk v.a. durch zwei Vorgaben der externen (,weltlichen“) Rechtsentwicklung angestoßen sind.

\subsection{Die deutsche Verfassungsrechtsprechung}

Nach deutschem Verfassungsrecht ${ }^{7}$ ist das Dienst- und Arbeitsrecht der Religionsgemeinschaften anerkannter Bestandteil ihres Selbstbestimmungsrechts, das den Kirchen gewährleistet, ihre eigenen Angelegenheiten selbständig innerhalb der Schranken des für alle geltenden Gesetzes zu ordnen und zu verwalten (Art. 140 GG i.V.m. Art. 137 Abs. 3 Weimarer Reichsverfassung (WRV)). Dabei sind sie auf Grund der ergänzend garantierten Eigenschaft als Körperschaften des öffentlichen Rechts (Art. 140 GG i.V.m. Art. 137 Abs. 5 WRV) befugt, die Dienstverhältnisse ihrer Amtsträger nach öffentlich-rechtlichen Grundsätzen zu ordnen. Unabhängig davon können sie sich kraft ihres Selbstbestimmungsrechts auch der Privatautonomie bedienen, um ein Dienstverhältnis zu begründen, das

6 „Disziplinierung von Mitarbeitenden“, „Mitgliederbindung mit arbeitsrechtlichen Mitteln“, "Zwangsmissionierung" etc.

${ }^{7}$ Vgl. u.a. Wolfgang Rüfner, Individualrechtliche Aspekte des kirchlichen Dienst- und Arbeitsrechts. Die besondere Loyalitätspflicht im kirchlichen Dienst, in: HbStKR Bd 2, \66, 2. Aufl. Berlin 1995, 901-926; Ulrich Hammer, Kirchliches Arbeitsrecht. Handbuch, Frankfurt a.M. 2002, 87ff; Reinhard Richardi, Arbeitsrecht in der Kirche. Staatliches Arbeitsrecht und kirchliches Dienstrecht, 4. Aufl. München 2003, \1f. 
kirchenspezifische Anforderungen umfasst. In diesem Fall erlangen kirchliche Arbeitsverhältnisse jedoch weder einseitig die Qualität kirchlichen Rechts, noch gilt etwa umgekehrt, dass die Kirchen dann das Selbstbestimmungsrecht über ihre eigenen Angelegenheiten verlieren. Schließen die Kirchen privatrechtliche Arbeitsverträge ab, so findet auf diese - als „schlichte Folge einer Rechtswahl“ grundsätzlich staatliches Arbeitsrecht Anwendung, ohne dass deshalb „die verfassungsrechtlich geschützte Eigenart des kirchlichen Dienstes, das spezifisch Kirchliche, das kirchliche Proprium " in Frage gestellt werden darf. ${ }^{8}$ Vielmehr gibt das kirchliche Selbstbestimmungsrecht den Ausschlag für die Frage, wie die im allgemeinen Arbeitsrecht gebrauchten unbestimmten Rechtsbegriffe9 auszufüllen sind.

Der aus Anlass eines Streitfalls aus dem katholischen Bereich getroffenen Grundsatzentscheidung des Bundesverfassungsgerichts vom 4. Juli 1985 zufolge ist es dem weltanschaulich-neutralen Staat nicht nur verwehrt, von sich aus festzustellen, welches die aus der kirchlichen Lehre folgenden inhaltlichen Maßstäbe für Loyalitätspflichten der Beschäftigten sind, und was als Verstoß gegen sie aufzufassen ist; er muss sich darüber hinaus auch eines Urteils darüber enthalten, welche beruflichen Tätigkeiten spezifisch kirchlicher Natur sind bzw. sich in abstufbarer Nähe oder Ferne zum kirchlichen Auftrag befinden. ${ }^{10}$ Begünstigt durch die Kirchenautonomie sind nach ständiger Rechtsprechung nicht nur die Kirchen selbst, sondern alle „der Kirche in bestimmter Weise zugeordneten Einrichtungen ohne Rücksicht auf ihre Rechtsform, wenn sie nach kirchlichem Selbstverständnis ihrem Zweck und ihrer Aufgabe entsprechend berufen sind, ein Stück des Auftrags der Kirche wahrzunehmen und zu erfüllen"..11

Somit können die Religionsgemeinschaften der religiösen Dimension ihres Wirkens auch im caritativ-diakonischen Bereich Rechnung tragen. Allerdings bleibt das religionsgemeinschaftliche Selbstbestimmungsrecht ein solches der verfassten Kirchen und geht nicht auf die ihnen zugeordneten Einrichtungen über; den Kirchen steht es frei, welche Einrichtungen sie am Schutz der Kirchenautonomie teilhaben lassen. Soweit sie dies tun, liegt die Kompetenz zur Festlegung kirchenspezifischer beruflicher Anforderungen, die dann von den staatli-

\footnotetext{
8 BVerfG 70, 138 (165).

9 Z.B. \626 BGB: Kündigung ,aus wichtigem Grund“, „Unzumutbarkeit“ der Fortsetzung des Dienstverhältnisses.

10 Die verfassten Kirchen haben die Befugnis, im Rahmen des Arbeitsrechts eigenständig und verbindlich festzulegen, „,was ,die Glaubwürdigkeit der Kirche und ihrer Verkündigung erfordert‘, was ,spezifisch kirchliche Aufgaben` sind, was ,Nähe' zu ihnen bedeutet, welches die, wesentlichen Grundsätze der Glaubens- und Sittenlehre' sind und was als - gegebenenfalls schwerer - Verstoß gegen diese anzusehen ist. Auch die Entscheidung darüber, ob und wie innerhalb der im kirchlichen Dienst tätigen Mitarbeiter eine ,Abstufung ' der Loyalitätspflichten eingreifen soll, ist grundsätzlich eine dem kirchlichen Selbstbestimmungsrecht unterliegende Angelegenheit.“ (BVerfGE 70, 138 [166]).

11 BVerfG 70, 138 (162).
} 
chen Arbeitsgerichten zu Grunde zu legen sind, zur Gänze bei den verfassten Kirchen selbst, die dabei freilich durch das für alle geltende Gesetz beschränkt sind, d.h. in diesem Fall durch das Willkürverbot (Art. 3 Abs. 1 GG), die guten Sitten ( $\int 138$ Abs. 1 BGB), den ordre publique (Art. 6 Einführungsgesetz zum BGB $)^{12}$ sowie die Arbeitsschutzgesetze.

Auch wer diese Kompetenzzuweisung seitens des religionsneutralen Staates für zu weitgehend hält, muss einräumen, dass aus ihr ein Gestaltungsauftrag an die Kirchen folgt, der ausgefüllt werden muss - und zwar sowohl um der Erwartungssicherheit der Mitarbeitenden willen, wie auch im Interesse einer Regelung, die dem kirchlichen Auftrag angemessen ist.

\subsection{Einwirkungen durch europäische Rechtsetzung}

a) Auf europarechtlicher Ebene hat der Rat der Europäischen Union auf der Grundlage von Art. 13 EG-Vertrag am 27.11.2000 die Richtlinie 2000/78/EG als arbeits-rechtliche Antidiskriminierungsrichtlinie erlassen, die in die mitgliedstaatlichen Rechtsordnungen umzusetzen ist. „Zweck dieser Richtlinie ist die Schaffung eines allgemeinen Rahmens zur Bekämpfung der Diskriminierung wegen der Religion oder Weltanschauung, einer Behinderung, des Alters oder der sexuellen Ausrich-tung in Beschäftigung und Beruf im Hinblick auf die Verwirklichung des Grundsatzes der Gleichbehandlung in den Mitgliedstaaten“ (Art. 1). Von den in Art. 2 näher bestimmten Diskriminierungsverboten lässt Art. 4 Ausnahmen zu, wobei Abs. 2 eine Spezialregelung für Kirchen und Weltanschauungsgemeinschaften darstellt. ${ }^{13}$ Die partielle Exemtion der Kirchen vom Diskriminierungsverbot basiert rechtsethisch auf dem Gedanken, dass das Ethos einer Überzeugungsgemeinschaft, die Trägerin der menschenrechtlichen Religionsfreiheit ist, ein relevanter Gesichtspunkt für gerechtfertigte Ungleichbehandlung sein kann. Diese wird durch die Bestimmung in dreifacher Hinsicht präzisiert:

Zunächst nimmt Art. 4 Abs. 2 Satz 1 die Ungleichbehandlung wegen des Merkmals der Nicht-Zugehörigkeit zur eigenen Religion oder Weltanschauung vom Diskriminierungsverbot aus. Für berufliche Tätigkeiten innerhalb von Kirchen

\footnotetext{
12 BVerfG 70, 138 (168).

13 Vgl. dazu v.a. Peter Hanau/Gregor Thüsing, Europarecht und kirchliches Arbeitsrecht. Bestandsaufnahme und Perspektiven, Baden-Baden 2001; Harald Schliemann, Europa und das deutsche kirchliche Arbeitsrecht. Kooperation oder Konfrontation?, in: Martin Dabrowski/Gerhard Robbers (Hg.), Europa und das deutsche kirchliche Arbeitsrecht, Münster 2003, 19-44; Jacob Joussen, Die Folgen der europäischen Diskriminierungsverbote für das kirchliche Arbeitsrecht, RdA 2003/Heft 1, 32-39; Detlef Kehlen, Europäische Antidiskriminierung und kirchliches Selbstbestimmungsrecht. Zur Auslegung von Art. 13 EG und Art. 4 der Richtlinie 2000/78/EG, Frankfurt a.M. 2003; Michael Germann/Heinrich de Wall, Kirchliche Dienstgemeinschaft und Europarecht, in: Rüdiger Krause/Winfried Veelken/Klaus Vieweg (Hg.), Recht der Wirtschaft und der Arbeit in Europa. Gedächtnisschrift für W. Blomeyer, Berlin 2004; 549-577; Christoph Link, Antidiskriminierung und kirchliches Arbeitsrecht, in: Krause/Veelken/Vieweg, ebd., 675-690.
} 
und Weltanschauungsgemeinschaften ist somit eine Ungleichbehandlung aus Gründen der Religion oder Weltanschauung durch den Arbeitgeber dann zulässig, wenn die Religion oder Weltanschauung des Arbeitnehmers „,nach der Art dieser Tätigkeiten oder der Umstände ihrer Ausübung eine wesentliche, rechtmäßige und gerechtfertigte berufliche Anforderung angesichts des Ethos der Organisation darstellt". - Sodann schließt Art. 4 Abs. 2 Satz 2 aus, dass die erlaubte Ungleichbehandlung aus Gründen der Religion auf Diskriminierungen aus anderen Gründen (also der Behinderung, des Alters oder der sexuellen Ausrichtung) ausgedehnt wird. - Schließlich erlaubt Art. 4 Abs. 2 Satz 3, dass die Kirchen und ihnen zugeordneten Organisationen ,im Einklang mit den einzelstaatlichen verfassungsrechtlichen Bestimmungen und Rechtsvorschriften von den für sie arbeitenden Personen verlangen, dass sie sich loyal und aufrichtig im Sinn des Ethos der Organisation verhalten“, sofern die Bestimmungen der Antidiskriminierungsrichtlinie „im [Ü]brigen eingehalten werden“.

b) Die Tragweite dieser Bestimmungen für den in der deutschen Rechtsprechung anerkannten Umfang des kirchlichen Selbstbestimmungsrechts ist in der juristischen Fachdiskussion umstritten:

Die Antidiskriminierungsrichtlinie setzt im gesamten Art. 4 Abs. 2 eine funktionsspezifische Differenzierung „nach Art der Tätigkeit“ voraus. Abstufungen dieser (oder anderer) Art vorzunehmen (oder auch nicht vorzunehmen) sowie über deren ,wesentliche, rechtmäßige und gerechtfertigte“ Anforderungen zu befinden, fällt nach deutscher Verfassungsrechtsprechung ausschließlich in die Kompetenz der Kirchen. Wer nun davon ausgeht, es sei auch im europäischen Gemeinschaftsrecht spätestens in Verbindung mit dem Erwägungsgrund Nr. 24 der Antidiskriminierungsrichtlinie (und der darin in Bezug genommenen Erklärung Nr. 11 der Schlussakte des Vertrags von Amsterdam ${ }^{14}$ ) anerkannt, dass die Mitgliedstaaten die Kompetenz hierzu bei den Kirchen belassen dürfen, kann zu dem Ergebnis gelangen, „dass die arbeitsrechtliche Ordnung der Kirchen in der Bundesrepublik Deutschland gemeinschaftsfest ist" ${ }^{\text {"15}}$. Dies wird dann - trotz Art. 4 Abs. 2 Satz 2 - z.B. auch für die generelle (nicht nur tätigkeitsbezogene) Unvereinbarkeit praktizierter Homosexualität mit einem Dienst in der katholischen Kirche angenommen.

Gegen die These von der „Gemeinschaftsfestigkeit“ des deutschen kirchlichen Arbeitsrechts stehen aber z.T. erheblich zurückhaltendere Stimmen, die - ungeachtet fehlender staatskirchenrechtlicher Kompetenzen des europäischen Gemeinschaftsrechts - bezweifeln, dass sich die deutsche Judikatur im vollen Umfang

14 „Die Europäische Union achtet den Status, den Kirchen und religiöse Vereinigungen oder Gemeinschaften in den Mitgliedstaaten nach deren Rechtsvorschriften genießen, und beeinträchtigt ihn nicht. Die Europäische Union achtet den Status von weltanschaulichen Gemeinschaften in gleicher Weise.“

15 Richardi (Anm. 7), \1 Rn. 38; im Ergebnis übereinstimmend: Hanau/Thüsing (Anm. 13); Joussen (Anm. 13), 36f. 
gegenüber der europäischen Rechtsentwicklung durchhalten lässt. ${ }^{16}$ Solche Skepsis sei schon deshalb angebracht, weil die menschenrechtliche Garantie der (auch kollektiven) Religionsfreiheit (Art. 9 Abs. 1 Europäische Menschenrechtskonvention) nur den Kern des kirchlichen Selbstbestimmungsrechts, nicht aber alle weitergehenden institutionellen Gewährleistungen im Sinn der korporativen Religionsfreiheit umfasse. ${ }^{17}$ Ferner bedeute das in Art. 4 Abs. 2 Satz 3 RL 2000/78/EG den Kirchen zugestandene Recht, spezifische Loyalitätserwartungen an ihre Mitarbeiter $\mathrm{zu}$ adressieren, nicht, dass ungerechtfertigte Ungleichbehandlungen zu Loyalitätsverletzungssanktionen umdefiniert werden dürfen; insofern komme auch hinsichtlich der Loyalitätspflichten im kirchlichen Arbeitsrecht das Problem der tätigkeitsbezogenen Abstufung wieder ins Spiel. ${ }^{18}$ Dies wirft die Frage auf, ob es auch nicht vom religiösen Ethos geprägte Dienste in der Kirche gibt. Sehr weitgehend ist die Prognose, die Regelung des Art. 4 Abs. 2 RL 2000/78/EG laufe im Grunde nur auf einen weit gefassten religiösen Tendenzschutz hinaus. ${ }^{19}$ Dies würde bedeuten, dass nicht die tendenzgeschützte Kirche nach ihren eigenen Maßstäben, sondern das staatliche Gericht den Schutzbereich zu definieren hat, der dann vom Tendenzbezug des jeweiligen Arbeitnehmers abhinge. ${ }^{20}$ Damit sei fraglich, ob eine Kündigung bei Kirchenaustritt für alle Mitarbeiter(gruppen) Bestand haben könnte. ${ }^{21}$ Harald Schliemann spitzt das Problem auf die Frage zu, inwieweit unter dieser Prämisse die caritativdiakonischen Einrichtungen, die aus EG-Sicht zunächst einmal als am Wirtschaftsleben beteiligte Dienstleister und Wettbewerber in den Blick kommen, überhaupt noch am Tendenzschutz partizipieren - insbesondere dann, wenn die Kirchen selbst nicht auf eine hinreichende Zahl religiös gebundener Mitarbeiter im Bereich der tätigen Nächstenliebe achten. ${ }^{22}$

Folgt man vorsichtshalber der skeptischeren (übrigens nicht zuletzt von Juristen protestantischer Provenienz vorgetragenen) Lesart, so verlangt die Antidiskriminierungsrichtlinie von den Religionsgemeinschaften noch einmal in anderer Weise als die deutsche Verfassungsrechtsprechung „eine (Selbst-)Vergewisserung ihrer Grundsätze“. ${ }^{23}$ Die Kirchen dürften gut beraten sein, die spezifischen Pflichten ihrer Arbeitnehmer(innen) von sich aus so zu kodifizieren, dass erkennbar wird, inwiefern diese Anforderungen als „,wesentliche, rechtmäßige und gerechtfertigte“

\footnotetext{
${ }^{16}$ Kehlen (Anm. 13); Link (Anm. 13); Schliemann (Anm. 13). Vgl. ferner Hans-Michael Heinig, Öffentlich-rechtliche Religionsgesellschaften. Studien zur Rechtsstellung der nach Art. 137 Abs. 5 WRV korporierten Religionsgesellschaften in Deutschland und in der EU, Berlin 2003.

17 Zusammenfassend Kehlen (Anm. 13), 204ff.

${ }^{18}$ Kehlen (Anm. 13), 198f; Link (Anm. 13), 688.

${ }_{19}$ Schliemann (Anm. 13).

${ }^{20}$ Vgl. zum Tendenzschutz Rüfner (Anm. 7), 905f; Richardi (Anm. 7), \6 Rnr. 25ff, \16 Rnr. 25ff.

${ }^{21}$ Kehlen (Anm. 13), 191f, 201.

22 Schliemann (Anm. 13), 34, 37f.

${ }^{23}$ Germann/de Wall (Anm. 13), $576 f$.
} 
gelten können - und das jetzt nicht nur in der kirchlichen Binnenperspektive, sondern auch bezogen auf ihre Plausibilisierbarkeit nach außen.

\section{Das geltende kirchliche Arbeitsrecht und die Initiativen zu einer EKD-Richtlinie - vergleichender Überblick}

\subsection{Die katholische Grundordnung des kirchlichen Dienstes}

Die Deutsche Katholische Bischofskonferenz hat dem in der erwähnten Leitentscheidung des Bundesverfassungsgerichts von 1985 enthaltenen „Imperativ“ des Staatskirchenrechts ${ }^{24}$ mit ihrer „Grundordnung des kirchlichen Dienstes im Rahmen kirchlicher Arbeitsverhältnisse“ vom 22. Sept. 1993 (GrOkathK) entsprochen. ${ }^{25}$ Darin wird als Voraussetzung für die Begründung des Arbeitsverhältnisses von allen in einer Einrichtung der katholischen Kirche Tätigen verlangt, „dass sie die Eigenart des kirchlichen Dienstes bejahen“; „pastorale, katechetische sowie in der Regel erzieherische und leitende Aufgaben" können nur einer Person übertragen werden, die der katholischen Kirche angehört (Art. 3 Abs. 1 u. 2).

Im übrigen wird eine deutlich differenzierte Abstufung der „Loyalitätsobliegenheiten" vorgenommen, die hauptsächlich an der Konfessionszugehörigkeit orientiert ist:

- Von katholischen Mitarbeitern ${ }^{26}$ wird erwartet, dass sie „die Grundsätze der katholischen Glaubens- und Sittenlehre anerkennen und beachten“. Von Mitarbeitern im pastoralen und erzieherischen Dienst sowie solchen, die auf Grund einer Missio canonica tätig sind oder leitende Funktionen ausüben, wird darüber hinaus das persönliche Lebenszeugnis im Sinne der Grundsätze der katholischen Glaubens- und Sittenlehre verlangt (Art. 4 Abs. 1).

\footnotetext{
${ }^{24}$ Heiner Marré, Zur Loyalität im Dienst der Kirche. Das Staatskirchenrecht als Imperativ, ThGl 78, (1988), 397-414.

25 Vgl. die folgenden Verweise im Text. Abgedruckt in: Sekretariat der Deutschen Bischofskonferenz (Hg.), Erklärung der deutschen Bischöfe / Grundordnung des kirchlichen Dienstes im Rahmen kirchlicher Arbeitsverhältnisse (= GrOkathK) (Die deutschen Bischöfe 51), 9. Aufl. Bonn 2003, 1521. Zur aktuellen Diskussion vgl.: Richard Puza, Die Amts- und Berufspflichten der kirchlich Bediensteten in Deutschland, ThQ 183, 2003, 39-70; Arnd Arntzen, Loyalität und Loyalitätsprobleme in kirchlichen Arbeitsverhältnissen. Eine Analyse des teilkirchlichen deutschen Arbeitsrechts und neuerer Leitungskonzepte im Caritasbereich, Bochum 2003; Klaus Lüdicke, Loyalität und Arbeitsverhältnis im Kirchendienst, in: Friedhelm Hengsbach/Ansgar Koschel (Hg.), 10 Jahre Grundordnung des kirchlichen Dienstes im Rahmen kirchlicher Arbeitsverhältnisse. Eine Bestandsaufnahme, Frankfurt a.M. 2004, 84-101; Andreas Weiß, Die Loyalität der Mitarbeiter im kirchlichen Dienst. Zur Festsetzung der Loyalitätsobliegenheiten in der Grundordnung, in: Hengsbach/Koschel (Hg.), 36-42; Eva Maria Öing, Loyalitätsbindungen des Arbeitnehmers im Dienst der katholischen Kirche, jur. Diss. Osnabrück 2004.

26 Soweit im Folgenden aus stilistischen Gründen nicht immer die inklusive Sprache beibehalten wird, ist die weibliche Form stets mitgemeint.
} 
- Nichtkatholische christliche Mitarbeiter sollen „die Wahrheiten und Werte des Evangeliums achten und dazu beitragen, sie in der Einrichtung zur Geltung zu bringen“" (Art. 4 Abs. 2).

- Nichtchristliche Mitarbeiter müssen bereit sein, ihre „Aufgaben im Sinne der Kirche zu erfüllen“ (Art. 4 Abs. 3).

- Alle Mitarbeiter haben kirchenfeindliches Verhalten zu unterlassen und dürfen ,in ihrer persönlichen Lebensführung die Glaubwürdigkeit der Kirche [...] nicht gefährden" (Art. 4 Abs. 4).

Verstöße gegen diese Obliegenheiten werden durch typische Regelbeispiele illustriert. ${ }^{27}$ Bei Mitarbeitern im pastoralen, erzieherischen und leitenden Dienst kommen solche Verstöße generell als schwerwiegende Kündigungsgründe in Betracht (Art. 5 Abs. 3). Bei den anderen Gruppen hängt die Möglichkeit zur Weiterbeschäftigung von der Art ihrer Aufgabe und dem Gewicht der Obliegenheitsverletzung ab (Art. 5 Abs. 4). Der Austritt aus der katholischen Kirche gilt immer als Kündigungsgrund; eine kirchenrechtlich ungültige Ehe dann, wenn sie unter glaubwürdigkeitsbeeinträchtigenden Umständen geschlossen wurde (Art. 5 Abs. 5).

Die katholische Kirche geht damit von einem primär konfessionsbezogenen Abstufungsmodell aus, innerhalb dessen sie selbst zusätzlich nach Tätigkeitsart und Glaubwürdigkeitsbeeinträchtigung differenziert. Damit hat sie das ihr verfassungsrechtlich gewährleistete Selbstbestimmungsrecht nach ihren eigenen Maßstäben ausgefüllt, ohne seinen Spielraum vollständig auszuschöpfen; eine Ausnahme stellt allerdings die Normierung der in Art. 5 Abs. 5 genannten Kündigungsgründe dar, die offenbar als absolute zu verstehen sind. ${ }^{28}$

\subsection{Gliedkirchen der EKD und Diakonisches Werk}

Auf evangelischer Seite ist es bislang nicht zu einer EKD-einheitlichen Regelung gekommen. Vielmehr regeln die Arbeits- bzw. Dienstvertragsordnungen oder Mitarbeitergesetze der kirchlichen Zusammenschlüsse, der Landeskirchen und des Diakonischen Werkes die Materie im Detail unterschiedlich:

a) Die Mitgliedschaft in der evangelischen Kirche wird im Bereich der verfassten Kirchen meistens als Regelvoraussetzung für die Begründung eines Beschäftigungsverhältnisses normiert. ${ }^{29}$ Ausnahmen gelten bei bestimmten Arbeitsbereichen für

\footnotetext{
27 „Kirchenaustritt“, „öffentliches Eintreten gegen tragende Grundsätze der katholischen Kirche (z.B. hinsichtlich der Abtreibung)“, „,schwerwiegende sittliche Verfehlungen“, „Abschluß einer nach dem Glaubensverständnis und der Rechtsordnung der Kirche ungültigen Ehe“, „Handlungen, die kirchenrechtlich als eindeutige Distanzierung von der katholischen Kirche anzusehen sind“.

${ }^{28}$ Den verfassungsrechtlichen Rahmen verlassen sieht hier Öing (Anm. 25), 146, 181.

${ }^{29}$ Z.B. $\int 1$ Abs. 2 Kirchliche Arbeits- und Vergütungsordnung (KAVO.UEK) v. 28.11.2002: „Die Beschäftigung als Mitarbeiter nach dieser Ordnung setzt grundsätzlich die Zugehörigkeit zur evangelischen Kirche voraus."
} 
Mitglieder anderer christlicher Kirchen. ${ }^{30}$ Eine Ausnahme für Personen, die keiner christlichen Kirche angehören, sieht die Evangelische Landeskirche in Baden vor, „wenn sich ihr Dienst im Wesentlichen auf die Wahrnehmung von internen Aufgaben im Verwaltungs-, Wirtschafts- und Technischen Dienst beschränkt" ${ }^{31}$ Teilweise kommen solche Ausnahmen auch dann in Betracht, wenn keine geeigneten Bewerber gefunden werden können ${ }^{32}$, oder bei befristeten Arbeitsverhältnissen. ${ }^{33}$ Der Kirchenaustritt oder „ein Verhalten, das eine grobe Missachtung der evangelischen Kirche darstellt", gelten als wichtige außerordentliche Kündigungsgründe. ${ }^{34}$

Die Evang.-Luth. Kirche in Bayern verzichtet auf eine generelle Normierung der Kirchenmitgliedschaft und verlangt als Voraussetzung für eine berufliche Mitarbeit zunächst nur, dass alle Mitarbeitenden ,die kirchliche Prägung und Tätigkeit der Einrichtung anerkennen".35 Ähnlich heißt es in den Arbeitsvertragsrichtlinien des Diakonischen Werkes der EKD lediglich: „Der diakonische Dienst geschieht im Auftrag Jesu Christi. Wer sich aus anderen Beweggründen zu diesem Dienst bereit findet, ist Mitarbeiterin und Mitarbeiter mit gleichen Rechten und Pflichten; sie bzw. er muss jedoch die evangelische Grundlage der diakonischen Arbeit anerkennen". 36

b) Auf weitergehende Lebensführungspflichten während des Arbeitsverhältnisses wird keineswegs durchweg Bezug genommen. ${ }^{37}$ Soweit dies der Fall ist, wird meist generalklauselartig das Erfordernis festgehalten, dass das dienstliche und außerdienstliche Verhalten dem Auftrag der Kirche zu entsprechen habe. ${ }^{38}$ In diesem Sinn formulieren auch die Arbeitsvertragsrichtlinien des Diakonischen Werks der EKD: „Alle in einer diakonischen Einrichtung tätigen Mitarbeiterinnen und Mitarbeiter bilden eine Dienstgemeinschaft. Von den Mitgliedern dieser Dienstgemeinschaft wird erwartet, dass ihr Verhalten innerhalb und außerhalb des Dienstes der Verantwortung für die Nächste und den Nächsten entspricht.“"39 Die Evangelische Landeskirche in Baden geht insofern weiter, als über die glaubwürdige Erfüllung des kirchlichen Auftrags hinaus die Bindung an „Schrift und

\footnotetext{
30 Z.B. $\int 4$ Abs. 2 MitarbeiterG.Konföderation ev. Kirchen in Niedersachsen i.d.F. v. 29.3.2001, KABl. S. 52.

${ }^{31}$ DV-Rahmenordnung Baden i.d.F. v. 21.10.1994, Gesetz- und Verordnungsblatt (GVBl). S.176.

32 Z.B. MitarbAusnG.EkiR i.d.F. v. 13.1. 2005, KABl. S.66

33 Z.B. \3 Abs. 2 KG betr. die Genehmigung von Arbeitsverträgen. EKBO v. 15.11.1997, KABl. S.219.

34 Z.B. \18 DVO.EKD i.d.F. v. 1.7.1991, ABl.EKD 1992, S.53.

$35 \rrbracket 2$ Abs. 2 ARR Berufl.Mitarbeit.ELKB, KABl. Nr. 1/2001.

$36 \$ 1$ Abs. 3 AVR-Diakonie.EKD.

${ }^{37}$ Z.B. nicht in LMG.Ev.-Luth. Landeskirche Sachsens i.d.F. v. 26.4.2004, ABl. S. A89.

${ }^{38}$ Z.B. $\$ 2$ DVO.EKD.

$39 \int 1$ Abs. 2 AVR-Diakonie.EKD.
} 
Bekenntnis und die Ordnung der Landeskirche“ erwartet wird; diese Bestimmung erfasst auch die Mitarbeiter des landeskirchlichen Diakonischen Werkes. ${ }^{40}$

Vor dem Hintergrund unterschiedlicher Konfessionszugehörigkeiten (und auch Tätigkeiten) der Mitarbeiter hat die Evang.-Luth. Kirche in Bayern - formal in deutlicher Anlehnung an das katholische Abstufungsmodell - eine insgesamt differenziertere Regelung getroffen. ${ }^{41}$ Wie in der GrOkathK werden die Loyalitätsobliegenheiten auch hinsichtlich der Verhaltensmerkmale genau abgestuft, wobei als übergeordnetes Kriterium die Konfessionszugehörigkeit zu Grunde gelegt wird:

- Der evangelischen Kirche angehörende Mitarbeiter sollen „Schrift und Bekenntnis anerkennen“. Mitarbeiter in Seelsorge, Unterweisung oder leitenden Funktionen sollen sich „in besonderer Weise darum bemühen, innerhalb und außerhalb des Dienstes christlichen Grundsätzen gerecht zu werden" ( $\int 6$ Abs. 2).

- Von anderen Christen ( $\int 4$ Abs. 2: Angehörige der Arbeitsgemeinschaft Christlicher Kirchen [ACK]) wird erwartet, dass sie „Schrift und Bekenntnis achten“ und „dazu beitragen, die Werte des Evangeliums in der Einrichtung zur Geltung zu bringen“ (\$ 6 Abs. 3).

- Sofern ausnahmsweise nichtchristliche Mitarbeiter eingestellt werden (\$ 4 Abs. 3), sollen diese ,den kirchlichen Auftrag beachten“ (\$ 6 Abs. 4).

- Für alle Mitarbeitenden gilt, dass sie sich loyal gegenüber der Evangelischen Kirche und ihrem Dienstgeber verhalten sollen (\$ 6 Abs. 2-4).

Als schwerwiegende Loyalitätsverstöße, die eine Kündigung aus kirchenspezifischen Gründen auslösen können, werden genannt: Kirchenaustritt, ein die evangelische Kirche und ihre Ordnungen grob missachtendes Verhalten, kirchenfeindliches Verhalten einschließlich der Mitgliedschaft in entsprechenden Organisationen, schwerwiegende persönliche sittliche Verfehlungen. Insbesondere bei Mitarbeitern in Seelsorge, Unterweisung oder leitenden Funktionen schließen die genannten Loyalitätsverstöße eine Weiterbeschäftigung aus ( 7 Abs. 3 und 5).

c) Zusammenfassend ist für den evangelischen Bereich festzuhalten: Allgemein wird die Anerkennung der evangelischen Prägung kirchlicher und diakonischer Arbeit vorausgesetzt.

Nach einem in den meisten verfassten Kirchen zugrundegelegten mitgliedschaftsbezogenen Regel-Ausnabme-Modell gilt die Mitgliedschaft in der/einer evangelischen Kirche als generelle Regel, von der jedoch Ausnahmen zugunsten von Mitgliedern anderer christlicher Kirchen, im Einzelfall auch zugunsten von Personen gemacht werden können, die keiner christlichen Kirche angehören. Auf Loyalitätsverpflichtungen wird dann meist nur durch eine Generalklausel verwiesen.

\footnotetext{
40 DV-Rahmenordnung Baden.

${ }^{41}$ ARR Berufl. Mitarbeit. ELKB, KABl. Nr.1/2001; darauf die Verweise im Text..
} 
Nach dem in der Evang.-Luth. Kirche in Bayern geltenden konfessionsberogenen Abstufungsmodell werden die Voraussetzungen für die Mitarbeit offener gehalten, die Loyalitätsobliegenheiten während des Dienstverhältnisses jedoch präziser beschrieben - und zwar abgestuft nach Konfessionszugehörigkeit und (jedenfalls ansatzweise) nach Tätigkeitsart; bei Pflichtverletzungen kommt auch das Gewicht der Glaubwürdigkeitsgefährdung ins Spiel.

Die Arbeitsvertragsrichtlinien des Diakonischen Werks der EKD begnügen sich mit einer offenen Umschreibung der Voraussetzungen zur beruflichen Mitarbeit und einer Generalklausel zu den Loyalitätspflichten.

\subsection{Die EKD-Initiativen}

Die Initiative zu einer EKD-Richtlinie bezüglich der Anforderungen an die berufliche Mitarbeit in Kirche und Diakonie geht auf das Jahr 1995 zurück. Ein erster Entwurf aus diesem Jahr (EKD-Richtlinienentwurf I) folgte dem konfessionsbezogenen Abstufungsmodell; 42 sein Wortlaut ist weitgehend in die Arbeitsrechtsregelung der Evang.-Luth. Kirche in Bayern aufgenommen worden. Die Ablehnung dieses Entwurfs durch die Mitarbeitenden hat dazu geführt, dass das Vorhaben offenbar erst vor dem Hintergrund der Entwicklungen auf europäischer Ebene wieder aufgegriffen wurde.

Eine in der Arbeitsgruppe der Leitenden Juristen der EKD beratene Fassung ${ }^{43}$ ist kaum verändert in den jetzt vorliegenden (gegenüber der Fassung von 1995 sehr viel knapper gehaltenen) EKD-Richtlinienentwurf II vom Februar 2004 eingegangen. ${ }^{44}$

- Dieser setzt hinsichtlich der Grundlagen des kirchlichen Dienstes mit der im Bereich der verfassten evangelischen Kirchen seit geraumer Zeit üblichen Standardformel für die kirchliche Dienstgemeinschaft ein: „Kirchlicher Dienst ist durch den Auftrag bestimmt, das Evangelium in Wort und Tat zu verkündigen. Alle Frauen und Männer, die in Anstellungsverhältnissen in Kirche und Diakonie tätig sind, wirken an der Erfüllung dieses Auftrags mit.“" (\$2 Abs. 1 Satz 1 u. 2).45

\footnotetext{
42 Entwurf der Richtlinie für eine Ordnung über die berufliche Mitarbeit in der Evangelischen Kirche und ihrer Diakonie sowie der Erklärung des Rates der Evangelischen Kirche in Deutschland dazu (Stand 10.2.1995).

43 Richtlinie über die Anforderungen der privatrechtlichen beruflichen Mitarbeit in der Evangelischen Kirche in Deutschland und ihres Diakonischen Werks (Entwurfsstand 19.8.2003; Az: 0340/1 und 2700/5.124-10).

${ }^{44}$ Darauf die folgenden Verweise im Text.

${ }^{45}$ Nahezu identisch ist der Wortlaut in Präambel MVG.EKD v. 6.11 .1992 (EKD-Texte 45). Offener formuliert MVG.Diakonie v. 10.6.1988: „Diakonie geschieht wie aller kirchlicher Dienst unter der Verheißung und dem Auftrag des Evangeliums und setzt eine vertrauensvolle Zusammenarbeit auch bei verschiedenartigen Dienst- und Lebensformen voraus. Zu dieser Dienstgemeinschaft sollen alle Mitarbeiter verantwortlich beitragen."
} 
- Als Anforderung bei der Begründung des Arbeitsverhältnisses gilt (nach der in $\int 3$ Abs. 1 Satz 1 missglückten Formulierung), dass alle Mitarbeitenden „Schrift und Bekenntnis achten und wahren und ihrem Handeln zugrunde legen".46 Außerdem sollen sie im Regelfall der evangelischen Kirche angehören ( $\int 3$ Abs. 1 Satz 2), was bisher für die Diakonie explizit nicht vorgesehen war. Bei Aufgaben, die nicht der Verkündigung, Seelsorge, Leitung oder Unterweisung zuzuordnen sind, soll, wenn nicht genügend geeignete evangelische Christ(inn)en gefunden werden können, die Mitgliedschaft in einer der ACK angehörenden Kirche genügen ( $\int 3$ Abs. 2 Satz 2). Aus dieser Soll-Bestimmung folgt, dass im Einzelfall und bei Bedarf auch Personen eingestellt werden können, die keiner Kirche angehören. Allerdings gilt als für eine kirchliche Beschäftigung ungeeignet, wer aus der evangelischen Kirche (gegebenenfalls auch einer anderen ACK-Kirche) ausgetreten ist ( $\int 3$ Abs. 3).

- Als Anforderung während des Arbeitsverhältnisses wird - neben loyalem Verhalten gegenüber der evangelischen Kirche als Arbeitgeber - erwartet, dass alle Mitarbeitenden (also auch die Nichtchristen) „dazu beitragen, das Evangelium in der Einrichtung zu bezeugen". Eine der übernommenen Verantwortung entsprechende, ,inner- und außerdienstliche Lebensführung“ wird explizit nur von den Mitarbeitern in Verkündigung, Seelsorge und Leitung erwartet ( $\int 4$ Satz 3). Diese Einschränkung steht allerdings in einer gewissen Spannung zu dem missglückten $\int 3$ Abs. 1 Satz 1.

- Bei Verstößen gegen die genannten Anforderungen kommt als ultima ratio eine außerordentliche Kündigung in Betracht, insbesondere bei Kirchenaustritt oder einem „Verhalten, das eine grobe Missachtung der evangelischen Kirche und ihrer Ordnungen" darstellt ( $\int 5$ Abs. 2).

Der EKD-Richtlinienentwurf II orientiert sich gegenüber der Version I stärker am mitgliedschaftsbezogenen Regel-Ausnahme-Modell und stellt sich in der Terminologie (Leitbegriff: „,berufliche Anforderungen“) auf die europäische Antidiskriminierungsrichtlinie ein. Im übrigen hat die knappere Fassung von Version II gegenüber der sehr viel durchdachter formulierten Version I zu einigen problematischen und missverständlichen Sätzen geführt.

\footnotetext{
${ }^{46}$ Was hier Verwirrung erzeugt, ist die Kumulation von Verhaltensmerkmalen, die (am deutlichsten in $\int 6$ ARR Berufl. Mitarbeit. ELKB) nur als Abstufung von „anerkennen“, über ,achten“ (bzw. respektieren) zu „beachten“ einen Sinn ergeben.
} 


\section{4. „Kirche“ und „Diakonie“ - theologische und kirchentheoretische Grundlagen}

Berufliche Mitarbeiterinnen und Mitarbeiter in kirchlichen und diakonischen Einrichtungen partizipieren an der Realisierung des Auftrags der Kirche. Diese Feststellung erfordert eine Verständigung darüber, was unter den mehrdeutigen Begriffen „Kirche“ und „Diakonie“ zu verstehen und wie deren „Auftrag“ zu beschreiben ist.

\subsection{Dreistufiger Kirchenbegriff}

Vorab ist es geboten, im Begriff „Kirche“ drei Bedeutungsebenen (nicht zu trennen, aber) zu unterscheiden: ${ }^{47}$ Nach evangelischem Verständnis ist „Kirche“ mit keiner erfahrbaren Sozialgestalt identisch, sondern bezeichnet zunächst im geistlichen, theologisch-dogmatischen Sinn die Gemeinschaft der Glaubenden, die ihren Ursprung im befreienden Zuspruch des Evangeliums und seiner durch den Heiligen Geist vermittelten existentiellen Gewissheit hat. Die solchermaßen geistlich konstituierte Gemeinschaft der Glaubenden, ihre „Gliedschaft“ am „Leib Christi“, ist menschlich unverfügbar und hinsichtlich ihres Umfangs und ihrer Grenzen verborgen.

Die Gemeinschaft der Glaubenden bleibt aber nicht ohne sichtbare Folgen. Diese manifestieren sich in den elementaren äußeren Handlungsvollzügen, die eine Glaubensgemeinschaft unverwechselbar als christlich kennzeichnen. Nach reformatorischem Sprachgebrauch steht der Ausdruck „Kirche“ (im Singular!) darum zweitens im liturgisch-ethischen Sinn für die signifikanten Praxisvollzüge bzw. Lebensäußerungen, durch die Christinnen und Christen auf den befreienden Zuspruch des Evangeliums antworten und ihm zu entsprechen versuchen.

Schließlich bezeichnet der Begriff „Kirche“ drittens im Rechtssinn die verfasste Kirche als partikularen christlichen Bekenntnisverband, der in der Realität nur im Plural existiert. Diese Kirchen im Rechtssinn sind als soziale Organisationen Mittel zur temporalen, quantitativen und qualitativen Koordination des Gemeinschaftshandelns von Christinnen und Christen. Unter Organisation sei hier die Zusammenordnung sozialer Handlungen zu einer Wirkeinheit verstanden, die eine

\footnotetext{
47 Am klarsten herausgestellt wurde der dreistufige Kirchenbegriff von Albrecht Ritschl, Die Begründung des Kirchenrechtes im evangelischen Begriff von der Kirche, ZKR 8 (1869), 220-279 (= in: ders., Gesammelte Aufsätze, Freiburg/Leipzig 1893, 100-146); vgl. weiterführend HansRichard Reuter, Der Begriff der Kirche in theologischer Sicht, in: Gerhard Rau/Hans-Richard Reuter/Klaus Schlaich, Das Recht der Kirche I. Zur Theorie des Kirchenrechts, Gütersloh 1997, 2375. Luther folgend - wenn auch mit problematischen Konsequenzen für den Rechtsbegriff des Kirchenrechts - arbeitet auch Johannes Heckel (Initia iuris ecclesiastici Protestantium, München 1950; ders., Lex Charitatis. Eine juristische Untersuchung über das Recht in der Theologie Martin Luthers, 2. Aufl. Köln/Wien 1973, 354ff) mit einem dreischichtigen Kirchenverständnis: ecclesia spiritualis, ecclesia universalis, ecclesia particularis. Zu Luther vgl. jetzt Gudrun Neebe, Apostolische Kirche. Grundunterscheidungen in Luthers Kirchenbegriff unter besonderer Berücksichtigung seiner Lehre von den notae ecclesiae, Berlin/New York 1997.
} 
Abgrenzung des Kreises der Mitwirkenden erlaubt und die rational, d.h. nach selbstgesetzten Regeln konstruiert ist. ${ }^{48}$ Organisationssoziologischen Einsichten zufolge ist des Näheren die Interdependenz dreier Faktoren bestimmend, nämlich: „Programm“ (was ist Zweck und Aufgabe der Organisation?), „Personal“ (wer ist auf Grund welcher persönlicher Merkmale zur Aufgabenerfüllung geeignet?) und „Struktur“ (wie ist die Organisationsform i. e. S. beschaffen?). Außerdem sind Organisationen im Allgemeinen durch die nichtkontingente Verknüpfung zweier kontingenter Sachverhalte gekennzeichnet, nämlich die Entscheidung über die Mitgliedschaft und die Festlegung von Struktur und Programm. ${ }^{49}$ Daran jedoch, dass die Kirchen in ihrer geistlichen Tiefendimension nicht durch eine rein freiwillentliche Entscheidung über Zugehörigkeit oder Nichtzugehörigkeit konstituiert sind und ihre Struktur und ihr Programm nur in dem Maße als variabel gelten können, als ihre signifikanten Praxisvollzüge gewahrt bleiben, zeigt sich die nur begrenzte Organisierbarkeit von Kirchen. In soziologischer Sicht kann man die Selbstverwaltungs- und Korporationsrechte der Religionsgemeinschaften aus Art. 140 GG i.V. mit Art. 137 WRV durchaus als legitimen Ausgleich dafür verstehen, dass die Kirchen über ihr „Programm“, ihre geistlich-religiös begründeten „Verbandszwecke“ nicht frei verfügen und sie nicht ins Belieben ihrer Mitglieder stellen können.

\subsection{Grundvollzüge der Kirche}

Die Gesamtheit der für die Christenheit signifikanten Praxisvollzüge wird heute in den reformatorischen Kirchen meist in biblischer Terminologie unter dem Doppelaspekt von „Zeugnis und Dienst“ umschrieben. ${ }^{50}$ In diesem Zusammenhang wird hervorgehoben, dass sich „Zeugnis“ und „Dienst“ „nicht auf zwei Bereiche“, sondern „auf zwei Aspekte“ der Glaubenspraxis beziehen. ${ }^{51}$ Deutlicher lassen sich Unterscheidung und Zusammengehörigkeit beider Aspekte vielleicht in der handlungstheoretischen Differenzierung von darstellendem und wirksamem Handeln fassen: ${ }^{52} \mathrm{Im}$ darstellenden Handeln findet das Selbst- und Weltverständnis einer Gemeinschaft unmittelbar Ausdruck; Wirkhandlungen hingegen greifen durch effektive Mittelwahl Zwecke realisierend in die Wirklichkeit ein.

\footnotetext{
48 Vgl. Niklas Luhmann, Art. Organisation I. HWP VI, 1326-28.

49 Vgl. Niklas Luhmann, Die Organisierbarkeit von Religionen und Kirchen, in: Jakobus Wössner (Hg.), Religion im Umbruch. Soziologische Beiträge zur Situation von Religion und Kirche in der gegenwärtigen Gesellschaft, Stuttgart 1972, 245-285, $278 \mathrm{f}$.

${ }_{50} \mathrm{Vgl}$. Leuenberger Konkordie 11, 13, 29, 36.

${ }^{51}$ Leuenberger Kirchengemeinschaft/ Gemeinschaft reformatorischer Kirchen in Europa (Hg.), Die Kirche Jesu Christi. Der reformatorische Beitrag zum ökumenischen Dialog über die kirchliche Einheit (Leuenberger Texte 1), Frankfurt a.M. 1995, 31.

52 Vgl. zum Folgenden (terminologisch im Anschluss an die Handlungstheorie Friedrich Schleiermachers, Die christliche Sitte nach den Grundsätzen der evangelischen Kirche im Zusammenhange dargestellt [SW I/12], 2. Aufl. Berlin 1884): Hans-Richard Reuter, Die Bedeutung der kirchlichen Dienste, Werke und Verbände im Leben der Kirche, PTh 85 (1996), 33-50; ders., Der Begriff der Kirche in theologischer Sicht (Anm. 47), 57ff.
} 
Dabei bleibt aber auch intentional darstellendes Handeln als soziales Faktum nie ohne (indirekte) Wirkungen; ebenso eignet jedem intentional wirksamen Handeln indirekt ein Moment der Darstellung, d.h. der Symbolisierung des Selbst- und Wirklichkeitsverständnisses der Gemeinschaft.

Von hier aus kann man sagen: Primär und unverwechselbar kommt die Glaubensgemeinschaft in der Feier des Gottesdienstes, also im liturgischen Handeln einer versammelten Gemeinde zur Darstellung. Deshalb sind Wortverkündigung und Feier der Sakramentsdarbietung nach reformatorischem Bekenntnis ${ }^{53}$ die unverwechselbaren Kennzeichen der Christenheit als darstellender Handlungsgemeinschaft und in diesem Sinn die expliziten notae ecclesiae, die jede verfasste Kirche zu garantieren hat.

Die reformatorische Tradition kennt aber über die expliziten notae ecclesiae im Bereich des darstellenden Handelns hinaus auch implizite Kennzeichen, die sich auf das wirksame Handeln der Christenheit in der Welt beziehen. ${ }^{54}$ Luther hat dafür die christliche Lebensführung gemäß der zweiten Tafel des Dekalogs herangezogen allerdings vor dem zeitbedingten Hintergrund einer christlichen Gesellschaft und bezogen auf die in seiner Ständelehre vorgezeichneten sozialen Abhängigkeitsverhältnisse. Unter den Bedingungen einer differenzierten Gesellschaft erscheint es angemessener, auch die elementaren Lebensäußerungen der Christenheit, die auf die wirksame Sozialgestaltung abzielen, in den darstellenden Grundvollzügen der Glaubensgemeinschaft (Wortverkündigung, Taufe und Herrenmahl) verankert zu sehen. Von daher sind für jedes wirksame Gemeinschaftshandeln von Christinnen und Christen die folgenden Dimensionen unverzichtbar:

- In Korrespondenz zur Wortverkündigung, die ihrerseits auf ein personales Bildungsgeschehen zielt: die Teilnahme an den Bildungsprozessen der Gesellschaft.

- In Korrespondenz zur Taufe, die symbolisiert, dass jedem Menschen eine unverlierbare Würde zukommt: die Teilnahme am Gerecbtigkeitshandeln und der Rechtspraxis der Gesellschaft.

- In Korrespondenz zur Feier des Herrenmahls, die das Solidaritätsethos der christlichen Gemeinschaft ausdrückt: die Praxis solidarischer Hilfe.

Bildungs-, Gerechtigkeits- und Hilfehandeln sind somit implizite, aber unverzichtbare Kennzeichen der „Kirche“. Damit ist gemeint, dass alle drei Praxisformen - noch vor ihrer Institutionalisierung durch die verfassten Kirchen - Grunddimensionen des Gemeinschaftshandelns von Christinnen und Christen sind. Von ihrer freien wie von ihrer durch die verfassten Kirchen organisierten

\footnotetext{
${ }^{53}$ Confessio Augustana (CA) Art. VII (BLSK 59f).

54 Wolfgang Huber (Kirche in der Zeitenwende, Gesellschaftlicher Wandel und Erneuerung der Kirche, Gütersloh 1998, 157ff) ist dem inhaltlich, jedoch mit der terminologischen Unterscheidung von „primären“ und „sekundären“ Kennzeichen der Kirche gefolgt.
} 
Gestalt gilt, dass die Christenheit auf diesen Handlungsfeldern etwas tut, was auch von Nichtchristen und mit ihnen gemeinsam getan werden kann. ${ }^{55}$

\subsection{Kirchliche Identität und diakonische Realität}

Die EKD versteht auch die organisierte Diakonie als „Wesens- und Lebensäußerung der Kirche“. ${ }^{66}$ Dies geschieht im Sinn des Postulats zu Recht, allerdings stößt die ekklesiologische Maxime der Einheit von Zeugnis und Dienst im Rahmen des kirchlich organisierten Hilfehandelns auf besondere Schwierigkeiten. Denn es erfolgt in der Bundesrepublik Deutschland nur zum geringsten Teil als Kommunitäten-, Vereins- oder auch nur Gemeindediakonie, d.h. als eine Zuwendung einzelner Mitglieder der christlichen Gemeinde zu den Hilfsbedürftigen unter ihnen, die als integraler Teil religiöser Praxis erfahren werden kann. Die organisierte Diakonie ist nicht nur im Kontext Kirche verortet; sie ist ebenso Teil eines sozialstaatlichen Arrangements, das über das Subsidiaritätsprinzip den Vorrang der Wohlfahrtsverbände bei der sozialen Leistungserbringung absichert und die Verbände in den Rang sozialpolitischer Akteure erhebt.

In protestantischer Perspektive ist sowohl die subsidiäre Reduktion staatlicher (All-) Zuständigkeit wie auch die subsidiäre Assistenz zugunsten eines Wohlfahrtspluralismus, der die weltanschaulich-kulturelle Vielfalt der gesellschaftlichen Kräfte (erkennbar!) widerspiegelt, sozialethisch wohlbegründet. Auch widerspricht die Teilnahme der Diakonie an der gesamtgesellschaftlichen Wohlfahrtsproduktion als solche keineswegs dem kirchlichen Auftrag - ist sie doch Konsequenz des Gedankens, dass die Kirche in Zeugnis und Dienst als „Kirche für andere“ (D. Bonhoeffer) zu existieren hat. So wie sie „durch Predigt und Sakrament die Botschaft von der freien Gnade Gottes auszurichten [hat] an alles Volk ${ }^{\text {" }},{ }^{77}$ so ist sie - nach dem Beispiel des barmherzigen Samariters - mit ihrem Hilfehandeln prinzipiell an jeden Menschen gewiesen, der ihr unabhängig von Herkunft und religiösem Bekenntnis zum hilfsbedürftigen Nächsten werden kann. Nach derselben diakonischen Urerzählung besteht sogar ein Primat der Wirkung der Hilfe vor dem Motiv, so dass im Notfall die Frage nach der Herkunft auch des Helfenden zurücktritt. Schließlich ist die Bejahung einer sozialpolitischen Rolle der Diakonie der Einsicht geschuldet, dass soziales Hilfehandeln im Licht des modernen Menschenrechtsdenkens und des biblischen Ethos nicht auf Taten individueller Barmherzigkeit verkürzt werden darf, sondern nach Prinzipien sozialer Gerech-

\footnotetext{
55 Vgl. Martin Luther, Von den Konziliis und Kirchen, WA 50, 509-653 (643.28f): ,[...] weil auch etliche Heiden sich in solchen wercken geübt und wol zu weilen heiliger scheinen, weder die Christen [...].“

56 Art. 15 Abs. 1 Grundordnung der EKD (GO.EKD). Einen Durchblick durch die komplexen, diesem Programmsatz empirisch korrespondierenden Strukturen gibt im Konfessionsvergleich Berthold Broll, Steuerung kirchlicher Wohlfahrtspflege durch die verfaßten Kirchen, Gütersloh 1999.

${ }^{57}$ Barmer Theologische Erklärung VI. These.
} 
Hans-Richard Reuter

tigkeit und mit der Erwartungssicherheit des Rechts erfolgen soll. ${ }^{8}$ Die Teilnahme der Diakonie an der gesamtgesellschaftlichen Sozialversorgung schließt deshalb eine dezidiert sozialanwaltliche Funktion für die „Mühseligen und Beladenen“ jedweder Provenienz ein.

Die funktionale Integration von impliziten Grundvollzügen der Kirche in die allgemeinen Gemeinwohlaktivitäten ist jedoch nicht ohne Probleme für ihr Profil. Die Kirche erbringt hier Leistungen für andere gesellschaftliche Teilsysteme, die es erfordern, „sich Fremdorientierungen zu unterstellen, um ankommen zu können " ${ }^{59}$ Dies gilt für die Diakonie als Organisation in besonderem Maße:60

Erstens hat die (dank sozialstaatlicher Refinanzierung starke) Expansion der diakonischen Arbeitsfelder in den letzten Jahrzehnten zu einem exponentiellen Wachstum des Personalbedarfs geführt. Konnte die Mitarbeiterschaft herkömmlich - den vereinsdiakonischen Anfängen im 19. Jahrhundert entsprechend - aus den diakonischen Berufen rekrutiert werden, die dem christlichen Nächstendienst qua Berufung verpflichtet waren, so zwangen die Rahmenbedingungen der Sozialstaatsdiakonie in großem Stil zur Einstellung von Personal, das oft eine nur geringe Identifikation mit dem christlichen Programm der Diakonie aufweist.

Zweitens sind die Sozialberufe Vorreiter in der Entwicklung neuer Professionen d.h. von Berufen, die sich auf der Grundlage eines spezifischen fachlichen Wissens anspruchsvollen Sachthematiken zu stellen haben, diese wegen ihrer existentiellen Relevanz auf der Beziehungsebene bearbeiten, und die die Standards ihrer beruflichen Tätigkeit autonom kontrollieren. ${ }^{11}$ Die (notwendige) Professionalisierung des Personals, die Betonung eigenverantworteter Fachlichkeit und die Orientierung an arbeitgeber-unspezifischen, wohl aber professionstypischen Standards sind weitere Faktoren dafür, dass Fragen der Wertbindung und des christlichen Engagements der Mitarbeiterschaft zurücktraten.

Diese Tendenz wurde drittens verstärkt durch die Übernahme sozialer Einrichtungen und ihres Personals in den Ländern der ehemaligen staatsatheistischen DDR in kirchliche Trägerschaft. Nach der Statistik der Diakonie standen zum 1.1.1994 in Deutschland insgesamt 370.000 Mitarbeiter(innen) im diakonischen

\footnotetext{
${ }^{58}$ Vgl. z.B. Hans-Richard Reuter, Politische Freiheit und soziale Gerechtigkeit. Ethische Aspekte der Sozialstaatlichkeit, in: Joachim Mehlhausen (Hg.), Recht - Macht - Gerechtigkeit, Gütersloh 1998, 146-160.

${ }^{59}$ Niklas Luhmann, Funktion der Religion, Frankfurt a.M. 1977, 59.

${ }^{60} \mathrm{Vgl}$. statt anderer die Analysen bei Karl-Fritz Daiber, Diakonie und kirchliche Identität. Studien zur diakonischen Praxis der Volkskirche, Hannover 1988, bes. 111ff. Zur Situation der Wohlfahrtsverbände allgemein vgl. Thomas Rauschenbach/Christoph Sachße/Thomas Olk (Hg.), Von der Wertgemeinschaft zum Dienstleistungsunternehmen. Jugend- und Wohlfahrtsverbände im Umbruch, Frankfurt a.M. 1996.

${ }^{61}$ Zur neueren Professionstheorie vgl. zusammenfassend Arno Combe/Werner Helsper (Hg.), Pädagogische Professionalität. Untersuchungen zum Typus pädagogischen Handelns, Frankfurt a.M. 1996.
} 
Dienst der evangelischen Kirche; 62 davon waren 59,2\% evangelisch, 22,7\% katholisch, 17,1\% konfessionslos. In Ostdeutschland waren 52,3\% evangelisch, $5,3 \%$ katholisch und immerhin 41,5\% konfessionslos. Die Anteile für Westdeutschland betrugen: 60,3\% evangelisch, 25,8\% katholisch, 12,7\% konfessionslos.

Viertens und neuestens stellt die forcierte Transformation der sozialen Sicherungssysteme, die den Sozialstaat zugunsten des Sozialmarkts zurücknimmt, auch das wohlbegründete sozialpolitische Selbstverständnis der kirchlichen Wohlfahrtsverbände samt ihrer Struktur in Frage: Das diakonisch-caritative Handeln steht vor der Zumutung eines Adressatenwechsels vom anspruchsberechtigten Bürger zum entweder leistungskräftigen Kunden oder aber bedürftigen Almosenempfänger; und die organisierte Diakonie ist mit dem Problem konfrontiert, wie sie sich weiterhin als sozialanwaltliche Organisation behaupten kann.

In idealtypischer Vereinfachung sind drei Möglichkeiten denkbar, mit der Spannung von kirchlicher Identität und diakonischer Realität umzugehen: ${ }^{63}$ In einem Konzentrationsmodell würde die Diakonie - wie in den Anfängen - als Gemeindediakonie und in enger Anbindung an die Verkündigung als Innere Mission begriffen. Der sozialethische und gesellschaftsdiakonische Anspruch der Kirche wäre damit allerdings zurückgenommen. - In einem organisatorischen Trennungsmodell nähme die Diakonie den Ökonomisierungsdruck zum Anlass, ihre Einheit durch Teilung in einen wertgrundierten sozialanwaltschaftlichen Verband und in einen betriebswirtschaftlich orientierten Unternehmensverband aufzugeben. ${ }^{64}$ In der Folge würden auch wertbestimmte Konflikte mit den indifferenten Teilen der Mitarbeiterschaft entfallen. Damit wäre jedoch die Einheit von Zeugnis und Dienst aufgekündigt. - Erkennt man beides aus theologischen Gründen als Irrwege, so bleibt die Aufgabe bestehen, die bezeichnete Spannung in einem Modell der offenen Kirche auszuhalten, das nicht nur unterschiedliche individuelle Religiositätsstile und Motivlagen der Beschäftigten akzeptiert, sondern auch Nichtchristen zur Mitarbeit einlädt. Die kirchliche Identität muss dann ,in einem bewusst offen gehaltenen Prozess immer neu gewonnen“ werden. ${ }^{65}$ Daraus folgt aber die Notwendigkeit, auch durch rechtliche Rahmenbedingungen dazu beizutragen, dass die offene Kirche Kirche bleibt.

\footnotetext{
62 Diakonisches Werk der EKD (Hg.), Statistik der Mitarbeiter/innen im diakonischen Dienst, Statistische Informationen Nr.3/1996; neuere Angaben existieren leider nicht. Die Gesamtzahl der Beschäftigten in Kirchen, Diakonie und Caritas wird heute auf 1,2 Mill. geschätzt; vgl. Schliemann (Anm. 13), 20.

${ }^{63}$ Vgl. Daiber (Anm. 60), $138 \mathrm{ff}$.

${ }^{64}$ Zur neueren Diskussion (auch in der Caritas) vgl. u.a.: Werner Krämer/Karl Gabriel/Norbert Zöllner (Hg.), Neoliberalismus als Leitbild für kirchliche Innovationsprozesse? Arbeitgeberin Kirche unter Marktdruck, Münster 2000; Johannes Eurich, Nächstenliebe als berechenbare Dienstleistung. Zur Situation der Diakonie zwischen Ökonomisierung, theologischem Selbstverständnis und Restrukturierung, ZEE 49 (2005), 58-70.
}

${ }^{65}$ Daiber (Anm. 60), 139 


\section{Differenzierte „Dienstgemeinschaft“ - zum personellen Geltungsbereich kirchenspezifischer Anforderungen}

Der EKD-Richtlinienentwurf II knüpft an den Gedanken der kirchlichen „Dienstgemeinschaft“ als maßgebliches, auch verfassungsrechtlich rezipiertes Prinzip für die Ordnung des kirchlichen Mitarbeiterrechts an. Das Konzept der „Dienstgemeinschaft" ${ }^{\text {"66 }}$ soll zum Ausdruck bringen, dass alle in Einrichtungen der Kirche Mitarbeitenden in gleicher Weise und unabhängig von ihrer besonderen beruflichen Aufgabe dem religiös bestimmten Auftrag der Kirche verpflichtet sind; daraus folgt, dass die Erfüllung dieses gemeinsamen Auftrags in vertrauensvoller Zusammenarbeit geschehen soll und entsprechende (bereits ungeschriebene) Verhaltenserwartungen einschließt. Während die ältere kontroverse Diskussion zur „Dienstgemeinschaft“ vorwiegend den aus ihr abgeleiteten Konsequenzen für das kollektive Arbeitsrecht (Stichwort: Dritter Weg und Ausschluss des Streikrechts für kirchliche Mitarbeiter) gewidmet war, steht mit dem EKDRichtlinienentwurf die Bedeutung des Konzepts für die Ausgestaltung der individualarbeitsrechtlichen Rechte und Pflichten zur Debatte. Wesentliche Divergenzen im Verständnis der „Dienstgemeinschaft" resultieren regelmäßig daraus, dass das Konzept von der subjektiven oder der objektiven Seite her ausgelegt werden kann. ${ }^{67}$

\subsection{Theologische Begründung im allgemeinen Priestertum}

Die Idee der Dienstgemeinschaft ist theologisch im „Priestertum aller Gläubigen“ begründet. ${ }^{68}$ Für das protestantische Verständnis ist maßgeblich, dass mit dieser Wendung Luther - in Abgrenzung gegen das römisch-katholische Amtspriestertum - den Dienst bezeichnet hat, mit dem alle Christinnen und Christen durch die Taufe betraut sind. ${ }^{69}$ Die Verwendung des biblischen Topos vom allgemeinen

66 Josef Jurina, Die Dienstgemeinschaft der Mitarbeiter des kirchlichen Dienstes, ZevKR 29 (1984), 171-188; Heinrich Beyer/Hans G. Nutzinger (Hg.), Erwerbsarbeit und Dienstgemeinschaft. Arbeitsbeziehungen in kirchlichen Einrichtungen - Eine empirische Untersuchung, Bochum 1991; Karl-Fritz Daiber, Die diakonische Anstalt als Dienstgemeinschaft, WzM 44 (1992), 193-204; Wolfgang Lienemann, Kirchlicher Dienst zwischen kirchlichem und staatlichem Recht, in: Gerhard Rau/Hans-Richard Reuter/Klaus Schlaich (Hg.), Das Recht der Kirche III. Zur Praxis des Kirchenrechts, Gütersloh 1994, 495-530; Matthias Hirschfeld, Die Dienstgemeinschaft im Arbeitsrecht der evangelischen Kirche. Zur Legitimitätsproblematik eines Rechtsbegriffs, Frankfurt 1999; Germann/de Wall (Anm. 13).

${ }^{67}$ Vgl. das Referat zum innerkirchlichen Debattenverlauf seit 1976 bei Hirschfeld (Anm. 66), 69ff.

${ }_{68}$ Armin Pahlke, Kirche und Koalitionsrecht. Zur Problematik des kirchlichen Arbeitsrechtsregelungsverfahrens, insbesondere des sog. Dritten Weges der Kirchen, Tübingen 1983, 41ff; Axel von Campenhausen, Die Verantwortung der Kirche und des Staates für die Regelung von Arbeitsverhältnissen im kirchlichen Bereich, Essener Gespräche 18 (1984), 9-39; Richardi (Anm. 7), \4, Rnr. 10-17.

${ }^{69}$ Weil die Glaubenden durch die in der Taufe zugeeignete Rechtfertigung Anteil an Jesus Christus und seinem Priestertum gewinnen, gilt: ,was ausz der Tauff krochen ist, das mag sich rumen, das es schon priester, Bischoff und Bapst geweyet sey"; Martin Luther, An den christlichen Adel deutscher Nation von des christlichen Standes Besserung (1520), WA 6, 404-469 (408). Vgl. zuletzt Harald 
Priestertum betont zum einen die gleiche Priesterwürde aller Christen vor Gott, die darin besteht, dass alle zur direkten Gemeinschaft mit ihm berufen und zum direkten Zugang zu ihm im Gebet befähigt sind, zum andern die gleiche Vollmacht aller zum Priesterdienst, der zum Ziel hat, dem Nächsten die in Christus eröffnete Gottesbeziehung zu bezeugen und ihm so in seinem Christwerden (und damit wiederum: Priestersein) zu helfen. ${ }^{70}$ Zum allgemeinen Priestertum gehören Luther zufolge Gebet, Fürbitte, Bezeugung des Evangeliums und der Gottesdienst im Alltag des christlichen Lebens. ${ }^{71}$

Das allgemeine Priestertum steht somit für die gleiche Würde und den gleichwertigen Dienst aller Getauften. Es bezieht sich auf die Christenheit als Taufgemeinschaft und gibt im paulinischen Sinn den vielfältigen Begabungen bzw. Charismen am „Leib Christi“ (1Kor. 12,12ff) Raum. Die Dienstgemeinschaftsidee des allgemeinen Priestertums ist eine strikt theologische Bestimmung, die nicht mit den Organisationsformen partikularkirchlicher Dienstverhältnisse gleichgesetzt werden darf. Denn die Dienstbarkeit des allgemeinen Priestertums entspringt der Freiheit eines Christenmenschen und folgt keiner äußeren Rechtspflicht. ${ }^{72}$ Ferner geht diese Freiheit zum Dienst keineswegs in den Arbeitsfeldern des organisierten kirchlichen Dienstes auf, sondern manifestiert sich dem reformatorischen Berufsgedanken zufolge auch und gerade dort, wo Christinnen und Christen ,in der Vielfalt und Ordnung weltlicher Berufe handeln und damit ihrer geistlichen Berufung äußere Gestalt zu geben versuchen. [...] Der Dienst der Kirche geht weit über den kirchlichen Dienst hinaus“.${ }^{73}$ Entscheidend sind der subjektive Faktor der glaubensbestimmten Teilhabe am Leib Christi und das daraus hervorgehende wertrationale Handeln.

Mit dem allgemeinen Priestertum ist des Weiteren eine Aussage über Begründung und Zuordnung der innerhalb der Kirchenorganisation zu institutionalisierenden Ämter verbunden: ${ }^{74}$ Alle in der Kirche (ob beruflich oder ehrenamtlich) wahrgenommenen Ämter stellen stets Ausdifferenzierungen des umfassenden Dienstes der Christenheit dar; sie ,begründen keine Herrschaft des einen über die anderen, sondern die Ausübung des der ganzen Gemeinde anvertrauten und befohlenen Dienstes. “75 Auch das ordinierte Amt, das zur öffentlichen Wortverkündigung

Goertz, Allgemeines Priestertum und ordiniertes Amt bei Luther, Marburg 1997; ferner Hans-Martin Barth, Einander Priester sein. Allgemeines Priestertum in ökumenischer Perspektive, Göttingen 1990.

${ }^{70} \mathrm{Im}$ Neuen Testament wird der Priestertitel im metaphorischen Sinn zur Bezeichnung Jesu Christi (vgl. Hebr 4-10) und aller Christen (IPetr 2,5 u. 9; Apk 1,6; 5,10 u. 20,6) gebraucht.

${ }^{71}$ Vgl. WA 7, 57.25f; WA 8, 416.12-16, 420.10-26.

${ }^{72}$ S. dazu Martin Luther, Von der Freiheit eines Christenmenschen, WA 7, 20-38.

${ }^{73}$ Lienemann (Anm. 66), 516f.

${ }^{74}$ Die amtstheologischen und -rechtlichen Fragen habe ich ausführlich behandelt in: Hans-Richard Reuter, Gutachten zum Pfarrerbild für eine Revision der Kirchenordnung der Evangelischen Kirche in Hessen und Nassau, April 2004, www.uni-muenster.de/Ethik/EKHN-Gutachten.pdf.

${ }^{75}$ Barmer Theologischen Erklärung IV. These. 
und Feier der Sakramente berufen ist, ${ }^{76}$ muss nach lutherischem Verständnis aus dem allgemeinen Priestertum der Getauften entwickelt werden: Um der guten Ordnung der öffentlichen Verkündigung und Sakramentsverwaltung willen gilt, dass die gleiche Vollmacht aller Getauften nicht mit dem gleichen Recht zur Ausübung dieser Vollmacht einhergeht, es zur Übertragung des Letzteren vielmehr einer ordentlichen Berufung bedarf. ${ }^{77}$ Dass das ordinierte Predigtamt in der lutherischen Tradition als einziges geordnetes Amt herausgestellt worden ist, weil es in besonderer Weise für das geistliche Identitätszentrum der Kirche einsteht, bedeutet nicht, dass es nach menschlichem Recht keine anderen geordneten Ämter in der Kirche zu geben hätte: Solcher (ehren- und hauptamtlicher) Dienste bedarf es zum geordneten Zusammenwirken des Predigtamts mit Vertretern der Gemeinde (Älteste, Kirchenvorsteher, Synodale), zur Gestaltung des gottesdienstlich-darstellenden Handelns der Kirche (Kirchenmusiker, Küster) sowie im Blick auf das gesamte organisations- und gesellschaftsbezogen-wirksame Handeln der Kirche. ${ }^{78}$ Dabei gilt: Durch alle Ämter in der Kirche soll das Evangelium bezeugt werden, jedoch besteht nur der Auftrag des Predigtamts (und der an ihm teilhabenden Dienste) explizit in der auf Glauben gerichteten öffentlichen Verkündigung. Demgegenüber besteht die eigene Würde aller anderen Dienste darunter auch und gerade des christlichen Liebesdienstes („Diakonat“) - darin, dass sie durch ihre Tätigkeit das Evangelium bezeugen, ohne intentional darauf abzuzielen, wiederum Glauben zu wecken und zu stärken. ${ }^{79}$

Hier provoziert die in den EKD-Richtlinienentwurf II ( $\$ 2$ Abs. 1 Satz 1) übernommene traditionelle Standardformulierung („Kirchlicher Dienst ist durch den Auftrag bestimmt, das Evangelium in Wort und Tat zu verkë̈ndigen ") insofern Missverständnisse, als sie ein Immediatverhältnis zwischen der Verkündigung durch das Predigtamt und dem Tatzeugnis anderer Dienste suggeriert, das so nicht besteht.

Die aus dem allgemeinen Priestertum abgeleitete Dienstgemeinschaftsidee lässt sich allerdings schon deshalb nicht umstandslos in einen Rechtsbegriff des partikularkirchlichen Mitarbeiterrechts überführen, weil dann nur getaufte Christen beschäftigt werden dürften.

\subsection{Rechtlich-objektives Verständnis}

Dem sucht eine andere Konzeption abzuhelfen, die sich kirchenrechtlich durchgesetzt hat. Danach ist die „Dienstgemeinschaft" dadurch konstituiert, dass alle in

\footnotetext{
${ }^{76}$ CA XIV (BSLK 66.10ff) i.V. mit CA VII (BSLK 60.1ff).

77 Vgl. CA XIV; Martin Luther, WA 6, 408.11ff; ders., De captivitate Babylonica ecclesiae praeludium (1520), WA 6, 484-573 (566.26-30); ders., De instituendis, WA 12, 189.21-27; ders., Von den Konziliis und Kirchen (1539), WA 50, 633.6-8.

$78 \mathrm{Zu}$ den berufsgeschichtlichen Aspekten vgl. Gerhard Buttler, Art. Kirchliche Berufe, TRE 19 (1990), $191 \mathrm{ff}$.

79 Vgl. Dorothea Wendebourg, Das Amt und die Ämter, ZevKR 45 (2000), 5-38.
} 
kirchlichen Organisationen und Einrichtungen Mitarbeitenden durch ihre formalarbeitsrechtliche Beziehung zur Kirche objektiv einer Wirkeinheit angehören, deren Zweck darin besteht, einen Teil des Auftrags der Kirche in der Welt zu erfüllen. Diese objektive Mitwirkung der Mitarbeiter am kirchlichen Auftrag ist unabhängig von ihren glaubensbestimmten Motivationen und Bindungen zu konstatieren; sie nimmt den Kooperationsverband der kirchlichen Mitarbeiterschaft von seiner zweckerationalen Seite her in den Blick. Dieses Verständnis klingt auch im zweiten Satz der evangelischen Standardformel an: „Alle Frauen und Männer, die in Anstellungsverhältnissen in Kirche und Diakonie tätig sind, wirken an der Erfüllung dieses Auftrags mit.“ (\2 Abs. 1 Satz 2 EKD-Richtlinienentwurf II).

Ist aus dieser Warte „die Arbeit in den kirchlichen Einrichtungen objektiv eine Teilnahme an der Erfüllung des kirchlichen Auftrags", so stellen sich jedoch Probleme ein, wenn z.B. von Jurina die „Dienstgemeinschaft“ im nächsten Schritt betrachtet wird als ,ein objektives Strukturprinzip des kirchlichen Dienstes, das in vielfältiger Hinsicht Maßstabsfunktion besitzt, aus dem sich Anforderungen an die kirchlichen Mitarbeiter ergeben, dessen Gültigkeit aber nicht von seiner subjektiven Annahme durch die Mitarbeiter abhängt." ${ }^{\text {"80 }}$ Dass die Tätigkeit aller Mitarbeiter objektiv in einem Mittelverhältnis zum Zweck der Kirche steht, ist eine zunächst organisationslogisch folgerichtige Sicht. Sie wird aber überzogen, wenn sie zum Ansatzpunkt dafür genommen wird, das im Leitbild des christlichen Dienstes begründete Ethos in Rechtspflichten für die gesamte, aus Christen und Nichtchristen zusammengesetzte Mitarbeiterschaft zu übertragen. Damit wäre zwar eine Unterwerfung unter Loyalitätsanforderungen begründet, die Anknüpfung der „Dienstgemeinschaft“ an das Priestertum der Getauften und die frei aktualisierte Teilhabe am Leib Christi jedoch gekappt - die „Dienstgemeinschaft“ würde unterschiedslos zur Pflicht- und „Disziplinargemeinschaft“. Außerdem liegt gegenläufig dazu im Gedanken der Zweckbezogenheit der kirchlichen Dienste zugleich „der Keim zu einer Abstufung der Loyalitätsobliegenheiten nach der Nähe der Aufgaben zum Auftrag der Kirche“, so dass sich von daher unter der Hand eine Affinität zu Maßstäben ergibt, wie sie auch dem allgemeinen Tendenzschutz zu Grunde liegen. 81

\subsection{Möglichkeiten und Grenzen der Abstufung}

Die beiden unterschiedlichen Konzepte der „Dienstgemeinschaft“ sind nicht einfach zur Deckung zu bringen. Erschlichene Identifizierungen von „Dienst der Kirche“ und „kirchlichem Dienst“ stoßen deshalb zu Recht auf breite theologische Kritik. ${ }^{82}$ Wenn die Kirche als Rechtsträger Anlass sieht, einerseits das ihr

\footnotetext{
${ }^{80}$ Jurina (Anm. 66), 174, 178. So auch die Mitglieder der kirchlichen Begleitgruppe in: Beyer/ Nutzinger (Anm. 56), 312-322.

${ }^{81}$ Auf diese beiden Probleme des rechtlich-objektiven Konzepts wird zutreffend hingewiesen von Germann/de Wall (Anm. 13), 563f.

82 Vgl. nur Daiber (Anm. 66); Lienemann (Anm. 66); Haspel (Anm. 5).
} 
verfassungsrechtlich gewährte Selbstbestimmungsrecht voll auszuschöpfen, andererseits aber offene Kirche bleiben möchte, so ist es unvermeidlich, Gesichtspunkte aus beiden Konzepten zu kombinieren; jedoch muss dies so geschehen, dass bekenntnis- und funktionsbezogene Gesichtspunkte in differenzierter Weise und in unterschiedlicher Gewichtung Berücksichtigung finden:

a) Gerade aus der Sicht evangelischer Ethik dient die Kirchenautonomie nicht der Befriedigung kirchlicher Machtansprüche, sondern wird um des Schutzes der freien (auch kollektiven) Religionsausübung willen gewährleistet und in Anspruch genommen. Deshalb muss auch ein differenziertes Verständnis der „Dienstgemeinschaft" primär der glaubensbestimmten Teilhabe am Dienst der Christenheit als Taufgemeinschaft Raum geben. Das bedeutet, dass auf der Ebene des Mitarbeiterrechts konfessionsbezogene Abstufungen zu treffen sind. In Anbetracht des partikularkirchlichen Charakters des Mitarbeiterrechts und der Beschäftigung auch von Nichtchristen muss - die Gesamtorientierung am reformatorisch verstandenen kirchlichen Auftrag vorausgesetzt - zwischen evangelischen, nicht-evangelischen und nicht-christlichen Mitarbeitern deutlich unterschieden werden.

b) Wie bemerkt liegt es gerade in der Logik des Gedankens, dass alle kirchlichen Mitarbeiter objektiv an der Erfüllung des Organisationszwecks der Kirche beteiligt sind, dann doch nach dem unterschiedlichen Grad dieser Beteiligung zu fragen und eine Differenzierung nach der jeweils erfabrbaren Nähe zum kirchlichen Auftrag vorzunehmen.

Prinzipiell ist es im Anschluss an die oben (5.1.) getroffenen Unterscheidungen ekklesiologisch ohne weiteres möglich, die beruflichen Mitarbeiter nach drei Gruppen zu differenzieren: Erstens Mitarbeiter mit geistlicher Beauftragung und Bezug zu den expliziten, religiösen Kernfunktionen der Kirche, die im Bereich ihres unverwechselbaren darstellenden Handelns tätig sind. Zweitens Angehörige der pädagogischen und medizinisch-therapeutischen Professionen sowie anderer akademischer Berufe (z.B. Juristen) im Bereich des organisations- und gesellschaftsbezogen-wirksamen Handelns der Kirche. Hier geht es um Tätigkeiten, die sich äußerlich und den fachlichen Anforderungen nach kaum von der entsprechenden außerkirchlichen Berufsausübung unterscheiden; dennoch ist daran festzuhalten, dass es hierbei um die impliziten Grundvollzüge der Kirche geht. Drittens Berufe mit eher instrumenteller Arbeitsweise, die nur mittelbaren oder keinen Bezug zum kirchlichen Profil haben.

Differenzierung nach der jeweils erfahrbaren Nähe zum kirchlichen Auftrag bedeutet aber nicht einfach Bereichsscheidung in „inneren“ und „äußeren“ Kirchendienst ${ }^{83}$ oder Differenzierung nach Berufsgruppen. Abstriche von kirchenspezifischen beruflichen Anforderungen bei der zweiten und dritten Gruppe können nicht von vornherein aus dem Tätigkeitstypus als solchem

${ }^{83}$ Siehe dazu Pahlke (Anm. 68), $46 f$. 
resultieren. ${ }^{84}$ Angesichts der äußeren Vergleichbarkeit des Professionshandelns etwa von Ärztinnen oder Erziehern in Gruppe 2 kommt es umso mehr darauf an, dass genügend Mitarbeiter rekrutiert werden können, die bereit sind, für die christliche Wertorientierung der Einrichtung und den evangelischen Geist des Hauses (Kindergarten, Schule, Krankenhaus etc.) einzustehen; 85 dies gilt nicht nur, aber insbesondere für Leitungspositionen. Auch die der Gruppe 3 zugehörigen Mitarbeiter scheiden nicht schon per se als Adressaten kirchenspezifischer Anforderungen aus, da beispielsweise der Bischofschauffeur eine andere Vertrauensstellung wahrnimmt als die Reinigungskraft, die Pfarramtssekretärin anders als der Kantinenchef in direkten Interaktionsbeziehungen mit den Mitgliedern einer Gemeinde steht und der Küster im Unterschied zum Hausmeister eines Krankenhauses dem gottesdienstlichen Geschehen zugeordnet ist.

Im Rahmen der Gesamtorientierung am reformatorisch verstandenen kirchlichen Auftrag und der konfessionsspezifischen Abstufungen bringen funktionsbezogene Differenzierungen Gesichtspunkte der Angemessenheit für die Einzelfallprüfung ins Spiel, die sowohl bei der Einstellung wie auf der Rechtsfolgenseite (der Entscheidung über eine Kündigung) zu beachten sind.

\section{Zwischen Ethos und Recht - zur inhaltlichen Festlegung kirchenspezifischer Anforderungen}

\subsection{Theologische Begründung im christlichen Gemeinschaftsethos}

Inhaltlich sind kirchliche Anforderungen an das eigene Mitarbeiterrecht am christlichen Gemeinschaftsethos zu orientieren, das sich der Kommunikation des Evangeliums verdankt und elementar manifestiert in der Taufe als Anfang und der Mahlfeier als Erneuerung des christlichen Lebens. Das apostolische Glaubensbekenntnis bezeichnet die Lebensform der Kirche (im Singular) als „sanctorum communio“. Damit ist nicht - wie die deutsche Übersetzung „Gemeinschaft der Heiligen“ suggerieren könnte - ein Status moralischer Vollkommenheit, sondern die Teilhabe an der Christusgemeinschaft und der Verheißung des Reiches Gottes gemeint. Die Kirche ist - so will das Bekenntnis sagen - die Gemeinschaft der

\footnotetext{
${ }^{84}$ Dies räumt auch Haspel (Anm. 5), 14f, ein, der eine ähnliche Trias vorschlägt, die inhaltliche Festlegung von Lebensführungsanforderungen aber an der für seine Konzeption entscheidenden Differenz von Amtsträgern und anderen Kirchenmitgliedern festmacht. Die in diesem Zusammenhang (bei Anm. 68) geäußerte Annahme, ein einheitlicher Standard seitens des kirchlichen Arbeitgebers sei gänzlich überflüssig, wird übrigens durch den Verweis auf Rüfner (Anm. 7), 921ff, nicht gestützt.

85 Vermittlungsmöglichkeiten zwischen religiöser Programmatik und professionellen Handlungslogiken skizziert Volkhard Krech, Religiöse Programmatik und diakonisches Handeln. Erwägungen zur Spezifik kirchlicher Wohlfahrtsverbände, in: Karl Gabriel (Hg.), Herausforderungen kirchlicher Wohlfahrtsverbände. Perspektiven im Spannungsfeld von Wertbindung, Ökonomie und Politik, Berlin 2001.
} 
„gerechtfertigten Sünder“, d.h. eine Gemeinschaft fehlbarer Menschen, die Gottes zuvorkommende Güte aus der Übermacht ihrer Verfehlungen befreit hat, und die darum ihren Lebenswandel aus Freiheit, wie fragmentarisch auch immer, an ihrer göttlichen Bestimmung zum Guten ausrichten können.

Reformatorische Theologie und evangelisches Kirchenrecht kennen keine der „katholischen Glaubens- und Sittenlehre" ${ }^{\text {86 }}$ vergleichbare normative Regulierung des christlichen Lebens, die sich unmittelbar in der kirchlichen Rechtsordnung widerspiegeln würde. Die Regeln des Gemeinschaftsethos haben nach evangelischem Verständnis den Status ethischer Leitlinien, die auf Befolgung aus Freiheit angelegt sind. Auch hinsichtlich des Teils ethischer Regeln, die rechtliche Qualität erlangen, gilt, dass die Funktion des Kirchenrechts primär in der verbindlichen Koordination des Gemeinschaftshandelns besteht, dass das kirchliche Recht deshalb keinesfalls (wie oftmals das staatliche) durch seine Zwangsbefugnis konstituiert zu denken ist, dass es aber als ultima ratio (wie alles Recht) auch nicht ohne jedes Sanktionsmittel bleiben kann.

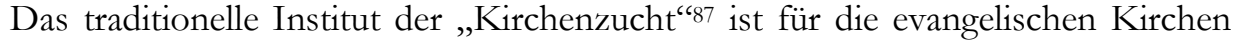
nicht Ausdruck eines in ihrer Verbandsgewalt begründeten eigenständigen kirchlichen Strafrechts. Deutlicher als im reformierten Bereich und im lutherischen Staatskirchentum tritt dies im Verständnis Luthers hervor: Die Ausübung der „Schlüsselgewalt“ (potestas clavium) 88 als äußerstes Mittel zur Bewahrung der Integrität und Identiät der Christusgemeinschaft gegen grobe öffentliche Verleugnung Christi in Wort und/oder Tat ${ }^{89}$ steht in unauflöslichem Bezug zur Verkündigung des Evangeliums. Luther selbst legte den Akzent deutlich stärker auf den Schutz des Glaubens und der Gottesbeziehung als auf die Konformität der Lebensführung, obwohl es Verhaltensweisen geben kann, die dem Christsein diametral widersprechen. Er verwirft den („großen") Bann insofern, als er nicht nur kirchliche, sondern auch obrigkeitliche Sanktionen zur Folge hat. „Als Maßnahme der Schlüsselgewalt kann der Bann [...] ausschließl[ich] geistliche, wenngleich im äußeren Kirchenwesen manifeste Konsequenzen nach sich ziehen." "90 Die „Kirchenzucht" bezieht sich somit auf den Zusammenhang zwischen dem geistlichen Status des Betroffenen (d.h. seiner Gliedschaft am Leib Christi im Glauben) und seiner Partizipation an den manifesten Gemeinschaftshandlungen der Christenheit (also der Zugehörigkeit des Getauften zur

\footnotetext{
86 Art. 1, Art. 4 Abs. 1 GrOkathK.

87 Vgl. dazu Christoph Link, Art. Kirchenzucht, EvStL 2. Bd., 2. Aufl. Stuttgart 1987, 1782-1787; John H. Leith/Hans-Jürgen Goertz, Art. Kirchenzucht, TRE 19 (1990), 173-191; Heinz Schilling (Hg.), Kirchenzucht und Sozialdisziplinierung im frühneuzeitlichen Europa, Berlin 1994; Gottfried Seebaß, Seelsorge, gemeindliche Sittenzucht oder reine Kirche - Zur Problematik des Zusammenhangs von Kirchenzucht und Abendmahl in der Reformation, epd-Dok. Nr. 44, 19. Oktober 2004, 19-32.

${ }^{88}$ CA XXVIII (BSLK 120ff).

${ }^{89}$ Schmalkaldische Artikel, 3. Teil Art. IX: gegen „offenbärliche halsstarrige Sunder“ (BSLK, 457.1f).

${ }^{90}$ Link (Anm. 87), 1783.
} 
communio sanctorum, der Kirche im liturgisch-ethischen Sinn). Die mit dem Bann ausgesprochene Suspendierung von der Feier des Abendmahls ist kein konstitutiver Rechtsakt, sondern zieht nur deklaratorisch die Konsequenzen, die der vom Betroffenen bereits vollzogene Selbstausschluss aus der geistlichen Gemeinschaft für ihr sichtbares Gemeinschaftshandeln hat. Außerdem soll die Verhängung des Banns mit seelsorgerlicher Intention der Besserung und Reintegration des Betroffenen dienen.

Wie die Bedeutung der so verstandenen „Kirchenzucht“ in einer volkskirchlichen Situation zu werten ist, in der ohnehin meist jeder, den sie treffen könnte, den gottesdienstlichen Gemeinschaftshandlungen einschließlich der Abendmahlsfeier fernbleibt, ist umstritten. ${ }^{91}$ Mag der seelsorgerliche Sinn kirchenzuchtlicher Maßnahmen mit guten Gründen bezweifelt werden, so sind sie rechtlich auf gravierende Fälle antichristlichen bzw. -kirchlichen Verhaltens zu beschränken. In unserem Kontext entscheidend ist aber die Feststellung: Maßnahmen der „Kirchenzucht“ sind kirchliche Sanktionen, die alle Kirchenmitglieder in ihrer Eigenschaft als Getaufte betreffen und nicht in ihrer Rolle als Amtsträger oder als beruflich Mitarbeitende. Es beruht deshalb auf einem Kategorienfehler, wenn Michael Haspel erstens die „Kirchenzucht“ systematisch auf einer Ebene mit der „Amtszucht" ansiedelt, sodann zweitens den Rechtsgrund für beschäftigten-adressierte Verhaltenserwartungen in die „Kirchenzucht“ verlegt, um daraufhin drittens jede arbeitsrechtliche Sanktionsmöglichkeit zu delegitimieren. ${ }^{92}$ So wie Amtsrecht und Mitarbeiterrecht als differente Ausprägungen des kirchlichen Dienstrechts vom allgemeinen Mitgliedschaftsrecht zu unterscheiden sind, so sind es auch die ihnen jeweils als äußerstes Mittel zugeordneten Sanktionen.

\subsection{Kirchenmitgliedschaft}

Die kirchlichen Dienste sind theologisch als Konkretisierung des allgemeinen Priestertums zu verstehen. Das allgemeine Priestertum ist das Priestertum der Getauften. Die Taufe jedoch führt (zusammen mit den Merkmalen des Bekenntnisstandes und des Wohnsitzes) in die rechtliche Mitgliedschaft einer Partikularkirche. ${ }^{93}$ Diese wiederum begründet Rechte und Pflichten, die in der evange-

\footnotetext{
${ }^{91}$ Vgl. Stellungnahme der Kammer für Theologie der EKD zum Beschluss der Landessynode der Ev. Kirche im Rheinland vom 15. Januar 2004 „Eingeladen sind alle. Warum die Kirche nicht vom Mahl des Herrn ausschließen darf", epd-Dok. Nr. 4a vom 25. Januar 2005.

${ }_{92}$ Haspel (Anm. 5), 6, 9, 16. Zutreffend dagegen rekurriert Konstantin von Notz, Lebensführungspflichten im evangelischen Kirchenrecht, Frankfurt a.M. 2003, 210ff, auf die „Kirchenzucht“ nur im Blick auf die ehrenamtlichen Mitarbeiter.

93 Vgl. Kirchenmitgliedschaftsgesetz der EKD vom 10.11.1976, ABl. EKD 1976, 389. Zum Thema u.a.: Peter Meinhold (Hg.), Das Problem der Kirchengliedschaft heute, Darmstadt 1979; Wolfgang Lienemann, Gesellschaftliche, rechtliche und theologische Probleme der Kirchenzugehörigkeit, SJKR 1 (1996), 67-106; Wolfgang Bock, Fragen des kirchlichen Mitgliedschaftsrechts, ZevKR 42 (1997), 319-337; Ulrich Seelemann, Kirchenmitgliedschaft als Voraussetzung kirchlicher Anstellungsverhältnisse, ZevKR 44 (1999), 226-243; Jan Hermelink, Praktische Theologie der Kirchen-
} 
lischen Kirche auch weitgehende Mitwirkungsrechte bei der Gestaltung des kirchlichen Lebens, der Besetzung von kirchlichen Ämtern und der Bildung kirchlicher Organe bis hin zur Teilhabe an der Kirchenleitung einschließen. Damit hängen Identität und Kontinuität der verfassten Kirche im Protestantismus in höherem Maße als in der römisch-katholischen Kirche davon ab, dass sie prinzipiell von allen Mitgliedern der Kirche mitgetragen werden.

Gewiss deckt sich die Gesamtheit derer, die getauft sind, nicht mit der Zahl der wahrhaft Gläubigen ${ }^{94}$, aber die Taufe bietet für das menschliche Urteil den einzig entscheidenden Anhaltspunkt dafür, dass jemand auf die Teilhabe am kirchlichen Auftrag angesprochen werden kann. Insofern erscheint es geboten, diese auf Grund von Taufe und Kirchenmitgliedschaft unterstellbare Ansprechbarkeit auf Verheißung und Auftrag der Kirche als „essentielles persönliches Eignungsmerkmal“, d.h. als personenbezogenes und nicht erst verhaltensbezogenes Merkmal anzusehen. ${ }^{95}$ Dies wird auch in $\int 3$ Abs. 3 EKD-Richtlinienentwurf II vorausgesetzt. Mit dem Kirchenaustritt geht diese Ansprechbarkeit zwar nicht verloren, die Taufe behält auch für den Ausgetretenen ihre unverlierbare Bedeutung, allerdings verliert er seine kirchlichen Rechte - dies jedoch nicht als Ausdruck einer „Strafe“, sondern als Folge des Respekts vor seiner freien Entscheidung gegen die kirchliche Organisationsmitgliedschaft. ${ }^{96}$ Wenn die Kirche die Mitgliedschaft zur Voraussetzung eines Beschäftigungsverhältnisses gemacht hat und ein Austritt deshalb die Kündigung auslöst, so wiederum nicht als „Strafe“, sondern weil objektiv die Geschäftsgrundlage des Vertragsverhältnisses entfallen ist. $^{97}$

Der Verzicht auf die Kirchenmitgliedschaft als grundsätzliche Voraussetzung beruflicher Mitarbeit stößt vom evangelischen Kirchenverständnis her aus zwei Gründen auf Bedenken: Erstens begibt sich die Kirche damit der Möglichkeit, ihre Dienste als Ausdruck des allgemeinen Priestertums und damit ihres geistlichreligiös begründeten Auftrags zu verstehen und in Anspruch zu nehmen. Zweitens muss in Kauf genommen werden, dass es dann in der Kirche abhängig Beschäftigte gibt, die nicht zugleich die vollen Mitwirkungsrechte in ihr ausüben können,

mitgliedschaft. Interdisziplinäre Untersuchungen zur Gestaltung kirchlicher Beteiligung, Göttingen 2000; Notz (Anm. 92), $177 \mathrm{ff}$.

$94 \mathrm{Vgl}$. Aurelius Augustinus, De baptismo contra Donatistas 5, 27, 28: „Viele scheinen drinnen zu sein, die draussen sind; und viele scheinen draussen zu sein, die drinnen sind." Martin Luther, WA 18, 653.28: „Abscondita est ecclesia, latent sancti.“

95 So m.E. mit Recht Germann/de Wall (Anm. 13), $570 \mathrm{f}$.

96 Die evangelische Kirche betrachtet den Kirchenaustritt anders als die römisch-katholische nicht als „schwerwiegendes Vergehen“" (so can. 1364 \& 1 CIC im Fall der Apostasie), da sie die christliche Taufgemeinschaft nicht mit der kirchlichen Rechtsgemeinschaft identifiziert und sich über den Tatbestand der Preisgabe des Glaubens kein Urteil anmaßen kann. Zum evangelischen Verständnis vgl. etwa: Kirchenamt der EKD (Hg.), Taufe und Kirchenaustritt. Theologische Erwägungen der Kammer für Theologie zum Dienst der evangelischen Kirche an den aus ihr Ausgetretenen (EKDTexte 66), Hannover 2000.

97 Richardi (Anm. 7), § 7, Rnr. 72ff. 
die somit - anders gesagt - nur Adressaten kirchlicher Gesetzgebung sind und nicht (prinzipiell) auch ihre Autoren. ${ }^{98}$ Das erste Bedenken kann dann zurückstehen, wenn Mitglieder anderer als der evangelischen Kirchen beschäftigt werden, die das Kriterium einer ökumenisch gültigen Taufe erfüllen. Das zweite jedoch bleibt bestehen, gleichgültig, ob es sich um katholische oder nicht-christliche Mitarbeiter handelt.

Es empfiehlt sich deshalb, von der Kirchenmitgliedschaft als genereller Regel auszugehen. Dem Leitgedanken einer offenen Kirche gemäß sind hier aber engherzige Lösungen zu vermeiden. Im Interesse des Gemeinwohls kann die Kirche mit allen Menschen guten Willens zusammenarbeiten. Dies gilt insbesondere für die sozialdiakonischen Arbeitsfelder, in denen im Bedarfsfall die Wirksamkeit der Hilfe wichtiger sein kann als ihre Motive; dies gilt ferner für Arbeitsbereiche mit interkulturellem Bezug, in denen Mitarbeiter anderer religiöser Herkunft von der Sache her gebraucht werden; dies gilt nicht zuletzt angesichts der sozialethischen Verantwortung der Kirche für die Bereitstellung von Arbeitsplätzen. Die Berücksichtigung dieser Gesichtspunkte trifft allerdings dann auf sorgfältig zu beachtende Grenzen, wenn die Prägung der kirchlichen Dienste durch evangelische Christinnen und Christen nicht mehr gewährleistet werden kann. Auch eine offene Kirche muss Kirche bleiben. Es sei darauf hingewiesen, dass Voraussetzung für eine Beschäftigung beim Deutschen Gewerkschaftsbund grundsätzlich die Gewerkschaftsmitgliedschaft ist - Ausnahmen bestehen nur bei kurzzeitigen Beschäftigungen im administrativen Bereich. Auch stellt ein Gewerkschaftsaustritt während des Beschäftigungsverhältnisses einen Kündigungsgrund dar. ${ }^{99}$ Im Bereich der evangelischen Kirche sollten - insbesondere bei dringendem personellem Bedarf - Ausnahmen vom Regelerfordernis der Kirchenmitgliedschaft in konfessionsspezifischer Abstufung möglich sein; dabei sind aber die Bedeutung der Stelle und die konfessionelle Zusammensetzung der Mitarbeiterschaft einer Einrichtung im Ganzen zu berücksichtigen.

Zur Förderung des christlichen Profils einer Einrichtung ist selbstverständlich mehr erforderlich als nur die Beachtung formaler Mitgliedschaftskriterien. Um den evangelischen „Geist des Hauses“ erfahrbar machen zu können, bedarf es der Initiierung von Leitbildprozessen ${ }^{100}$, geeigneter Aus- und Fortbildungsmaßnahmen, loyalitätsfördernder Personalführung und -entwicklung u.a.m. Dies erübrigt aber nicht die Aufgabe des Rechts, die Rahmenbedingungen zu gewährleisten, innerhalb deren sich solche (selber nicht rechtlich steuerbaren) Prozesse entfalten können.

\footnotetext{
${ }^{98}$ Letzteres könnte wegen der klerikal-hierarchischen Leitungsstruktur auf katholischer Seite sogar leichter hingenommen werden; von daher fällt ein eigenes Licht auf den Umstand, dass die GrOkathK nicht von einer generellen Mitgliedschaftsregel ausgeht.

${ }^{99}$ Der DGB beruft sich insoweit auf seine koalitionspolitische Zielsetzung (Brief des DGB Bundesvorstands an den Vf. vom 1.3.05).

100 Vgl. z.B. Arntzen (Anm. 25), $225 \mathrm{ff}$.
} 


\subsection{Verhaltensanforderungen}

Der Protestantismus kennt kein Sonderethos für bestimmte Gruppen von Christen. Die kirchlichen Dienste empfangen nach reformatorischem Verständnis ihre Prägung und Ausrichtung durch das allgemeine christliche Gemeinschaftsethos. In der evangelischen Kirche findet das konsentierte Gemeinschaftsethos seinen Niederschlag einerseits (stärker im Binnenbezug) in den sog. Lebensordnungen, andererseits (stärker im Außenbezug) v.a. in synodalen Kundgebungen, Worten, Denkschriften usw. Die Lebensordnungen werden neuerdings unter dem Begriff der „Leitlinien kirchlichen Lebens“ sehr viel deutlicher als früher ${ }^{101}$ von der in christlicher Freiheit zu leistenden Gestaltungsaufgabe her gedacht und damit ausdrücklich ethisch begründet. ${ }^{102}$ Kirchliche Äußerungen zu gesellschaftlichen Fragen wiederum sind Orientierungshilfen zur individuellen und kollektiven Urteilsbildung, die sich nach Maßgabe evangelischer Ethik in reflexiver Aneignung der Tradition und in sachgemäßer Analyse der Gegenwartssituation, somit hermeneutisch-diskursiv vollzieht. ${ }^{103}$

Die einschlägigen Konsenstexte im Raum der EKD, die der ethischen Reflexion der Lebensformen gewidmet sind, machen deutlich, dass praktizierte Homosexualität als solche (sowie das Leben in einer gleichgeschlechtlichen Partnerschaft) nicht als Verstoß gegen Verhaltensanforderungen für privatrechtlich Mitarbeitende in Betracht kommen können; ${ }^{104}$ es wird lediglich empfohlen, die Öffnung des Pfarramts für homosexuell lebende Menschen von Kriterien im Einzelfall abhängig zu machen. ${ }^{105}$

101 Die Lebensordnungen verstanden sich noch im vorigen Jahrhundert als Beschreibung der objektiv geltenden kirchlichen Sitte, was sich insbesondere auf lutherischer Seite mit der Einforderung des normativen Charakters vorgegebener sozialer Ordnungen verband und den Lebensordnungen einen juridischen Charakter verlieh. Vgl. dazu Michael Plathow, Lehre und Ordnung im Leben der Kirche heute. Dogmatische, rechtstheologische und pastoraltheologische Überlegungen zu den Lebens- und Visitationsordnungen unserer evangelischen Kirche, Göttingen 1982.

102 Vgl. Ordnung des kirchlichen Lebens der Evangelischen Kirche der Union, Berlin 1999; Leitlinien kirchlichen Lebens der Vereinigten Evangelisch-Lutherischen Kirche Deutschland (VELKD). Handreichung für eine Lebensordnung, Gütersloh 2003. Vgl. dazu Lothar Stempin, Ordnung als Prozeß. Veränderte Orientierungs- und Steuerungskonzepte christlicher Lebensgestaltung am Beispiel der „Leitlinien kirchlichen Lebens“ der VELKD, Gütersloh 1999.

103 Vgl. bis auf weiteres: Rat der EKD (Hg.), Aufgaben und Grenzen kirchlicher Äußerungen zu gesellschaftlichen Fragen. Eine Denkschrift der Kammer für soziale Ordnung der EKD (1970), in: Die Denkschriften der Evangelischen Kirche in Deutschland Bd 1/1, Gütersloh 1978, 43-76.

$104 \mathrm{Vgl}$. Ordnung des kirchlichen Lebens EKU (Anm. 102), 67ff; Leitlinien des kirchlichen Lebens VELKD (Anm. 102), 66ff. Joussen (Anm. 13), 37f, behauptet fälschlich und ohne Beleg, praktizierte Homosexualität stelle auch für die evangelische Kirche „einen Verstoß gegen die Religion“ dar.

$105 \mathrm{Vgl}$. Kirchenamt der EKD (Hg.), Mit Spannungen leben. Eine Orientierungshilfe des Rates der Evangelischen Kirche in Deutschland zum Thema „Homosexualität und Kirche“ (EKD-Texte 57), Hannover 1996. Wichtigere Fragen könnten dann entstehen, wenn die Chance ergriffen würde, „,deutlicher als bisher der Orientierung auf eine Schalom-Ordnung mit den Prinzipien Gerechtigkeit, Frieden und Bewahrung der Schöpfung für das Leben der Kirche eine verbindlichere Gestalt zu geben“ - so mit Recht Haspel (Anm. 5), 26. 
Die gleiche materielle Geltung des christlichen Gemeinschaftsethos für alle Christinnen und Christen schließt nicht aus, dass Unterschiede in rechtlich-formeller Hinsicht bestehen. Selbstverständlich können für kirchliche Mitarbeiter Anforderungen positiviert werden, die zwar alle die Koordination der durch das Gemeinschaftsethos geprägten Dienste bezwecken, dies jedoch in einer die Unterschiedlichkeit der Aufgaben berücksichtigenden Weise. ${ }^{106}$ Der Rechtsgrund dieser Pflichten liegt nicht etwa im Modus ihrer möglichen Sanktionierung, sondern in Form und Inhalt des Dienstauftrags selbst. Juristisch werden dabei Leistungstreuepflichten, Loyalitätspflichten und Lebensführungspflichten unterschieden: Leistungstreuepflichten sind jedem Schuldverhältnis immanent, sie gebieten, die Arbeit (in Tun und Unterlassen) so auszuführen, dass der vom Arbeitgeber angestrebte Zweck realisiert werden kann. Loyalitätspflichten und Lebensführungspflichten beziehen sich über die Erbringung des rechtsgeschäftlich Zugesagten hinaus auf das allgemeine Verhalten des Arbeitnehmers. Dabei handelt es sich bei den Loyalitätspflichten um Gebote ,der Rücksicht und Redlichkeit gegenüber den Zielen des Arbeitsgebers, die nicht durch schädliches Begleitverhalten gefährdet werden dürfen“.107 Lebensführungspflichten dagegen - oft auch „Loyalitätsobliegenheiten“ genannt ${ }^{108}$ - sind Anforderungen an die außerdienstliche persönliche Lebensführung des Mitarbeiters, deren Verletzung Auswirkungen auf die dienstliche Verpflichtung haben kann. Auch im nicht-kirchlichen Bereich kann durch das außerdienstliche Verhalten das Vertrauen in die dienstliche Zuverlässigkeit des Betroffenen erschüttert oder das Ansehen des Anstellungsträgers beeinträchtigt werden. Gegen die Loyalitätspflichten verstößt demnach der Arzt einer Alkoholikerklinik, der in einer benachbarten Gastwirtschaft seinen Patienten Runden anbietet; gegen die Lebensführungspflichten jedoch verstößt derselbe Arzt, wenn er selbst trinkt und zum Alkoholiker wird. ${ }^{109}$

a) Bei ordinierten Amtsträgern (und Kirchenbeamten) erfolgt die Festlegung der Verhaltensanforderungen durch die Normen des kircheneigenen Dienstrechts. Diese wiederum knüpfen für die Träger des ordinierten Amts theologisch an die

\footnotetext{
106 Vgl. zum Gesamtkomplex: Notz (Anm. 92). Ansonsten ist im Blick auf die hier interessierenden Fragen vor allem das Pfarrerdienstrecht bearbeitet worden, vgl. z.B.: Hartmut Maurer, Die Pflichten des Pfarrers aus Ordination und Dienstverhältnis, ZevKR 32 (1987), 571-598; Karl-Heinrich Lütcke, Pflichten des Pfarrers aus Ordination und Dienstverhältnis, ZevKR 33 (1988), 1-15; Hartmut Maurer, Bestehen für die Lebensführung von Pfarrern und Kirchenbeamten besondere rechtliche Voraussetzungen? ZevKR 38 (1993), 381-396; Günther Linnenbrink, Zur Frage der Lebensführung kirchlicher Mitarbeiter - insbesondere der Pfarrerschaft, ZevKR 38 (1993), 381-396; Paul Koller, Lebensführung und Pfarrerdienstrecht aus der Sicht eines Theologen, in: Rau/Reuter/Schlaich (Anm. 47), 153-168; Roland Tompert, Lebensführung und Pfarrerdienstrecht aus der Sicht eines Juristen, ebd., 169-199.

${ }_{107}$ Notz (Anm. 92), 35.

${ }^{108} \mathrm{Da}$ sie vom Arbeitgeber nicht auf Grund positiv-rechtlicher Erfüllungsansprüche eingefordert, sondern nur durch Abmahnung, Kündigung oder (bei Beamten) Verhängung disziplinarrechtlicher Maßnahmen beantwortet werden können; vgl. Rüfner (Anm. 7), 914; Notz (Anm. 92), 37. Eben deshalb hält Öing (Anm. 25), 60ff, die Bezeichnung „Obliegenheiten“ für einen Euphemismus.

${ }^{109}$ Lüdicke (Anm. 25), 86.
} 
ethischen Bindungen an, die aus dem mit der Ordination übertragenen besonderen Auftrag folgen: Als eine einmalige Segnungs- und Sendungshandlung zielt die Ordination auf ein bleibendes persönliches Lebenszeugnis; aus der Verpflichtung zur öffentlichen Verkündigung und Sakramentsverwaltung folgt die Bindung an Schrift und Bekenntnis und die Anforderung, durch die eigene Lebensführung dem Evangelium nicht zu widersprechen; das Amt der Einheit erfordert besondere Rücksichtnahme auf unterschiedliche Frömmigkeitsformen und politische Vorstellungen in der Gemeinde. ${ }^{110}$ Weitere, nicht aus der Ordination selbst, sondern nur aus dem hauptamtlichen Dienstverhältnis folgende Pflichten können hier außer Betracht bleiben. Denn entscheidend in unserem Zusammenhang ist: Auch die an die ordinierten Amtsträger adressierten Verhaltenserwartungen sind allein in dem mit dem Amt funktionell verbundenen Auftrag begründet - nicht etwa in einer besonderen geistlichen Qualität des Amtes, auch nicht in der irrigen Annahme, die Verkündigung hinge von der persönlichen Würdigkeit des Verkündigers ab. Gerade im Blick auf die ordinierten Amtsträger gilt es einem naheliegenden Missverständnis zu wehren, das ihr Verhalten zum Garanten gelingender Evangeliumskommunikation macht. ${ }^{111}$ Will man den - in strikt theologischer Betrachtung durchaus ambivalenten - Topos der „Glaubwürdigkeit“ verwenden, so wäre eher in doppelter Negation zu formulieren, dass durch das Verhalten des Verkündigers das Zeugnis nicht unglaubwürdig werden soll. ${ }^{112}$ Durchaus gelungen ist hier $\int 4$ Satz 3 EKD-Richtlinienentwurf II: „Von Mitarbeiterinnen und Mitarbeitern in der Verkündigung, Seelsorge oder Unterweisung wird eine inner- und außerdienstliche Lebensführung erwartet, die der übernommenen Verantwortung entspricht.“

Zur Sanktionierung dienstrechtlicher Verstöße gilt in der EKD bekanntlich ein kircheneigenes Dissiplinarrecht, ${ }^{113}$ gegen das allerdings insofern Einwände bestehen, ${ }^{114}$ als es dank seiner Herkunft aus dem staatlichen Beamtenrecht die Disziplinarsanktionen über Gebühr mit strafrechtsdogmatischen Kategorien belastet.

b) Bei privatrechtlich Mitarbeitenden folgen die außerdienstlichen Nebenpflichten aus dem kircblich modifizierten Arbeitsrecht. Aus guten theologischen Gründen dehnt die Evangelische Kirche in Deutschland die Ordination nicht auf Dienste aus, deren Auftrag nicht in der intentional Glauben weckenden öffentlichen Verkündigung

110 Vgl. Maurer (Anm. 106), 406; Reuter (Anm. 74), 36f.

${ }^{111}$ Nach CA V ist es der „spiritus sanctus, qui fidem efficit, ubi et quando visum est Deo“ (BSLK, 57.5-58.1).

112 Maurer (Anm. 106), 406; kritisch zur „Glaubwürdigkeit“ des Pfarrers/der Pfarrerin auch Koller (Anm. 106), 158ff.

113 Vgl. Wolfgang Strietzel, Das Disziplinarrecht der deutschen evangelischen Landeskirchen und ihrer Zusammenschlüsse unter besonderer Berücksichtigung der kirchlichen Rechtsprechung, Tübingen 1988; René Pahud de Mortanges, Zwischen Vergebung und Vergeltung. Eine Analyse des kirchlichen Straf- und Disziplinarrechts, Baden-Baden 1992.

114 Vgl. Albert Stein, Braucht die Kirche noch ein Disziplinarrecht?, in: ders., Kirchenrecht in theologischer Verantwortung, Wien 1990, 135-144.; Koller (Anm. 106), 163; Tompert (Anm. 106), $193 \mathrm{ff}$. 
und Sakramentsverwaltung besteht. Auch gottesdienstliche Einführungshandlungen für kirchliche Mitarbeiter, die nicht am Predigtamt teilhaben, sind keineswegs mit der Ordination $\mathrm{zu}$ verwechseln und haben nicht deren spezifische (dogmatische oder) ethische Bindungen zur Folge. Sie begründen also weder eine auf die Lehre bezogene Verpflichtung auf Schrift und Bekenntnis, noch Anforderungen, die auf ein bleibendes persönliches Lebenszeugnis zielen, noch Obliegenheiten, die aus der Vermeidung einer Diskrepanz zwischen persönlicher Verkündigung und individuellem Verhalten resultieren könnten, und auch keine Unterlassungspflichten, die sich aus der besonderen Verantwortung für die Einheit der Gemeinde ableiten ließen. Dies alles würde auch dann gelten, wenn die innerhalb der EKD existierenden Überlegungen zur Ausgestaltung des Diakonats als gegenüber dem Predigtamt eigenständiges ${ }^{115}$,,geordnetes Amt in der allgemeinen Liebespflicht der Christen"116 eine rechtliche Konkretisierung und Umsetzung erführen. Privatrechtlich Beschäftigte etwa im diakonischen Bereich haben auch dann nicht am geordneten Amt der Verkündigung teil, wenn ihre Einführung und Beauftragung im liturgischen Rahmen geschieht.

Dies erfordert - wie schon bemerkt - eine Präzisierung der in den EKDRichtlinienentwurf II übernommenen evangelischen Standardumschreibung der „Dienstgemeinschaft“. Sowenig im übrigen Art. 4 GrOkathK erwartet, dass evangelische Arbeitnehmer(innen) „die Grundsätze der katholischen Glaubensund Sittenlehre anerkennen und beachten", sowenig sollte durch $\int 3$ Abs. 1 Satz 1 EKD-Richtlinienentwurf II Katholiken oder Nichtchristen zugemutet werden, dass sie die reformatorisch verstandenen Bezugsgrößen „Schrift und Bekenntnis“ nicht nur ,achten“, sondern auch ,wahren und ihrem Handeln zugrundelegen“.

Aus der Tatsache, dass in das kirchliche Arbeitsrecht keine Lebensführungspflichten übernommen werden dürfen, die ethischen Bindungen aus der Ordination gleichkämen, folgt aber nicht der Ausschluss jeglicher kirchenspezifischer Anforderungen an das inner- und auch außerdienstliche Verhalten von privatrechtlich Beschäftigten. Es wird in diesem Zusammenhang von den Betroffenen (übrigens auch von Pfarrerinnen und Pfarrern) oft übersehen, dass es schon soziologisch zum Spezifikum der erwähnten Professionen im pädagogischen, medizinischen und therapeutischen Bereich gehört, außerdienstlichen Verhaltenserwartungen zu unterliegen. Da es beim Professionshandeln generell um Sachthematiken geht, die auf der Beziehungsebene zu bearbeiten sind, ist immer die Person in die berufliche Tätigkeit involviert und wirkt über den aktuellen Kontakt

\footnotetext{
115 Ungenau in diesem Punkt: Haspel (Anm. 5), 10.

116 Kirchenamt der EKD (Hg.), Der evangelische Diakonat als geordnetes Amt der Kirche. Ein Beitrag der Kammer für Theologie der Evangelischen Kirche in Deutschland (EKD-Texte 58), Hannover 1996, 10; sowie Hans-Martin Müller, Evangelischer Diakonat als kirchliches Amt, ZevKR 45 (2000), 57-71.
} 
hinaus. ${ }^{117}$ Allerdings lassen sich die Maßstäbe für Loyalitäts- und Lebensführungspflichten rechtlich nur äußerst allgemein fassen; ferner müssen sie dem Faktum einer differenzierten „Dienstgemeinschaft“ Rechnung tragen.

Eine Möglichkeit besteht darin, sich mit einer Generalklausel zu begnügen, die in \4 Satz 1 EKD-Richtlinienentwurf II lautet: „Je nach Aufgabenbereich übernehmen Mitarbeiterinnen und Mitarbeiter Verantwortung für die glaubwürdige Erfüllung kirchlicher und diakonischer Aufgaben“ - wobei die „Glaubwürdigkeit“ hier letztlich nicht vom Einzelverhalten, sondern von der Integrität und Akzeptanz der arbeitsteilig organisierten Einrichtung im Ganzen abhängt. Missverständlich und angesichts der (und sei es ausnahmsweisen) Einbeziehung von Nichtchristen problematisch ist dann aber wieder die Formulierung, alle Mitarbeiter sollten „dazu beitragen, das Evangelium in der Einrichtung zu bezeugen“ (so \4 Satz 2 EKD-Richtlinienentwurf II).

Gegenüber einer Lösung, die sich auf eine sehr allgemeine Generalklausel beschränkt, eindeutiger und daher vorzugswürdig ist der in $\ 4$ Richtlinienentwurf I EKD ${ }^{118}$ gewählte Weg, die Verhaltensanforderungen konfessionsspezifisch (und auch nach beruflicher Stellung) abgestuft zu umschreiben: Lebensfübrungspflicbten werden hier nur von evangelischen Mitarbeitenden „mit Aufgaben in der öffentlichen Wortverkündigung, in der Seelsorge oder christlichen Unterweisung oder die leitend in den Bereichen Erziehung, Pflege und Betreuung tätig sind“", erwartet, nämlich „dass sie sich in besonderer Weise darum bemühen, innerhalb und außerhalb des Dienstes christlichen Grundsätzen gerecht zu werden“. An andere christliche Mitarbeiter können positive Loyalitätspflichten adressiert werden, die sich auf das dienstliche Verhalten beziehen: etwa dazu beizutragen, „die Werte des Evangeliums in der Einrichtung zur Geltung zu bringen“. Die Anforderungen an die nichtchristlichen Mitarbeiter sind dann auf die Loyalität gegenüber dem Dienstgeber reduzierbar, die als Verpflichtung zur Wahrung der Interessen des Arbeitsgebers ohnehin jedem Arbeitsverhältnis innewohnt.

Zur Sanktionierung von Loyalitätsverstößen dienen die Regeln des allgemeinen Kündigungs- und Kündigungsschutzrechts. Die Sanktion ist hier vertraglich und nicht etwa mitgliedschaftsrechtlich begründet. ${ }^{119}$ Wie schon bemerkt ist es irrig, die (gewiss nur als ultima ratio einzusetzende) Kündigung unter die Mittel der Kirchenzucht zu rechnen bzw. als deren theologisch illegitimes Substitut zu interpretieren. ${ }^{20}$ Kirchenzucht geschieht, wo und wenn sie vollzogen wird, zum Schutz der Glaubensgemeinschaft gegenüber einem Christen als Kirchenmitglied mit Folgen für seinen mitgliedschaftsrechtlichen Status; eine Kündigung erfolgt

\footnotetext{
117 Vgl. (nicht nur) für den Pfarrberuf: Isolde Karle, Der Pfarrberuf als Profession. Eine Berufstheorie im Kontext der modernen Gesellschaft, 2. Aufl. Gütersloh 2001, 72ff; Reuter (Anm. 74), 22.

${ }^{118}$ Fast gleichlautend in $\int 6$ ARR Berufl. Mitarbeit Evang.-Luth. Kirche in Bayern.

119 Vgl. auch Germann/de Wall (Anm. 13), 552.

${ }^{120}$ So durchweg Haspel (Anm. 5), bes. 18.
} 
zum Schutz der kirchlichen Kooperationsgemeinschaft gegenüber einem Christen (oder Nichtchristen) als Mitarbeiter der Kirche mit Konsequenzen für sein Vertragsverhältnis zur Kirche. Spricht die Kirche als Arbeitgeberin eine Kündigung aus, so nicht, um Integrität und Identität der Christusgemeinschaft gegen grobe öffentliche Verfehlungen ihrer Mitglieder zu schützen, sondern weil sie festgestellt hat, dass das Verhalten eines Mitarbeiters in schwerwiegender Weise gegen die vertraglich übernommen Pflichten eines kirchlichen Dienstes verstößt. Wenn die Kirche dies nach ihren eigenen - möglichst differenzierten - Maßstäben für sich selbst geklärt hat und diese Entscheidung anschließend der Rechtskontrolle durch ein staatliches Arbeitsgericht offen steht, so kann darin kein Verstoß gegen die 5. These der Barmer Theologischen Erklärung gesehen werden.

\section{Schluss und Empfehlungen}

a) Gegen die EKD-Initiative zu einer Vereinheitlichung der wesentlichen kirchenspezifischen Anforderungen an die berufliche Mitarbeit, die im Regelfall die Kirchenmitgliedschaft vorsieht, bestehen aus theologischer Sicht keine prinzipiellen Einwände.

Die Frage, ob dies durch Erlass einer Richtlinie nach Art. 9 Buchst. b der Grundordnung der Evangelischen Kirche in Deutschland oder nicht besser durch ein Kirchengesetz geschehen sollte, wurde hier nicht erörtert. Der Vf. würde allerdings einer kirchengesetzlichen Lösung den Vorzug geben.

In Anbetracht der Veränderung, die das Regelerfordernis der Kirchenmitgliedschaft gegenüber den Arbeitsvertragsrichtlinien des Diakonischen Werks bedeutet, wäre bei der Umsetzung einer Richtlinie oder eines Kirchengesetzes der EKD dringend zu beachten, dass Mitarbeitende in der Diakonie, die unter anderen Voraussetzungen ein kirchliches Beschäftigungsverhältnis eingegangen sind, keinem gewissenswidrigen Druck zum Kircheneintritt ausgesetzt werden.

b) Wie in den vorstehenden Ausführungen deutlich geworden ist, bedarf der EKD-Richtlinienentwurf II jedoch der Überarbeitung. Falls man hierzu nicht in größerem Umfang auf den Wortlaut von EKD-Richtlinienentwurf I zurückgreifen möchte, werden zumindest die folgenden Änderungen empfohlen:

\ 2 Abs. 1 Satz 1 und 2 wie folgt:

Der Dienst der Kirche ist durch den Auftrag bestimmt, das Evangelium in Wort und Tat zu bezengen. Alle Frauen und Männer, die in Anstellungsverbältnissen in Kirche und Diakonie tätig sind, tragen in unterschiedlicher Weise dazu bei, dass dieser Auftrag erfüllt werden kann.

\ 3 Abs. 1 Satz 1 entfällt 
In $\int 3$ Abs. 3 Satz 1 entfällt die Formulierung:

wer gegen die sich aus $\int 2$ ergebenden Grundpflichten verstößt21

$\int 4$ wie folgt:

(1) Je nach Aufgabenbereich übernehmen Mitarbeiterinnen und Mitarbeiter Verantwortung für die glaubwürdige Erfüllung kirchlicher und diakonischer Aufgaben. Sie haben sich daher loyal gegenüber der evangelischen Kirche zu verhalten.

(2) Von evangelischen Mitarbeiterinnen und Mitarbeitern wird erwartet, dass sie Schrift und Bekenntnis anerkennen. Sofern sie in der Verkündigung, Seelsorge oder Unterweisung tätig sind, wird eine inner- und außerdienstliche Lebensfübrung erwartet, die der übernommenen Verantwortung entspricht.

(3) Von christlichen Mitarbeiterinnen und Mitarbeitern wird erwartet, dass sie Schrift und Bekenntnis achten und für die christliche Prägung ihrer Einrichtung eintreten.

(4) Nichtchristliche Mitarbeiterinnen und Mitarbeiter baben den kirchlichen Auftrag zu beachten und die ihnen übertragenen Aufgaben im Sinn der Kirche zu erfüllen.

121 Dieser Satzteil scheint aus einer früheren Redaktionsstufe zu stammen, in der $\int 3$ Abs. 1 Satz 1 noch in $\int 2$ Abs. 1 untergebracht war (vgl. Entwurfsstand 19.8.2003; Az: 0340/1 und 2700/5.12410). Außerdem: Wie kann gegen die aus der Grundbestimmung des kirchlichen Dienstes folgenden Pflichten verstoßen werden, wenn das Arbeitsverhältnis noch gar nicht begründet ist? 
Reinhard Richardi

\section{Arbeitsrecht in der Diakonie ${ }^{*}$}

\section{Diakonie und Arbeitsrecht - zwei Begriffe}

\section{Selbstverständnis der Diakonie}

Zwei Grundfragen, auf die das Thema sich bezieht, bedürfen zunächst der Beantwortung. Was ist Diakonie, und was hat man unter Arbeitsrecht zu verstehen?

Was sind die Verbände der Diakonie - nur Verbände der freien Wohlfahrtspflege, oder sind sie Wesens- und Lebensäußerung der evangelischen Kirche? Das für die Sozialarbeit maßgebliche Subsidiaritätsprinzip hat das Betätigungsfeld der Diakonie erheblich ausgeweitet, zugleich aber ihre Abhängigkeit von der Zuwendung staatlicher Finanzmittel begründet. Sie hat damit einen Sitz im Sozialstaat erhalten, muss sich insoweit also aus der Sicht des Staates so behandeln lassen wie die anderen Verbände der freien Wohlfahrtspflege. Damit wird die Diakonie aber in ihrem Selbstverständnis gekränkt; denn nach ihrer Herkunft geht es ihr nicht um eine Sozialagentur im Dienst des Sozialstaats, sondern sie ist Wesens- und Lebensäußerung der evangelischen Kirche.

\footnotetext{
${ }^{*}$ Vortrag auf der Mitgliederversammlung des Diakonischen Werks Hannover am 05.05.2004.
} 
Die Theologie und die ihr entsprechende kirchenrechtliche Ordnung heben drei Grundfunktionen der Kirche hervor, welche die Mitte ihres Wirkungsverhältnisses bilden: die Verkündigung des Wortes Gottes, der Vollzug der Sakramente und der Dienst tätiger Nächstenliebe.

Gottesdienst braucht und fordert den Dienst für die Mitmenschen. Jeder Einzelne ist für die Erfüllung dieses Gebots in die Nachfolge Christi berufen. Diesen Auftrag kann er bei seiner Mitarbeit in staatlichen Organisationen oder sonstigen Verbänden erfüllen. Der Sendungsauftrag zur Erfüllung der Nächstenliebe beschränkt sich aber nicht auf die dienende Nachfolge des Einzelnen, sondern erfordert, wie es in der richtigen Übersetzung des griechischen Textes in 2 Kor. 8,4 heißt, auch ein Zusammenstehen vieler in einer "Gemeinschaft des Dienstes“ (koinonia tes diakonias). Wer in zu diesem Zweck gebildeten Einrichtungen tätig wird, trägt dazu bei, dass die Einrichtung ihren Teil am Sendungsauftrag der Kirche erfüllen kann.

Diese Gemeinschaft des Dienstes ist nicht mit der Kirche als Gemeinschaft gleichzusetzen; sie ergibt sich aber aus dem Auftrag zur Verkündigung und zum Dienst am Mitmenschen durch ein Zusammenwirken in einer „Gemeinschaft des Dienstes“. Daraus folgt zweierlei: Die Dienstgemeinschaft ist kein Verband, der keinen Interessengegensatz der in ihr tätigen Mitarbeiter kennt, sondern sie ist das Leitprinzip zur Erfüllung des der Einrichtung gestellten Sendungsauftrags. Damit steht in untrennbarem Zusammenhang, dass jedenfalls für die Erfüllung der Nächstenliebe nicht nur evangelische, sondern auch andere Christen und Nichtchristen in den Dienst genommen werden können, wenn sie sich freiwillig dazu bereit erklären, zwar nicht im Verkündigungsdienst, aber bei der Wahrnehmung anderer Aufgaben einen Beitrag zur Erfüllung des Sendungsauftrags der Kirche zu leisten, wie für die katholische Kirche der Papst dies im Universitätsgesetz ausdrücklich anerkannt hat. Es geht insoweit um nichts anderes als um die Umsetzung der Schriftstelle, nach der Jesus auf die Feststellung seiner Jünger, draußen warteten seine Mutter und seine Brüder, erwiderte: „Wer ist meine Mutter, und wer sind meine Brüder?“ und die Antwort gab: „Denn wer den Willen meines himmlischen Vaters erfüllt, der ist für mich Bruder und Schwester und Mutter" (Mt. 12, 46-50).

Damit steht fest, dass die Diakonie, wenn ihr die Freiheit im Sozialstaat gewährleistet bleiben soll, keine Sozialagentur im Dienst des Sozialstaats ist, sondern als Wesens- und Lebensäußerung der evangelischen Kirche ihrem eigenen Auftrag folgt, den die Verfassung als dem Sozialstaat vorgegeben achtet.

\section{Weltliches und kirchliches Arbeitsrecht - eine Scheinalternative}

Bei der Diakonie entfaltet die Kirche ihre Grundfunktion zur Nächstenliebe in den Formen des staatlichen Rechts. Ihre Einrichtungen werden in den Organisationsformen des Privatrechts geführt. Für die Begründung und Gestal- 
tung der Beschäftigungsverhältnisse gilt die Vertragsfreiheit als Grundprinzip. Von ihrem Grundansatz her ermöglicht sie, das religiös geprägte Selbstverständnis vom Wesen und Auftrag des kirchlichen Dienstes durchzusetzen; denn eine der Kirche zugeordnete Einrichtung ist nicht gezwungen, bei einem abweichenden Selbstverständnis ihres Kontrahenten ein Vertragsverhältnis mit ihm zu begründen. Da aber wegen der Besonderheit der abhängigen Arbeit die bloße Vertragsfreiheit nicht ausreicht, um einen sozialgerechten Interessenausgleich nach dem Prinzip der Vertragsgerechtigkeit zu gewährleisten, hat der Staat ihr durch Gesetz Grenzen gesetzt. Für die Diakonie folgt daraus, dass auf Begründung und Gestaltung von Arbeitsverhältnissen das staatliche Arbeitsrecht Anwendung findet. Es ist, wie das Bundesverfassungsgericht es einmal formuliert hat, „die schlichte Folge einer Rechtswahl“"1.

Die Feststellung der Anwendung staatlichen Arbeitsrechts bedeutet keineswegs, das es so anzuwenden ist wie in einer Fabrik bei der Herstellung von Autos oder in einem Kaufhaus beim Vertrieb von Waren. Die Säkularisierung der gesellschaftlichen Ordnung hat dazu geführt, dass die Besonderheit kirchlicher Ordnung nicht mehr wahrgenommen wird; es wird unterstellt, dass sie im Arbeitsrecht keinen Platz habe. Damit werden Chancen vergeben, die sich gerade aus der Geltung des sog. ,weltlichen Arbeitsrechts“ ergeben, nämlich aus der in ihm begründeten Verfassungsgarantie für das Selbstbestimmungsrecht der Religionsgesellschaft. Ein der Kirche zugeordneter Arbeitgeber, der einen Arbeitsvertrag abschließt, nimmt nicht nur die allgemeine Vertragsfreiheit für sich in Anspruch, sondern er hat mit ihr zugleich auch teil an dem der Kirche verfassungsrechtlich gewährleisteten Selbstbestimmungsrecht. Mit deutlichen Worten hat das Bundesverfassungsrecht gesagt: „Die Verfassungsgarantie des Selbstbestimmungsrechts bleibt für die Gestaltung dieser Arbeitsverhältnisse wesentlich. “2

Der Gegensatz von weltlichem und kirchlichem Arbeitsrecht ist daher eine Scheinalternative; denn bei einer Zuordnung zur Kirche ergibt sich aus dem „weltlichen Arbeitsrecht“, dass kirchliches Recht anzuwenden ist. Die Verfassungsgarantie des Selbstbestimmungsrechts bedeutet keine Ausklammerung aus der staatlichen Rechtsordnung, sondern sie begründet im Gegenteil nicht als Privilegierung, sondern als Ausprägung einer freiheitsrechtlichen Dimension eine Sonderstellung innerhalb der staatlichen Rechtsordnung. Diese Feststellung mag überraschen, ist aber vor allem zu beachten, wenn man glaubt, durch Ausgründungen Finanzierungsprobleme zu lösen. Für das Arbeitsrecht bildet das Tarifrecht nur einen Ausschnitt und ist keineswegs sein Mittelpunkt. Doch bevor dies im Einzelnen behandelt wird, muss zunächst die juristische Grundlage der Beurteilung skizziert werden.

\footnotetext{
${ }^{1}$ BVerfGE 70, 138 (165).

2 BVerfGE 70, 138 (165).
} 


\section{Staatskirchenrechtliche Grundlagen kirchlicher Arbeits- verfassung}

\section{Weimarer Kirchenartikel als Bestandteil des Grundgesetzes}

Der Staat der Bundesrepublik Deutschland ist nach seiner Verfassung religionsfreundlich, und er wird es auch bei der Einbeziehung in die Europäische Union bleiben. Die Trennung von Staat und Kirche bedeutet daher nicht, dass der Staat die Kirche in ihrem öffentlichen Wirken unter eine Zwangsordnung stellt, in der sie nicht anders behandelt wird als Daimler-Chrysler oder auch das Rote Kreuz. Der Staat hat sein Verhältnis zu den Kirchen durch Rezeption der Kirchenartikel aus der Weimarer Reichsverfassung (WRV) geregelt. Durch Art. 140 GG i.V. mit Art. 137 Abs. 3 WRV ist den Religionsgesellschaften das Selbstbestimmungsrecht innerhalb der Schranken des für alle geltenden Gesetzes gewährleistet. Aus dem verfassungssystematischen Zusammenhang mit dem Grundrecht der Religionsfreiheit (Art. 4 GG), das unter keinem Gesetzesvorbehalt steht, ergibt sich, dass der Staat über das für alle geltende Gesetz keine Herrschaftsbefugnis über die Kirche und deren Dienst erhält. Er muss deshalb, wie das Bundesverfassungsgericht mehrfach festgestellt hat, bei der Gestaltung der sozialen Ordnung den Kirchen eigene Wege offen halten, damit sie von der zur Wahrnehmung ihrer Aufgaben unerlässlichen Freiheit der Bestimmung über Organisation, Normsetzung und Verwaltung Gebrauch machen können. ${ }^{3}$

\section{Privatautonomie und Verfassungsgarantie des Selbstbestimmungsrechts}

Die Verfassungsgarantie des Selbstbestimmungsrechts beschränkt sich, wie das Bundesverfassungsgericht ebenfalls mehrfach festgestellt hat, nicht nur auf die sog. verfasste Kirche, sondern bezieht alle der Kirche in bestimmter Weise zugeordneten Einrichtungen ohne Rücksicht auf ihre Rechtsform ein, wenn die Einrichtungen nach kirchlichem Selbstverständnis ihrem Zweck oder ihrer Aufgabe entsprechend berufen sind, ein Stück des Auftrags der Kirche wahrzunehmen und zu erfüllen. ${ }^{4}$ Bei privatrechtlich verselbständigten Einrichtungen bestimmen drei Kriterien die Zuordnung zur Kirche: die Wahrnehmung einer Grundfunktion der Kirche nach ihrem Selbstverständnis, die Absicherung durch den Willen der Verbandsmitglieder oder der Stifter, kurz formuliert: die Satzung, und schließlich die Absicherung durch die Verbindung mit den Amtsträgern der Kirche. So ist beispielsweise für das Staatskirchenrecht die Einrichtung, die sich der mit dem Petrusamt verbundenen bischöflichen Hirtengewalt entzieht, nicht mehr der katholischen Kirche zugeordnet. Das Bundesverfassungsgericht verlangt, dass die Einrichtung, wie es wörtlich heißt, „teilhat an der Verwirklichung

\footnotetext{
${ }^{3}$ BVerfGE 53, 366 (401); 57, 220 (244); 66, 1 (20); 70, 138 (164).

${ }^{4}$ BVerfGE 46, 73 (85f.); 53, 366 (391); 57, 220 (242); 70, 138 (162).
} 
eines Stückes Auftrag der Kirche im Geist katholischer Religiosität, im Einklang mit dem Bekenntnis der katholischen Kirche und in Verbindung mit den Amtsträgern der katholischen Kirche“".5 Entsprechend hat es für den Bereich der evangelischen Kirche festgestellt, dass die Einrichtung die Aufgabe im Einklang mit dem Bekenntnis der Kirche und in Verbindung mit deren Amtsträgern wahrnimmt. ${ }^{6}$

Kein Verband ist daher gegen seinen Willen ein Verband der Diakonie, wie auch kein Verband sich als ein der Kirche zugeordneter Verband bezeichnen kann, wenn ihm die Anerkennung durch die rechtmäßige kirchliche Autorität fehlt. Dem Staatskirchenrecht entspricht, was das Kirchenrecht für eine katholische Einrichtung verlangt: Keine Einrichtung darf sich ohne die Zustimmung der zuständigen katholischen Autorität „katholisch“ nennen; und Gleiches gilt entsprechend für die evangelische Kirche.

\section{Schlussfolgerung für die Geltung des „kirchlichen Arbeitsrechts“}

Wenn eine Einrichtung der Kirche zugeordnet ist, sichert ihr das Staatskirchenrecht, dass das staatliche Arbeitsrecht mit den Maßgaben der kirchlichen Ordnung auf die Begründung und den Inhalt der mit ihr bestehenden Arbeitsverhältnisse Anwendung findet. Das ist für sie aber keine Option, von der sonst für Arbeitsverhältnisse geltenden Ordnung abzuweichen, sondern bedeutet, dass wegen der Zuordnung zur Kirche in ihr die kirchenrechtlich legitimierte Ordnung Anwendung findet. Das verfassungsrechtlich verbürgte Selbstbestimmungsrecht ist nämlich kein Recht der Einrichtung, sondern ein Recht der Religionsgesellschaft. Daraus folgt, dass dieses Selbstbestimmungsrecht sich nach den von der verfassten Kirche anerkannten Maßstäben richtet, worin die kirchenspezifische Besonderheit des in der Einrichtung zu erbringenden Dienstes liegt, mit allen Folgen für die Gestaltung der Arbeitgeber-Arbeitnehmer-Beziehungen. ${ }^{7}$ Es beruht nicht auf der Satzungsautonomie und steht daher auch nicht zu deren Disposition. Eine privatrechtlich verselbständigte Einrichtung handelt deshalb rechtswidrig, wenn sie bei Aufrechterhaltung der Zuordnung zur Kirche die kirchliche Ordnung in den Arbeitgeber-Arbeitnehmer-Beziehungen nicht anwendet. Sie kann zwar durch entsprechende Satzungsänderung ihre Zuordnung zur Kirche preisgeben; sie unterliegt dann aber - möglicherweise als Tendenzunternehmen - dem allgemeinen Arbeitsrecht.

Der Staat respektiert, dass die Kirche für den Bereich der ihr zugeordneten Einrichtungen verbindlich festlegen kann, wer nach ihrem Selbstverständnis geeignet und befähigt ist, die im Arbeitsvertrag vorgesehene Aufgabe so zu erfüllen,

\footnotetext{
${ }^{5}$ BVerfGE 46, 73 (87).

${ }^{6}$ BVerfGE 53, 366 (392).

7 BVerfGE 70, $138(166,168)$.
} 
wie es ihrem religiös geprägten Sendungsauftrag entspricht. Sie kann daher auch dem Arbeitnehmer kirchenspezifische Loyalitätsobliegenheiten auferlegen, deren Verletzung eine Kündigung rechtfertigen. Das Bundesverfassungsgericht verweist insoweit auf die Maßstäbe der verfassten Kirche, räumt also kein Arbeitgeberprivileg ein, die entsprechenden Vorgaben selbst festzulegen.

Zur Sicherung der Glaubwürdigkeit des kirchlichen Dienstes haben die Kirchen, wenn man von der Nordelbischen Kirche und der Kirche in Berlin-Brandenburg absieht, für die Regelung der Arbeitsentgelte und der sonstigen profanen Arbeitsbedingungen das Arbeitsrechtsregelungsverfahren des „Dritten Weges“ eingeführt, um nicht in Tarifauseinandersetzungen mit der Möglichkeit des Arbeitskampfes verwickelt zu werden. Deshalb scheidet ein Arbeitskampf in der Diakonie aus. Die Sonderstellung bezieht sich auch auf die Betriebsverfassung; denn das staatliche Betriebsverfassungsgesetz findet nach dessen $\int 118$ Abs. 2 auf die Religionsgemeinschaften und ihre karitativen und erzieherischen Einrichtungen ohne Rücksicht auf deren Rechtsform keine Anwendung, sondern es gilt das durch Kirchengesetz geschaffene Mitarbeitervertretungsrecht. Eine Einrichtung, die durch ihre Organe festlegt, dass die kirchenrechtliche Ordnung in ihr keine Anwendung findet, muss deshalb hinnehmen, dass in ihr eine Gewerkschaft den Abschluss eines Tarifvertrags durch Streik erzwingt, und sie muss hinnehmen, dass ein Betriebsrat mit den im Betriebsverfassungsgesetz vorgesehenen Mitwirkungs- und Mitbestimmungsrechten gebildet wird. ${ }^{8}$

\section{Flucht aus dem kirchlichen Arbeitsrecht durch Ausgründung}

\section{Erscheinungsformen}

Die Finanzierungspraxis des Staats hat die karitativen Einrichtungen vor ein Dilemma gestellt. Sie sollen zum einen mit Wettbewerbern konkurrieren, die einen Wettbewerbsvorteil aus einem geringeren Lohnniveau erzielen, und sie sind zum anderen durch die Festlegung im „Dritten Weg“ an Tarife gebunden, die für sie ausschließen, auf derselben Stufe in Wettbewerb zu treten. Es ist deshalb sehr wohl verständlich, dass man das Heil in Ausgründungen sucht, um bestehende Einrichtungen aufrechtzuerhalten. Der Gesetzgeber hat durch das Umwandlungsgesetz derartige Strukturveränderungen erleichtert. Dabei hat man allerdings zu beachten, dass eine Ausgründung durch Spaltung zunächst ausschließlich den Rechtsträger betrifft. An die Stelle des bisherigen Vereins tritt für den abgespaltenen Vermögensteil der neue Rechtsträger, der eine Kapitalgesellschaft sein kann. Eine derartige Abspaltung muss nicht zur Folge haben, dass die Zuordnung zur

\footnotetext{
${ }^{8}$ Ebenso für die Betriebsverfassung bereits Arbeitsgericht Mönchengladbach, ZMV 2001, 244ff.
} 
Kirche aufgehoben wird. Hier ergeben sich allerdings Schranken aus der Besonderheit der Gesellschaftsform; denn das verfassungsrechtlich gewährleistete Selbstbestimmungsrecht gestattet der Kirche nicht, eine vom staatlichen Recht verschiedene Aktiengesellschaft oder Gesellschaft mit beschränkter Haftung zu gründen. Es hängt deshalb vom Gesellschaftsrecht ab, ob und inwieweit die $\mathrm{Zu}$ ordnungskriterien eingehalten werden können. Für die Aktiengesellschaft gilt dabei als Prinzip, dass eine Satzungsfreiheit nur nach Maßgabe des Aktiengesetzes besteht, während es für die GmbH umgekehrt ist; es besteht Satzungsfreiheit in den Grenzen des GmbH-Gesetzes.

Deshalb kann bei Ausgründung in eine GmbH die Zuordnung zur Kirche satzungsrechtlich abgesichert bleiben. Eine derartige Ausgründung hat dann allerdings nicht zur Folge, dass das Recht des „Dritten Weges“ keine Anwendung findet. Dieser Konsequenz entgeht die Einrichtung, die Teile ausgliedert, nur, wenn sie für den ausgegliederten Teil die Zuordnung zur Kirche preisgibt.

\section{2. Übergang der Arbeitsverhältnisse}

Jede Ausgliederung bedeutet für die von ihr betroffenen Arbeitnehmer eine Gefahr. Deshalb ergibt sich aus dem Umwandlungsgesetz, dass der hinreichend bekannte $\int$ 613a BGB Anwendung findet. Bei der Spaltung hat der Arbeitgeber kein Auswahlrecht, sondern mit ihr tritt der neue Rechtsträger in die Arbeitsverhältnisse mit den Arbeitnehmern ein, die in den übergegangenen Betrieb oder Betriebsteil organisatorisch eingegliedert sind. Es handelt sich um einen Vertragsübergang, durch den der Erwerber nicht viel gewinnt; denn er muss das Arbeitsverhältnis mit dem bisherigen Vertragsinhalt fortsetzen. Häufig glaubt man, dass der Arbeitgeber die bisher maßgebliche kollektive Ordnung nach Ablauf eines Jahres einseitig aufkündigen oder zumindest durch Tarifvertrag oder Betriebsvereinbarung für den Arbeitnehmer verschlechtern kann. Diese Vorstellung beruht aber auf einer Fehlinterpretation des Gesetzes; denn die in ihm festgelegte Fortgeltungsanordnung und die Möglichkeit einer vorherigen Ablösung (613a Abs. 1 Satz 2 und 3 BGB) beziehen sich nur auf eine normativ geltende Kollektivvertragsordnung. Sie gelten daher, wie das Bundesarbeitsgericht klargestellt hat, nicht für Verträge, die auf Arbeitsrechtsregelungen des „Dritten Weges“ Bezug nehmen. ${ }^{9}$ Darin liegt zum einen ein Vorteil, weil die Vertragsanpassung im Einverständnis mit dem Arbeitnehmer vor Jahresfrist erfolgen kann, zum anderen aber auch ein Nachteil, weil sie ohne Zustimmung des Arbeitnehmers lediglich durch eine Änderungskündigung durchsetzbar ist, die zur Entgeltanpassung bei Geltung des Kündigungsschutzgesetzes nur unter außerordentlich engen Voraussetzungen von den staatlichen Arbeitsgerichten als sozial gerechtfertigt anerkannt wird.

\footnotetext{
${ }^{9}$ BAG AP Nr. 53 zu Art. 140 GG.
} 
Für die von einer Ausgliederung betroffenen Arbeitnehmer besteht daher ein hoher Schutzwall; aber er ist für sie ohne Wert, wenn die ausgegliederte Einrichtung sich am Markt nicht zu behaupten weiß. Vor einer erzwungenen oder auch freiwilligen Stilllegung schützt kein Kündigungsschutz den Arbeitsplatz. Es ist sogar durch das Grundrecht der Berufsfreiheit gesichert, dass niemand die Rolle des Arbeitgebers übernehmen muss und daher ein Arbeitgeber auch aus ihr ausscheiden kann.

\section{Anpassungsnotwendigkeit für die Zuordnung zur Kirche}

Die diakonischen Einrichtungen stehen heute vor der Zentralfrage, dass die Finanzierung durch die Kostenträger nicht mehr deren Aufwand deckt. Zugespitzt wird deshalb die Frage gestellt: Was nützt noch der „Dritte Weg““, wenn die diakonischen Rechtsträger ihn wirtschaftlich nicht mehr gehen können? Darin liegt in der Tat ein Dilemma. Zugleich wird aber auch deutlich, dass der „Dritte Weg" sehr wohl ein Verhandlungsgleichgewicht der Mitarbeiter gewährleistet. Das ist in der Vergangenheit vielfach bestritten worden. Sollte aber eine Anpassungsnotwendigkeit am Widerstand der Mitarbeitervertreter scheitern können, so wird dadurch geradezu dokumentiert, dass ein Verhandlungsgleichgewicht besteht.

Bisher wurde bereits deutlich, dass man den Verpflichtungen des „Dritten Weges“ nur mit einer Einverständniserklärung der einzelnen Arbeitnehmer entgehen kann. Sie kann nicht durch die Zustimmung der Mitarbeitervertretung ersetzt werden; denn ebenso wenig wie der Betriebsrat hat auch eine nach kirchlichem Recht gebildete Mitarbeitervertretung die Kompetenz zur Änderung des Vertragsinhalts. Für den Betriebsrat hat dies das Bundesarbeitsgericht ausdrücklich festgestellt. ${ }^{10}$

Bei der Gestaltung des Verfahrens nach dem „Dritten Weg“ ist offenkundig ein Problem nicht gelöst, das so auch im öffentlichen Dienst besteht. Wird in der Erwerbswirtschaft durch Streik ein Tarifvertrag erzwungen, der für die Arbeitgeberseite finanziell nicht tragbar ist, so ist die Folge dort die Insolvenz der Unternehmen. Selbst wenn man sie vermeiden kann, der Tarifvertrag aber als wirtschaftlich unvernünftig angesehen wird, besteht zum einen die Möglichkeit, über Preis-erhöhungen die Belastung an Abnehmer weiterzugeben. Wo dies nicht möglich erscheint, kann man zum anderen durch Auslagerungen in Billiglohnstaaten den wirtschaftlichen Ausgleich herbeiführen.

Wie dem öffentlichen Dienst ist auch den karitativen Einrichtungen diese Möglichkeit verschlossen. Der Unterschied zur Erwerbswirtschaft besteht hier in der Abhängigkeit von einer Fremdfinanzierung. Weil diese Abhängigkeit auch den Mitarbeitervertretern bekannt ist, gebietet die wirtschaftliche Vernunft eine Konsensbereitschaft; denn die Alternative der Schließung oder Ausgründung, die

${ }^{10}$ BAG AP Nr. 83 zu $\ 77$ BetrVG 1972. 
durch das Arbeitsrechtsregelungsverfahren des „Dritten Weges“ nicht verhindert werden kann, ist für die abhängig beschäftigten Mitarbeiter stets die schlechteste Lösung.

Dennoch lässt sich nicht ausschließen, dass bei einer Parität Blockaden eintreten. Das Bundesverfassungsgericht musste sich in dem bekannten Mitbestimmungsurteil vom 1. März 197911 mit der Problematik bei der Besetzung des Aufsichtsrats befassen, der für die dem Mitbestimmungsgesetz unterfallenden Gesellschaften die Unternehmensleitung auswählt und kontrolliert. Von der Feststellung einer Verfassungswidrigkeit konnte es absehen, weil der Anteilseignerseite ein leichtes Übergewicht in der Wahrnehmung der dem Aufsichtsrat eingeräumten Befugnisse eingeräumt ist.

Was dort für die Funktionsfähigkeit der Unternehmen gilt, muss hier wegen der Besonderheit einer der Kirche zugeordneten Einrichtung Beachtung finden. Gegen den Paritätsgrundsatz darf man deshalb nicht in Stellung bringen, dass in Verfahrensordnungen des „Dritten Weges“ ein bischöfliches bzw. synodales Letztentscheidungsrecht verankert ist oder, wo nicht vorhanden, verankert wird. Entscheidend ist allerdings, dass die Kompetenz durch die Besonderheit des kirchlichen Auftrags legitimiert wird. Wenn dies der Fall ist, kann man das Letztentscheidungsrecht des Bischofs oder der Synode nicht als Kriterium heranziehen, um die Gleichwertigkeit des „Dritten Weges“ mit dem Tarifvertragssystem in Frage zu stellen. Das Bundesarbeitsgericht hat anerkannt, dass die bloße Möglichkeit des Letztentscheidungsrechts nicht ausreicht, um zu dem Ergebnis zu kommen, dass eine Regelung des „Dritten Weges“ nicht dem Paritätserfordernis entspricht. ${ }^{12}$ Wie der Bischof, der die umfassende Verantwortung für das Heil der ihm anvertrauten Gläubigen trägt, nicht einfach als „Arbeitgeber“ verstanden werden kann, gilt Gleiches für die Synode in der evangelischen Kirche.

\footnotetext{
${ }^{11}$ BVerfGE 50, $290 \mathrm{ff}$.

12 BAG AP Nr. 1 zu \10a AVR Caritasverband.
} 

Ulrich Hammer

\section{Dritter Weg und Tarifvertrag - Gegensatz oder notwendige Ergänzung?*}

\section{Einführung}

In einer Zeit, in der der Ausstieg aus dem kirchlichen Arbeitsrecht als besondere Managementtugend erscheint, um Kosten zu sparen, wirkt die Frage nach dem Verhältnis von Drittem Weg und Tarifvertrag eher künstlich. Was kann den kirchlichen Einrichtungen schon eine Tarifbindung bringen, wo vielen von ihnen doch bereits die Bindung an den Dritten Weg mit seinen kirchlichen Arbeitsvertragsordnungen als zunehmend unzumutbare finanzielle Belastung erscheint? Ist da die Verabschiedung kirchlicher Einrichtungen von den klassischen Instrumenten des staatlichen Arbeitsrechts, einschließlich des Tarifvertrags, nicht schon längst so irreversibel geworden, dass an kirchengemäße Tarifverträge gar nicht mehr zu denken ist?

\footnotetext{
* Schriftliche Fassung eines Power-Point-Vortrags im Rahmen des Management-Symposiums „Diakonie im Ausverkauf? Der Dritte Weg auf dem Prüfstand“ am 29.09. 2005 in Kästorf. Die Vortragsform ist weitgehend beibehalten worden.
} 
Wie immer, der Schein trügt auch hier. Zum einen schließen Nordelbische und Berlin-Brandenburgische evangelische Landeskirchen und mit ihnen zahlreiche einzelne kirchliche Einrichtungen nach wie vor Tarifverträge ab. Zum anderen führt das kirchliche Arbeitsrecht in wachsendem Ausmaß zu kirchlichen Gremien und Organen besonderer Art - von den Arbeitsrechtskommissionen bis hin zu eigenen kirchlichen Arbeitsgerichtsbarkeiten der beiden deutschen Großkirchen -, die angesichts schwindender Kirchensteuereinnahmen und systematischer Unterfinanzierung sozialer Einrichtungen jedenfalls finanziell deplaziert wirken. Entscheidend ist jedoch, dass das staatliche Arbeitsrecht mit der betrieblichen (Betriebsräte) und überbetrieblichen (Tarifverträge) Mitbestimmung ein System fein abgestimmter Steuerungsinstrumente der Arbeitsbedingungen bereitstellt, zu dem sich die Kirchen im säkularen Bereich unvermindert und geradezu empathisch bekennen, während es sich im kirchlichen Bereich auch als Ausdruck der christlichen Dienstgemeinschaft deuten lässt. Die Beharrung auf einem eigenen kirchlichen Arbeitsrecht stellt daher ein permanentes Paradoxon dar, das evangelische und katholische Kirchen - wie zu zeigen sein wird: unnötigerweise - in akute Erklärungsnot bringt.

Allerdings müssen die Kirchen und ihre Einrichtungen die Ablehnung kirchengemäßer Tarifverträge mit einem hohen Preis bezahlen. Mangels in der Praxis verbindlicher Regelungen der Arbeitsbedingungen führt der Dritte Weg zu ihrer Zersplitterung, die sich, namentlich im evangelischen Bereich, zwischen den verschiedenen Landeskirchen sowie zwischen einzelnen Einrichtungen unterschiedlich entwickeln und dadurch nicht nur den Wettbewerb mit verschiedenen privaten Anbietern, die sich an keinerlei feste Tarife halten, sondern auch mit anderen kirchlichen Einrichtungen zu Lasten der Leistungsqualität verzerren können. Zwar verpflichten sich kirchliche Einrichtungen, die dem Diakonischen Werk oder der Caritas angehören, satzungsrechtlich auf deren Arbeitsvertragsordnungen. Auch wenn immer wieder Fälle der Abweichung von diesen Arbeitsvertragsordnungen vorkommen, sind bis dato noch keine Einrichtungen mit vereinsrechtlichen Sanktionen, z.B. dem Ausschluss aus Diakonie oder Caritas und damit aus dem Schutzbereich des kirchlichen Arbeitsrechts, belegt worden, obwohl dies zulässig wäre. Im Gegenteil: Kirchliche Einrichtungen suchen heute oftmals selbst den Weg aus dem kirchlichen Arbeitsrecht, weil sie sich davon kostengünstigere Arbeitsbedingungen und - angesichts eines 70-80\% igen Anteils der Personalkosten an den Gesamtkosten - deutliche Wettbewerbsvorteile gegenüber der Konkurrenz versprechen. Dadurch entsteht indessen die Gefahr einer sog. Abwärtsspirale, bei der nicht nur die Qualität der Leistungen, die gerade in Einrichtungen des Sozial- und Gesundheitswesens maßgeblich von der Qualifikation ihrer Beschäftigten abhängt, sondern auch die Wettbewerbsfähigkeit dauerhaft leiden. Denn wie es so schön heißt: Qualität kostet und die Konkurrenz schläft nicht. Andere Einrichtungen werden gezwungen gleich zu ziehen mit der 
Folge, dass das Qualitätsniveau kirchlicher Einrichtungen insgesamt zu sinken droht.

Hier können kirchengemäße Tarifverträge Abhilfe schaffen, weil deren normative Wirkung ( $\int 1$ Tarifvertragsgesetz $=$ TVG) gegenüber Berufsverbänden (Gewerkschaften), Arbeitgebervereinigungen oder einzelnen Arbeitgebern ( $\int 2$ TVG) willkürliche Verschlechterungen der Arbeitsbedingungen verhindern. Wenn kirchenrechtlich dafür gesorgt wird, dass kirchliche Arbeitgeber ihre Tarifbindung ( $\int 3$ TVG) anerkennen, sorgt die unmittelbare und zwingende Wirkung der Tarifnormen ( $\int 4$ TVG) für gleiche Wettbewerbsbedingungen zugunsten einer Konkurrenz um die besseren Lösungen anstatt um die niedrigsten Entgelte. Die „Kirchengemäßheit“ von Tarifverträgen würde überdies dafür sorgen, dass die besondere Eigenart des kirchlichen Dienstes, das sog. kirchliche Proprium, wie es in der Dienstgemeinschaft als Leitbild kirchlicher Einrichtungen ausgedrückt ist, bewahrt bleibt und, was gesellschaftspolitisch im Grunde viel wichtiger ist, von den Berufsverbänden (Gewerkschaften) ausdrücklich anerkannt und respektiert wird.

Unbestritten gilt das Tarifvertragsrecht auch für die Kirchen und ihre Einrichtungen. Ob sie Tarifverträge schließen oder nicht entscheiden sie - wie andere Arbeitgeber auch - nach eigenem Ermessen. Denn auch das kirchliche Arbeitsrecht kann dem staatlichen nicht entkommen. Es gilt immer noch, was das Bundesverfassungsgericht 1985 in die schlichten Worte gefasst hat: „Bedienen sich die Kirchen wie jedermann der Privatautonomie zur Begründung von Arbeitsverhältnissen, so findet auf diese das staatliche Arbeitsrecht Anwendung“. ${ }^{1}$

\section{Rechtsqualität des Dritten Wegs ${ }^{2}$}

Wird das kirchliche Arbeitsrecht in das staatliche Rechtssystem eingeordnet, unter dem es wie alle gesellschaftlichen Mächte steht, zeigen sich seine Defizite - und vice versa die Vorzüge, die das Tarifvertragsrecht auch den Kirchen und ihren Einrichtungen bietet.

Der Dritte Weg beruht auf arbeitsrechtlichen Gleichstellungsabreden, durch die kirchlichen Beschäftigten gleiche Arbeitsbedingungen gewährt werden. Erst durch die arbeitsvertragliche Vereinbarung sog. dynamischer Verweisungsklauseln werden die Beschlüsse kirchlicher Arbeitsrechtskommissionen zwischen einzelnen kirchlichen Arbeitgebern - Dienstgebern - und einzelnen kirchlichen Beschäftigten - Dienstnehmern - rechtlich wirksam. Aus eigener Kraft sind Arbeits-

\footnotetext{
1 BVerfGE 70, 138, 165.

2 Siehe hierzu Ulrich Hammer, Die Rechtsqualität kirchlicher Arbeitsvertragsordnungen im Spiegel der BAG-Rechtsprechung, in: AuR 2002, S. 49; ders., Kirchliches Arbeitsrecht, 2002, S. 416 ff.; ders., Neuere Entwicklungen der Normqualität kirchlicher Arbeitsvertragsordnungen, in: ZTR 2002, 302, 304; ders., Neues zur Normqualität kirchlicher Arbeitsvertragsordnungen?, in: ZTR 2003, 281.
} 
rechtskommissionen des Dritten Wegs dazu nicht in der Lage. Insbesondere können sie kirchlichen Arbeitsvertragsordnungen keine normative, d.h. unmittelbare und zwingende Wirkung auf die Arbeitsverträge verleihen, wie sie Tarifverträge besitzen. Den Kirchen ist von der Verfassung des Grundgesetzes keine arbeitsrechtliche Gesetzgebungskompetenz zugewiesen. ${ }^{3}$ Art. 140 GG i. V. m. Art. 137 Abs. 3 WRV, der hier als einzige Kompetenznorm zu Gebote stünde, wenn er denn eine wäre, drückt sich ähnlich dem Bundesverfassungsgericht insoweit schlicht aber klar aus: „Jede Religionsgemeinschaft ordnet und verwaltet ihre Angelegenheiten selbständig innerbalb der Scbranken des für alle geltenden Gesetzes" (Hervorhebung v. Verf.).

Zu den für alle geltenden Gesetzen gehört aber auch Art. 74 Nr. 12 GG, der die (konkurrierende) Gesetzgebungskompetenz des Bundes im Arbeitsrecht bestimmt. ${ }^{4}$ Der Dritte Weg stellt rechtlich nichts anderes dar als Arbeitsvertragsrecht, konkreter: Kirchliches Satzungsrecht (Beschlüsse der Arbeitsrechtskommissionen), das durch Einzelarbeitsvertrag zum Arbeitsvertragsrecht wird und ausschließlich als solches rechtlich wirkt.

\section{Leistungsbestimmung durch einen unabhängigen Dritten?}

Die Rechtsqualität auf dem Dritten Weg zustande gekommener kirchlicher Arbeitsvertragsordnungen schwächt diese und macht sie gegen inhaltliche Billigkeitskontrollen durch die Arbeitsgerichte anfällig, stellt also das kirchliche Proprium, die Eigenart des kirchlichen Dienstes, entgegen den Absichten des Dritten Wegs in Wirklichkeit unter Kuratel des Staates. Das unterscheidet kirchliche Arbeitsvertragsordnungen grundlegend von Tarifverträgen.

\subsection{Inhaltskontrolle statt Rechtskontrolle}

Auf der Ebene des Einzelvertragsrechts gilt nicht, was das Bundesverfassungsgericht für Tarifverträge konstatiert hat, ${ }^{5}$ dass sie grundsätzlich geeignet und bestimmt sind, „die strukturelle Unterlegenheit der einzelnen Arbeitnehmer beim Abschluss von Arbeitsverträgen durch kollektives Handeln auszugleichen und damit ein annähernd gleichgewichtiges Aushandeln der Löhne und Arbeitsbedin-

\footnotetext{
3 Missverständlich ist insoweit Reinhard Richardi, Arbeitsrecht in der Kirche. Staatliches Arbeitsrecht und kirchliches Dienstrecht, 4. Aufl., 2003, S. 34 ff., der von einer arbeitsrechtlichen Regelungsautonomie der Kirchen für ihre Einrichtungen spricht.

${ }^{4} \mathrm{Zu}$ den - freilich nicht ganz unkomplizierten - Abgrenzungskriterien zwischen Kirchenautonomie und staatlicher Gesetzgebungskompetenz vgl. im einzelnen Hammer, Kirchliches Arbeitsrecht, 2002, S. 105 ff. (Drittes Kapitel: Die Kirchen und das staatliche Arbeitsrecht).

${ }^{5}$ BVerfGE 84, 212, 229; E 92, 365, 395; sh. auch Kühling, Arbeitskampf in der Diakonie, online im Internet: http://72.14.203.104/search?q=cache:W4wetYfxn1sJ:www.diag-mav.org/rechtspr/komment/streikrecht.htm+strukturelle+Unterlegenheit+der+einzelnen+Arbeitnehmer+beim +Abschlu $\% \mathrm{C} 3 \% 9 \mathrm{~F}+$ von + Arbeitsvertr $\% \mathrm{C} 3 \% \mathrm{~A} 4 \mathrm{gen} \& \mathrm{hl}=\mathrm{de} \& \mathrm{gl}=\mathrm{de} \& \mathrm{ct}=\mathrm{clnk} \& \mathrm{~cd}=1 \& \mathrm{lr}=\mathrm{lang} \_\mathrm{de}(27.1 .2006)$.
} 
gungen zu ermöglichen“; Tarifverträge unterliegen daher keiner Inhaltskontrolle am Kriterium der Billigkeit, sondern nur einer eingeschränkten Rechtskontrolle an höherrangigem Gesetzes- und Verfassungsrecht. ${ }^{6}$ Kirchliche Arbeitsvertragsordnungen als Bestimmungen des Dritten Wegs bewertet das Bundesarbeitsgericht ${ }^{7}$ hingegen grundsätzlich als allgemeine Arbeitsvertragsbedingungen, die der kirchliche Arbeitgeber kraft seiner strukturellen Überlegenheit gegenüber dem einzelnen Arbeitnehmer einseitig durchsetzen kann. Weil aber „kein Gleichgewicht der Vertragspartner einen angemessenen Vertragsinhalt gewährleistet, weil entweder die Vertragsparität gestört ist oder eine Vertragspartei aus anderen Gründen allein den Inhalt des Vertragsverhältnisses gestalten kann", 8 unterliegen Arbeitsverträge außerhalb des Geltungsbereichs von Tarifverträgen nach ständiger Rechtsprechung des Bundesarbeitsgerichts grundsätzlich neben der Rechtskontrolle auch der inhaltlichen Billigkeitskontrolle durch die Arbeitsgerichte. ${ }^{9}$

\subsection{Eingeschränkte Inhaltskontrolle der Beschlüsse Arbeitsrechtlicher Kommissionen}

Freilich ist dabei zu berücksichtigen, dass kirchliche Arbeitsvertragsordnungen auf dem Dritten Weg durch Beschlüsse paritätisch mit Arbeitnehmer- und Arbeitgebervertretern besetzter arbeitsrechtlicher Kommissionen zustande kommen, womit die strukturelle Unterlegenheit kirchlicher Beschäftigter beim Abschluss von Arbeitsverträgen wenigstens teilweise gemildert ist. Der Dritte Weg ist darauf angelegt, eine wesentliche Funktion der Tarifautonomie zu ersetzen: Die Herstellung einer Verhandlungslage, in der sich Arbeitnehmer und Arbeitgeber unabhängig und gleichgewichtig gegenüberstehen. Ob dieses Modell tatsächlich geeignet ist, die strukturelle Unterlegenheit des einzelnen Arbeitnehmers verfassungskonform auszugleichen, erscheint hingegen fraglich; erfahrungsgemäß ist es am Verhandlungstisch leichter, den status quo zu verteidigen, als Veränderungen gegen die Interessen des Gegenspielers durchzusetzen. ${ }^{10}$ Es ist aber regelmäßig die Arbeitnehmerseite in kirchlichen Arbeitsrechtskommissionen, die den status quo, z.B. durch Übernahme von Tarifergebnissen des öffentlichen Dienstes, verändern will. Hinzukommen grundsätzliche Einwände gegen die Un-abhängigkeit kirchlicher Arbeitsrechtskommissionen.

\footnotetext{
${ }^{6}$ Vgl. dazu im einzelnen ErfK/Dieterich Art. 9 GG Rn 87 ff.

${ }^{7}$ Bundesarbeitsgericht (BAG) 14, 61, $63=$ AP Nr. 77 zu Art. 3 GG.

${ }^{8}$ BAG 23, 160, 163.

9 BAG 23, 160, 163 f. = AP Nr. 1 zu \305 BGB Billigkeitskontrolle; AP Nr. 40 zu \242 BGB Gleichbehandlung.

${ }^{10} \mathrm{Vgl}$. Kühling, Arbeitskampf in der Diakonie (Anm. 5).
} 


\subsection{Einwände gegen die „Unabhängigkeit“ kirchlicher Arbeitsrechtskom- missionen}

Die paritätische Besetzung kirchlicher Arbeitsrechtskommissionen mit Arbeitnehmer- und Arbeitgebervertretern kann lediglich eine numerische, d.h. formelle Parität herstellen, während die materielle Parität Gleichgewichtigkeit im umfassenden Sinne verlangt. Hierfür benötigen die Arbeitnehmervertreter in kirchlichen Arbeitsrechtskommissionen mindestens die Gewährleistung sach- und fachkompetenter Unterstützung, die der auf Arbeitgeberseite gleichwertig sein muss. ${ }^{11}$ Eine solche Sach- und Fachkompetenz besitzen aber in der Regel nur Berufsverbände bzw. Gewerkschaften. Letztlich läuft das darauf hinaus, dass sich Arbeitnehmervertreter in kirchlichen Arbeitsrechtskommissionen von Berufsverbänden bzw. Gewerkschaften („Verbänden“) unterstützen lassen müssten, „ohne dass [...] der kirchliche Gesetzgeber verpflichtet ist, ihnen [den Berufsverbänden bzw. Gewerkschaften, d. Verf.] besondere Befugnisse zuzuweisen“. ${ }^{12}$

Offen bleibt dabei, wie die Gewerkschaften die sach- und fachkompetente Unterstützung der Arbeitnehmerseite in kirchlichen Arbeitsrechtskommissionen ohne eigene Rechte durchsetzen und finanzieren sollen. Als sach- und fachkompetente Unterstützung der Arbeitnehmerseite wären sie in kirchlichen Arbeitsrechtskommissionen, gleichsam auf jederzeitigen Widerruf, kirchenrechtlich nur geduldet. Schon das wirkt paritätswidrig. Zu finanzieren wäre ihr Engagement darüber hinaus aus Mitgliedsbeiträgen. Dazu müssen sie aber auch in kirchlichen Einrichtungen mit allen ihnen arbeitsrechtlich zu Gebote stehenden Mitteln Mitglieder werben können. ${ }^{13}$ Ein wesentliches Instrument der gewerkschaftlichen Mitgliederwerbung ist indessen ihre Fähigkeit zum Abschluss von Tarifverträgen. Ohne dieses Recht ist ihre sach- und fachkompetente Unterstützung der Arbeitnehmerseite in kirchlichen Arbeitsrechtskommissionen gegenüber kirchlichen Beschäftigten nicht werbewirksam darstellbar und daher von Grund auf gefährdet. Sie liefe Gefahr, auf Dauer für die Berufsverbände bzw. Gewerkschaften zum finanziellen Fiasko zu werden. Eine Lösung der materiellen Ungleichgewichtigkeit zwischen Arbeitnehmer- und Arbeitgeberseite in kirchlichen Arbeitsrechtskommissionen ist das nicht. ${ }^{14}$

\footnotetext{
${ }^{11}$ Richardi, Arbeitsrecht in der Kirche. Staatliches Arbeitsrecht und kirchliches Dienstrecht, 4. Aufl., 2003, S. 229 f.

12 Richardi, a. a. O.

13 Vgl. dazu BVerfGE 57, 220, wonach das Zutrittsrecht nicht betriebsangehöriger Gewerkschaftsvertreter zu kirchlichen Einrichtungen ausgeschlossen werden kann, weil das Betriebsverfassungsgesetz, in dem dies gesetzlich geregelt ist, für die Kirchen und ihre Einrichtungen nach $₫ 118$ Abs. 2 BetrVG nicht gilt; vgl. dagegen allerdings die neuere Entscheidung BVerfG 93, 352, wonach das Zutrittsrecht generell in den Schutzbereich des gewerkschaftlichen Betätigungsrechts fällt und deshalb auch gegenüber kirchlichen Einrichtungen unbeschränkt gilt.

14 So bestimmt denn auch $₫ 11$ Abs. 8 Kirchengesetz der Konföderation evangelischer Kirchen in Niedersachsen zur Regelung des Arbeitsrechts für Einrichtungen der Diakonie (Arbeitsrechts-
} 


\subsection{Die Rechtsprechung des Bundesarbeitsgerichts}

Gleichwohl hat das Bundesarbeitsgericht kirchliche Arbeitsrechtskommissionen vom einseitigen Arbeitgeberdiktat abgehoben. Nicht dass für die soziale Gleichgewichtigkeit der Sozialpartner eine numerisch paritätische Zusammensetzung kirchlicher Arbeitsrechtskommissionen genügte. ${ }^{15}$ Die wenn auch in diesem Sinne nur formelle Parität kirchlicher Arbeitsrechtskommissionen bei der Beschlussfassung über kirchliche Arbeitsvertragsordnungen unterscheidet sich jedoch von der strukturellen Unterlegenheit bei der Aushandlung von Einzelarbeitsverträgen. Denn immerhin treten in kirchlichen Arbeitsrechtskommissionen nicht Arbeitnehmer einzeln einem Arbeitgeber gegenüber, sondern ein Arbeitnehmerkollektiv einem Arbeitgeberkollektiv unter dem Vorsitz einer unabhängigen Verhandlungsleitung. Das muss nicht, kann aber einen Unterschied zur Verhandlungssituation bei Arbeitsverträgen ausmachen. ${ }^{16} \mathrm{Ob}$ dies eine Ausnahme kirchlicher Arbeitsvertragsordnungen von der Situation bei der Aushandlung von Einzelarbeitsvertragsordnungen rechtfertigt, soll hier dahingestellt bleiben. ${ }^{17}$ Fakt ist, dass das Bundesarbeitsgericht diese Ausnahme macht mit dem Ergebnis, ${ }^{18}$ dass an die Stelle der unbeschränkten Inhaltskontrolle kirchlicher Arbeitsvertragsordnungen und damit der Beschlüsse kirchlicher Arbeitsrechtskommissionen am Kriterium der Billigkeit nach \315 BGB eine beschränkte Inhaltskontrolle auf „offenbare Unbilligkeit“ nach den \$S 317, 319 BGB tritt.

\subsection{Bloße Rechtskontrolle bei Übernahme anderweitig ausgehandelter Tarifverträge}

Noch weiter geht das Bundesarbeitsgericht, indem es die Inhaltskontrolle kirchlicher Arbeitsvertragsordnungen vollständig suspendiert, zugunsten einer bloßen Rechtskontrolle, wenn durch sie ganz oder im wesentlichen anderweitig ausge-

regelungsgesetz Diakonie - ARRGD) v. 11. 10. 1997 relativ vage: „Zur Vorbereitung der Sitzungen der Arbeitsrechtlichen Kommission sind beide Seiten berechtigt, Besprechungen ihrer jeweiligen Seite durchzuführen... Beide Seiten können zu diesen Sitzungen Sachkundige hinzuziehen. Die Sachkundigen erhalten Reisekosten nach den in der Konföderation geltenden Bestimmungen. Über die Erstattung darüber hinaus entstehender Kosten entscheiden der oder die Vorsitzende oder der oder die stellvertretende Vorsitzende der Arbeitsrechtlichen Kommission im Einvernehmen. Kann ein Einvernehmen nicht hergestellt werden, entscheidet der oder die Vorsitzende der Schlichtungskommission." Im Internet: http://www.diakonie-braunschweig.de/opencms/export/ sites/DiakonischesWerk/_system/Organisation/DW-Geschaeftsstelle/Dateien/arrg-d.pdf. (28.05.2006)

15 So aber offenbar Hanau/Thüsing, Arbeitsrechtliche Konsequenzen beim Betriebsübergang kirchlicher Einrichtungen, KuR 2000, 165, S. 174 f.

16 Z.B. besteht nicht einmal formelle Parität, wenn ein Beschluss mit Mehrheit gefasst werden kann, auf Arbeitnehmerseite aber ein Personalchef oder Rentner mitwirken, wie das in der Praxis schon vorgekommen ist.

17 Dieterich - ErfK/Dieterich Art. 4 GG Rn 53 - würde es wohl verneinen, mindestens solange auf dem Dritten Weg kirchliche Arbeitsrechtskommissionen nicht abschließend entscheiden, weil sich Bischof oder Synode ein Letztentscheidungsrecht vorbehalten.

18 BAG AP Nr. 24 zu \ 611 BGB Kirchendienst = BAG NZA 1997, S. 55, 56. 
handelte Tarifverträge übernommen werden. ${ }^{19}$ Die der Rechtswirkung von Tarifverträgen hierdurch angenäherte Geltungskraft kirchlicher Arbeitsvertragsordnungen, soweit sie anderweitig ausgehandelte Tarifwerke im Wesentlichen übernehmen, besitzt zwar durchaus eine innere Logik. Wenn die Kirchen und ihre Einrichtungen durch Beschluss kirchlicher Arbeitsrechtskommissionen anderweitig ausgehandelte Tarifverträge im wesentlichen übernehmen und lediglich mit Regelungen ihrer eigenen Angelegenheiten - Dienstgemeinschaft - ergänzen, handelt es sich zwar nicht formell, wohl aber inhaltlich immer noch um Tarifverträge, die nun einmal keiner Inhaltskontrolle, sondern lediglich einer Rechtskontrolle durch die staatlichen Arbeitsgerichte unterliegen. Dennoch stellt die der Rechtswirkung von Tarifverträgen angenäherte Geltungskraft kirchlicher Arbeitsvertragsordnungen einen tiefen Eingriff in die Koalitionsfreiheit namentlich der Gewerkschaften, aber auch (kirchlicher) Arbeitgebervereinigungen dar, ${ }^{20}$ die als Parteien möglicher kirchengemäßer Tarifverträge in Frage kommen. Vor allem die Gewerkschaften werden sozusagen ihres ureigenen Produkts, nämlich anderweitig, in der Regel für den öffentlichen Dienst ausgehandelter Tarifverträge, „enteignet“ und mit ihnen im Wege einzelarbeitsvertraglicher Gleichstellungsabreden in Arbeitsverträgen kirchlicher Beschäftigter zu dem wesentlichen Zweck konfrontiert, aus Betrieben und Unternehmen - hier: kirchlichen Einrichtungen - herausgehalten zu werden.

\section{Kirchliche Arbeitsvertragsordnungen - keine Tarifverträge}

Gleichwohl ist auch diese Rechtsprechung des BAG aus kirchlicher Sicht nur solange ausreichend, wie die Kirchen und ihre Einrichtungen namentlich die Tarifwerke des öffentlichen Dienstes mit mehr oder weniger geringen Abweichungen wörtlich übernehmen ${ }^{21}$. Gerade in jüngster Zeit wird jedoch ihr Bestreben immer deutlicher, eigene, von Tarifverträgen des öffentlichen Dienstes abgekoppelte Tarifwerke auf dem Dritten Weg zu schaffen, ${ }^{22}$ ohne dadurch der rechtlichen Privilegierung einer nur eingeschränkten Rechtskontrolle zu entsagen, wie sie nur Tarifverträgen zukommt. Deshalb streben sie eine Gleichstellung kirchlicher Arbeitsvertragsordnungen mit Tarifverträgen hinsichtlich der Rechtswirkungen

\footnotetext{
19 BAG ZMV 1997, 190; BAG NZA 1997, 659; BAG AP Nr. 22 zu \611 BGB Ausbildungsbeihilfe.

20 Z.B. des Verbandes Diakonischer Dienstgeber in Deutschland (VdDD); vgl. dazu online im Internet: www.v3d.de.

21 Z.B. kirchliche Arbeitsvertragsrichtlinien (AVR), Bundesangestelltentarif Kirchliche Fassung (BAT-KF), Kirchliche Anstellungsordnung (KAO) usw.

22 So hat z.B. die Arbeitsrechtskommission Niedersachsen (ARK-N) der Konföderation evangelischer Kirchen in Niedersachsen, der die ev.-luth. Landeskirchen Braunschweig, Hannover, Oldenburg, Schaumburg-Lippe und die ev.-reformierte Kirche Leer angehören, am 12. 09. 2003 ein komplettes Tarifwerk verabschiedet, das unter dem Arbeitstitel „Arbeitsvertragsrichtlinien Modern“ (AVR Modern) als AVR-K am 01.01.2004 in Kraft getreten ist und für alle Einrichtungen gilt, die sich dem Arbeitsrechtsregelungsgesetz der Diakonie (ARRG-D) angeschlossen haben.
} 
an. Das Bundesarbeitsgericht scheint sie darin $\mathrm{zu}$ unterstützen. ${ }^{23}$ In mehreren Entscheidungen hat es durch sog. obiter dicta, d.h. für die Entscheidungen selbst unmaßgebliche Ausführungen, die Möglichkeit einer rein kirchenrechtlichen Lösung des Problems angedeutet.

Zwar hält es weiter an seiner ständigen Rechtsprechung fest, dass kirchliche Arbeitsvertragsordnungen keine Tarifverträge sind und ihnen auch nicht gleichgestellt werden können. In seiner Entscheidung vom 06.11.1996, ${ }^{24}$ bei der es um Regelungen des sog. Bundesangestelltentarifvertrags - Kirchliche Fassung (BATKF) der Evangelischen Kirche im Rheinland ging, stellte der 10. Senat des Bundesarbeitsgerichts unmissverständlich klar, dass kirchliche Arbeitsvertragsordnungen keine Tarifverträge sind und ihnen auch nicht gleichgestellt werden können. ${ }^{25}$ Dies ist ständige Rechtsprechung des BAG bis in die jüngste Zeit. ${ }^{26}$ In seiner Entscheidung vom 19.02.2003 fasst es sie noch einmal zusammen: ${ }^{27} \mathrm{Nach}$ ständiger Rechtsprechung des BAG handelt es sich bei kirchlichen Arbeitsrechtsregelungen nicht um Tarifverträge im Sinne des Tarifvertragsgesetzes, weil sie nicht nach dessen Maßgabe zu Stande gekommen sind. ${ }^{28}$

\section{Normative Wirkung kirchlicher Arbeitsvertragsordnungen?}

Gleichwohl deuten die oben erwähnten obiter dicta auf ein Bestreben hin, diese Rechtsprechung zugunsten der Kirchen zu ändern. Dabei handelt es sich indessen um eine noch nicht abgeschlossene und in sich widersprüchliche Entwicklung, von der sich heute noch nicht klar erkennen lässt, in welche Richtung sie geht. Vieles spricht im Gegenteil dafür, dass sie sich nicht durchsetzen wird. Dies soll an 3 zentralen Entscheidungen des BAG verdeutlicht werden. ${ }^{29}$

In seiner Entscheidung vom 06.11.1996 ging es zwar nur um die Begründung der auf eine Rechtskontrolle beschränkten Überprüfung kirchlicher Arbeitsvertragsordnungen, ${ }^{30}$ „,soweit Tarifvertragsregelungen ganz oder mit im wesentlichen gleichen Inhalten übernommen werden“. ${ }^{31}$ Diese rechtfertigt das BAG mit der

\footnotetext{
23 Vgl. dazu aus jüngerer Zeit: BAG v. 19. 02.2003, NZA 2004, 54.

24 BAG NZA 1997, S. 659.

25 BAG NZA 1997, S. 659, $660 \mathrm{f}$.

26 Vgl. dazu BAG v. 17. 04. 1996, NZA 1997, 56.

27 BAG v. 19. 02. 2003, 54, 57.

28 Vgl. nur BAG v. 20. 03. 2001, NZA 2002, $1402=$ AP GG Art. 140 Br. $53=$ EzA BGB \ 613a BGB Nr. 208 = ZMV 2002, 299; BAG v. 15. 11. 2001, NZA 2002, $1055=$ ZMV 2001, 302, jeweils m. w. N.

${ }^{29}$ BAG v. 06. 11. 1996, NZA 1997, 778; BAG v. 20. 03. 2002, NZA 2002, 1402; BAG v. 19. 02. 2003, NZA 2004, 54.

30 BAG v. 06. 11. 1996, NZA 1997, 778.

31 BAG a. a. O. LS 1.
} 
besonderen rechtlichen Privilegierung von Tarifverträgen, ${ }^{32}$ die auf der Vermutung beruht, „dass sie den Interessen beider Seiten gerecht werden und keiner Seite ein unzumutbares Übergewicht vermittelt wird“. Daraus folge für Tarifverträge eine sog. „materielle Richtigkeitsgewähr“, die ihre normative Wirkung rechtfertigt. Zugleich stellt das BAG jedoch die nicht näher diskutierte These auf, dass diese materielle Richtigkeitsgewähr und mithin auch ihre normative Wirkung gleichermaßen für kirchliche Arbeitsvertragsordnungen - hier: die Arbeitsvertragsrichtlinien-Caritas (AVR-Caritas) - gelte: „Die materielle Richtigkeitsgewähr tarifvertraglicher Regelungen beruht [...] darauf, dass sie [die Tarifvertragsparteien, d. Verf.] als gleichgewichtig durchsetzungsfähig angesehen werden. Die zuletzt genannte Voraussetzung ist aber innerhalb der Arbeitsrechtlichen Kommission bei den Kirchen gleichermaßen gegeben. Deren paritätische Besetzung und die Weisungsunabhängigkeit ihrer Mitglieder gewährleistet, dass keine der beiden Seiten das Übergewicht erreichen kann.“

Diese Auffassung ist jedoch nicht haltbar. ${ }^{33}$ Sie verkennt die Unterschiede beim Zustandekommen von Tarifverträgen sowie bei der Aushandlung kirchlicher Arbeitsvertragsordnungen und verwechselt die materielle Parität mit der formellen. Bei der Aushandlung von Tarifverträgen ist nicht etwa die paritätische Besetzung der jeweiligen Verhandlungskommissionen ausschlaggebend, sondern der Zwang zur Einigung. In kirchlichen Arbeitsrechtskommissionen entspräche dies dem Erfordernis der Einstimmigkeit für das Zustandekommen kirchlicher Arbeitsvertragsordnungen, während in der Regel aber nur eine qualifizierte 2/3oder 3/4-Mehrheit, manchmal sogar die einfache Mehrheit genügt. Auch sind die jeweiligen Mitglieder der Verhandlungskommissionen bei Tarifverhandlungen gerade nicht unabhängig vom Willen ihrer Mitglieder, sondern satzungsrechtlich an ihn gebunden. Nur damit lässt sich die Geltung von Tarifverträgen für und gegen die Mitglieder der verhandelnden Gewerkschaften und Arbeitgebervereinigungen begründen. Die Weisungsunabhängigkeit der Mitglieder kirchlicher Arbeitsrechtskommissionen steht ihrer Parität daher in Wirklichkeit entgegen. Im übrigen kann von Weisungsunabhängigkeit der Arbeitnehmervertreter in kirchlichen Arbeitsrechtskommissionen keine Rede sein, wenn ihnen, wie das in der Praxis schon vorgekommen ist, auf Arbeitgeberseite der eigene Chef gegenüber sitzen kann. Selbst wenn aber davon ausgegangen wird, dass sowohl Arbeitnehmervertreter, als auch Arbeitgebervertreter in kirchlichen Arbeitsrechtskommissionen ihre Entscheidungen unabhängig von sachfremden äußeren Einflüssen fällen können, handelt es sich doch nur um eine formelle, nicht aber um eine - wie bei der Aushandlung von Tarifverträgen - materielle Parität. ${ }^{34}$ Entscheidend ist aber letztere, weil nur sie die erforderliche Gleichgewichtigkeit der Verhandlungs-

\footnotetext{
32 BAG a. a. O., S. 779.

33 Vgl. dazu des Näheren schon o. Abschn. 3.c.

34 Zur Unterscheidung zwischen materieller und formeller Parität und ihrer Bedeutung für die Gleichgewichtigkeit der jeweiligen Verhandlungspositionen vgl. o. Abschn. 3.c.
} 
parteien begründen kann, an die erst die Vermutung materieller Richtigkeit des ausgehandelten Tarifvertrags knüpft. Eine normative Wirkung kirchlicher Arbeitsvertragsordnungen lässt sich demnach mit der nur formellen Parität von Arbeitnehmer- und Arbeitgebervertretern in kirchlichen Arbeitsrechtkommissionen schwerlich begründen.

In seiner Entscheidung vom 20.03.2002 vollzieht das BAG denn auch einen Begründungswechsel, ${ }^{35}$ indem es nunmehr ausdrücklich betont, ${ }^{36}$ dass ,,nach der ständigen Rechtsprechung des Bundesarbeitsgerichts [...] kirchliche Arbeitsrechtsregelungen die Arbeitsverhältnisse nicht unmittelbar und zwingend gestalten (können), sondern [...] stets der vertraglichen Transformation durch Einzelvertrag, Gesamtzusage oder Einheitsregelung [bedürfen]“. Dies lasse sich weder aus dem kirchlichen Selbstbestimmungsrecht (Art. 140 GG i. V. m. Art. 137 Abs. 3 WRV), noch aus der analogen Anwendung des Tarifvertragsgesetzes begründen. Allerdings belässt es das BAG nicht dabei, ${ }^{37}$ sondern wirft stattdessen die Frage auf, ob die normative Wirkung kirchlicher Arbeitsvertragsordnungen nicht auch kirchenrechtlich angeordnet werden könnte. Das wirft freilich die Frage auf, wie eine solche Anordnung Rechtswirkungen für Arbeitsverträge kirchlicher Beschäftigter entfalten soll. Denn diese richten sich nach staatlichem, säkularen Arbeitsrecht, das für kirchliches Recht prinzipiell unerreichbar ist, was das BAG an anderer Stelle der gleichen Entscheidung auch ausdrücklich betont. ${ }^{38}$ „Weder die verfasste Kirche noch selbständige kirchliche Einrichtungen können Normen erlassen, die unmittelbar mit gesetzesgleicher Wirkung die Arbeitsverhältnisse von kirchlichen Mitarbeitern gestalten“.39 Auch die kirchengesetzliche Anordnung der normativen Wirkung kirchlicher Arbeitsvertragsordnungen kann daher nur Kirchenmitglieder und diese nur ,wegen ihrer kirchlichen Rechte und Pflichten [...] nicht aber [...] wegen ihrer Rechte und Pflichten als Arbeitnehmer [erreichen]“.40 Ein Kirchengesetz, das kirchlichen Arbeitsvertragsordnungen normative Wirkung verleihen wollte, bliebe daher ohne Wirkung auf die Arbeitsverhältnisse kirchlicher Beschäftigter.

In seiner Entscheidung vom 19.02.2003 schließlich bemüht sich das BAG überhaupt nicht mehr um eine Begründung, ${ }^{41}$ sondern unterstellt hypothetisch die normative Wirkung kirchlicher Arbeitsvertragsordnungen, indem es den Klageanspruch zwei Mal prüft, zum einen im Wege der eingeschränkten Billigkeitskontrolle nach $\iint 317,319$ BGB, zum anderen im Wege der Rechtskontrolle nach

\footnotetext{
35 BAG NZA 2002, 1402.

${ }^{36}$ BAG a. a. O., S. 1404.

${ }^{37}$ BAG a. a. O., S. 1405.

38 a. a. O., S. 1404.

${ }^{39}$ Dütz, Die „Tarif“-Wirkung von kirchlichen Arbeitsrechtsregelungen, FS Schaub, 1998, S. 164; BVerfGE 70, 138, 166.

${ }^{40}$ Dütz, a. a. O.

${ }^{41}$ BAG v. 19. 02. 2003, NZA 2004, 54.
} 
den für Tarifverträgen geltenden Maßstäben: ${ }^{42}$ „Nach st. Rspr. des BAG handelt es sich bei kirchlichen Arbeitsrechtsregelungen nicht um Tarifverträge i. S. des Tarifvertragsgesetzes, weil sie nicht nach dessen Maßgabe zu Stande gekommen $\operatorname{sind}^{43}$. Ob die inhaltliche Kontrolle von Arbeitsrechtsregelungen durch staatliche Gerichte deshalb als eine - eingeschränkte - Billigkeitskontrolle nach $\int \mathbb{S} 317,319$ BGB vorzunehmen ist ${ }^{44}$ oder ob sie sich gleichwohl - wie bei Tarifverträgen - auf eine reine Rechtskontrolle zu beschränken hat ${ }^{45}$, bedarf vorliegend keiner Entscheidung. Denn die Arbeitsrechtsregelung [...] hält nach beiden Maßstäben der rechtlichen Prüfung stand.“

Zusammenfassend lässt sich sagen, dass die BAG-Rechtsprechung, wenn auch mit wechselnden Begründungen, zwar in die Richtung einer normativen Rechtswirkung kirchlicher Arbeitsvertragsordnungen tendiert, wenn diese kirchenrechtlich angeordnet wurde, diese Tendenz aber als äußerst unsicher einzustufen ist, zum einen weil sie der eigenen Rechtsprechung widerspricht, zum anderen weil sie die Trennung zwischen kirchlichem und staatlichem Rechtskreis und damit die verfassungsrechtliche Trennung von Kirche und Staat (Art. 140 GG i. V. m. Art. 137 Abs. 1 WRV) durchbrechen würde.

\section{Bedeutung der normativen Wirkung kirchlicher Arbeitsver- tragsordnungen}

Spätestens hier ist die Frage zu stellen, warum um die normative Wirkung kirchlicher Arbeitsvertragsordnungen ein derartiger rechtlicher Aufwand betrieben wird. Warum begnügen sich die Kirchen und ihre Einrichtungen nicht mit der - durch $\int \$ 317,319$ BGB bereits privilegierten - eingeschränkten Inhaltskontrolle kirchlicher Arbeitsvertragsordnungen? Woher kommt das signifikante Bedürfnis, für kirchliche Arbeitsvertragsordnungen, wenn sie schon keine Tarifverträge sind, wenigstens deren Rechtswirkungen zu erlangen? Diese Fragen stellen sich umso mehr als es den Kirchen und ihren Einrichtungen nach wie vor frei steht, selbst sog. kirchengemäße Tarifverträge abzuschließen, deren normative Wirkung sich

\footnotetext{
42 BAG a. a. O., 57.

43 st. Rspr., vgl. Nur BAG v. 20. 03. 2002, NZA 2002, $1402=$ AP GG Art. 140 Nr. $53=$ EzA BGB \613a Nr. 208 = ZMV 2002, 299; BAG v. 15. 11. 2001, NZA 2002, 1055 = ZMV 2001, 302; jew. m. w. N.

44 So grdl. BAG NZA 1997, $55=$ AP BGB \ 611 Kirchendienst Nr. $24=$ EzA BGB $\int 611$ Gratifikation, Prämie Nr. 140.

${ }^{45}$ So z. B. Gehring/Thiele, in: ArbR BGB, 2. Aufl. \630 Anhang Rdnrn. 167 f.; Richardi, ArbeitsR in der Kirche, 3. Aufl., $\int 15$ Rdnrn. 39 f.; Schliemann, in: Festschrift f. Hanau, S. 577, 597; Thüsing, Anm. zu AP BGB \611 Kirchendienst Nr. 24 und - jedenfalls für solche Arbeitsrechtsregelungen, die einen Tarifvertrag ganz oder im Wesentlichen übernehmen -. BAG v. 06. 11. 1996, BAGE 84, $282=\mathrm{NZA} 1997,778=\mathrm{AP}$ AVR \& 10a Caritasverband Nr. $1=$ EzA BGB $\int 611$ Ausbildungsbeihilfe Nr. 16, im Anschluss daran BAG v. 28. 01. 1998, NZA-RR 1998, $424=$ AP AVR $₫ 12$ Caritasverband Nr. $11=$ EzA BGB $\ 611$ Kirchliche Arbeitnehmer Nr. 44.
} 
unmittelbar aus dem Tarifvertragsgesetz ergeben würde. Offenbar fürchten sie jedoch, sich dadurch säkularen Einwirkungen auf ihr Selbstverständnis in Glaubens- und Gewissensfragen sowie ihre Kirchenautonomie auszusetzen mit der Folge, dass die kirchliche Dienstgemeinschaft gefährdet würde. Dass dem indessen nicht so ist, zeigen bereits die zahlreichen bestehenden Tarifverträge mit Kirchen und ihren Einrichtungen. Denn sog. kirchengemäße Tarifverträge zeichnen sich gerade dadurch aus, dass sie das Kirchliche Proprium, die Dienstgemeinschaft, respektieren. Im übrigen sind sie nicht gezwungen Tarifregelungen zuzustimmen, die das nicht tun. Ihre Möglichkeit, auf den Dritten Weg auszuweichen, bleibt ihnen sowohl kirchenrechtlich als auch verfassungsrechtlich (Art. 140 GG i. V. m. Art. 137 Abs. 3 WRV), d.h. durch säkulares Recht garantiert. Auch ihr Plädoyer für Mitbestimmung durch Tarifverträge im säkularen Bereich wäre glaubwürdiger, wenn sie sich in ihren eigenen Angelegenheiten dazu bekennen würden. Deshalb noch einmal: Warum dieser ganze rechtliche Aufwand um die normative Wirkung kirchlicher Arbeitsvertragsordnungen, wenn mit kirchengemäßen Tarifverträgen bei ungleich geringerem Aufwand das Gleiche zu erreichen wäre?

Die Gründe sind relativ einfach: ${ }^{46}$ Nur die normative Wirkung kirchlicher Arbeitsvertragsordnungen kann deren gleichmäßige Geltung für alle kirchlichen Arbeitsverhältnisse garantieren. Diese aber wiederum ist Voraussetzung für die Bewältigung des wirtschaftlichen und sozialen Strukturwandels, dem namentlich kirchliche Einrichtungen des Gesundheits- und Sozialwesens ausgesetzt sind. Andererseits ist die Furcht der Kirchen durchaus verständlich, der Abschluss von kirchengemäßen Tarifverträgen könnte den Dritten Weg ein für alle Mal irreversibel versperren. Denn sie wissen aus eigener Erfahrung am besten, dass Glaubenswahrheiten für gläubige Menschen unverrückbare Gewissheiten darstellen, von Nicht- oder Andersgläubigen aber jederzeit in Frage gestellt werden können. Ob dies indessen tatsächlich so sein muss, ist zu prüfen. Zunächst aber zur Bedeutung der normativen Wirkung kirchlicher Arbeitsvertragsordnungen und dann erst zur Frage, wie den Kirchen und ihren Einrichtungen hinsichtlich der Bewahrung ihrer kirchlichen Eigenart auch durch Tarifverträge Gewissheit gegeben werden kann.

Auch kirchliche Einrichtungen sind, zumal unter dem Diktat leerer Staatskassen, das die Kostenträger zu massiven Einsparungen zwingt, dem freien Wettbewerb ausgesetzt, der kirchliche wie säkulare Arbeitgeber zur „Tarifflucht“, in diesem Fall aus der Geltung kirchlicher Arbeitsvertragsordnungen, verleitet. Die damit verbundene Zersplitterung der Arbeitsbedingungen wirkt indessen nicht nur gegenüber der kirchlichen Dienstgemeinschaft, sondern auch gegenüber notwendigen Produktivitätssteigerungen durch Organisations-, Personal- und Kostenentwicklung kontraproduktiv. Nicht Sparen schlechthin, d.h. um jeden, auch den Preis von Personalabbau, Entgelt- oder Leistungskürzungen, ist angesagt, sondern

${ }^{46}$ Vgl. dazu auch o. Abschn. 1. 
„intelligentes Sparen“ durch Verbesserung der Organisation, Optimierung von Prozessen und Weiterqualifizierung des Personals. ${ }^{47}$ Kirchliche Einrichtungen, die auf lineare Verschlechterungen von Arbeitsbedingungen, namentlich Kürzungen der Arbeitsentgelte, ausweichen, verlieren gegenüber Einrichtungen, die das aufgrund ihrer Tarifbindung nicht können, automatisch an Wettbewerbsfähigkeit.

Vergleichsweise schlechtere Arbeitsbedingungen mögen bei drohendem Arbeitsplatzverlust gegenüber den Beschäftigten durchsetzbar sein. Sie vermindern aber die Wettbewerbsfähigkeit schon im Hinblick auf die Rekrutierung qualifizierten Personals, von dem die Dienstleistungsqualität und damit die Qualität der Leistungen gerade bei sozialen Einrichtungen maßgeblich abhängt. Dadurch können kirchliche Einrichtungen schnell in einen Teufelskreis geraten, der vorhandene Wettbewerbsnachteile bis zur unvermeidbaren Insolvenz verschärft, wenn nicht rechtzeitig betriebswirtschaftlich gegengesteuert wird. Einrichtungen, die verminderte Einnahmen oder erhöhte Ausgaben durch lineare Verschlechterungen der Arbeitsbedingungen kompensieren, bewahren im Vergleich zu ihren Wettbewerbern unproduktive (Organisations-, Personal- und Kosten-)Strukturen. Das rächt sich spätestens bei der nächsten Einnahmenkürzung oder Ausgabenerhöhung, dann allerdings mit der zusätzlichen Belastung eines zwischenzeitlich, im Vergleich zur Konkurrenz, die sich der Mühsal eines komplexen Organisations-, Personal- und Kostenentwicklungsprozesse unterzogen hat, gewachsenen und kaum mehr einholbaren Produktivitätsrückstands. Deshalb ist es für kirchliche Einrichtungen von herausragender Bedeutung, dass sie sich, ebenso wie säkulare Einrichtungen des Gesundheits- und Sozialwesens, betriebswirtschaftlich aufstellen. Dazu muss ihnen aber der bequeme Weg in die lineare Kürzung des größten Ausgabenpostens, den die Personalkosten mit 60\% bis 80\% der Gesamtkosten nun einmal ausmachen, versperrt sein. Dies ist nur durch gleiche Arbeitsbedingungen und Arbeitsentgelte aller kirchlichen Einrichtungen zu erreichen, die durch eine gleichmäßige normative Geltung kirchlicher Arbeitsvertragsordnungen in allen Einrichtungen mindestens auf dem Niveau säkularer Organisationen garantiert werden. Die Annäherung kirchlicher Arbeitsvertragsordnungen an Tarifverträge hinsichtlich ihrer Rechtswirkungen stellt so gesehen eine unabdingbare betriebswirtschaftliche Notwendigkeit dar.

47 Vgl. dazu Dagmar Deckstein, Die Porsche-Therapie. Operation Krankenhaus: „Heute nach einem halben Jahr machen wir alles besser". Wie Unternehmensberater des Autoherstellers und von McKinsey den Pulsschlag in der Freiburger Herzchirurgie erhöhten - ein Lehrstück für intelligentes Sparen, Süddeutsche Zeitung Nr. 47 v. 25./26. 02. 2006, S. 36. 


\section{Das Integrierte Kommissions- und Tarifmodell als Lösung des Dilemmas}

Die bisher gesuchten Lösungen zur Sicherung der normativen Wirkung kirchlicher Arbeitsvertragsordnungen sind zur Lösung des Dilemmas, in dem sich die Kirchen mit ihren Einrichtungen befinden, untauglich. Da der kirchliche vom säkularen, staatlichen Rechtskreis getrennt ist, ${ }^{48}$ bedarf es für die Geltung von Rechtsnormen des einen Rechtskreises im anderen stets der Vermittlung durch besondere Rechtsvorschrift des anderen Rechtskreises. Mit anderen Worten, staatliches Recht gilt zwar als Ausdruck der demokratischen Volkssouveränität allgemein, also auch für die Kirchen und ihre Einrichtungen unmittelbar; soweit es das durch Art. 140 GG i. V. m. Art. 137 WRV geschützte kirchliche Proprium die Dienstgemeinschaft - betrifft, jedoch nur kraft kirchenrechtlicher Vermittlung. Umgekehrt gilt kirchliches Recht nur für die Kirchen und im staatlichen Bereich lediglich dann, wenn dies eine staatliche Norm ausdrücklich bestimmt. Deshalb kann die kirchenrechtliche Anordnung der normativen Wirkung kirchlicher Arbeitsvertragsordnungen die nach staatlichem Recht geregelten und zu beurteilenden Arbeitsverhältnisse kirchlicher Beschäftigter nicht erreichen. Dütz drückt das so aus: „Die Kirche betreffende Rechtssätze sind deswegen entweder als kirchliches oder als staatliches Recht zu qualifizieren, es sei denn, sie erfüllen ausnahmsweise die Voraussetzungen beider Rechtskreise oder sie wirken kraft besonderer Vermittlung des jeweils anderen Rechtskreises in diesen hinein. Damit entfällt die Möglichkeit, alle privatrechtlichen Anstellungsverhältnisse kirchlicher Mitarbeiter mit den Regelungen des ,Dritten Wegs‘ unmittelbar und zwingend i. S. gesetzesgleicher verbindlicher Normwirkung zu erreichen. “49

Interessant ist die Ausnahme, die Dütz hier macht. Die Voraussetzungen beider Rechtskreise, des kirchlichen und des staatlichen, erfüllt z.B. das Mitarbeitervertretungsrecht, das kirchliches Recht ist, aber gleichwohl, mangels einer staatlichen Regelung, in den staatlichen Bereich hineinwirkt. Dahinter steckt indessen ein allgemeiner Grundsatz: Zum Überschneidungsbereich kirchlichen und staatlichen Rechts gehören alle - kirchlichen oder staatlichen - Regelungen, die die eigenen Angelegenheiten der Kirchen - die Dienstgemeinschaft als Ausdruck ihres Selbstverständnisses in Glaubens- und Gewissenfragen - betreffen. Das Bundesverfassungsgericht hat dies beispielhaft wie folgt formuliert: „Bedienen sich die Kirchen wie jedermann der Privatautonomie zur Begründung von Arbeitsverhältnissen, so findet auf diese das staatliche Arbeitsrecht Anwendung. Dies ist die schlichte Folge einer Rechtswahl. Die Einbeziehung der kirchlichen Arbeitsverhältnisse in das staatliche Arbeitsrecht hebt indessen deren Zugehörigkeit zu den ,eigenen Angelegenheiten' der Kirche nicht auf [...] Das schließt ein, dass die Kirchen der

48 Zur Trennung von Staat und Kirche sowie ihren Auswirkungen auf das (kirchliche) Arbeitsrecht vgl. Hammer, Kirchliches Arbeitsrecht, 2002, S. 105 ff.

${ }^{49}$ Dütz, Die „Tarif“-Wirkung von kirchlichen Arbeitsrechtsregelungen, FS Schaub 1998, S. 157, 162. 
Gestaltung des kirchlichen Dienstes auch dann, wenn sie ihn auf der Grundlage von Arbeitsverträgen regeln, das besondere Leitbild einer christlichen Dienstgemeinschaft aller ihrer Mitarbeiter zugrunde legen können. “50

Wahrend Regelungen zur Dienstgemeinschaft folglich dem kirchlichen Rechtskreis angehören, zählt das gesamte Arbeitsvertragsrecht zum staatlichen. Deshalb ist es richtig, insoweit statt von einer Bereichstrennung zwischen dem kirchlichen und dem staatlichen Rechtskreis von einer Funktionstrennung zu sprechen ${ }^{51}$. Diese Funktionstrennung wirkt sich auch auf das Verhältnis von Drittem Weg und Tarifautonomie aus. Unzweifelhaft sind nicht nur kirchliche Beschäftigte bzw. ihre Gewerkschaften, sondern auch kirchliche Arbeitgeber bzw. ihre Arbeitgeberverbände tariffähig. Zugleich sind sie aber auch grundsätzlich fähig, an der Gestaltung kirchlicher Arbeitsvertragsordnungen auf dem Dritten Weg mitzuwirken.

Die Kirchen und ihre Einrichtungen stehen, unter Beachtung ihrer verfassungsrechtlich geschützten Eigenart, auf dem Boden des staatlichen Rechts. Zwar wäre es auch den Gewerkschaften unbenommen, in kirchlichen Arbeitsrechtskommissionen mitzuwirken; teilweise tun sie das auch. Als Einheitsgewerkschaften, die überparteilich und religiös neutral sind, können sie sich aber grundsätzlich nicht auf den Boden kirchlichen Rechts stellen, soweit dies Glaubens- und Gewissensfragen betrifft. Daher stellt sich die Frage, wie gleichwohl kirchlicher und staatlicher Rechtskreis in diesem Überschneidungsbereich zueinander gebracht werden können, ohne ihre prinzipielle Unterscheidung als Folge der Trennung von Staat und Kirche einzubüßen.

Betrachtet man die Dinge genauer, ist die Lösung verblüffend einfach. Sie besteht in dem hier so genannten „Integrierten Kommissions- und Tarifmodell“, das unter Beachtung kirchlicher und staatlicher Rechtsvorschriften ein sog. Doppelrechtsverhältnis begründen würde. Dieses Doppelrechtsverhältnis besteht bereits heute. Denn die Beschlüsse kirchlicher Arbeitsrechtskommissionen gründen sich zwar auf kirchliche Rechtsvorschriften und setzen daher Kirchenrecht, zugleich gründen sie sich aufgrund ihrer Funktion als unabhängige Dritte i. S. d. SS 317, 319 BGB sowie dynamischer Verweisungsklauseln in den Arbeitsverträgen kirchlicher Beschäftigter aber auch auf staatliches Arbeits(vertrags)recht und setzen damit staatliches Recht. Es gibt keinen Grund dieses Doppelrechtsverhältnis, das letztlich auf verfassungsrechtlichen Vorgaben des Art. 140 GG i. V. m. Art. 137 Abs. 3 WRV in der rechtsverbindlichen Interpretation des Bundesverfassungsgerichts beruht, nicht von der Ebene des Individualarbeitsrechts auch auf die Ebene des kollektiven Arbeitsrechts zu heben. Angesichts der zitierten klaren Ansage des Bundesverfassungsgerichts zum Arbeitsverhältnis als Überschneidungsbereich zwischen kirchlichem und staatlichem Rechtskreis lässt sich die Frage stellen, ob das „Integrierte Kommissions- und Tarifmodell“ nicht insoweit

\footnotetext{
${ }^{50}$ BVerfGE 70, 138, 165.

51 Vgl. dazu ausführlich Hammer, Kirchliches Arbeitsrecht, 2002, S. 105 ff., 128.
} 
sogar verfassungsrechtlich geboten ist. Denn wenn ein Modell - Kommissionsmodell - das andere - Tarifmodell - nicht von vornherein verdrängen kann - und umgekehrt - dann muss ein Beteiligungsrahmen angeboten werden, der dem verfassungsrechtlichen Status der jeweiligen Protagonisten, aus Art. 140 GG i. V. m. Art. 137 Abs. 3 WRV (Dienstgemeinschaft) einerseits sowie Art. 9 Abs. 3 GG (Tarifautonomie) andererseits, entspricht.

\section{Grundstrukturen eines Integrierten Kommissions- und Tarifmodells ${ }^{52}$}

Um die Grundstrukturen eines solchen Modells vorzustellen, sind die gemeinsame Ausgangslage, dann das Tarifmodell und das Kommissionsmodell und schließlich, angesichts der verfassungsrechtlichen (Funktions-)Trennung von kirchlichem und staatlichem Rechtskreis, die Möglichkeiten ihrer Integration zu erörtern. Auf dieser Grundlage könnte ein integriertes Tarif- und Kommissionsmodell - hier nur sehr grob skizziert - wie folgt aussehen:

\section{Gemeinsame Ausgangslage}

Beide Modelle verfolgen das Ziel formeller und materieller Parität von Arbeitnehmer- und Arbeitgeberseite im Sinne der Herstellung eines Verhandlungsgleichgewichts, bei dem keine Seite der anderen strukturell überlegen ist. ${ }^{53}$ Unterschiede bestehen allerdings hinsichtlich der Konstruktion dieser Parität. Während sie im Kommissionsmodell numerisch hergestellt wird und deshalb letztlich - nur formeller Natur ist, gilt das Tarifmodell als geeignet und bestimmt, „die strukturelle Unterlegenheit der einzelnen Arbeitnehmer beim Abschluss von Arbeitsverträgen durch kollektives Handeln auszugleichen und damit ein annähernd gleichgewichtiges Aushandeln der Löhne und Arbeitsbedingungen [im formellen und materiellen Sinne, U.H.] zu ermöglichen".54

\section{Tarifmodell}

Beim Tarifmodell kann eine Seite ohne die Zustimmung der anderen keinen Tarifvertrag abschließen. Das erfordert mindestens eine - ggf. qualifizierte - Mehrheit auf beiden Seiten. ${ }^{55}$ Bei Tarifverhandlungen sitzt der, durch eine oder mehrere Gewerkschaften bzw. Berufsverbände repräsentierten Verhandlungskommission der Arbeitnehmerseite eine, durch einen oder mehrere Arbeitgeber (in der Regel in

\footnotetext{
52 Vgl. dazu des Näheren: Hammer, Kirchliches Arbeitsrecht, 2002, S. 136 ff., 138 ff.

53 Zur Frage, inwieweit das den einzelnen Modellen auch tatsächlich gelingt, vgl. o. Abschn. 3.

${ }^{54}$ BVerfGE 84, 212, 229; E 92, 365, 395; sh. auch Kühling, Arbeitskampf in der Diakonie.

55 Welche Mehrheiten erforderlich sind, entscheidet jeweils jede Seite für sich selbst, i. d. R. durch Satzungsrecht.
} 
Form eines oder mehrerer Arbeitgeberverbände) repräsentierte Verhandlungskommission der Arbeitgeberseite gegenüber. ${ }^{56}$ Welche personelle Stärke die Verhandlungskommissionen besitzen, ist dabei offen. Meistens einigen sich beide Seiten vor Beginn von Tarifverhandlungen über die Anzahl der Personen auf jeder Seite. Fachleute und Berater können jederzeit hinzu gezogen werden.

Einigen sich - meistens nach Anhörung weiterer Verbandsgremien bzw. -organe (z.B. Tarifkommission) - beide Seiten (Verhandlungskommissionen), kommt ein Tarifvertrag zustande, der in den Formen des Tarifvertragsgesetzes unterzeichnet und ausgefertigt werden muss, um sowohl für alle Gewerkschaftsmitglieder, als auch für alle verbandsangehörigen Arbeitgeber normativ verbindlich zu werden.

Kommissionsmodell

Beim Kommissionsmodell müssen Beschlüsse meist nur mit qualifizierter Mehrheit gefasst werden. Das neu gefasste Kommissionsmodell der Konföderation evangelischer Kirchen in Niedersachsen hingegen geht einen Schritt weiter: ${ }^{57}$ Hier können Kommissionsbeschlüsse nur noch einstimmig auf der Grundlage einer, ggf. qualifizierten, Mehrheitsbildung beider Seiten gefasst werden; dieses Modell unterscheidet sich hinsichtlich der Voraussetzungen (wohl aber hinsichtlich der Wirkungen) praktisch nicht (mehr) vom Tarifmodell.

Auch beim Kommissionsmodell sitzt der Arbeitgeber- bzw. Dienstgeberseite eine zahlenmäßig gleich starke Arbeitnehmer- bzw. Dienstnehmerseite gegenüber, die miteinander „verhandeln“. Die beiden „Verhandlungskommissionen“ (Arbeitnehmer- und Arbeitgeberbank) fungieren - kirchenrechtlich - gleichsam als „Unterkommissionen“ einer „Gemeinsamen Kommission“ (Arbeitsrechtliche Kommission), teilweise mit eigenen Vorsitzenden, die sich, z.B. beim Kommissionsmodell der Konföderation, im Vorsitz der „Gemeinsamen Kommission“ jährlich in der Weise abwechseln, dass eine Seite den Vorsitz, die andere den stellvertretenden Vorsitz erhält.

\section{Integriertes Kommissions- und Tarifmodell}

Es liegt auf der Hand, dass beide Modelle integrationsfähig sind: Werden z.B. im Kommissionsmodell der Konföderation beide „Bänke“ mit Verbandsvertretern Gewerkschaften und Arbeitgeberverbänden - besetzt, zu denen nach freier Entscheidung der Verbände auf jeder Seite auch Mitarbeitervertreterinnen undvertreter oder einzelne Arbeitgeber aus besonders wichtigen und großen Einrichtungen, oder von den Beschäftigten auf der einen und den Arbeitgebern auf der anderen in Urwahl bestellte „Delegierte“ in jeweils gleich großer Anzahl gehören

\footnotetext{
56 Jede Seite bestimmt ihre Zusammensetzung selbst, z. B. durch Vereinbarungen zwischen den verschiedenen Verbänden bzw. Beteiligten einer Seite.

57 Arbeitsrechtsregelungsgesetz Diakonie (ARRGD) v. 11. 10. 1997, in Kraft getreten am 01. 01. 1998, online im Internet: http://www.evangelische-konfoederation.de/
} 
können, ${ }^{58}$ und wird einstimmig ein Beschluss gefasst, werden Arbeitsbedingungen gesetzt, die durch Kirchen- bzw. Satzungsrecht für alle kirchlichen Einrichtungen verbindlich und vermittels der in den Arbeitsverträgen enthaltenen sog. dynamischen Verweisungsklauseln arbeitsrechtlich für alle Beschäftigten per Gleichstellungsabrede wirksam gemacht werden.

Unterschreiben Zug um Zug gleichzeitig die Verbände beider Seiten den kirchenrechtlich gefassten Beschluss, so wird er als Tarifvertrag wirksam mit der Folge normativer Verbindlichkeit für alle verbandsangehörigen Beschäftigten und Arbeitgeber sowie einer nur eingeschränkten Rechtskontrolle durch die Arbeitsgerichte.

Das Ergebnis der Verhandlungen in einer so besetzten Arbeitsrechtlichen Kommission wäre folglich ein doppeltes: Kirchenrechtlich ein Kommissionsbeschluss, arbeitsrechtlich ein Tarifvertrag nach dem staatlichen Tarifvertragsgesetz. Da hierfür jeweils unterschiedliche, klar voneinander zu trennende Rechtsakte erforderlich sind - Beschlussfassung einerseits, Unterfertigung als Tarifvertrag andererseits -, blieben auch der kirchliche und der staatliche Rechtskreis klar voneinander getrennt. Lediglich der Verhandlungsprozess verliefe integriert in dem Sinne, dass er zugleich die kirchenrechtliche Beschlussfassung wie auch die tarifrechtliche Einigung vorbereitet.

Die konkrete Ausgestaltung eines integrierten Modells könnte zwischen Kirchen bzw. kirchlichen Arbeitgebern und Gewerkschaften ausgehandelt und entsprechend den vorhandenen Rechtsetzungsverfahren - kirchenrechtlich als Kirchengesetz bzw. satzungsrechtlich und tarifrechtlich als kollektive Gesamtvereinbarung inhaltsgleich in Kraft gesetzt werden.

Ebenso kann sowohl dem kirchlichen, als auch dem staatlichen (Arbeits-)Recht Genüge getan werden: Durch Kirchengesetz können im Rahmen eines integrierten Kommissions- und Tarifmodells gefasste Beschlüsse bzw. Vereinbarungen kirchenrechtlich bzw. durch Unterzeichnung seitens der auf der Arbeitnehmerseite vertretenen Gewerkschaften und der auf der Arbeitgeberseite vertretenen Arbeitgeber(-verbände) nach staatlichem Tarifvertragsrecht als Tarifvertrag - mit normativer Wirkung - in Kraft gesetzt werden.

Das klingt vielleicht kompliziert, ist es aber keineswegs. So könnten im Falle der Konföderation die Strukturen der Arbeitsrechtlichen Kommission weitgehend beibehalten werden. Zwar blieben auch beim Integrierten Kommissions- und Tarifmodell ein Vorsitz und ein stellvertretender Vorsitz erhalten, der im Wechsel beider Seiten besetzt werden müsste. Da Vorsitz und stellvertretender Vorsitz zwischen beiden Seiten geteilt werden, würde das aber nicht die Stimmenverhält-

\footnotetext{
${ }^{58}$ Voraussetzung hierfür wäre freilich, dass den Gewerkschaften durch das kirchliche Mitarbeitervertretungsrecht die Möglichkeit eingeräumt wird, zu den Mitarbeitervertretungswahlen (oder evtl. Urwahlen) gewerkschaftliche Listen zu bilden.
} 
nisse beeinflussen. Vorsitz und stellvertretender Vorsitz erhielten auf diese Weise vielmehr die Funktion einer Art gemeinsamen Geschäftstelle beider Seiten.

Das integrierte Kommissions- und Tarifmodell ist der praktische Beleg dafür, dass sich kirchliches und gewerkschaftliches Selbstverständnis nicht ausschließen, dass die Kirchen die Anerkennung der Gewerkschaften als unverzichtbare gesellschaftliche Kraft (wie im Gemeinsamen Sozialwort der Kirchen hervorgehoben) auch für sich selbst gelten lassen und dass die bestehenden - weltanschaulich und religiös neutralen - Einheitsgewerkschaften das glaubens- und bekenntnismäßige Selbstverständnis der Kirchen respektieren. 
Manfred Freyermuth, Peter Fündeling, Lothar Stempin

\title{
Was heißt Solidarität in der „Dienstgemeinschaft"?
}

\author{
Drei Perspektiven aus der Praxis*
}

\section{Manfred Freyermuth:}

Ich habe lange überlegt, wie ich anfange und wie ich dieses Thema angehe. Ich kann einiges an Erfahrung einbringen, wenn man über dieses Thema „Dritter Weg“" spricht. Seit mehr als zwanzig Jahren bin ich in der Diakonie beschäftigt und annähernd solange Mitglied in unterschiedlichen Arbeitsrechtlichen Kommissionen. So habe ich an manchen Gesetzgebungsverfahren teilgenommen und auf der Arbeitnehmerseite die Entwicklung mit beeinflusst.

Wir sind z.Zt. in einer ganz spannenden und kritischen Phase, was unser System angeht. Aus diesem Grund findet ja heute auch die Tagung statt. Es ist sicher kein Zufall, dass in den nächsten Monaten in verschiedenen Landeskirchen ähnliche Tagungen stattfinden werden. Das macht deutlich, dass das Thema auf der Tagesordnung ist, weil die Frage ansteht:

\footnotetext{
${ }^{*}$ Die folgenden Positionen wurden auf dem Symposium „Diakonie im Ausverkauf?. Der Dritte Weg auf dem Prüfstand“ am 29. September 2005 zur Frage „Was heißt Solidarität in der ,Dienstgemeinschaft?"“ vorgetragen. In der Niederschrift wurde die Vortragsform deshalb beibehalten.
} 


\section{Ist das Konzept des „Dritten Weges“, noch geeignet, die anstehenden Probleme zu bewältigen?}

In der Diakonie, aber auch ganz verstärkt in der verfassten Kirche, stellt man fest, dass man möglicherweise an Grenzen kommt. Es stellt sich die Frage: „Kann dieses System das leisten, was heute erforderlich ist?" Die Kirchen haben, das ist ja mehrfach angesprochen worden, ein Selbstbestimmungsrecht auf Grund unserer Verfassung - das ergibt sich aus Artikel 4 GG (Religionsfreiheit) in Verbindung mit Artikel 140 Weimarer Reichsverfassung (WRV), der dieses Selbstbestimmungsrecht festlegt und damit den Kirchen die Möglichkeit einräumt, ihre eigenen Angelegenheiten zu regeln. Bundesrichter Prof. Hans-Wolf Friedrich hat es vorhin gesagt: Die Kirchen sind im Prinzip frei, die Schranke ist das für alle geltende Gesetz. Ich bin der Auffassung, dass sich aus dieser „Privilegierung“ durch die Verfassung die Pflicht ergibt, die Mitarbeiterinnen und Mitarbeiter in der Kirche und in der Diakonie im Vergleich mit anderen Arbeitnehmerinnen und Arbeitnehmer mindestens gleich zu stellen. Die Kirche hat sich für das Konzept des „Dritten Weges“ entschieden. Zentraler Punkt hierbei ist die Frage der Dienstgemeinschaft. Und da fangen die Probleme an. Die Idee der Dienstgemeinschaft ist theologisch im Priestertum aller Gläubigen begründet. Luther hat damit den Dienst aller Christen und Christinnen bezeichnet, die durch die Taufe damit betraut sind. Das allgemeine Priestertum steht somit für die gleiche Würde und den gleichwertigen Dienst aller Getauften. Es bezieht sich auf die Christenheit als Taufgemeinschaft. Die Dienstgemeinschaftsidee des allgemeinen Priestertums ist strikt theologisch zu verstehen und kann nicht mit den Organisationsformen partikularkirchlicher Dienstverhältnisse gleichgesetzt werden. Denn die Dienstbarkeit des allgemeinen Priestertums entspringt der Freiheit des Christenmenschen und folgt keiner äußeren Rechts-pflicht. Alle Kirchen, alle Ämter, die wir wahrnehmen, stellen eine Ausdifferenzierung dieses Auftrages dar und umfassen und begründen keine Herrschaft übereinander.

\section{Zum Problem eines theologischen Begriffs im Arbeitsrecht}

Die Übertragung des theologischen Begriffs der Dienstgemeinschaft in das Arbeitsrecht ist das eigentliche Problem. Danach ist die Dienstgemeinschaft dadurch konstituiert, dass alle in kirchlichen Organisationen und Einrichtungen Mitarbeitenden durch ihre formale arbeitsrechtliche Beziehung zur Kirche objektiv einer Wirkungseinheit angehören, deren Zweck darin besteht, einen Teil des Auftrages der Kirche zu erfüllen. Die organisierte Diakonie ist aber nicht nur im Kontext der Kirche verortet, sie ist ebenso Teil eines sozialstaatlichen Arrangements, das über das Subsidiaritätsprinzip den Vorrang der Wohlfahrtspflege bei sozialen Leistungen absichert und Verbände in den Rang sozialpolitischer Akteure erhebt. Die Diakonie erbringt Leistungen für andere gesellschaftliche Teilsysteme, die es erfordern, sich Fremdorientierungen zu unterstellen. 
Da fangen die Probleme an: Das Subsidiaritätsprinzip in der Wohlfahrtspflege hat zur Expansion der diakonischen Arbeitsfelder in den letzten Jahrzehnten und zu einem riesigen Wachstum des Personalbedarfs geführt. Seit der Wiedervereinigung 1990 bis heute ist die Zahl der Mitarbeiterinnen und Mitarbeiter von 200.000 auf über 420.000 angewachsen. Durch die Übernahme zahlreicher ehemals staatlicher Einrichtungen in den neuen Bundesländern war dort das Wachstum besonders stark. Die Mitarbeiterschaft ist deshalb sehr heterogen. Nicht alle arbeiten aus christlichen Motiven bei uns, sondern auch, weil sie ihrem Berufsethos folgen, und sie durch Arbeit ihren Lebensunterhalt absichern wollen. In den diakonischen Einrichtungen in den neuen Bundesländern sind getaufte Christen in der Minderheit. Hier stößt das Dienstgemeinschaftskonzept an seine Grenzen. Der Refinanzierungsdruck führt dazu, dass diakonische Einrichtungen sich immer stärker als Sozialunternehmen verstehen, mit allen sich daraus ergebenden Konflikten. Unter diesen Bedingungen werden mit dem Begriff der Dienstgemeinschaft Erwartungen geweckt, die große Organisationen per se nicht erfüllen können.

\section{Dreißig Jahre „Dritter Weg“}

Wenn man sich die Ergebnisse von jetzt dreißig Jahren „Dritter Weg“ anschaut, dann stellt man fest, dass es den Kirchen eben nicht gelungen ist, ein eigenständiges Tarifrecht zu entwickeln. Alle kirchlichen Arbeitsverträge sind bis jetzt noch weitestgehend abgeleitet von dem Tarifvertrag des Öffentlichen Dienstes, dem Bundesangestelltentarif (BAT). Die Mitbestimmungsrechte der Mitarbeitervertretungen bleiben weit hinter den staatlichen Mitbestimmungsrechten zurück, wirtschaftliche Mitbestimmung gibt es nur rudimentär und Unternehmensmitbestimmung in Aufsichtsgremien findet nur ausnahmsweise statt. Hierarchien und Bezahlung orientieren sich an bewährten weltlichen Systemen. Wenn man Anspruch und Wirklichkeit vergleicht, muss man feststellen, dass das Konzept des „Dritten Weges“ und der Dienstgemeinschaft bisher nicht eingelöst worden ist. Die Folge ist eine riesige Glaubwürdigkeitslücke.

\section{Statt Dienstgemeinschaft besser: Sozialpartnerschaft}

Ich bin für die Ersetzung des Begriffs „Dienstgemeinschaft“ im arbeitsrechtlichen Sinne durch den Begriff „Sozialpartnerschaft“. Sozialpartnerschaft macht deutlich, dass auf der einen Seite die Arbeitnehmer und Arbeitnehmerinnen, auf der anderen Seite die Arbeitgeber partnerschaftlich Arbeitsbedingungen festlegen. Wir haben so nicht die Situation, die wir immer wieder als Mitarbeitervertreter erleben, dass es Enttäuschungen gibt, weil das, was versprochen wird, durch den Begriff Dienstgemeinschaft häufig nicht eingelöst werden kann. Wir können aber, wenn wir uns diesen Begriff zueigen machen, Systeme entwickeln, die so ausgestaltet sind, dass sie Partizipation ermöglichen. Letzten Endes werden wir uns dadurch dem Dienstgemeinschaftsbegriff annähern können. 
Wenn man sich die Entwicklung in Niedersachsen anschaut, ist festzustellen, dass wir als einzige Arbeitsrechtliche Kommission der Diakonie das Konzept der Sozialpartnerschaft umgesetzt haben. Es unterscheidet sich fundamental von allen anderen kirchlichen Arbeitsrechtsregelungen in der Bundesrepublik. Das Grundprinzip der Sozialpartnerschaft wird von der Arbeitnehmer- und Arbeitgeberseite umgesetzt und praktiziert. Im Arbeitsrechtsregelungsgesetz Diakonie (ARRGD) der Konföderation der ev. Kirchen in Niedersachsen ist das Konsensprinzip beim Verfahren der Arbeitsrechtssetzung festgelegt. Beschlüsse zu arbeitsrechtlichen Regelungen werden durch Zustimmungserklärungen der beiden Seiten gefasst. Mehrheitsbeschlüsse sind ausgeschlossen. Kommt kein Beschluss zustande, kann jede Seite die Schlichtung anrufen. Das Schlichtungsverfahren ist zweistufig ausgestaltet. In jeder Phase des Verfahrens können beide Seiten Beschlüsse durch neue Verhandlungen herbeiführen. Ein Schlichtungsspruch wird nur wirksam, wenn beide Seiten zustimmen. Dadurch ist sichergestellt, dass Arbeitsrechtsregelungen nur im Konsens zustande kommen. Das ist die Umsetzung des Prinzips der Sozialpartnerschaft in der Arbeitsrechtsregelung. Wir haben in den letzten Jahren bewiesen, dass wir mit diesem Prinzip die notwendigen Anpassungsschritte vorantreiben können. Nach einem langen Verhandlungsprozess hat die Arbeitsrechtliche Kommission der Diakonie in Niedersachsen eine weit reichende Reform der Arbeitsvertragsrichtlinien umgesetzt. Inhaltlich haben wir uns dabei von der Orientierung am Öffentlichen Dienst gelöst und eine völlig neue Entgeltordnung verabschiedet.

\section{Betriebliche Öffnungsklauseln als flexible Instrumente}

In diesem Jahr hat die Arbeitsrechtliche Kommission durch die Einführung von betrieblichen Öffnungsklauseln den Weg der Reform fortgesetzt. Bei Vorliegen einer schwierigen Wettbewerbssituation können die Betriebspartner vor Ort die Entgelte in einem von der Kommission vorgegebenen Korridor reduzieren. Das macht deutlich, dass man sich von der Überhöhung des Begriffs „Dienstgemeinschaft", der theologisch richtig ist und deshalb gar nicht in Frage gestellt zu werden braucht, verabschieden kann. Zugleich kann man sich dem Konzept der Sozialpartnerschaft annähern. Es ermöglicht, Regelungen zu finden, mit deren Hilfe die schwierigen Anpassungsprozesse, in denen sich die Diakonie z.Zt. befindet, bewältigt werden können. Dieses Konzept beinhaltet aber Verfahrensregelungen, die die strukturelle Überlegenheit der Arbeitgeberseite begrenzen, weil nur so ein Verhandeln auf Augenhöhe möglich wird. Das wird am Arbeitsrechtsregelungsgesetz der Diakonie in Niedersachsen deutlich.

Leider müssen wir heute vielfach erleben, dass das Konzept von Partnerschaft und Partizipation nicht umgesetzt wird. Es ist von „Selbstbestimmung“ die Rede, aber im falschen Sinne, nämlich als „selbst Bestimmen“. Die Konflikte in den Einrichtungen und in den Werken nehmen ständig zu und werden immer schärfer. Wenn z.B. Arbeitsrechtliche Kommissionen nicht die gewünschten 
Beschlüsse fassen, werden durch die Synoden, wie zuletzt in Berlin-Brandenburg, die gesetzlichen Grundlagen für die Arbeitsrechtssetzung geändert und damit in die Parität eingegriffen. Von Gleichberechtigung und Partnerschaft keine Spur. Das Reaktionsmuster: Wenn die Arbeitnehmer - das scheinen immer die Schuldigen zu sein - nicht die notwendige Einsicht haben, dass bestimmte Dinge verändert werden müssen, dann wird einfach das Gesetz geändert oder die Arbeitnehmervertreter werden ausgetauscht. Besser kann man nicht dokumentieren, dass der Dienstgemeinschaftsbegriff nicht ernst gemeint ist. Mitarbeiterinnen und Mitarbeiter werden frustriert, die Motivation beeinträchtigt. Bei vielen Mitarbeiterinnen und Mitarbeitern bleibt Enttäuschung zurück. Ihr Leistungspotenzial kann so nicht ausgeschöpft werden, was letzten Endes die Qualität diakonischer Arbeit erheblich mindert.

\section{Was heißt Sozialpartnerschaft in der Diakonie?}

Wenn wir aber den Weg einer echten Sozialpartnerschaft gehen, sind wir in der Lage, die Probleme zu lösen, das haben wir gezeigt. Unabdingbar ist aber, dass sich alle diakonischen und kirchliche Einrichtungen, ohne jede Ausnahme, an die vorgegebenen Spielregeln halten. Jeder, der diese Spielregeln missachtet, - sei es, dass er das Mitbestimmungsgesetz der Mitarbeitervertretung ignoriert, oder eine eigene Regelung kreiert - trägt dazu bei, dass die Glaubwürdigkeit von Kirche und Diakonie bei den Mitarbeiterinnen und Mitarbeitern aber auch in der Gesellschaft Schaden nimmt. Mitarbeiterinnen und Mitarbeiter sind diejenigen, die als Multiplikatoren vor Ort berichten, wie diakonische Arbeitgeber mit ihren Mitarbeiterinnen und Mitarbeitern umgehen.

Von vielen leitenden Kirchenvertretern wird die Macht nur als Kraft verstanden, Ziele auch gegen den Widerstand anderer durchzusetzen. Macht muss aber verantwortlich gebraucht werden. Das Zurücknehmen der vorhandenen Macht und die Fähigkeit zur Kooperation sind die Voraussetzungen dafür, dass das System des „Dritten Weges“ funktionieren kann; Selbstbindung ist also gefordert, auch wenn es - wie wir gehört haben - rechtlich möglich ist, von dem gemeinsamen Konsens abzuweichen. Das Selbstbestimmungsrecht ermöglicht den Kirchen und ihrer Diakonie ihre Angelegenheiten selbst zu regeln. Das heißt aber nicht, dass der Dritte Weg alternativlos ist. Kirche und Diakonie könnten auch, wie in den fünfziger Jahren üblich, den ersten Weg anwenden. Ebenso wäre die Anwendung des staatlichen Arbeits- und Tarifrechts möglich. Aber wenn man sich auf dieses Konzept verpflichtet hat, dann muss es ohne jede Ausnahme umgesetzt werden, weil nur das die Freiheit schafft, notwendige Anpassungsprozesse mit der entsprechenden Sicherheit anzugehen. Und insofern glaube ich auch, dass das, was die meinen Ausführungen zugrunde liegenden Frage war: „Ist Solidarität möglich in einer Dienstgemeinschaft?“, ganz klar mit ,ja “ beantwortet werden kann. Ich bin sogar der Überzeugung, dass wir besser sein können als 
vergleichbare Systeme in der freien Wirtschaft. Und daran sollten wir gemeinsam arbeiten, vielen Dank!

\section{Peter Fündeling:}

\section{Dienstgemeinschaft als "geglaubtes Bild“ und als erfahrbare Realität}

Dienstgemeinschaft verstehe ich in zweierlei Hinsicht: Sie ist einerseits „geglaubtes Bild“ und andererseits erfahrbare Realität.

Zum „geglaubten“ Bild: Jeder Mitarbeiter und jede Mitarbeiterin dient dem Verkündigungsauftrag der Kirche. Jeder und jede übt diesen Dienst aber nicht allein, sondern in der Gemeinschaft aller kirchlichen Mitarbeiter und Mitarbeiterinnen aus. Diese Dienstgemeinschaft ist damit Stärkung und Halt für den einzelnen Mitarbeiter; sie bietet die Chance zu geschwisterlichem Gespräch und gibt die Möglichkeit, im Umgang der Mitarbeiter und Mitarbeiterinnen untereinander das Evangelium zu leben.

Das Bild orientiert sich am Priestertum aller Gläubigen und an dem neutestamentlichen Bild vom einen Leib, an dem viele Glieder je nach ihrem Können und ihrer besonderen Funktion Dienst tun. Der Dienst ist zwar verschieden, aber die Verantwortung für die rechte Verkündigung tragen alle gemeinsam. Das gilt unabhängig davon, aus welchen Motiven der Einzelne tätig ist: Mit dem Eintritt in den kirchlichen Dienst wird er unweigerlich ein Glied dieses Leibes. (Das ist z.B. ein Grund dafür, dass bei Bewerbern ohne evangelisch-lutherisches Bekenntnis auch geprüft werden muss, ob ihnen der Dienst überhaupt zugemutet werden kann.)

Dienstgemeinschaft ist aber ebenso erfahrbare Realität. Oft wird jedoch diese Realität nur als Konflikt zum Thema: Die meisten Mitarbeiter in der Diakonie und sehr viele in der verfassten Kirche üben ihre Tätigkeit allein zum Broterwerb aus. Ihnen ist es mehr oder weniger egal, bei welchem Arbeitgeber sie tätig sind. Es ist durchaus nachzuvollziehen, dass solche Mitarbeiter verständnislos bis abwehrend reagieren, wenn sie auf den kirchlichen Charakter ihrer Tätigkeit angesprochen werden. Diese Situation stellt ein erhebliches Problem für das Miteinander in der Mitarbeiterschaft dar, aber auch für die Außenwahrnehmung kirchlicher Dienste. 
Dazu möchte ich aus einem Aktenstück der Landessynode zitieren:

„Neben dieser administrativen Ebene spielt die geistliche Ebene, die geistliche Ausrichtung der Mitarbeiterin bzw. des Mitarbeiters eine Rolle in den Arbeitsbeziehungen der Kirche.

,Diese Verschränkung der verschiedenen ... Ebenen markiert den zentralen Konfliktherd im Bereich kirchlicher Arbeitsplätze. Wer sagt, wann welche der Ebenen im Vordergrund und welche im Hintergrund stehen soll? Wer hat in einer bestimmten Situation die Definitionsmacht, was Kirche überhaupt ist?... ${ }^{1}$

Der Begriff der ,Dienstgemeinschaft legt die Interessengleichheit von Arbeitgeber und Arbeitnehmer nahe, die aber nur in Teilen gegeben ist. Die Ungeklärtheit dieses Verhältnisses und der jeweiligen Erwartungen führt vielerorts zu Konflikten. Sowohl die Mitarbeiterschaft wie auch die Anstellungsträger müssen den Gedanken der Dienstgemeinschaft alltäglich füllen, wenn es mehr als ein bedrückender Anspruch sein soll.

Das Verhältnis der Kirche zu ihren Mitarbeiterinnen und Mitarbeitern lässt sich nicht allein in arbeitsrechtlichen Kategorien abhandeln. Alle Mitarbeiter und Mitarbeiterinnen sind dafür verantwortlich, dass das besondere Profil ihrer Arbeit sichtbar wird. Auf Seiten der Mitarbeiterschaft setzt dies die Bereitschaft voraus, ihre Arbeit nicht als reinen Broterwerb und genau per Dienstanweisung geregelten Job zu sehen. Auf Seiten des kirchlichen Arbeitgebers und dessen handelnden Personen setzt es die Bereitschaft voraus, die Mitarbeiter und Mitarbeiterinnen nicht nur als Kostenfaktor, sondern als ,Arbeiter im Weinberg Gottes' wahrzunehmen, sie nicht unangemessen zu belasten und ihre Arbeit angemessen zu vergüten. ...

Der Arbeitsweltausschuss hält erfreut fest, dass der überwiegende Teil der Personalangelegenheiten ohne große Probleme verläuft und der Anspruch, auch ,Dienstgemeinschaft" zu sein, weitgehend mit Leben gefüllt wird.“2

$\mathrm{Ob}$ diese Feststellung zutrifft, können Sie für Ihre jeweiligen Einrichtungen selbst am besten beurteilen. Ich vermute, dass das Bild unterschiedlich ist.

\section{Realität: Der Dritte Weg als Erfolgsmodell steht nicht zur Disposition}

Den Dritten Weg gibt es seit Ende der 1970er Jahre. Er hat zahlreiche Arbeitsrechtsregelungen hervorgebracht, nach denen Hunderttausende, wenn nicht Millionen, von Dienstverhältnissen abgeschlossen worden sind und rechtlich behandelt werden. Der Dritte Weg ist - wenn auch für verfasste Kirche und Diakonie unterschiedlich - im Wesentlichen von staatlicher und kirchlicher

\footnotetext{
1 A. Böhmer, Arbeitsplatz Evangelische Kirche, in: Bauer, A./Gröning, K., Institutionsgeschichte, Tübingen 1995.

2 Aktenstücke der 22. Landessynode, Nr. 143, vom 02. Mai 2001, S. 4.
} 
Rechtsprechung anerkannt worden; auch in der Literatur wird der Dritte Weg mehrheitlich positiv behandelt. Schließlich ist auch darauf hinzuweisen, dass der Bundesgesetzgeber in einer Reihe von Gesetzen den Dritten Weg dem Tarifvertrag gleichgestellt hat.

Der Dritte Weg ist aber nicht nur in äußerlicher oder rechtlicher Hinsicht ein Erfolgsmodell: In den vergangen 25 Jahren ist es gelungen, Konflikte in kirchengemäßer Weise zu lösen: Partnerschaftlich, paritätisch, unter Wahrung des Prinzips der Lohngerechtigkeit, ohne Arbeitskampf. (Dazu als Anmerkung: Nach meinem Dafürhalten würde sich der Dritte Weg auch überall dort zur Tarifgestaltung eignen, wo sich nicht Kapitalinteressen und Arbeitneh-merinteressen gegenüberstehen, also z.B. im öffentlichen Dienst bei Bund, Ländern und Kommunen.) Staatskirchenrechtlich beruht der Dritte Weg auf dem Selbstbestimmungsrecht der Kirchen, wie es im Grundgesetz iVm der Weimarer Reichsverfassung niedergelegt ist.

Da die beiden großen Kirchen sich für den Dritten Weg entschieden haben und dies somit auch für unsere Landeskirche gilt, bedeutet dies: Kirchlichen (und damit auch diakonischen) Einrichtungen ist der 2. Weg und der 1. Weg und jeder andere Weg versperrt, wenn sie sich denn zur Kirche rechnen lassen wollen. Verlässt also eine Einrichtung den Dritten Weg, stellt sich die Frage, ob sie überhaupt noch als kirchliche/diakonische Einrichtung angesehen werden kann. M.E. ist das dann nicht mehr der Fall. Würden die Kirchen etwas anderes tolerieren, würden sie riskieren, dass der Staat das Selbstbestimmungsrecht als offenbar überflüssig, weil in einem wesentlichen Teil ausgehöhlt, betrachten könnte. Die Streichung des Selbstbestimmungsrechts im GG wäre dann nur eine logische Konsequenz.

Ich sehe den Dritten Weg als Erfolgsmodell, will aber auch meine Kritik nicht verschweigen: Ich meine, dass wir alle in den vergangenen Jahren die Möglichkeiten des Dritten Weges noch nicht recht ausgeschöpft haben. Grund dafür ist die bisherige - verständliche - Orientierung am Tarifrecht in Bund, Ländern und Kommunen. Wir haben fast alles nachvollzogen, was dort beschlossen wurde; es wäre sicher glücklicher gewesen, wenn wir früher eigene Vorstellungen entwickelt hätten.

\section{Die wirtschaftliche Situation zwingt zum Handeln}

„Mit schöner Regelmäßigkeit sind Berichte über diakonische Einrichtungen zu lesen, die beabsichtigen, eigene Gehaltstarife einzuführen. [...] Der wirtschaftliche Konkurrenzdruck auf dem, sozialen Markt ${ }^{`}$ zwingt nach Aussage der Verantwortlichen zum Ausscheren aus den bisherigen kirchlichen Tarifwerken $[\ldots]^{“} .3$

\footnotetext{
${ }^{3}$ Glawatz-Wellert, Tarifflucht und kirchliches Selbstbestimmungsrecht, in: Diakonie 2005, S. 68.
} 
Der Wahrheit wegen muss man allerdings hinzufügen: Nicht in jeder Einrichtung ist es der Kostendruck von außen, der zur wirtschaftlichen Schieflage führt: Manchmal sind die Probleme auch hausgemacht, z.B. durch mangelnde Professionalität beim Mitarbeitereinsatz. Diese Einschränkung ändert aber nichts an der generellen Feststellung: Diakonische Einrichtungen stehen unter erheblichem Konkurrenzdruck; die Finanzlage der öffentlichen Hand, aber auch die im Zuge der Vergrößerung der EU auf den Markt drängenden Mitbewerber gestalten die Lage schwierig.

Was hier über die Diakonie gesagt wird, gilt in ähnlicher Weise auch für die verfasste Kirche: Sowohl Kirche als auch Diakonie haben sich bis vor kurzem am öffentlichen Dienst und seinem Tarifsystem orientiert. Dies lag nahe, weil die Trennung des kirchlichen Dienstes vom staatlichen Dienst ja noch kein halbes Jahrhundert bestand. Auch glaubte man, so am besten mit dem Staat um die Arbeitskräfte konkurrieren zu können.

Der Staat ist von uns allen in den vergangenen Jahrzehnten so ausgebeutet worden, dass er inzwischen praktisch handlungsunfähig ist. Meldungen über die Neuschulden belegen dies genauso wie der Umstand, dass man immer öfter von Klagen gegen vermeintlich oder tatsächlich verfassungswidrige Haushalte lesen muss (jüngstes Beispiel: Niedersachsen). Wir hätten sicher eher merken müssen, dass die Belastungen der öffentlichen Haushalte so groß wurden, dass nun der Kollaps droht. Auf kirchlicher Seite ist zwar an manchen - leider nicht an allen Stellen Vorsorge für schlechtere Zeiten getroffen worden; diese Rücklagen reichen aber jetzt offenkundig nicht aus, weiter im Gleichschritt mit dem „Schuldenmacher Staat" zu marschieren.

Nun zeigt sich, dass diese Gefolgschaft in die Sackgasse führt: Die Kirchensteuern nehmen aus den bekannten Gründen rapide ab, und wenn auch unsere Landeskirche immer eher eine vorsichtige Finanzpolitik betrieben hat und in den fetten Jahren Rücklagen gebildet hat, so ist doch jetzt spätestens der Zeitpunkt zum Handeln gekommen. Die neuen Tarifverträge für Bund und Kommunen, die gerade erst unterzeichnet worden sind, bieten auch keinen Ausweg, - zumindest verringern sie die Personalkosten nicht.

Unsere Landeskirche verfolgt die notwendige Anpassung in einem kombinierten Modell: Wir setzen nicht nur allein auf den Abbau von Arbeitsplätzen oder alternativ dazu allein auf die Verringerung der Gehälter, sondern wollen beides miteinander kombinieren. Damit streben wir an, einerseits nicht mehr Arbeitsplätze abbauen zu müssen als nötig. Wir glauben, dass die Solidarität aller gefordert ist, um möglichst viele Arbeitsplätze zu erhalten, vor allem, um den kirchlichen Auftrag weiterhin möglichst vielfältig wahrzunehmen. Das bedingt aber auf der anderen Seite, dass wir die bisherigen Vergütungen usw. nicht halten können. 


\section{Tarifflucht und Dritter Weg haben nur bedingt miteinander zu tun}

Es muss also etwas geschehen - nur was? Sieht sich eine Einrichtung in finanziellen Problemen, stellt sie schnell fest, dass die Personalkosten der größte Brocken sind. Also muss vor allem hieran gekürzt werden. In vielen Fällen in der Vergangenheit sollte dies auch rasch geschehen, weil die Wahrheit über die finanzielle Lage zu spät erkannt wurde.

In dieser Situation liegt die Erwägung nahe, ein anderes, billigeres Tarifwerk zu benutzen, das Hilfe verspricht. Aber: Machen wir uns klar, was das bedeutet: Die Einrichtung hat sich als Mitglied des Diakonischen Werks ausdrücklich schriftlich verpflichtet, das diakonische Arbeitsvertragsrecht (AVR) anzuwenden. Die Einrichtung begeht jetzt also Tarifflucht.

An dieser Stelle wird deutlich: Diese Tarifflucht hat zunächst einmal überhaupt nichts mit der Art und Weise zu tun, wie das diakonische Arbeitsrecht entstanden ist, also durch den Dritten Weg. Das zeigt folgende Kontrollüberlegung: Hätte nämlich die Einrichtung zuvor Arbeitsrechtsregelungen angewandt, die als Tarifvertrag zustande gekommen wären, so würde sie ebenfalls Tarifflucht begehen, wenn sie sich davon abwendet. Daraus folgere ich: Belastend für die Situation der Einrichtungen ist also nicht der Weg, auf dem Arbeitsrechtsregelungen zustande kommen, sondern der Inhalt der Regelungen selbst. Es hat daher keinen Sinn, die Abkehr vom Dritten Weg zu fordern und damit die Hoffnung zu verbinden, wenn man nur Tarifverträge abschließen würde, würde sich alles wie von selbst zum Besseren wenden.

Eine kleine Einschränkung muss ich hier allerdings machen: Es war bislang mühsamer, die Regelungen, die im Dritten Weg entstanden, öffentlich zu verteidigen, weil die Gewerkschaften diesen Weg bekämpft haben. Dieser Aufwand entfällt natürlich beim Abschluss von Tarifverträgen. Allerdings gibt die jüngste Entwicklung in der Konföderation Anlass zu einem Hoffnungsschimmer: Die Gewerkschaft ver.di hat angekündigt, sie wolle sich in der Arbeits- und Dienstrechtlichen Kommission der Konföderation (also der Kommission für die verfasste Kirche) am Dritten Weg beteiligen, und zwar von der nächsten Amtszeit ab 01.11.2005 an. Zwar hat ver.di Bedingungen für eine Änderung der Verfahrensregelungen gestellt; diese werden wir jedoch sorgfältig prüfen. Ich hoffe, dass ver.di die Erklärung, am Dritten Weg teilnehmen zu wollen, ernst meint.

\section{Heutiges Handeln innerhalb des Dritten Weges erfordert Umdenken}

Ich habe bereits darauf hingewiesen, dass die Arbeitsrechtlichen Kommissionen in der Vergangenheit mehr oder weniger den BAT und ähnliche Tarifverträge übernommen haben. Die Arbeitsrechtliche Kommission der Konföderation für die Diakonie hat diesen Weg schon vor einiger Zeit verlassen und die „Arbeitsvertragsrichtlinien - modern“ (AVR-K) entwickelt. Ihr ist dafür ein Kompliment 
zu machen, denn es zeigt sich: Hier wurde der vorhandene Gestaltungsraum genutzt.

Den Gestaltungsraum zu nutzen, bedeutet aber: Sowohl die Arbeitgeberseite als auch die Mitarbeiterseite müssen bereit sein, höhere Verantwortung wahrzunehmen und ihre Ängste vor Veränderungen zu überwinden.

Beide Seiten müssen uneingeschränkt bereit sein, vertrauensvoll miteinander umzugehen. Hier mangelt es gelegentlich: Es wird versucht, mit Tricks zu arbeiten. Beide Seiten müssen das unterlassen, ebenso wie Unterstellungen oder den Aufbau von Feindbildern. Beide Seiten müssen partnerschaftlich miteinander verhandeln: Das meint: Ich versetze mich in die Rolle der anderen Seite und denke für die jeweils andere Seite - aus deren Sicht - mit. Wahrheit und Klarheit gehören selbstverständlich auch dazu, ebenso die Bereitschaft, auf veränderte Rahmenbedingungen schnell zu reagieren. Zum Leitbild der Dienstgemeinschaft gehört auch das Prinzip der Lohngerechtigkeit, das Maßstab und Verpflichtung sein muss, und zwar sowohl für Mitglieder kirchenleitender Organe wie auch kirchlicher Mitarbeitervereinigungen und Mitarbeitervertretungen.

Für die Arbeitgeberseite gilt besonders: Verantwortung wahrnehmen heißt, dass Konflikte nicht verschleiert werden dürfen. Zahlen und Argumente gehören auf den Verhandlungstisch, ohne dass die Mitarbeiterseite darum betteln muss. Verantwortung wahrnehmen kann aber auch heißen, bereit zu sein, notfalls die Schlichtung anzurufen. Moralischer Druck darf auf die Mitarbeiterseite nicht ausgeübt werden; z. B. kann es kein Argument sein, zu behaupten, der Gedanke der Dienstgemeinschaft erfordere diese oder jene Maßnahme zum Nachteil der Mitarbeiter. Stattdessen gilt: Wenn solche Beschlüsse anstehen, wird von der Arbeitgeberseite erwartet, nüchtern, konkret und überzeugend die Folgen darzulegen, die sich aus einem Unterlassen eines solchen Beschlusses ergeben würden.

Die Arbeitnehmerseite kann und muss Verantwortung dadurch wahrnehmen, dass den Mitarbeitern keine falschen Versprechungen gemacht werden. Kompromissvereinbarungen sollten ihnen so vermittelt werden, dass die dahinterstehenden Zwänge erkennbar werden. Dass die Arbeitnehmer für unangenehme Beschlüsse mit einstehen, gehört selbstverständlich auch dazu.

\section{Ziel: Erhalt kirchlich-diakonischer Arbeitsfelder und der damit verbundenen Arbeitsplätze}

Kirchliche Arbeit - diakonische Arbeit ist natürlich mitgemeint - dient keinem Selbstzweck oder der Maximierung von Profitinteressen. Sie dient dem Verkündigungsauftrag: Möglichst vielen Menschen das Evangelium von Jesus Christus nahe $\mathrm{zu}$ bringen und möglichst umfassend diakonisch-helfend tätig zu sein. Dies geschieht durch Mitarbeiter und Mitarbeiterinnen, ehrenamtliche und bezahlte. Ziel muss es sein, möglichst viele kirchliche und diakonische Arbeitsfelder zu 
erhalten und dazu auch möglichst viele bezahlte Arbeitsplätze zu sichern. Das wird unter den ökonomischen Bedingungen heute so nicht möglich sein; die kirchlichen Tarife müssen sich stärker als bislang am Markt orientieren. Damit werden Einbußen verbunden sein. Anders geht es nicht; in manchen Fällen wird es daher nicht zu vermeiden sein, dass diese auch zum Abbau von Arbeitsplätzen führen (können).

Hier sehe ich die größte Aufgabe, die vor den Arbeitsrechtlichen Kommissionen liegt. Dabei hielte ich es für verfehlt, wenn die Kommissionen sich dieser Aufgabe dadurch entledigen, dass sie möglichst weitgehende betriebliche Öffnungsklauseln beschließen.

M.E. müssen sich die Kommissionen mit der Realität in den Betrieben und Einrichtungen so intensiv auseinandersetzen, dass sie für den gesamten Geltungsbereich der Arbeitsrechtsordnung zu zutreffenden Beschlüssen kommen. Das schließt auch besondere Regelungen für verschiedene Sparten ein. Es sollte dagegen möglichst vermieden werden, Mitarbeitervertretungen mit der Aufgabe zu belasten, tarifliche Regelungen für ihren Betrieb aushandeln zu müssen. Ich meine, dass Mitarbeitervertretungen dann rechtlich und politisch in eine schwierige Rolle kommen, wenn sie verstärkt in die betriebliche Tarifgestaltung eingeschaltet werden. Für Notfälle können aber Betriebsvereinbarungen in Betracht kommen, damit schnell eine akute Notlage überwunden werden kann, auf die die Arbeitsrechtliche Kommission nicht schnell genug reagieren kann. ${ }^{4}$

Ich hoffe, dass ich Ihnen zeigen konnte, dass der Dritte Weg nicht chancenlos ist. Wenn Arbeitgeber und Arbeitnehmer beherzt ihre jeweilige Verantwortung wahrnehmen, können auch auf diesem, allein kirchengemäßen Weg Lösungen für die gegenwärtigen Probleme gefunden werden und damit die Zukunft kirchlicher Dienstverhältnisse angemessen gestaltet werden.

\footnotetext{
${ }^{4}$ Noch weiter geht Harald Schliemann (Tarifvorbehalt des \ 77 III BetrVG und kirchliches Arbeitsrecht, in: NZA 2005, S. 976 ff.), der rechtspolitische Bedenken gegen das Tätigwerden der Mitarbeitervertretung auch bei Notlagenvereinbarungen erhebt. Ein innerbetriebliches, mit der Mitarbeitervertretung vereinbartes Sanierungskonzept hat das ArbG Hameln als Grund für eine Änderungskündigung akzeptiert (Urteil vom 19.05.2005, 1 Ca 698/04); das Urteil ist jedoch noch nicht rechtskräftig.
} 


\section{Lothar Stempin:}

„Dienstgemeinschaft“ ist ein theologisch hoch aufgeladener und zugleich belasteter Begriff. In der aktuellen Situation der Diakonie liegt in ihm eine enorm klärende Kraft, und darum ist es gut, dass wir um diesen Begriff ringen und streiten. Nach meinem Verständnis geht es dabei um die Ausrichtung und die Verständigung über den Weg der Diakonie in den nächsten Jahrzehnten. Allerdings wird die Erklärungskraft dieses Leitbegriffes deutlich geschmälert, wenn man seine Mehrdimensionalität übersieht.

Diese Mehrdimensionalität lässt sich, analog zu den ekklesiologischen Bestimmungen, in einer dreifachen Weise beschreiben. „Dienstgemeinschaft“ gibt es zunächst „in“ und „mit“ einer Ordnung. Im Vordergrund steht bei dieser Betrachtung das Dienstrecht. Dienstgemeinschaft konkretisiert sich in der kirchengemäßen Weise, Arbeitsrecht zu setzen. Damit ist gleichsam der rechtliche Schatten der Dienstgemeinschaft gekennzeichnet. Das Arbeitsrecht ist in den vergangenen Jahrzehnten der zentrale Bereich gewesen, in dem die Zuordnung der Diakonie zur Kirche formuliert wurde. Dienstgemeinschaft wird damit als Rechts- und Ordnungsbegriff ausgelegt und die Kompatibilität dieser Ordnung zur allgemeinen Rechtsordnung betont. Aber das ist nur eine Dimension. Daneben gibt es eine zweite: „Dienstgemeinschaft“ als spirituell gegründete Glaubensgemeinschaft. Oder zugespitzt gesagt: „Dienstgemeinschaft“ als Ordensgemeinschaft. In dieser Hinsicht wird Dienstgemeinschaft als die besondere Form der Beziehungen der Christen untereinander und in ihrem Weltverhältnis gefasst, die in der Jesusbewegung selbst ihren Ursprung hat. Das Neue am Kreis der Jesusjünger war nicht ihre Organisationsform, sondern das seiner Sendung zugrunde liegende Selbstverständnis: Jesus unterstellte diesen Kreis dem Grundprinzip des Dienens. Und drittens: „Dienstgemeinschaft“ als Gestaltungs- und Verantwortungsgemeinschaft. In dieser Hinsicht stellt sich z. B. heute die Frage, wie wir solidarisch und verantwortlich die Dienstverhältnisse und die Konflikte miteinander klären. Vor allem aber erwachsen aus der Dienstgemeinschaft in dieser Betrachtung signifikante Praxisvollzüge und Lebensäußerungen von Christen, die auf den befreienden Zuspruch des Evangeliums antworten und ihm in eigener Verantwortungsgestalt zu entsprechen versuchen.

Diese drei Dimensionen von Dienstgemeinschaft haben ihre Entsprechung in dem, was über den dreifachen Kirchenbegriff gesagt worden ist - der rechtlichformellen Dimension, der spirituellen Dimension und der Handlungsgestalt. Diese Bezogenheit ist für mich zentral, und mir liegt daran, diese drei Dimensionen von Dienstgemeinschaft in gleicher Weise zur Geltung zu bringen. Damit formuliere ich zugleich meine Kritik an der Verwendung des Dienstgemeinschaftsbegriffs: Wir reden in einer verkehrten Priorisierung über Dienstgemeinschaft. Wir 
beginnen immer zuerst die rechtliche Dimension von Dienstgemeinschaft auszulegen und zu erklären. Das bedeutet nach reformatorischem Kirchenverständnis, das Pferd von hinten aufzuzäumen. So kommt man nicht voran. Nur wenn wir von vorne beginnen, zuerst die Diakonie des Geistes entfalten, dann die Diakonie des Zeugnisses und schließlich die Diakonie des Rechtes, können wir die Fragen nach dem Ort und der Gestalt von Diakonie in unserer Gesellschaft beantworten. Es geht ja nicht vorrangig darum, wie man Dienstverhältnisse oder Konflikte regelt, sondern wir reden hier über strategische Fragen der Ausrichtung von Diakonie - auch in ihrem Verhältnis zu der verfassten Kirche und zu den staatlichen und öffentlichen Institutionen.

Die genannten drei Dimensionen von Dienstgemeinschaft müssen auch für die Praxis leitend sein. Die konkrete Solidarität in der Dienstgemeinschaft soll deshalb unter drei Fragestellungen thematisieren werden:

\section{Ist der Rechtsbegriff der Dienstgemeinschaft durch die tatsächliche Gestaltung der Arbeitsverhältnisse in einem inhaltlichen Sinn noch gefüllt?}

Das ist die erste Frage. Die Arbeitsrechtssetzung der vergangenen Jahren in der Diakonie, insbesondere in der Arbeitsrechtlichen Kommission in Niedersachsen, ist für mich ein deutlicher Beleg dafür, dass Dienstgemeinschaft auch in einem inhaltlichen Sinne gelebt und mit konkreten Ergebnissen gestaltet werden kann. Eine kleine Einschränkung möchte ich machen: Der Apostel Paulus schreibt im Römerbrief von dem den Heiden ins Herz geschriebenen Gesetz, d. h. bezogen auf unsere Situation weiß ich nicht immer, ob in dem Bewusstsein von gelebter Dienstgemeinschaft auch diese Ergebnisse erreicht worden sind. Dienstgemeinschaft ist in den vergangenen Jahrzehnten stark als Rechtsbegriff gefasst worden. Aber damit ist in meinen Augen ein kategorialer Fehler gemacht worden. Dienstgemeinschaft hat eine rechtliche Seite. Aber wenn wir dahin kommen, dass wir die Ergebnisse eines im Geiste der Dienstgemeinschaft geführten Verhandlungsprozesses nur so sehen, dass hier staatsanaloge Ergebnisse vorliegen, dann kommen wir in Schwierigkeiten. Leider ist es ja so, dass die Kirchen sich entschieden haben, ihr Selbstbestimmungsrecht in dienstrechtlichen Fragen letztlich staatsanalog auszugestalten. In dieser Folge wird die BAT-Orientierung und vieles andere durchgehalten. Der Rechtsrahmen der Bundesrepublik Deutschland nötigt uns, unser Arbeitsrecht mit staatlichem Recht kompatibel zu machen, nicht aber es analog zu ihm setzen. Die Dienstverhältnisse in der Diakonie müssen aus inhaltlichen Gründen mehr sein als allgemeines Arbeitsrecht. Das ist das Motiv des Dritten Weges, und das ist zugleich das Problem, mit dem wir umgehen müssen. Es ist eine Last, die wir aus der Kirchenbindung tatsächlich mit uns tragen.

Die Überformung der Dienstgemeinschaft ist aber nicht nur rechtlich, sondern auch inhaltlich zu konstatieren. Wenn wir in der Begrifflichkeit dahin gekommen 
sind, dass nicht mehr von Dienstnehmern und Dienstgebern geredet wird, sondern von Arbeitnehmern und Arbeitgebern, wenn, wie wir vorhin in einem Beitrag gehört haben, von Interessenausgleich oder Klärung der Interessen gesprochen wird und von Sozialpartnerschaft, dann befinden wir uns in einer Logik und in einer Vorstellungswelt, die nach meinem Verständnis nicht mit dem Begriff der Dienstgemeinschaft kompatibel ist. Dann denken wir in den Gegensätzen von Kapital und Arbeit, dann fügen wir Interessengegensätze und Meinungsverschiedenheiten in diesen Deutungsrahmen und adoptieren die fremden Elemente des Interessenausgleiches und der Mitbestimmung. Das ist nicht der Geist und der Inhalt von Dienstgemeinschaft, wie ich ihn mir vorstelle. Oder ich sage es doch noch einmal zugespitzt: Wenn wir diesem nachgeben - und das ist ja an vielen Stellen so in Gang gesetzt worden -, dann vollziehen wir einen Akt der Selbstsäkularisierung von Kirche und Diakonie, der unaufhaltsam zum Ende des kirchlichen Selbstbestimmungsrechtes führt.

Hinzu kommt eine eklatante theologische Verkürzung des Verständnisses von Dienstgemeinschaft. Wir maßen uns an, Dienstgemeinschaft immer nur als das Verhältnis von Dienstgeber und Dienstnehmern zu sehen. Die Neuausrichtung der Diakonie von den Menschen her zu denken, die Hilfsbedürftigen als Subjekte von Diakonie und der Offenbarung Gottes zu sehen, die uns zeigen, wie das leidende Angesicht Gottes selbst in der Welt erscheint, muss doch deutlich machen, dass auch diese Menschen, mit denen wir in den Einrichtungen zusammenleben, zu dieser Dienstgemeinschaft dazugehören. Was ist das für eine Hybris, wenn wir immer nur in unseren arbeitsrechtlichen Verhältnissen Dienstgemeinschaft in dieser Weise vereinnahmen! Natürlich ist diese Orientierung insbesondere der Dienstnehmerseite, wie ich eben angedeutet habe, an der Logik gewerkschaftlichen Denkens auf der einen Seite nicht allein zu kritisieren. Auf Dienstgeberseite erlebe ich durchaus, dass Einrichtungsleitungen auftreten und sich wie Unternehmer gerieren, die dem neoliberalen Flötenspiel des freien Marktes folgen oder gar nach Gutsherrenart den Rechtsrahmen der Bundesrepublik mit ihren Reitstiefeln treten. Insgesamt bemerke ich einen Verlust an Erdung in der christlichen Tradition und Frömmigkeit auf beiden Seiten. Ich will da nicht mit dem Finger auf die einen oder anderen zeigen; ich kann es aus der Erfahrung des Diakonischen Werkes in Braunschweig beschreiben, und das ist wirklich traurig und bitter.

Damit komme ich zu der zweiten Frage:

\section{Welche Probleme ergeben sich heute bei der Gestaltung der mit dem Begriff „Dienstgemeinschaft“ intendierten vertrauensvollen partnerschaftlichen Zusammenarbeit?}

Aus dem oben Gesagten ergibt sich unmittelbar ein Defizit bei der Gestaltung der vertrauensvollen und geistlichen Zusammenarbeit und des geistlichen Zusammen- 
lebens in den Einrichtungen und Dienststellen der Diakonie. Die Kommunikation und die Verfahrenswege sind nicht dem Begriff von Dienstgemeinschaft angemessen. Die Mitarbeitervertretungen werden häufig nicht zeitnah über Personalveränderungen informiert. Die Transparenz und die Informationsflüsse sind nicht so, wie es eigentlich der Dienstgemeinschaft angemessen wäre. Man meint immer noch von der Einrichtungsleitungsseite her, der Mitarbeiterschaft z. B. bestimmte Zahlen vorenthalten zu müssen. Außerdem fehlen Erfahrungsräume geistlicher Gemeinschaft. Bei diesen Defiziten blicke ich vorrangig auf die Leitungsebene der Einrichtungen, denn die Ausgestaltung dieser Dimension gehört in erster Linie zu ihren Aufgaben. Es ist eine geistliche Führungsaufgabe, die hier wahrgenommen werden muss. In der Führungshaltung und den Kommunikationsstrukturen, aber auch in den praktischen Vollzügen dienstrechtlicher Vorgänge sind Defizite unübersehbar. Die fehlende Sensibilität in den Verfahren führt zu Skepsis oder - wie angesprochen - zu Misstrauen auf Seiten der Dienstnehmer, was ich verstehen kann. Nur gelegentlich und in wenigen „Vorzeigeeinrichtungen“ gibt es eine echte Teilhabe der Dienstnehmer an Überlegungen zur Entwicklung der Einrichtung und des Dienstes. Die Frage nach der Solidarität in der Dienstgemeinschaft ist also differenziert zu beantworten. Das Bewusstsein für die gemeinsame Gestaltungsaufgabe zu wecken, bedarf der ausdauernden und nachhaltigen Initiative von Dienstgebern und Dienstnehmern.

Nun möchte ich auf den dritten Gedanken und die dritte Frage eingehen:

\section{Welche Chancen einer zukunftsgerechten Personalarbeit gibt es innerhalb des Dritten Weges auch über die arbeitsrechtlichen Fragen hinaus?}

Für Dienstnehmer und Dienstgeber gilt: Aus dem kirchlich-diakonischen Arbeitsrecht erwachsen zwar nicht unmittelbar Lebensführungsverpflichtungen, gleichwohl muss aber deutlich sein, dass sich über die Rechtsbindung hinaus eine persönliche und geistliche Verpflichtung für diejenigen ergibt, die in der Diakonie tätig sind. Die isolierte Bearbeitung von Personalentwicklungsaufgaben als fachliche Professionalisierung wird so nicht fortzuführen sein. Uns stellt sich auch die Aufgabe, Personalentwicklung als Person-Bildung in Gang zu setzen. Menschen haben Fragen nach der inhaltlichen Begründung ihres Tuns und nach der Verankerung ihrer Überzeugungen in ihrer Person und ihrer täglichen Praxis. Dies kann tatsächlich in theologischen Tagungen und Gesprächskreisen zu ethischen Fragen vorangebracht werden. Ich spüre ein Interesse an diesen Fragen. Was die gesamte spirituelle Ausprägung angeht, erlebe ich, wie berührt und erfüllt Menschen sind, wenn wir mit ihnen zu Einkehrtagen eine Woche in einem Kloster sind und tatsächlich eine geistliche Erfahrung erschlossen wird. Oder wenn wir mit unseren leitenden Mitarbeitenden theologische Fragen diskutieren, dann merke ich, wie viel Interesse da ist. Menschen haben Interesse, die Einrichtungen nach den sie leitenden Vorstellungen, nach ihrem christlichen 
Ethos zu gestalten. Dienstgemeinschaft kann als Gestaltungsgemeinschaft gefördert werden. Das geht weit über Leitbildprozesse hinaus. Und damit ist Diakonie tatsächlich in einer Ausgestaltung als Dienstgemeinschaft eine gemeinsame Frageund Suchbewegung, nicht im klassisch belehrenden Sinne, sondern tatsächlich in dem Sinne, dass der eine des anderen Last trägt oder der eine an den Gaben des anderen teilhat. Dienstgemeinschaft als Gestaltungsgemeinschaft fördert die Kulturentwicklung diakonischer Einrichtungen. Hier ergeben sich auch ganz andere Formen von Konfliktlösungen und Führungsstrategien. Ich teile nicht die Skepsis derer, die sagen, dass der Dritte Weg und die Mechanismen nicht auch konfliktfähig und konfliktbereit sind. Es ist doch längst bewiesen, dass uns dies gelingt.

Ich komme zum Schluss: Diakonie ohne gestaltete und gelebte Dienstgemeinschaft in diesen drei Dimensionen verliert sich selbst und wird zu einem blinden Spiegel oder einer tönernen Schelle. Das ist nicht nur ein inhaltliches Argument, sondern Ausdruck der Überzeugung, dass wir in der Diakonie letztlich unsere Selbstgestaltungskraft entweder finden oder uns in der Diakonie verlieren werden. Wir werden dann den Weg antreten, dass wir uns entweder an den Markt verlieren und dort das Heil suchen, oder wir werden uns wie bisher an den Staat klammern, der uns aber nicht mehr „liebt“. Das heißt: Wir müssen unseren eigenen Weg finden. Darum lassen Sie uns nicht weiter vom Weg und vom Ziel abirren, sondern die Prioritäten richtig setzen; denn nach altdeutschem Grundsatz folgen die Rechts-vorschriften den inhaltlichen Bestimmungen. Und deshalb ist Heilung und Besserung nicht oder nicht zuerst auf dem formalen Weg zu erlangen, sondern aus der Rückkehr zu den Inhalten und der Umkehr zu den geistlichen Quellen der Diakonie. 



\section{Klaus Tanner}

\section{„Wem diene ich, wenn ich diene?“. Zum Verhältnis von Individualismus und Dienstgemeinschaft.}

Das Wort „dienen“ ist profillos geworden oder es weckt altertümliche Vorstellungen und Assoziationen. Wer will heute schon noch dienen? Beim Militär wird gedient und im vielgeschmähten Beamtentum gibt es die Dienstverpflichtung, den Diensteid, das Dienstrecht und schließlich spielt der Dienstgedanke auf dem weiten Feld der kirchlichen Arbeit eine Rolle. „Dienen“ klingt nach Gehorsam, Unterwerfung, Knechtschaft, Abhängigkeit. Wer will das noch in einer Zeit, in der Selbständigkeit, Freiheit und Selbstverwirklichung als erstrebenswert gelten?

Das Verständnis von „dienen“ ist in unserem Kulturkreis eng mit dem Christentum verbunden. Ein kurzer Blick auf die Sprachgeschichte zeigt, „Dienst" hat seine Wurzeln im sakralen Bereich. Das deutsche Wörterbuch der Gebrüder Grimm erläutert, Dienst bezeichne „Handlungen und Übungen, die Gebräuche, womit man die Gottheit verehrt, die Verrichtungen der Priester, cultus. “1

\footnotetext{
* Zuerst veröffentlicht in: Die Diakonie Schwester. Neue Folge der Blätter aus dem Evangelischen Diakonieverein Berlin-Zehlendorf e.V. und aus dem Zehlendorfer Verband für Evangelische Diakonie, 94. Jahrgang, Nr. 5, Mai 1998, S. 116-122.

${ }^{1}$ Jacob und Wilhelm Grimm, Deutsches Wörterbuch Bd. II, Leipzig 1860, Sp. 1115.
} 
Wir sind vorsichtig geworden, wenn zu vollmundig vom Dienen geredet wird und das mit gutem Grund. Mit der Aufforderung, sich doch in Dienst nehmen zu lassen, z. B. für Nation und Vaterland, ist in unserem Jahrhundert viel Unheil angerichtet worden. Im Rücken haben wir bei diesem Wort den Ballast eines furchtbaren Missbrauches. Aber der Missbrauch des Dienstgedankens kann und darf nicht all die mit diskreditieren, die mit ihrem Leben dem Guten gedient haben.

\section{Dienst als Schlüsselbegriff kirchlicher Wirklichkeit}

Neben dem umgangsprachlichen und unscharfen Gebrauch gibt es die theologischen und kirchlichen Verwendungskontexte. Im Leitbild des Diakonischen Werkes heißt es: „Wir sind eine Dienstgemeinschaft von Frauen und Männern im Haupt- und Ehrenamt“. „Dienst“ ist ein Schlüsselbegriff aus den evangelischen (wie katholischen) Diskussionen um das angemessene Verständnis kirchlicher Wirklichkeit. Für das evangelische Verständnis weist dieser Begriff über die vierte These der Barmer theologischen Erklärung zurück auf grundsätzliche Aussagen im Neuen Testament über die Regelung des Zusammenlebens unter Christen. ${ }^{2}$ Die Frage nach der konkreten Ausgestaltung dieses Zusammenlebens war und ist bis auf den heutigen Tag konfliktträchtig. Das Konfliktpotential liegt im Sachverhalt selbst, um den es geht, das christliche Leben im Alltag der Welt. An der Christentumsgeschichte lässt sich studieren: Es gibt kein einheitliches Lebens- und Organisationsideal, das sich aus den christlichen Quellen direkt ableiten ließe. Schon in der Frühzeit des Christentums wurden die Leitideale in verschiedene, oft gegensätzliche Lebensformen umgesetzt.

In jedem Verständnis von Christsein und Kirche müssen allerdings auf die eine oder andere Weise zwei Dimensionen berücksichtigt werden: Einerseits die geistlich-geistige Dimension, die Aspekte des idealen, normativen Bildes christlicher und kirchlicher Existenz, wie es sich aus den biblischen Quellen ergibt und die im Verhältnis dazu immer gebrochene Realität dieser Existenz im Alltag des christlichen Lebens. Diese Polarität ist spannungs- und konfliktreich, im individuellen Leben wie in den organisatorischen Abläufen in kirchlichen Einrichtungen. Mit Begriffspaaren wie sichtbare, unsichtbar Kirche, Empirie und Theologie der Kirche, Geist- und Rechtsgestalt der Kirche wurde immer wieder in der Christentumsgeschichte versucht, diese Spannung einzufangen.

\footnotetext{
2 Vgl. die vierte These der Barmer Erklärung: „Ihr wisset, daß die weltlichen Fürsten herrschen, und die Oberherren haben Gewalt, So soll es nicht sein unter euch; sondern so jemand will unter euch gewaltig sein, der sei euer Diener.“ (Mt 20, 25.26.) Die verschiedenen Ämter in der Kirche begründen keine Herrschaft der einen über die anderen, sondern die Ausübung des der ganzen Gemeinde anvertrauten und befohlenen Dienstes."
} 
Auch im Begriff der „Dienstgemeinschaft“ spiegelt sich diese Polarität. Der Spannungsreichtum schimmert durch in den Erläuterungen zum Leitsatz des Leitbildes. Dort heißt es u.a.: „Wir bleiben verpflichtet, theologisch begründet, sozial kompetent, fachlich qualifiziert, ökonomisch verantwortlich und ökologisch orientiert zu handeln“. Wer wüsste nicht, dass die Aufgabe, die hier formulierten Orientierungspunkte in ein ausgewogenes Verhältnis zu bringen, etwa vergleichbar ist mit der Suche nach der Auflösung des Gordischen Knotens. Gleichwohl wird diese Zielformulierung deswegen nicht sinnlos. Sie bezeichnet das Spannungsfeld von geistigen und materiellen Gütern, in dem sich christliches Handeln in diakonischen Einrichtungen vollzieht und diese Güter haben offensichtlich eine unterschiedliche Struktur. Ein geistiges Gut, z.B. eine guter Gedanke, wird nicht durch den Gebrauch verbraucht. Er kann immer wieder neu inspirieren. Ein Euro dagegen kann nur einmal ausgeben werden. Er wird für den, der ihn gebraucht, verbraucht. An dieser Bruchlinie von knappen materiellen Ressourcen und den von sich aus unbegrenzten ideellen Orientierungen bilden sich in der Gegenwart auch in der Diakonie eine Vielzahl schmerzhafter Konflikte. Die Diakonie ist entstanden im Zusammenhang mit der Herausbildung der modernen Industriegesellschaft in Deutschland und dem damit gekoppelten Aufbau neuer sozialer Sicherungssysteme. Wenn das klassische Modell der Industriegesellschaft und des deutschen Sozialstaates bis in die Fundamente hinein verändert wird, wie wir das in der Gegenwart erleben, dann lässt das die rechtliche und ökonomische Verankerung der Diakonie nicht unberührt. Diese Veränderung der Rahmenbedingungen schlägt durch bis auf den Personalschlüssel in diakonischen Einrichtungen.

\section{Hohe normative Ideale der „Dienstgemeinschaft“}

Am Verständnis der „Dienstgemeinschaft" kristallisieren sich die Probleme besonders deshalb, weil er nicht nur ein theologisch gefüllter, sondern zugleich auch ein juristisch relevanter Begriff nach 1945 geworden ist. Er ging ein in die Fundamente des Neubaus des kirchlichen Arbeitsrechts. Der Artikel 140 des Grundgesetzes in Verbindung mit dem Artikel 137 Abs. 3 der Weimarer Reichsverfassung erlaubte den Kirchen eine eigenständige Ausgestaltung des Arbeitsrechts, das unter dem Schlagwort des sog. „Dritten Weges“ bekannt wurde. Dieses kirchliche Arbeitsrecht unter dem Leitgedanken der „Dienstgemeinschaft“ ist mit hohen normativen Idealen durchsetzt, leidet aber unter Realisierungsdefiziten und ist deshalb mit guten Gründen immer wieder auch der Kritik unterzogen worden. ${ }^{3}$ Vor allem in Zeiten knapper werdender Mittel steht es erneut und verschärft auf dem Prüfstand. Auch das Ideal der „Dienstgemeinschaft“ bietet kein automatisch

\footnotetext{
${ }^{3}$ Vgl. dazu die von Heinrich Beyer und Hans G. Nutzinger unter Mitarbeit von Holger Fischer herausgegebene Studie: Erwerbsarbeit und Dienstgemeinschaft. Arbeitsbeziehungen in kirchlichen Einrichtungen. Eine Empirische Untersuchung, Bochum 1991.
} 
funktionierendes Schutzschild gegen Finanzknappheit und daraus resultierende innerkirchliche Verteilungskämpfe. Schnell wird dann das Kind mit dem Bade ausgeschüttet und der Gedanke des Dienstes zur bloßen Augenwischerei erklärt. In dieser Situation der grundsätzlichen Hinterfragung des Dienstgedankens ist es wichtig, sich dessen ursprünglichen Sinn und jene Veränderungen der Rahmenbedingungen zu vergegenwärtigen, die die Akzeptanz dieses Sinnes erschweren.

Die Frage, „wem diene ich, wenn ich diene?", ist nicht leicht zu beantworten. Dienen heißt elementar: Es spielen dort, wo ich mich in Dienst nehmen lasse, mehr als meine eigenen Handlungsziele eine Rolle. Indem ich dieses andere, was über meine Interessen hinausgeht, unterstütze und stärke, befördere ich mit meinem Tun noch etwas, was sich meiner Selbstbestimmung entzieht. Im Dienen lasse ich mich mitbestimmen von jenem größeren Kontext, in den ich mich einordne.

In den Managementphilosophien und Unternehmensstrategien, die so schnell wechseln wie die Mode, wird zur Zeit viel von Humankapital, Human-RessourcesManagement und was es da noch alles an schönen neuen „mitarbeiterorientierten" Strategien gibt, gesprochen. Der alte Dienstgedanke erscheint dabei in gewandelter Gestalt. Die Mitarbeiterinnen und Mitarbeiter sollen die Unternehmensziele zu ihren eigenen machen und nicht nur das Ziel verfolgen, möglichst viel Geld mit möglichst wenig Aufwand zu verdienen. Jeder soll sich mit seinen Fähigkeiten zum Wohl der Entwicklung des Unternehmens engagieren. Die Methoden tendieren dazu, die letzten Reserven der Mitarbeiter zu mobilisieren, die Mitarbeiter innerlich zu vergemeinschaften und an die Unternehmen zu binden. Wenn solche weitreichenden Ansprüche erhoben werden, ist es wichtig, sich genau Rechenschaft darüber zu geben, von wem Mann oder Frau in den Dienst genommen werden soll. Der Dienstgedanke fordert die Klärung von Machtverhältnissen und Interessenlagen. Man soll schon genau hinschauen, wer da zum Dienen auffordert oder motivieren will.

Der Blick in die Geschichte des Christentums zeigt, dass das aufklärende Erörtern von Machtfragen mit dem Begriff des Dienens eng verknüpft ist. Es wurde eingeschärft wie wichtig es ist, zu unterscheiden zwischen dem richtigen und dem falschen Gottes-Dienst. Was ist gefährlich daran, den falschen Mächten zu dienen? In der Bibel wird gewarnt: Wer den falschen Göttern dient, der wird zu Fall geraten $($ Ex 23,33). Wer sich dem Falschen unterordnet, bedroht das eigene Leben. Beim Dienst handelt es sich offenbar um eine riskante Sache. Sie tendiert dazu, ideologisch aufgeladen zu werden und der Einzelne kann seine eigene Existenz dadurch gefährden, dass er sich für das Falsche in Dienst nehmen lässt.

Der Gedanke des Dienens führt in das Zentrum der christlichen Ethik. Es gibt in der Ethik ein Grundproblem, das sich so formulieren lässt: Wie kommen Menschen eigentlich überhaupt in die Lage, ihren Willen so auszurichten, dass sie dabei mehr als ihre eigenen Interessen eine Rolle spielen lassen? Wie gelingt es, offen 
dafür zu werden, mehr als das eigene Wohlergehen in den Blick zu nehmen? Ethik hat es immer mit der Bereitschaft zum Verzicht zu tun, die eigenen Anliegen unmittelbar, ohne Rücksicht auf andere, durchzusetzen. Offenbar muss sich beim Einzelnen ein bestimmtes Selbstverständnis ausbilden, damit er von sich absehen und genauer auf den anderen hinsehen kann. Im Christentum spielt die Überzeugung, dass solch ein Wandel des Selbstverständnisses sinnvoll, erstrebenswert und möglich ist, eine zentrale Rolle.

\section{Christliche Existenz und Dienst als Ausdruck des Dankes}

Das christliche Ethos des Dienens ist die Folge solch eines gewandelten Selbstverständnisses. Christliche Existenz und Dienen werden zu wechselseitig aufeinander verweisenden Begriffen.

Eine der klassischen Aussagen findet sich in einem der Briefe des neuen Testamentes: „Dienet ein jeglicher mit der Gabe, die er empfangen hat“ (1 Petr 4,10). Die Aufforderung an die Christen, das eigene Handeln an den Nächsten zu orientieren, ist mit dem Hinweis verbunden, dass diesem Handlungsvermögen etwas vorausliegt, was nicht als Produkt des eigenen Tuns zu verstehen ist. Jedem Menschen wird zuerst etwas geschenkt, bevor er sich durch eigene Leistung Ansprüche „verdienen“ kann. Mit der Bereitschaft zum Dienst entspricht der Mensch dem grundlegenden Sachverhalt des Lebens, dass wir immer mehr sind, als das, was wir aus uns selbst gemacht haben. Dabei ist der religiöse Bezugsrahmen für dieses Verständnis von Dienst entscheidend. Solcher Dienst ist die Antwort des sich als Geschöpf verstehenden Menschen darauf, dass ihm das Leben geschenkt worden ist. Im Verhältnis zu dieser grundlegenden Beziehung werden alle anderen Dienstverhältnisse zwischen Menschen hinsichtlich ihres Verfügungsanspruches beschränkt. Keiner solchen Beziehung verdanken wir unser Leben im umfassenden Sinn und deshalb gibt es in keiner von ihnen das Recht, totale Unterordnung zu verlangen. In jedem Fall aber gilt: Dienst als Ausdruck des Dankes bleibt rückgekoppelt an das Wissen um Empfangenes. Im Alltag schattet sich von diesem Zusammenhang immer wieder etwas ab. Einer Person, der ich viel verdanke, weiß ich mich mehr verpflichtet als einem Menschen, der in meinem Leben bisher keine Rolle spielte. Dankbarkeit und Bereitschaft zum Dienst sind offenbar rückgebunden an eine gemeinsame Geschichte. Die Geschichte, die Menschen miteinander hatten, beeinflusst ihre Bereitschaft zum Dienst, im Guten, wie im Schlechten. An einer anderen Schlüsselstelle im Neuen Testament heißt es: „Ihr seid zur Freiheit berufen und durch die Liebe dient einer dem anderen“ (Gal 5,13). Dienst ist in dieser Perspektive eine Lebensgestalt der Freiheit. Christlicher Glaube wird ausgelegt als eine spezifische Form von Freiheitsbewusstsein, das sich konkretisiert in der Bereitschaft zum Dienst am Nächsten, denn im Lichte des Glaubens erscheint jedes menschliche Antlitz als ein liebenswertes Geschöpf. Zum theologi- 
schen Nachdenken gehört im Christentum die Reflexion darauf, auf welche Weise ein bestimmtes Selbstverständnis sich in unseren Beziehungen zu den Mitmenschen auswirkt. Martin Luther hat diesen Zusammenhang in seiner reformatorischen Hauptschrift „Von der Freiheit eines Christenmenschen“ in das Zentrum seiner Auslegung des Verständnisses einer vom Glauben geprägten Lebensführung gestellt. Sie beginnt mit der Doppelthese: „Ein Christenmensch ist ein freier Herr über alle Dinge und niemand untertan. Ein Christenmensch ist ein dienstbarer Knecht aller Dinge und jedermann untertan. " 4 Das christliche Leben wird hier in seiner Gesamtheit unter dem Vorzeichen des „Dienens“ begriffen. Für Luther „fließt aus dem Glauben die Liebe zu Gott und aus der Liebe ein freies, williges, fröhliches Leben, dem Nächsten umsonst zu dienen. “5

Was heute alltagssprachlich in einen Gegensatz gebracht wird, Freiheit und Dienst, wird hier eng verknüpft. „Freiheit“ bezeichnet nicht die Möglichkeit zur beliebigen, willkürlichen Bestimmung des Willens, je nach dem, was mir gerade in den Sinn kommt. „Freiheit“ wird vielmehr verstanden als eine moralische Fähigkeit, mehr zu sehen als nur das eigene Interesse. Die Grundfrage, an der das christliche Verständnis menschlicher Existenz ansetzt, lautet, wie kommt der Mensch überhaupt in die Lage, einen freien Blick zu bekommen, der offen ist für die Nöte des Anderen? Solche Freiheit von sich selbst ist alles andere als selbstverständlich. Sie gehört nicht zu jener Ausstattung, die uns von Natur aus mitgegeben ist.

\section{Dienen in Freiheit - für das Gemeinwohl}

Die Geschichte des Dienstethos, wie es in der Gegenwart noch in Gestalt von beamtenrechtlichen Regelungen oder in der Diakonie vorhanden ist, ist geprägt durch Sozialmodelle und Sozialvorstellungen, die es so heute nicht mehr gibt. Eine kleines Beispiel soll die Wandlungen, die hier im Blick sind, etwas veranschaulichen.

In einem kleinen Ort in Oberfranken gibt es eine schöne, alte protestantische Kirche, in der die Kanzel direkt über dem Altar, im Zentrum des Altarraumes, angebracht ist. Auf dem Kanzeldeckel stehen zwei Engel. Jeder von ihnen hält eine Gebotstafel. Gegenüber der Kanzel befindet sich auf der Empore die Fürstenloge. Wenn der Fürst in der Loge saß und auf die Kanzel blickte, wurden ihm immer die zehn Gebote mit vor die Augen gehalten. Er konnte nicht das gepredigte Wort hören, ohne zugleich daran erinnert zu werden, dass er als absolutistische Obrigkeit nicht vollkommen frei war. Mochte der Fürst auch gegenüber dem predigenden Pfarrer das Gefühl haben, der Mächtigere zu sein, so wurde

\footnotetext{
${ }^{4}$ Martin Luther, Von der Freiheit eines Christenmenschen (1520), zitiert nach: Luther Deutsch hg. v. Kurt Aland Bd. 2, Göttingen 1962, S. 251 f.

${ }^{5}$ A.a.O., S. 270.
} 
seine Macht doch zugleich relativiert durch den Hinweis auf die Macht des Gottes, der als Geber der Grundordnung des Zusammenlebens galt. Die Boten Gottes mit den zehn Geboten symbolisierten die Verbindlichkeit eines ethischen Rahmens, dem alle, auch der Fürst, unterstellt waren. In diesen Rahmen war der Dienstgedanke eingeordnet. Leitend war dabei das Bild des Organismus. Es gab festgelegte Aufgaben und Funktionen. Jeder musste an seinem Ort seinen Teil dazu beitragen, damit das gemeinsame Leben funktioniert. Dieses Bild des sozialen Zusammenhanges war in seinen Fundamenten statisch und zugleich waren Teile und Ganzes harmonisch einander zugeordnet. Auch die Obrigkeit war eingebunden in diese vorgegebene Ordnung. Sie hatte sich an sie zu halten und konnte sie nicht nach eigenem Belieben ändern. Jeder war in dieser Sozialordnung partiell frei und zugleich partiell verpflichtet, dienend eingebunden in das Funktionssystem des Ganzen. Freiheitsgrade waren davon abhängig, welcher Herrschaft man dienen musste. Für das Zusammenleben wurde als Leitziel die Förderung des Gemeinwohles formuliert. Mit ihm wurde die Ausweitung der Staatstätigkeit legitimiert. Das bonum commune, die allgemeine Wohlfahrt stellte den Schlüsselbegriff dieser alten Soziallehren dar. Ethisch abqualifiziert wurde der Eigennutz. Gemeinwohl geht vor Eigennutz lautete der ethische Imperativ. ${ }^{6}$ Es gab zu jener Zeit noch keine ausdifferenzierte und rechtlich geschützte Privatsphäre und kaum eine dem Staat gegenüber selbständige Gesellschaft, in der der Eigennutz zu einem wesentlichen Motor gesellschaftlicher Veränderung hätte werden können. Dienstverhältnisse waren in diesem Gemeinwesen langfristige gegenseitige Treueverhältnisse, die nicht einfach aufgelöst werden konnten. Sie waren kaum zeitlich befristet, sondern ermöglichten eine dauerhafte stabile Zuschreibung von Verantwortung. In diesem Kontext bildeten sich die Grundzüge des Dienstethos, das bis heute im Beamtentum ${ }^{7}$ und auch in diakonischen Einrichtungen nachwirkt.

Das kurz skizzierte Sozialmodell gehört der Vergangenheit an. Die zehn Gebote werden heute nicht mehr von allen als die entscheidende ethische Grundlage für das Zusammenleben anerkannt. Wo es keinen Konsens mehr über gemeinsam anzustrebende Ziele gibt, wird es schwer, jemanden zu bitten, sich in den Dienst einer ,gemeinsamen Sache" nehmen zu lassen. Mit Gott als Hintergrundsrechtfertigung für ethische Überzeugungen und als Garanten einer unveränderlichen Sozialordnung, an die sich alle halten müssen, egal ob in Führungs- oder Dienstfunktion, lassen sich bestenfalls noch Festtagsreden halten, im Kampf um Zuschüsse und Pflegesätze dürfte das keine erfolgreiche Argumentationsstrategie mehr sein. Im Prozess der Modernisierung, wie er sich im engen Verbund mit der Industrialisierung durchsetzte, löste sich die harmonische Organismusvorstellung auf. Mit Marktmechanismen wurde auf die verändernde Kraft des Eigennutzes gesetzt.

\footnotetext{
${ }^{6}$ Vgl. Winfried Schulz, Vom Gemeinwohl zum Eigennutz. Über den Normenwandel in der ständischen Gesellschaft der frühen Neuzeit, in: Historische Zeitschrift 243 (1986), S. 591-626.

7 Zu den historischen Wurzeln vgl. Michael Stolleis, Grundzüge der Beamtenethik (1550-1650), in: Ders., Staat und Staatsräson in der frühen Neuzeit, Frankfurt a. M. 1990, S. 197-231.
} 
Die Struktur des Zusammenlebens hat sich dadurch grundlegend geändert. Damit ist aber auch der Rahmen weggebrochen, in dem das traditionelle Dienstethos verortet war. Der Umbau des gesamten Bereichs der Sozialpolitik mit Hilfe des Drucks von Marktmechanismen schlägt durch auf die ethischen Grundlagen sozialen Handelns. Alte Anschauungen können hier nicht einfach bruchlos weitertradiert werden. Indiz für diesen Umbruch sind die zur Zeit allerorten in den Wohlfahrtsverbänden intensiv geführten Leitbilddebatten, ${ }^{8}$ mit deren Hilfe ein adäquates Selbstverständnis profiliert werden soll. ${ }^{9}$

\section{Der Wandel zur befristeten Verbindlichkeit}

Im Zuge der Modernisierung werden soziale Beziehungen verrechtlicht und damit partiell entpersonalisiert. Verrechtlichung bedeutet Rationalisierung und Versachlichung von Beziehungen zwischen Menschen. Hilfe auf der Grundlage von Rechten macht frei von persönlicher Willkür, von Gunst oder Ungunst. Die Rechte des Individuums gegenüber der Gemeinschaft wurden damit gestärkt. Insofern hat diese Modernisierung auch zu einem Zugewinn an individueller Freiheit geführt. Wir alle leben gut mit den positiven Folgen dieser Rationalisierung, Versachlichung und Verrechtlichung. Mit ihnen erfolgte auch eine stärkere Ausdifferenzierung von öffentlichem und privatem Leben. Der Gedanke des Vertragsschlusses wird zum Grundmuster für das Verständnis sozialer Beziehungen. Mit einem Vertrag werden individuelle Nutzenkalküle in ein Verhältnis gesetzt. Es wird nicht mehr direkt Bezug genommen auf die Förderung eines allgemeinen Wohls. Vor allem aber sind Vertragsverhältnisse immer begrenzt, hinsichtlich des Vertragszwecks und der Vertragsdauer. Der Gemeinwohlbegriff wird zwar beibehalten aber in seinem Kern verändert. Niemand, kein Politiker, Philosoph, Jurist oder Theologe kann unter modernen Bedingungen den Inhalt und Umfang des Gemeinwohls präzise definieren. Gemeinwohl ist keine substantielle, vorgegebene Größe mehr, sondern das Ergebnis von nicht abschließbaren, konfliktreichen Prozessen der Abstimmung von Interessen unter Zuhilfenahme von Verträglichkeitskriterien. ${ }^{10}$ Als entscheidende Antriebkraft in sozialen Prozessen wird nun auch in der ökonomischen Theorie der Eigennutz anerkannt. Ein Klassiker der marktwirtschaftlichen Steuerung wie Adam Smith verabschiedete keineswegs den

\footnotetext{
8 Vgl. Michael Ebertz, „Leitbildnerei” in sozialen Dienstleistungsorganisationen. Über den Zwang zur Selbstthematisierung von organisierter Diakonie und Caritas, in: Rainer Öhlschläger u. HansMartin Brüll (Hg.), Unternehmen Barmherzigkeit: Identität und Wandel sozialer Dienstleistungen. Baden-Baden 1996, S. 39-51.

${ }_{9}$ Über das Spannungsfeld, in dem sich sich dieses Selbstverständnis bildet vgl. Thomas Rauschenbach, Christoph Sachße, Thomas Olk (Hg.), Von der Wertgemeinschaft zum Dienstleistungsunternehmen. Jugend- und Wohlfahrtsverbände im Umbruch, Frankfurt a. M. 1995.

10 Die Denkschrift der Evangelischen Kirche „Gemeinwohl und Eigennutz”, (Gütersloh 1991) versuchte die Präzisierung mittels der drei Verträglichkeitskriterien: Sozialverträglichkeit, internationale Verträglichkeit, ökologische Verträglichkeit (a.a.O. Ziffer 151 ff.).
} 
Glauben an die Harmonie, der im alten Organismusmodell eine zentrale Rolle gespielt hatte. Er kehrte in gewandelter Gestalt wieder im Vertrauen auf die „unsichtbare Hand". Sie sollte garantieren, dass die Einzelinteressen letztlich doch zum Wohl des Ganzen zusammenwirken müssen. Da sich dieser Optimismus als Trugschluss erwies - offensichtlich lässt sich die Gestaltaufgabe, die mit der menschlichen Freiheit verbunden ist, nicht an anonyme Kräfte delegieren - wurde bald wieder versucht, mit staatlicher Rahmengesetzgebung einen sozialverträglichen Ausgleich zu stimulieren. Aufgelöst wurde in diesen Modellen aber die Statik und Beständigkeit der alten Ordnungsvorstellungen. An ihre Stelle trat eine Dynamik, in der Konflikte zum Motor permanenter Veränderung gemacht wurden. Im neuen, am Paradigma des Marktes ausgerichteten Sozialmodell ist nicht mehr die alles tragende Harmonie und Wohlgeordnetheit das Erste, sondern die Konflikthaftigkeit von sozialen Prozessen rückt sehr vielmehr in den Vordergrund. Wenn das anerkannt wird, dann sollte auch der christliche Glaube in den Einrichtungen nicht dazu benutzt werden, die faktischen Interessengegensätze und Konflikte unter Harmoniedruck zu setzen und die Individuen auf einen kaum noch greifbaren und nicht mehr garantierbaren, übergeordneten Gesamtzweck zu verpflichten.

Die langfristige Zuschreibung von Verantwortung ist bei diesem Konzept nur noch schwer möglich. Das gehört zur Kehrseite dieser effizienzsteigernden Dynamisierung. Auf den Märkten wird gewonnen und verloren, Anbieter tauchen auf, werden verdrängt, geraten unter Konkurrenzdruck und verschwinden wieder. In diesem Marktmodell kann es keine unbegrenzten gegenseitigen Verpflichtungen mehr geben. Aus unbefristeten werden befristete Verbindlichkeiten. Die für das alte Sozialmodell konstitutive langfristige Zuschreibung von Verantwortung, die die in einem Dienstverhältnis einander Zugeordneten in vielerlei Dimensionen ihres Lebens aneinander band, löst sich auf. Ein Unternehmen, das vom Markt verschwindet, kann seinen MitarbeiterInnen nichts mehr garantieren. Eine $\mathrm{GmbH}$ ist eben eine Gesellschaft mit beschränkter Haftung. Wenn sie nicht mehr existiert, macht es wenig Sinn, ihr gegenüber noch Ansprüche zu formulieren. Mit innerer Notwendigkeit korrespondiert dieser Logik der Begrenzung von Verbindlichkeiten auf Unternehmensseite auf der Arbeitnehmerseite eine Begrenzung der Bereitschaft, sich voll und ganz in den Dienst nehmen zu lassen. Auch die Umstellung sozialer Integrations- und Steuerungsmechanismen hat ihren Preis; die Substanz der innerbetrieblichen sozialen Beziehungen und der auf den Märkten Agierenden wird dadurch gleichsam verschlankt. Die Begrenzung von Dienst- und Treueverhältnissen ist ein Merkmal moderner, marktförmig organisierter Sozialbeziehungen. Wer Vermarktung im sozialen Bereich will, muss die kalkulatorische Logik solcher Anspruchsbegrenzung akzeptieren. Er kann legitimerweise nicht von Mitarbeitern verlangen, dass sie sich mit ihrer ganzen Person in den Dienst des Unternehmens stellen. Auch in der Diakonie sollten Mitarbeiterinnen und Mitarbeiter nicht mit dem Hinweis auf den christlichen Dienstgedanken unter Verpflichtungs- 
und Vergemeinschaftungsdruck gesetzt werden. Wo Geld und Recht die Arbeitsbeziehungen regeln, sie versachlicht und rationalisiert sind, ist es problematisch, wenn versucht wird, diese Mechanismen auf Kosten der Mitarbeiter partiell dadurch wieder auszuhebeln, dass noch eine zweite Ebene moralischer Verpflichtung eingezogen wird, von der aus im Konfliktfall Mitarbeiter unter Druck gesetzt werden können. Die Flexibilisierung und Durchökonomisierung der Arbeitswelt minimiert für alle Beteiligten die langfristige Verlässlichkeit. Betriebsbedingte Kündigungen sind möglich. Man sollte im Gegenzug als Kompensation von den Mitarbeitern nicht mehr verlangen, als das, was im Rahmen von zweckrationalen Regelungen eines Unternehmens sinnvoll ist.

\section{Bereitschaft zum Dienst als Gestaltung von Freiheit}

Ist vor dem Hintergrund des skizzierten Wandels das alte Dienstethos vollkommen obsolet geworden? Gibt es einen bleibend wichtigen Kern des Dienstgedankens? In den letzten Jahren hat es eine intensive sozialphilosophische, weit in die Sozialarbeit hineinstrahlende Diskussion gegeben, die unter dem Stichwort des „Kommunitarismus“ geführt wurde. ${ }^{11}$ Einen Aspekt dieser facettenreichen Debatte möchte ich kurz hervorheben. In ihr wurde betont, unhistorische, von allen kulturellen Kontexten abstrahierende ökonomische Modelle, die nur mit individuellen Nutzenkalkülen operieren, seien zu einfach, um unsere faktische soziale Welt zu beschreiben. Nicht alles im Leben lässt sich marktförmig organisieren und monetär kalkulieren. Kein Mensch ist nur Vertragspartner und jeder ist mehr als ein nutzenkalkulierendes Wesen, wie das in bestimmten rational-choice-Theorien der Ökonomen unterstellt wird. Der aus Traditionen sich speisende Gemeinsinn bleibt eine wichtige Ressource für das Zusammenleben der Menschen. Die Vorstellung von einem emotionslosen Individuum, das jenseits aller sozialen und historischen Kontexte existiert, wurde als eine theoretische Fiktion kritisiert, ohne jedoch mit dieser Kritik die positiven Seiten der modernen Individualisierung pauschal herabzuwürdigen. Ohne das, was einst Dienst hieß, die Bereitschaft, sich vom Leben anderer anrühren und in Pflicht nehmen zu lassen, kann offenbar keine Gesellschaft existieren. Individualisierung muss nicht automatisch zur Entsolidarisierung und nachträglichen, künstlichen Konstruktion von Formen des gemeinsamen Lebens führen. Vielmehr bilden sich offenbar auch unter modernen, rationalisierten Bedingungen neue, solidarische Formen des Zusammenlebens. Anschließend an Ulrich Beck hat Bischof Kamphaus von einem „solidarischen Individualismus" gesprochen, den es in unserer Gesellschaft auch gebe. „Solidarischer Individualismus“ heißt, ich zitiere den Limburger Bischof: „Immer

\footnotetext{
11 Vgl. Axel Honneth (Hg.), Kommunitarismus. Eine Debatte über die moralischen Grundlagen moderner Gesellschaften, Frankfurt a. M. 1993; Christel Zahlmann (Hg.), Kommunitarismus in der Diskussion. Eine streitbare Einführung, Berlin 1994; Kommunitarismus und praktische Politik. Forschungsjournal Neue soziale Bewegungen Jg. 8 (1995), Heft 2.
} 
mehr Menschen in unserer Gesellschaft sehen Moral als Teil ihres persönlichen Lebensentwurfes, weniger als Beachtung eines Pflichtenkataloges. Daher verbinden sie mit moralischem Handeln das Gefühl persönlicher Befriedigung. "12 Solcher solidarische Individualismus fordert kein Zurück hinter die Rationalisierung, Versachlichung und Individualisierung eines Teils unserer Sozialbeziehungen. Aber er macht Ernst damit, dass Freiheit mehr ist als die Möglichkeit zur willkürlichen Selbstbestimmung. Die Würde freier Wesen liegt vielmehr darin, dass sie fähig sind, aus eigener Einsicht sich selbst zu verpflichten, das Antlitz des anderen $\mathrm{zu}$ achten und ihr Wohlergehen zum eigenen Anliegen zu machen. Dienst bezeichnet in dieser Perspektive alles andere als blinden Gehorsam oder schwächliche Einordnung in vorgegebene Machtverhältnisse. Im Gegenteil, diese Haltung ist ein Ausdruck innerer Stärke. Solche Bereitschaft zum Dienst ist eine Lebensgestalt von Freiheit. Die Freiheit und Kraft zum Perspektivenwechsel in der Wahrnehmung der eigenen und der fremden Lebensgeschichte wurde in unserer christlichen Tradition als eine Folge des Glaubens beschrieben. Die Freiheit, sich so als Dienenden zu verstehen setzt voraus, dass der Mensch frei ist von der Sorge um sich selbst. In unserer christlichen Tradition wurde an dieser Stelle von der Tugend der Gelassenheit gesprochen. Solche innere Ruhe als Quelle von Tatkraft bedarf des Vertrauens darauf, dass ich mich nicht verliere in den sozialen Prozessen, in die ich mich hineinbegebe. Wenn ich Angst habe, dass ich kaputt gehe, wenn ich mich in die Lebensgeschichten anderer verwickeln lasse oder ihr Leiden $\mathrm{zu}$ nahe an mich heranlasse, dann kann ich ihnen nicht frei begegnen. Insofern bedarf gerade alle Arbeit, die sich intensiv auf Menschen, ihre Lebensgeschichten, ihre Leiden und ihre Freuden einlässt, mehr als nur eines stabilen rechtlichen und finanziellen Rahmens. Sie bedarf einer inneren Einstellung, die einst mit dem Wort „Dienst“ umschrieben wurde.

Ich will abschließend in fünf Punkten meine Überlegungen zusammenfassen.

1. Wer zum Dienst motivieren will, muss Machtstrukturen und eigene Interessen offen legen. Nur so lässt sich der berechtigten Angst vor Missbrauch und Instrumentalisierung der individuellen Bereitschaft begegnen.

2. Wer zum Dienst motivieren will, muss einen Konsens herstellen über Ziele, die von möglichst vielen als anzustrebende anerkannt werden.

3. Dienstbereitschaft lässt sich nicht von außen fordern oder erzwingen. Das ist eine Einsicht, die wir gerade aus unserer christlichen Tradition mitbringen. Die innere Einstellung, die Gesinnung, der Geist, aus dem heraus einer handelt, lässt sich auch nicht mit Mitteln des Rechts erzwingen. Sie kann nur freiwillig, aus eigener individueller Zustimmung heraus entstehen. Dienst kann nur freiwillige Selbstbindung sein und ist nicht rechtlich einzuklagen.

${ }^{12}$ Franz Kamphaus, Kinder der Freiheit sind wir alle, Süddeutsche Zeitung vom 26. Nov. 1996, S. 8. 
4. Dienstbereitschaft entsteht nur dort, wo es ein Gefühl des Vertrauens und der Stärke in das eigene Vermögen gibt. Aus Angst, sich zu verlieren wird keine Dienstbereitschaft entstehen. Innere Freiheit von der Sorge um das eigene Wohlergehen ist eine wichtige Bedingung dafür, dass die Wahrnehmung sich erweitern und öffnen kann für die Belange der anderen.

5. Dienstbereitschaft bezeichnet eine Haltung der Offenheit und Kreativität, die befähigt, nicht starr zu handeln nach Regeln, sondern situationsgerecht zu handeln. Nach christlichem Verständnis ist der Glaube eine Kraft, die es ermöglicht, jenseits starrer Formen sensibel auf das zu reagieren, was vor Augen liegt. 


\author{
Günther Schanz
}

\title{
Unternehmen als Wertegemeinschaften
}

In betriebswirtschaftlicher Perspektive sind Unternehmen zuallererst soziotechnische Gebilde bzw. Systeme, errichtet und betrieben zum Zweck der Gewinnerzielung. Es wird also, verkürzt ausgedrückt, auf ein organisiertes „Zusammen-

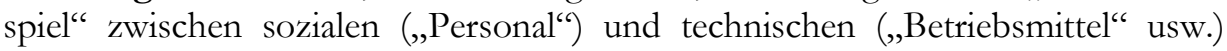
Faktoren abgestellt. Was das Ziel bzw. den Zweck dieses Zusammenspiels anbelangt, so muss die Praxis hier zwangsläufig ohne die Vorstellung von Gewinnmaximierung auskommen und sich stattdessen von der Vorstellung einer angemessenen Verzinsung des eingesetzten Kapitals leiten lassen. Neben dem Gewinnstreben können auch das Streben nach Umsatz oder nach einem möglichst hohen Marktanteil Bedeutung erlangen. Dem Liquiditätsstreben schließlich ist der Charakter einer Nebenbedingung zuzuschreiben.

\footnotetext{
* Vortrag auf dem Symposion in Kästorf (30. September 2005) „Diakonie im Ausverkauf? Der Dritte Weg auf dem Prüfstand“.
} 


\section{Die Idee der Wertegemeinschaft}

Diese Vorbemerkungen sind erforderlich, um die Interpretation vom Unternehmen als einer Wertegemeinschaft angemessen einzuordnen: Sie ist selbstverständlich keine globale Alternative zur eingangs skizzierten Vorstellung, sondern lenkt den Blick auf eine zusätzliche, bis vor relativ kurzer Zeit wenig beachtete Facette des Unternehmens(geschehens) - von der man nach Lage der Dinge allerdings annehmen muss, dass ihre konkrete Ausprägung die Wettbewerbs- und Erfolgsposition des sozio-technischen Gebildes nachhaltig zu beeinflussen vermag. Gemeint ist die „Kultur“ dieses Gebildes bzw. kurz: die Unternehmenskultur. Dabei ist, wie sich zeigen wird, das Konzept der Unternehmenskultur mit der Vorstellung vom Unternehmen als einer Wertegemeinschaft auf das Engste verbunden: Wertegemeinschaften sind Kulturgemeinschaften.

Zumindest implizit war man sich der Gegenwärtigkeit eines „kulturellen Faktors“ vermutlich schon lange bewusst; dies vor allem in der Unternehmenspraxis. Indiz dafür ist beispielsweise die (heute etwas altertümlich anmutende) Rede vom „Stil des Hauses“, die darauf zweifellos abzielt. In den Focus des Interesses gelangte dieser Faktor allerdings erst seit Beginn der 1980er Jahre. Bis dahin hätte, wie ein Beobachter sich ausdrückt, ,in der Wirtschaftspraxis jedermann einen scharfen Trennstrich zum kulturellen Bereich gezogen. ,Kultur ${ }^{\star}$ wurde mit Kunst, Spiel und Unterhaltung, mit Freizeit und Emotion assoziiert, deutlich unbelastet von den ,Zwängen des Erwerbslebens', wie sie im Betrieb herrschen, wo Sachkenntnis, Leistung und Ratio gefordert sind. Zwar wusste man, dass auch mit ,Kultur Geschäfte gemacht werden können, aber das Geschäft selbst hat nicht und ist nicht Kultur."

Damals wurde auch erstmals nicht nur beiläufig und zufällig, sondern gezielt und systematisch von einer Corporate Culture gesprochen und auf die zentrale Bedeutung von Werten aufmerksam gemacht, die offensichtlich markante Kristallisationspunkte der Unternehmenskultur darstellen: „Unternehmen, die ihre Eigenständigkeit entwickeln, indem sie Werte formen, Helden machen, Riten und Rituale schriftlich fixieren und das kulturelle Netzwerk anerkennen, sind im Vorteil. Diese Unternehmen haben Werte und Grundsätze zu bieten - nicht nur Produkte. Sie können mit Geschichten aufwarten - nicht nur Gewinne machen... Kurz, diese Unternehmen sind menschliche Institutionen, die ihren Beschäftigten während der Arbeit und noch darüber hinaus einen Sinn ihres Tuns vermitteln." ${ }^{2}$ Entnommen ist diese Passage einer 1982 erschienenen, 1987 ins Deutsche übersetzten Publikation. Von ihr sollten - Sprachstil und Wortwahl zeigen dies

\footnotetext{
${ }^{1}$ E. Dülfer, Organisationskultur. Phänomen - Philosophie - Technologie. Eine Einführung in die Diskussion, in: ders. (Hrsg.), Organisationskultur. Phänomen - Philosophie - Technologie, Stuttgart 1988, S. 1-20, hier S. 2.

2 T.E. Deal/A.A. Kennedy, Unternehmenserfolg durch Unternehmenskultur, Bonn 1987, S. 80.
} 
überdeutlich - vor allem Praktiker bzw. Manager angesprochen werden. Ferner wird der Eindruck vermittelt, dass es sich bei dem kulturellen Geflecht offensichtlich um alles andere als um einen spröden Gegenstand handelt: Nicht von Strukturen oder Bilanzen ist die Rede, sondern von Helden und Ritualen...

Der englische Untertitel des Buches von Deal/Kennedy - Rites and Rituals of Corporate Life - ist neutral formuliert. Der deutsche Übersetzer war da deutlich draufgängerischer und titelte mutig: Unternehmenserfolg durch Unternehmenskultur! Ob er damit wohl bedacht hat, dass dies für die meisten Leser wohl keine neutrale Formulierung ist?3

Wie kam man überhaupt in den frühen 1980er Jahren auf die Idee, dass der Unternehmenserfolg nicht nur klug gewählten Strategien und den stützenden organisatorischen Regelungen sowie ausgeklügelten Leistungsanreizen, sondern auch der Unternehmenskultur zu danken ist? Genuin „akademisches“ Interesse war es jedenfalls nicht, das den Blick in diese Richtung lenkte. Entdeckung und Aufstieg des Kulturkonzepts sind vielmehr maßgeblich dem Tatbestand zuzuschreiben, dass seinerzeit viele US-amerikanische und wenig später auch westeuropäische Unternehmen angesichts der so genannten japanischen Herausforderung zunehmend in wirtschaftliche Bedrängnis gerieten. ${ }^{4}$ Die nicht lange auf sich warten lassende Ursachenanalyse förderte $\mathrm{zu}$ Tage, dass die ökonomische Potenz japanischer Unternehmen maßgeblich auf gewisse Wertemuster zurückzuführen ist, die den Kern einer (japantypischen) Managementphilosophie bilden und „zu einer spirituellen Struktur von hoher Effizienz führen."

Genauer besehen ist dies kein Hinweis auf spezifische unternehmenskulturelle, sondern auf landeskulturelle Eigenheiten, eine Art „Makrobetrachtung des Kultureinflusses" " also. Aber es lag natürlich nahe, den Gedanken auch auf das einzelne Unternehmen zu übertragen. Deal/Kennedy haben diesen Schritt vollzogen, aber auch die Unternehmensberater Thomas J. Peters und Robert H. Waterman. Letztere begaben sich auf die „Suche nach Spitzenleistungen“ und fanden dabei heraus, was man ,,von den besten US-Unternehmen lernen kann“.7 Das Ergebnis ihrer Suche soll hier in der gebotenen Kürze mitgeteilt werden: Es kommt nicht nur auf die organisationale Hardware in Form von Strategien,

\footnotetext{
${ }^{3}$ Anmerkung: „Erfolg“ kann, fachterminologisch korrekt, sowohl „Gewinn“ als auch „Verlust“ sein.

${ }^{4}$ G. Schanz, Organisationsgestaltung. Management von Arbeitsteilung und Koordination, 2. Aufl, München 1994, S. 275.

5 R.T. Pascale/A.G. Athos, Geheimnis und Kunst des japanischen Managements, München 1982 (im Original: The Art of Japanese Management. Applications for American Executives, New York 1981), S. 57.

${ }^{6}$ Dülfer 1988, S. 7.

7 Die gewählte Formulierung ist ein etwas spielerischer Umgang mit Titel und Untertitel von T.J. Peters; R.H. Waterman, Auf der Suche nach Spitzenleistungen. Was man von den bestgeführten USUnternehmen lernen kann, Landsberg a.L. 1984 (im Original: In Search of Excellence. Lessons from America"s Best-Run Companies, New York 1982).
} 
Strukturen und Systemen an, sondern auch auf den ,richtigen“ Umgang mit Softwarefaktoren. Obwohl nicht ausdrücklich so bezeichnet, sondern mit Begriffen wie „Stil“, „Spezialkenntnisse“, „Stammpersonal“ und „Selbstverständnis“ zum Ausdruck gebracht, steckt darin auch die Vorstellung von einer spezifischen Unternehmenskultur.

Zum unaufhaltsamen Aufstieg des Kulturthemas trug noch etwas Weiteres bei, vermutlich sogar maßgeblich: Es handelt sich um ein ausgesprochen ideales Beratungsprodukt, bietet es doch Problemlösungen, „die allgemein genug sind, um vielseitig absetzbar zu sein, und in der Handhabung problematisch genug, um die Hinzuziehung eines Berater-Experten unabdingbar erscheinen zu lassen."

\section{Charakterisierung des Wertegefüges}

Als Zwischenfazit lässt sich an dieser Stelle feststellen, dass die Interpretation von Unternehmen als Wertegemeinschaften auf dem Konzept der Unternehmenskultur aufbaut bzw. in dieses eingebettet ist. Statt von „Unternehmenskultur“ kann dabei auch von „Organisationskultur“ gesprochen werden; ein Begriff, der neben Krankenhäusern, Gefängnissen, Schulen oder Universitäten auch Diakonische Werke einbezieht.

Im Folgenden ist der Frage nachzugehen, was man sich unter den die Gemeinschaft konstituierenden Werten vorzustellen hat und auf welche Weise diese wirksam zu werden pflegen. Ausgangspunkt muss abermals das Kulturkonzept sein. Zugrunde zu legen ist dabei das Begriffsverständnis der Anthropologie, wo „Kultur“ - hier zunächst ohne jeden Bezug zu irgendwelchen Institutionen - für materielle, geistig-moralische und auch künstlerische Werte steht, die das Denken und Handeln einer Gruppe bzw. einer Kategorie von Menschen prägen. Kultur ist, weil individuelle Unterschiede unberücksichtigt bleiben, folglich ein kollektives Phänomen. ${ }^{9} \mathrm{Zu}$ beobachten und damit auch dem wissenschaftlichen Zugriff sich öffnend ist es deshalb, weil Kultur über Werte und Einstellungen verhaltenswirksam wird. Werte sind dabei eher globale Orientierungsmuster, Einstellungen hingegen haben - so sehen dies Sozialpsychologen - stets einen konkreten Objektbezug.

Ein wichtiger Beitrag zum Verständnis des Phänomens „Unternehmenskultur“ ist dem Organisationspsychologen Edgar H. Schein zu verdanken. Gemäß des von

\footnotetext{
8 M. Ebers, Der Aufstieg des Themas „Organisationskultur“ in problem- und disziplingeschichtlicher Perspektive, in: E. Dülfer (Hrsg.), Organisationskultur. Phänomen - Philosophie Technologie, Stuttgart 1988, S. 23-47, hier S. 31.

9 Vgl. etwa G. Hofstede, Stichwort „Kultur und Organisation“, in: E. Grochla (Hrsg.), Handwörterbuch der Organisation, 2. Aufl., Stuttgart 1980, Sp. 1168-1182., hier Sp. 1169.
} 
ihm entwickelten Modells lassen sich hier drei Kulturebenen unterscheiden: ${ }^{10}$ Artefakte (sowie Kreationen), Werte und Grundannahmen.

Artefakte - die Bezeichnung lässt es erahnen - sind die sichtbaren, für außerhalb der Kulturgemeinschaft stehende allerdings nicht ohne weiteres dechiffrierbaren Ausprägungen der Unternehmenskultur, gewissermaßen deren Oberfläche also. Die schon beiläufig erwähnten Riten und Rituale zählen dazu, ferner spezifische Sprachregelungen und Umgangsformen, Symbole und Mythen usw., und es steht außer Frage, dass sich derartiges unschwer auch auf diakonische Werke beziehen lässt.

Dasselbe ist von der zweiten Kulturebene, den Werten (bzw. Wertvorstellungen), anzunehmen. Bei ihnen handelt es sich um teils sichtbare, teils aber auch unbewusst dem Verhalten und Handeln zugrunde liegende Kulturmerkmale. Sie bestimmen beispielsweise darüber, wie die Unternehmensrealität wahrgenommen und welchen Prioritäten gefolgt wird, beziehen sich auf das Verständnis von Richtig oder Falsch oder fungieren als moralische Anker.

Die dritte Kulturebene schließlich bilden Grundannahmen. Obwohl von der Ebene der Werte kaum überschneidungsfrei abzugrenzen, stellen sie die kulturelle Kernsubstanz bzw. eine Art „Weltanschauung“ dar. Sie werden als Selbstverständlichkeiten angenommen, sind unsichtbar und fungieren als unbewusst wirksame Verhaltensrichtschnur. „Grundannahmen fallen ... in den Bereich des Nichtverhandelbaren" "11 - basta!

Dass zwischen den beiden zuletzt genannten Ebenen eine enge Beziehung besteht, geht schon daraus hervor, dass Werte zu Grundannahmen werden können, etwa deshalb, weil sie sich nachhaltig bewährt haben. Ferner ist anzumerken, dass sich die Rede von einer Wertegemeinschaft selbstverständlich auch auf die Ebene der Grundannahmen bezieht. Schließlich geht es hier um so fundamental bedeutsame Dinge wie Vorstellungen über die Natur des Menschen, den Charakter zwischenmenschlicher Beziehungen, das Wahrheitsverständnis oder die Interpretation der Umwelt (... als bedrohlich, herausfordernd, übermächtig, bezwingbar usw). ${ }^{12}$

Die Kenntnis der Struktur der Grundannahmen leistet nicht nur Hilfe bei der Entschlüsselung von Artefakten und des Wertegefüges im engeren Sinn, sondern auch bei Versuchen, auf die Unternehmens- bzw. Organisationskultur gestaltend Einfluss zu nehmen. Wie noch aufzuzeigen sein wird, erweist sich dies gelegentlich nicht nur ökonomisch motivierter Überlegungen wegen als erforderlich, sondern ist auch ethischer Gründe wegen geradezu geboten.

\footnotetext{
${ }^{10}$ E.H. Schein, Organizational Culture and Leadership, 2. Aufl., San Francisco-Washington-London 1985, S. 13 ff.

11 W. Neubauer, Organisationskultur, Stuttgart 2003, S. 64.

12 Vgl. hierzu ausführlich Schanz 1994 (Anm. 4), S. 283 f.
} 


\section{Koordinationsfunktion des Wertegefüges}

Als weiteres Zwischenfazit lässt sich festhalten, dass das Unternehmensgeschehen durch das aus Artefakten, Werten im engeren Sinn und Grundannahmen bestehende kulturelle Netz in bestimmter Weise gesteuert wird. Im Folgenden ist zu zeigen, dass und weshalb diese Steuerung mehr oder weniger unbemerkt bzw. automatisch stattfindet. Dabei kann eine Metapher hilfreich sein: Dieses Netz fungiert über weite Strecken als Autopilot, wie er etwa in Flugzeugen zum Einsatz kommt, um diese ,auf Kurs“ zu halten. Im Fall des Wertegefüges besteht dieses „auf Kurs halten“ darin, dass den Mitarbeitern im Prinzip klar ist, was von ihnen erwartet - oder auch nicht erwartet - wird. Wenn sich dieses Wissen auf ihr Verhalten durchschlägt, dann äußert sich das, abstrakt ausgedrückt, in einer Reduktion der Verhaltensvarianz. Dies wiederum läuft auf Verhaltensstandardisierung hinaus und lässt sich so interpretieren, dass Werten (bzw. dem gesamten kulturellen Netzwerk) eine Koordinationsfunktion zukommt.

Nun ist die Unternehmenskultur beileibe nicht der einzige Koordinationsmechanismus, durch den das Unternehmensgeschehen „zusammengehalten“ wird. Von grundsätzlicher Bedeutung ist hier die von Vorgesetzten ausgeübte hierarchische Koordination, ferner Koordination in Form von direkter wechselseitiger Abstimmung zwischen den an einer Problemlösung beteiligten Personen (auch: Selbstkoordination). Hier wie dort ist aber davon auszugehen, dass geteilte kulturelle Werte sowohl die hierarchische Koordination als auch die Selbstkoordination erleichtern. ${ }^{13}$

\section{Kulturtypen im tiefenpsychologischen Raster}

Wenn von Kultur und den sie tragenden Werten die Rede ist, dann ist die Wahrscheinlichkeit ziemlich groß, dass dabei an etwas Erhabenes gedacht wird. Der gesamten Thematik scheint zudem etwas Normatives anzuhaften. Von derartigen Sentimentalitäten sollte man allerdings möglichst schnell Abschied nehmen und stattdessen ganz realwissenschaftlich-nüchtern an die Sache herangehen: Jedes Unternehmen hat eine spezifische Kultur und damit auch eine spezifische Werteordnung. Diese Kultur kann eher schwach oder recht stark ausgeprägt sein; sie mag uns ziemlich fragwürdig oder im positiven Sinn beeindruckend, wenig zeitgemäß oder ausgesprochen modern erscheinen. Wie auch immer: Man tut gut daran, zumindest auf dieser Ebene mit der Kultur- bzw. Werteproblematik neutral umzugehen.

\footnotetext{
13 Anzumerken ist ferner noch, dass Standardisierung nicht nur über geteilte Werte erfolgt, sondern auch in Form von Arbeitsprozessen, von Arbeitsergebnissen und in Gestalt von Fähigkeiten bzw. Kenntnissen. In allen diesen Fällen kann, ohne dass dies hier erläuterungsbedürftig ist, von „Vorwegkoordination“" gesprochen werden.
} 
Eine solche Perspektive macht sensibel für Kulturtypen, die man ganz bewusst mittels einer tiefenpsychologischen Terminologie charakterisiert hat und deren Fragwürdigkeiten geradezu ins Auge stechen: ${ }^{14}$

- So ist etwa die paranoide Kultur gekennzeichnet durch eine Atmosphäre des Misstrauens und der Angst; durch die permanente Bereitschaft, „Angriffe“ zurückzuschlagen; durch eine hohe Sensitivität für „Bedrohungen" jedweder Art; durch die ständige Suche nach versteckten Absichten anderer.

- Eine zwanghafte Kultur zeigt sich in übertriebenem Perfektionismus und Detailbesessenheit; in permanenter Angst vor dem Chaos; im möglichst emotionslosen Umgang untereinander u.v.m.

- Im Zentrum der dramatischen Kultur wiederum steht der sich selbst grandios in Szene setzende „Führer“, dessen charismatische Ausstrahlung deshalb fragwürdig erscheint, weil seine Mitarbeiter von ihm in starke Abhängigkeit geraten.

- Indizien für eine depressive Kultur sind eine pessimistische Zukunftsperspektive und Angst vor persönlichem Versagen; ein von Routinen bestimmtes Verhalten oder ein hohes Maß an empfundener Schutzbedürftigkeit.

- $\mathrm{Zu}$ nennen ist schließlich die schizoide Kultur, charakterisiert durch eine hohe Distanz der Unternehmensspitze und durch Konkurrenzkämpfe, Koalitionsbildung sowie taktische Spielchen auf den darunter liegenden Hierarchieebenen. Energieverschleiß durch interne Machtkämpfe, sprunghaftes Entscheidungsverhalten oder das Fehlen einer konsistenten Gesamtstrategie sind die fast logische Folge.

Das Nachdenken darüber, ob hier realistische Beschreibungen vorliegen, kann dem Leser überlassen bleiben...

\section{„Marktrealitäten“ als kulturbestimmende Faktoren}

Die Empfehlung, mit dem Kulturthema unsentimental umzugehen, gewinnt an Gewicht, wenn eine ganz anders geartete Typologie betrachtet wird. Sie ist der schon erwähnten Studie von Deal/Kennedy entnommen, wo zwischen einer

- Macho-Kultur der harten Männer,

- einer Harte Arbeit-viel Spaß-Kultur,

- einer Risiko-Kultur und

- einer Verfahrens-Kultur

unterschieden wird. ${ }^{15}$

${ }^{14}$ M.F.R. Kets de Vries/D. Miller, Personality, Culture, and Organization, in: Academy of Management Review (1986), Heft 11, S. 266-279. 
Wie anders sollte man es werten: Mit „Kultur“ wird zuweilen recht „hemdsärmelig“ umgegangen. Die zur Charakterisierung gewählten Begrifflichkeiten sollten allerdings nicht der Erkenntnis im Wege stehen, dass so (oder ähnlich) zu differenzieren Sinn macht und insofern auch nicht unseriös ist. Als kulturkonstituierende Faktoren fungieren hier Marktrealitäten - einerseits das mit dem Geschäft verbundene Risiko, andererseits die Schnelligkeit des Feedbacks auf Strategien und Entscheidungen. Und in der Tat: Es macht schon sehr viel aus, ob man im Baugewerbe oder als Autohändler tätig ist, Investitionsgüter herstellt oder Medikamente entwickelt. Die prägende Kraft derartiger Realitäten äußert sich darin, dass sie die Vorlieben, den Stil und die Gewohnheiten der Unternehmensmitglieder nachhaltig beeinflussen. Deal/Kennedy legen dies durchweg auf amüsante Weise dar. So etwa sind die „Helden“ der „Harte Arbeit-viel SpaßKultur“" „die Superverkäufer, die Charmeure, die ein Iglu ebenso leicht einem Eskimo wie einem Sonnenanbeter verkaufen könnten... Die Besten in dieser Kultur sind freundlich, trinkfest und ,Hallo Leute-Typen. Sie kennen keine Sorgen und hängen auch keinem Aberglauben nach. Während in der MachoKultur der Erfolgreiche zum Star wird, zählt hier das Team, weil es auf den Einzelnen nicht ankommt. Das Team bringt die Menge. Darum sind Verkaufswettbewerbe so wichtig. Jeder will zu der erfolgreichen Gruppe gehören, die nach Hawaii fährt." "16

Es ist offensichtlich, dass der Blick hier weniger auf Werte oder gar auf Grundannahmen, sondern auf Artefakte (und Kreationen) gelenkt wird - die aber, dies sei wiederholt, durchaus in den „tieferen“ Kulturebenen verwurzelt sind. Zu den Artefakten gehören (und von Deal/Kennedy ebenfalls ,launig“ beschrieben) auch der Kleidungs- oder Wohnstil, bestimmte Sprachregelungen oder BegrüBungsrituals sowie charakteristische Sportaktivitäten. Bezüglich Letzterer meinen sie (augenzwinkernd), dass man etwa von Folgendem auszugehen habe: „Die Individualisten unter den harten Burschen schätzen Sportarten wie Tennis, bei denen es Mann gegen Mann geht. Squash mögen sie besonders, weil es eben ,in ist und den Killer-Instinkt fördert. Die Menschen aus der Arbeit-Spaß-Kultur bevorzugen Mannschaftssportarten, vor allem aber Basketball und Fußball, weil diese Spiele viel Aktion und Bewegung fordern. In Risiko-Kulturen spielt man dagegen lieber Golf oder radelt. Verfahrens-Leute joggen oder schwimmen." ${ }^{17}$

In Passagen wie diesen zeigt sich die eingangs erwähnte „Lebendigkeit" des Kultur- und Wertethemas besonders deutlich. Als Vertreter eines Faches, das ansonsten wenig Witziges zu bieten hat, ist man dafür gelegentlich ausgesprochen dankbar.

\footnotetext{
${ }^{15}$ Deal/Kennedy 1987 (anm. 2), S. $151 \mathrm{ff}$.

${ }^{16}$ Ebd., S. 157.

${ }^{17}$ Ebd., S. 164.
} 


\section{„Starke“ und „schwache“ Kulturen}

Weitere Typologien ließen sich anführen; allesamt Belege dafür, mit welcher Vehemenz sich Organisationstheorie und Managementlehre des Themas „Unternehmenskultur" angenommen haben. Stattdessen soll der Blick nun auf ein Detailproblem gelenkt werden: Auf die Intensität von Unternehmenskulturen und damit auf das (offensichtliche) Phänomen, dass Unternehmenskulturen unterschiedlich stark ausgeprägt sein können.

Aus nahe liegenden, aber damit nicht unbedingt auch aus guten Gründen stoßen hierbei „starke“ Kulturen auf besonderes Interesse. Worin aber unterscheiden sich diese von „schwachen“ Kulturen? Man hat gleich drei Kriterien vorgeschlagen, anhand derer eine Beurteilung der Intensität einer Kultur möglich sein soll - ihre Prägnanz, ihren Verbreitungsgrad und ihre Verankerungstiefe. ${ }^{18}$

Kulturelle Prägnanz stellt auf ein - messtechnisch wie immer geartetes - Maß für die Klarheit der kulturvermittelnden Elemente (Werte, Rituale usw.) ab. Eine "starke“ Kultur würde sich etwa durch eindeutige, unverwechselbare Vorstellungen über gewünschte oder unerwünschte Verhaltensweisen und Ziele auszeichnen. Der Kulturinhalt spielt dabei übrigens keine Rolle. Das kulturspezifische Muster könnte also durchaus wenig anspruchsvoll und vielleicht sogar moralisch fragwürdig sein.

Der Verbreitungsgrad einer Kultur ist definiert als Anteil jener Unternehmensmitglieder, für die der Kulturkern - die zentralen Wertvorstellungen also - und das umgebende Netzwerk der Symbole, Rituale, Verhaltensrichtlinien usw. im täglichen Verhalten Verbindlichkeit erlangen. Für sich allein genommen würde sich eine „starke“ Kultur dadurch auszeichnen, dass eine große Zahl, möglicherweise sogar alle Mitarbeiter eines Unternehmens dieselben Wertvorstellungen teilen und das erwähnte Netzwerk anerkennen. Das dürfte am ehesten dann möglich sein, wenn es sich um eine sehr homogene Kultur handelt. Bei kultureller Heterogenität, die sich insbesondere als Folge widersprüchlicher Subkulturen innerhalb eines Unternehmens ergeben kann, wäre dann von einer eher schwach ausgebildeten Gesamtkultur auszugehen. ${ }^{19}$

Kulturen können sich darüber hinaus durch voneinander abweichende Grade ihrer „Verinnerlichung“ abheben, durch ihre Verankerungstiefe also. Bemerkbar machen können sich derartige Unterschiede insbesondere in kritischen Situationen. Hier kann das gemeinsame Wertesystem entweder erhalten bleiben und vielleicht sogar weiter stabilisieren oder der schnellen Erosion anheimfallen. Letzteres wäre ein Indiz für eine „schwache“ Kultur.

\footnotetext{
${ }^{18}$ V. Sathe, Implications of Corporate Culture: A Manager's Guide to Action, in: Organizational Dynamics (1983), Heft 3, S. 4-23.

${ }_{19}$ Nebenbei ist damit angedeutet, dass sich verschiedene Teilbereiche eines Unternehmens in kultureller Hinsicht mitunter beträchtlich voneinander unterscheiden.
} 
An dieser Stelle bietet sich der Hinweis an, dass die Kulturintensität bei der Kooperation zwischen und insbesondere bei der Fusion von Unternehmen eine wichtige Einflussgröße sein kann. Man weiß ja, dass solche Vorhaben in der Praxis nur allzu oft scheitern, obwohl viele wirtschaftliche Argumente recht eindeutig für sie zu sprechen scheinen. Kulturelle Unvereinbarkeit ist der Hauptgrund - was leider meist erst in einem viel zu späten Stadium bemerkt wird.

\section{Funktionale und dysfunktionale Wirkungen „starker“ Kulturen}

Ceteris paribus ist $\mathrm{zu}$ vermuten, dass insbesondere beim Aufeinandertreffen „starker“ Kulturen mit Derartigem zu rechnen ist. Das führt zu dem Versuch, die Wirkungen von kultureller Stärke ganz generell einzuschätzen. Sie sind - das sei vorweggenommen - durch und durch ambivalent. Es lohnt sich also, zwischen positiven bzw. funktionalen und negativen bzw. dysfunktionalen Begleiterscheinungen zu differenzieren.

Was erstere - die funktionalen Wirkungen ,starker“ Kulturen - anbelangt, so ist zunächst das Bild vom Autopiloten in Erinnerung zu bringen: Weitestgehend geteilte, tief „verinnerlichte“ und natürlich auch „klare“ Wertvorstellungen haben einen nicht zu unterschätzenden Koordinationseffekt in dem Sinn, dass die Leistungsbeiträge der Unternehmensmitglieder auf gemeinsame Ziele ausgerichtet werden. Eine „starke“ Kultur lässt ferner erwarten, dass die Unternehmensmitglieder über bloß kalkulatives Engagement hinaus auch emotionales Engagement einbringen. Es besteht ein Basiskonsens, der sich u.a. in Gestalt eines starken „Wir-Gefühls“ äußert. All dies kann sich - leicht vorstellbar - auch motivationsfördernd bemerkbar machen.

Aber es gibt auch dysfunktionale Aspekte „starker“ Kulturen. Bemerkbar machen sie sich insbesondere in kritischen Situationen, dann aber sehr nachhaltig. Hinzuweisen ist zunächst auf die ihnen häufig innewohnenden Abschließungstendenzen mit der Folge, dass Warnsignale unbemerkt bleiben und neue Herausforderungen und Chancen immer dann ignoriert oder gar verdrängt werden, wenn sie mit der bestehenden Kultur inkompatibel sind. Auch Einbußen an Flexibilität sind in Rechnung zu stellen, weil man notwendige Anpassungen möglicherweise als Bedrohung der kulturellen Identität interpretiert. Im Extremfall kann sich eine kollektive Vermeidungshaltung mit der Folge einstellen, dass notwendige Prozesse der Selbstreflexion be- oder gar verhindert werden.

Im Umkehrschluss wird deutlich, dass auch vergleichsweise „schwache“ Kulturen vorteilhaft sein können. Letzten Endes ist wohl davon auszugehen, dass die jeweilige Situation maßgeblich darüber bestimmt, welche Kulturintensität sich als günstig oder ungünstig erweist.

Ohne ausführliche Erörterung ist dem noch hinzufügen, dass speziell die Entwicklung und Umsetzung von moralischer Kompetenz von einer „mittel- 
starken“ Unternehmenskultur besonders unterstützt zu werden scheint. Dies begründet sich damit, dass ein solcher Hintergrund vergleichsweise gut geeignet ist, moralisch relevante Konfliktsituationen zu erkennen. Während nämlich eine „starke“ Kultur wegen der in ihr herrschenden Wertkonformität die Wahrscheinlichkeit der Wahrnehmung von Wertkonflikten deutlich reduziert, tendiert eine „schwache“ Kultur zur Anomie. Unter der Voraussetzung geeigneter Kulturinhalte - etwa „Toleranz“, „Offenheit“ und „Kritik“ sowie der Existenz verständigungsorientierter Kommunikationsstrukturen - spricht dann alles für eine „,Kultur mittlerer Intensität ${ }^{6}$ mit ausreichend Gelegenheit, Wertinkonsistenzen und -konflikte zu erfahren." 20

\section{Möglichkeiten der Kulturgestaltung}

Es ist nunmehr der Frage nachzugehen, wie es um die Möglichkeiten einer (mehr oder weniger) gezielten Gestaltung von Unternehmenskulturen bestellt ist. Wer ihr in der einschlägigen Literatur nachgeht, stößt unweigerlich auf zwei weit auseinander liegende Standpunkte - den kulturalistischen und den der Kulturingenieure. Das ist natürlich eine idealtypische Gegenüberstellung, aber es lohnt sich, die beiden Extrempositionen ein wenig unter die Lupe zu nehmen. Dies erfolgt hier vorwiegend in der Absicht, eine realistische Einschätzung bezüglich der Gestaltbarkeit von Unternehmenskulturen zu gewinnen.

„Kulturalisten“ mag man vielleicht schon deshalb sympathisch finden, weil sie uns irgendwie „ehrfürchtig“ erscheinen: Eine Unternehmenskultur, so argumentieren sie, sei etwas organisch Gewachsenes; hier gestaltend einzugreifen sei ein unzulässiger Eingriff in eine Lebens-, Sinn- oder eben Wertegemeinschaft. Man stellt sogar die Frage - und ich zitiere wörtlich - ob denn „die Idee, Kulturentwicklungsprozesse zu lenken und damit letztendlich zu ,beherrschen', nicht die äußerste Steigerung eines technokratischen Zeitgeistes und als solche im Grunde ein zutiefst zynischer Gedanke“ sei.

Was im ersten Moment vielleicht als moralisch besonders überzeugende Position „durchgeht“, erweist sich bei näherem Nachdenken eher als äußerste Steigerung von - nun, nennen wir's beim Namen - Verantwortungslosigkeit. Der Blick zurück auf einige der vorgestellten Kulturtypen genügt, um dies zu begründen. Sollte man etwa eine Misstrauen und Angst erzeugende, Abwehrhandlungen begünstigende Kultur wirklich so belassen? Und passt hier überhaupt die Vorstellung, derartiges sei organisch gewachsen? Es scheint eher angebracht, von unkontrollierter Wucherung zu sprechen.

${ }^{20}$ M. Rebstock, Organisation und Ethik. Zur Entwicklung und Umsetzung individueller und moralischer Kompetenz in Unternehmen, Frankfurt am Main 1992, S. 191. 
Nun läuft dieser Kommentar keineswegs auf ein Plädoyer für den - wohlgemerkt: idealtypischen - Standpunkt der „Kulturingenieure“ hinaus. Die Vorstellung von einer weitestgehenden Mach- und Beherrschbarkeit von Unternehmenskulturen ist schlicht naiv und ignorant, denn sie übersieht die Bindungskraft von Traditionen, die prägende Wirkung der Geschichte (hier: von Sozialsystemen) also. Aber wir können es uns leisten, den Kulturingenieuren mit Gelassenheit zu begegnen, denn als Protagonisten radikaler und schneller Eingriffe in kulturelle Netzwerke müssen sie mit praktischer Erfolglosigkeit rechnen.

Was nun könnte eine überzeugende Alternative zu den beiden Standpunkten sein? Sie muss irgendwo dazwischen liegen, darf aber natürlich keinen faulen Kompromiss darstellen. Es geht also weniger darum, den (berühmt-berüchtigten) „goldenen Mittelweg“ einzuschlagen, sondern eine realistische Perspektive bezüglich der Möglichkeiten aufzuzeigen, wie sich Unternehmenskulturen aktiv gestalten lassen.

Dabei ist zunächst einmal der erwähnten Bindungskraft von Tradition und Geschichte Rechnung zu tragen. Ein schlagartiger Wandel wird sich daher zwar nicht herbeiführen lassen, Kurskorrekturen aber sehr wohl. Man hat sich also, mit anderen Worten, von der Vorstellung eines evolutionären Prozesses leiten zu lassen, und es steht durchaus nicht fest, dass dabei auch immer exakt das herauskommt, was ursprünglich angestrebt wurde. Wer mit Theorie und Praxis der Organisationsentwicklung vertraut ist, ${ }^{21}$ wird gegen die hier vorgetragene Argumentation vermutlich wenig einzuwenden haben. Zudem muss mit Widerständen gerechnet werden, denn Veränderungen ist nun einmal ein nicht zu unterschätzendes Bedrohungspotenzial inhärent. Immanuel Kant war gewiss nicht der erste, der dies wusste, aber er hat es klar ausgesprochen: „Alle Veränderung macht mich bange" ${ }^{22}$ schrieb er in einem Brief an einen Freund und verlieh damit einem (damals wie heute) weit verbreitetem Gefühl Ausdruck.

\section{Instrumente der Kulturentwicklung}

Damit stellt sich ganz zwanglos die Frage, mit Hilfe welcher Instrumente sich Unternehmenskulturen gestalten bzw. entwickeln lassen. Sie öffnet die Tür zu einem weiten Feld möglicher Interventionsstrategien und -maßnahmen, das hier allerdings nur exemplarisch skizziert werden kann.

Obwohl man im ersten Moment vielleicht geneigt sein wird, zwischen „Kultur“ (einem organisationalen „Softwarefaktor") und „Struktur“ (tendenziell zur organisationalen „Hardware“ zählend) etwas ausgesprochen Gegensätzliches zu sehen, können strukturelle Regelungen durchaus in den Dienst der Kulturentwicklung

\footnotetext{
${ }^{21}$ Vgl. Schanz 1994 (Anm. 4), S. 382 ff.

22 Zitiert nach Ch. Helferich, Geschichte der Philosophie, Stuttgart 1985, S. 185.
} 
gestellt werden. Ganz ähnlich hat auch Geert Hofstede argumentiert, dessen Arbeiten viel zum Verständnis von Kulturphänomenen beigetragen haben. Obwohl es sich, so seine Überlegung, bei der Kultur um ein „weiches“ Merkmal handelt, erfordert ihre Veränderung in eine gewünschte Richtung „harte“ Maßnahmen im Hinblick auf eine Änderung von Strukturen und Prozessen. ${ }^{23}$ Um hier bei den strukturellen Regelungen zu bleiben: Geht es etwa darum, eine Atmosphäre der Offenheit zu schaffen, dann sind Möglichkeiten für einen intensiven Informations- und Erfahrungsaustausch zu schaffen, etwa mittels Bildung von Projektgruppen oder von auf Dauer existierenden Einrichtungen - bis hin zur so genannten Matrixorganisation. Was hier exemplarisch angeführt wurde, ließe sich selbstverständlich noch stark erweitern.

Praxisbewährt sind Unternehmensleitbilder als Mittel der Kulturentwicklung. Wenn sie nicht nur auf dem Papier stehen, drücken sie unter anderem „einen anerkannten Basiskonsens aus, der unmittelbar integrierend wirkt, auf dem aber auch Meinungsverschiedenheiten austragbar sind bzw. geschlichtet werden können. “24 Ihre Adressaten sind sämtliche Mitarbeiter eines Unternehmens. Leitbilder sollen ein gemeinsames „Weltbild“ vermitteln, das Gefühl also, einer Wertegemeinschaft anzugehören. Fast regelmäßig sind Führungsgrundsätze Bestandteil solcher Leitbilder.

Kulturgestaltung kann ferner mittels gezielter Personalselektion betrieben werden, also auf nicht-strukturelle Weise. Dabei ist vorrangig an die Besetzung relativ hochrangiger Managementpositionen zu denken, weil Führungskräfte nun einmal auf die Unternehmenskultur besonders stark Einfluss nehmen. Dazu bedarf es relativ präziser Vorstellungen über die gewünschte Richtung der kulturellen Verschiebung und natürlich auch Wissen darüber, welche Persönlichkeitstypen sie ggf. herbeiführen können. Weil solches Wissen unternehmensintern nicht ohne weiteres verfügbar ist, muss hier vermutlich auf kompetente Personalberatung zurückgegriffen werden.

\section{Schlussbemerkung}

Es ist nun eine spannende Frage, ob und in wie weit die hier angestellten Überlegungen zu Unternehmen als Wertegemeinschaften sich auch auf andere Institutionen anwenden lassen, also etwa auch auf Diakonische Werke. Obwohl klar ist, dass bei Letzteren teilweise andere Rahmenbedingungen und natürlich auch historische Hintergründe vorliegen, fallen doch wesentliche Gemeinsamkeiten auf: Hier wie dort handelt es sich um Organisationen, die, über alle Unterschiede im Detail hinweg, eine identische Merkmalsstruktur aufweisen:

${ }^{23}$ G. Hofstede, Interkulturelle Zusammenarbeit, Wiesbaden 1983; vgl. auch Neubauer 2003, S. 179.

${ }^{24}$ E. Gabele/H. Kretschmer, Unternehmensgrundsätze als Instrument der Unternehmensführung, in: Zeitschrift für betriebswirtschaftliche Forschung (1983), S. 716-726, hier S. 719. 
- Es sind Interaktionssysteme (mit Schwerpunkt auf der sozialen Interaktion),

- die spezifische Ziele verfolgen, gleichzeitig aber auch

- Instrumente im Hinblick auf die persönlichen Ziele ihrer Mitglieder darstellen,

- sich der Arbeitsteilung und der Koordination als Mittel der Zielerreichung bedienen, und schließlich

- Kontinuität in dem Sinn aufweisen, dass sie über längere Zeit hinweg existieren.

Solche Gebilde haben eine Kultur und stellen sich damit als Wertegemeinschaften dar, eine Vorstellung übrigens, die in der Diakonie zumindest implizit wesentlich tiefer verwurzelt sein dürfte als im Bereich privater oder öffentlicher Unternehmen. Dabei ist es eine Frage der Wortwahl, ob von einer Wertegemeinschaft oder einer Glaubensgemeinschaft gesprochen wird; inhaltlich ist zumindest annähernd dasselbe gemeint.

Wie dem auch sei: Aus organisationstheoretischer Sicht hat „Kultur“ und das sie im Kern ausmachende Wertegefüge eine Koordinationsfunktion. Dies gilt im Hinblick auf jedweden Organisationstyp. Vielleicht gelingt es einem Sprachbild, einer Metapher also, besser als tausend Worten auszudrücken, was damit gemeint ist: geteilte Werte sind der Leim, der eine Organisation zusammenhält. 
Reiner Anselm

\section{Konflikt und Konsens. Ethische Aspekte zur Auseinandersetzung um den „Dritten Weg““*}

\section{Ethik und Kompromiss nach dem Ende der „großen Erzählungen“}

„Ethik hat es mit Konsens zu tun. Ihr konkreter Stoff aber sind Konflikte." ${ }_{1}$ So evident diese Formel Trutz Rendtorffs auf den ersten Blick zu sein scheint, so voraussetzungsreich ist sie doch zugleich. Sie markiert zunächst die Einsicht, dass die Frage nach der Ethik nicht als eine Frage der Theorie auftritt. Der Ruf nach Ethik hat vielmehr immer einen konkret angebbaren Ort. Es sind die mit bestimmten Berufen und Handlungsfeldern gegebenen Auseinandersetzungen um das Richtige und das Gute, die den Ruf nach Ethik ertönen lassen. Dieser Ruf resultiert dabei in aller Regel aus einem verlorenen gegangenen Konsens, und von der Ethik wird erwartet, dass sie diesen verloren gegangenen Konsens wieder her-

\footnotetext{
* Vortrag auf dem 6. Kästorfer Managementsymposion „Diakonie im Ausverkauf? Der Dritte Weg auf dem Prüfstand“ am 30. September 2005. Die Vortragsform ist weitgehend beibehalten worden.

1 Trutz Rendtorff: Vom Beruf der Ethik, in: Nachrichten der Ev.-luth. Kirche in Bayern 54 (1999), 161-167, 161 .
} 
zustellen vermag. Die Vorstellungen von diesem Konsens sind meist klar umrissen: Ethik soll die eigene Position mit zusätzlicher Legitimität ausstatten - und wird darin leicht erneut zur Quelle von Konflikten. Denn obwohl dieses legitimatorische Interesse oft mit „Ethik“ verbunden wird, kann die Ethik unter den Bedingungen moderner, ausdifferenzierter Gesellschaften keineswegs per se bereits Konsens garantieren. Ihr stehen nämlich keine allgemeinen Kriterien zur Verfügung, auf deren Grundlage sie zwischen widerstreitenden Auffassungen entscheiden könnte. Nach dem „Ende der großen Erzählungen“ (Jean Franois Lyotard) ist auch die Ethik geprägt von verschiedenen „Erzähltraditionen“, die sich teilweise überschneiden, teilweise aber auch inkompatibel zueinander verhalten. An die Stelle der großen, integrierenden Weltanschauungen ist in der Moderne die Pluralität verschiedener, kleinräumiger Systeme getreten. Diese Pluralisierung folgt dem Erfolgsmodell der Moderne: Die Effizienz und Fortschrittsdynamik verdankt sich einer immer weiter reichenden funktionalen Differenzierung der Gesellschaft und ihrer einzelnen Substrukturen; in deren Folge bilden sich dann auch einzelne, unterschiedliche Milieus und Moralen aus - das Wachstum und damit in gewisser Weise auch der Erfolg der Diakonie mit ihren immer vielfältigeren Aktivitäten und Professionen bildet ein anschauliches Beispiel für diesen Differenzierungsprozess.

Die entsprechenden, unterschiedlichen Moralen treten zunächst einmal mit gleichen Ansprüchen nebeneinander auf - ohne hierarchische Ordnung. Zu Konflikten kommt es immer dann, wenn nun solche unterschiedlichen Moralen, Erzähltraditionen oder Deutekulturen miteinander in Widerstreit treten. Dabei ist, ich habe es schon angedeutet, der Rekurs auf die Ethik zunächst häufig Teil des Problems und nicht dessen Lösung. Der Königsweg der Modere besteht angesichts dieser Situation in einer möglichst konsequenten Verrechtlichung der Problemlagen, in der Suche also nach Regeln, die unabhängig von den verschiedenen Traditionen und Prägungen als verbindlich anerkannt werden oder aufgrund der Ausübung des staatlichen Gewaltmonopols verbindlich anerkannt werden müssen.

Auch mit dieser Verrechtlichung sind jedoch die Probleme nur selten gelöst. Vielmehr kehren sie in aller Regel wieder, wenn verschiedene konkrete Problemlagen und Handlungsalternativen unter die notwendig abstrakten Regeln des Rechts subsumiert werden müssen und dabei unterschiedliche Güter, aber auch unterschiedliche Interpretationen gegeneinander abgewogen werden sollen. Eine solche Abwägung verlangt nach Maßstäben, und wo diese nicht allein durch die Sache selbst gegeben sind - etwa im Falle von logischen Widersprüchen - müssen erneut einzelne „Erzählkulturen“ als Lieferanten für solche Maßstäbe fungieren. Die jüngeren Urteile zur Abwägung etwa zwischen positiver und negativer Religionsfreiheit legen dafür ein deutliches Zeugnis ab. Abgekürzt formuliert geht es dabei immer um eine adäquate Verhältnisbestimmung von Recht und Gerechtigkeit, von Legalität und Legitimität. In diesen Bestimmungsprozessen kommt erneut die Ethik ins Spiel, aber nun in einer veränderten Rolle: In dieser, gewis- 
sermaßen zweiten Phase ethischer Theoriebildung geht es nun darum, die einzelnen Beurteilungsmaßstäbe und die ihnen zu Grunde liegenden Erzählungen miteinander in Beziehung zu setzen und dabei zugleich Rechenschaft über die eigenen Leitmaßstäbe abzulegen.

Mit dieser Beschreibung lässt sich die Aufgabe der Ethik genauer bestimmen: Ethik ist keine Disziplin, die reißbrettartig am Schreibtisch Entscheidungen dekretieren und entsprechende Normen auf dem Weg rationaler Argumentation herstellen kann; sie ist vielmehr eine hermeneutische Wissenschaft, die auf das Verständnis von maßstabbildenden Erzählungen und ihren korrespondierenden Kulturen, auch den entsprechenden Unternehmenskulturen, ausgerichtet ist. Sie folgt damit zugleich einer bestimmten Sicht des Menschen, der im Wesentlichen ein "Geschichten erzählendes Tier" ist, wie der amerikanische Philosoph Alasdair MacIntyre die antike Formel vom zoon logon echon variiert. ${ }^{2}$ Der Mensch unterscheidet sich von allen anderen Lebewesen also nicht nur durch seine Rationalität oder sein Selbstbewusstsein, sondern durch seine Fähigkeit zur Narration und damit zur Kulturbildung. Auf die Bedeutung dieser Narrationen für die Gestaltung von Kompromissen wird später, im dritten Teil, noch einmal zurückzukommen sein.

So verstanden, ist die Ethik nun auch nicht mehr die Disziplin, mit der eigene Vorstellungen untermauert werden können. Vielmehr führt die ethische Reflexion zunächst zu einer Relativierung der eigenen Position, insofern sie auf die Abhängigkeit der individuellen Meinungsbildung von der jeweiligen Tradition hinweist. Durch diese Relativierung kann sie eine Verflüssigung eingefahrener Beurteilungsmuster bewirken und damit zugleich die Suche nach Verständigung motivieren. In dieser Perspektive kann jedoch eine intendierte Verständigung immer nur in Gestalt eines Kompromisses erreicht werden. Der Konsens also, der von der Ethik erwartet wird, kann, soll er einen Konflikt beenden, immer nur ein beschränkter Konsens, ein Konsens über Verfahrensfragen und über Grundlagen sein, der schließlich in einen Kompromiss im Blick auf die Bewertung einer konkreten Situation mündet.

Ein solcher Kompromiss ist dabei keineswegs eine Kapitulation vor dem vermeintlich Unabänderlichen und darin ein höchstens hinzunehmendes, besser aber nicht aktiv anzustrebendes Handlungsziel. Es ist vielmehr diejenige Art der Konsensfindung, die der Komplexität ethischer Konfliktlagen angemessen ist. Für die Methodik der Ethik ist diese Kompromissfindung außerordentlich anspruchsvoll. Sie verlangt nämlich nicht nur die Fähigkeit zu einer präzisen Beschreibung der ethischen Konflikte, und zwar sowohl ihrer Sachdimension wie auch ihrer Wertund Normdimension, sondern auch die Fähigkeit, zu verstehen, aus welchen Traditionen oder eben Erzählungszusammenhängen sich die jeweiligen miteinander in

2 Alasdair MacIntyre: Der Verlust der Tugend. Zur moralischen Krise der Gegenwart, Frankfurt /M. 1987, 288. 
Widerspruch stehenden Urteile speisen. Beide Kompetenzen müssen in der ethischen Reflexion ihren Niederschlag finden. Ehe wir überhaupt in die im engeren Sinne ethische Beurteilung und in die Suche nach einem Kompromiss eintreten können, gilt es zuallererst, eine Situation adäquat zu verstehen: Es muss identifiziert werden, worin die Konflikte bestehen, ob und welche ethischen Normen und Werte hier überhaupt tangiert werden. Sodann ist danach zu fragen, welche Herkunft solche unterschiedlichen Normen und Werte haben und worin möglicherweise Überschneidungen vorliegen.

In dieser Kompromisssuche geht die Aufgabenbestimmung der Ethik jedoch nicht auf. Denn der Prozess des Verstehens und des Abwägens unterschiedlicher Traditionen geht immer auch einher mit der Fortschreibung von Geschichten und dann auch der Konstruktion von neuen Kulturen. So können bestimmte gelungene Formen der Konfliktlösung selbst eine neue Kultur begründen und darin für weitere Entscheidungen entlastend wirken. Wenn ich recht sehe, geht es in dem Streit um den Dritten Weg im kirchlichen Arbeitsrecht - und damit auch dem der Diakonie - letztlich auch um die Frage, wie denn die große Erzählung der Diakonie als eine Form gelebten Christentums in Zukunft fortgeschrieben werden soll. Dies möchte ich im Folgenden in dem eingangs bereits angekündigten zweiten Schritt zunächst verdeutlichen, ehe ich dann in einem dritten Schritt umreißen werde, welchen Beitrag theologische Reflexion in diesem Zusammenhang leisten kann; dabei soll also das noch einmal explizit thematisch werden, was in der bisherigen Argumentation implizit bereits immer präsent gewesen ist.

\section{Alte Narrative und neue gesellschaftliche Orte: Herausforderungen der Diakonie im 21. Jahrhundert}

Die Auseinandersetzung um die Zukunft des „Dritten Weges“ ist, wie bereits angedeutet, die Folge davon, dass die Pluralisierung der leitenden Erzählungen nun auch die Diakonie und ihre Tätigkeitspraxis erreicht hat. Mit dieser Pluralisierung wird jedoch das bislang fraglos akzeptierte, leitende Bild der Diakonie brüchig. Dies führt nicht nur dazu, dass vielen die Identität der Diakonie selbst unsicher wird, worauf innerkirchlich versucht wird, darauf mit zahlreichen Leitbildprozessen zu reagieren. Die Pluralisierung führt auch zu einem Plausibilitätsverlust in der Bevölkerung, da die Akzeptanz der Diakonie und die damit durchaus verbundenen Privilegien nun in eine Spannung zu dem traditionellen Leitbild und der ihm korrespondierenden Ursprungserzählung treten, - eine Spannung, die ohne Fortschreibung der alten Erzählung dahin tendiert, zum Schisma zu werden.

Diese Ursprungserzählung sei hier nur kurz in Erinnerung gerufen, denn sie lässt sich in jeder Wichern-Biographie entsprechend nachlesen: Ein engagierter Christ sieht die ihn umgebende Not und beschließt, dagegen vorzugehen und den Leidenden wieder eine Perspektive zu geben. Sein Charisma führt dazu, dass er mit 
diesem Anliegen nicht alleine bleibt, sondern eine Gruppe Gleichgesinnter um sich schart. Gemeinsam etablieren sie institutionalisierte Formen der Armenhilfe. Die gemeinsame Aufgabe und die Abgrenzung zwischen Helfern und Hilfebedürftigen schafft genügend Identifikationspotenzial. Man versteht sich als eine Gemeinschaft, deren innere Verfassungsstruktur zunächst nebensächlich, zumindest untergeordnet ist. Zusammen mit dem aus dem Glauben resultierenden Bewusstsein, gemeinsam zur Kirche Christi zu gehören, versteht man sich als diakonische Gemeinschaft, die gemeinsam den Dienst leistet im Namen und zur Ehre Christi. Diese Ursprungserzählung kann dann auch bekenntnishaft reformuliert werden, etwa mit der 4. These der Barmer Theologischen Erklärung, in der es heißt: „Ihr wisset, daß die weltlichen Fürsten herrschen, und die Oberherren haben Gewalt. So soll es nicht sein unter euch; sondern so jemand will unter euch gewaltig sein, der sei euer Diener (Mt 20,25.26). Die verschiedenen Ämter in der Kirche begründen keine Herrschaft der einen über die anderen, sondern die Ausübung des der ganzen Gemeinde anvertrauten und befohlenen Dienstes.“ Oder, kurz und bündig im Leitbild des Diakonischen Werkes: „Wir sind eine Dienstgemeinschaft von Frauen und Männern im Ehrenamt.“

Charakteristisch für die Implikationen dieser Ursprungserzählung ist die institutionell-organisatorische Unbestimmtheit, die mit ihnen einhergehen. Die Vorstellung der Dienstgemeinschaft begründet keine eigene Organisationsstruktur; dies ist auch nicht notwendig, weil die Diakonie hier einfach die Sozialphilosophie der sie umgebenden, ständisch geordneten Gesellschaft übernehmen kann - oder zumindest meint, diese übernehmen zu können. Deren Grundgedanke lautet: Harmonie durch Anerkennung von Ungleichheit nach dem Vorbild des Organismus: Wenn jeder in dieser Gemeinschaft die Aufgaben ausführt, die ihm zugedacht sind, dann ist zugleich in bestmöglicher Weise für das Wohl aller gesorgt. Gleichzeitig folgt aus der Organismusvorstellung auch eine hierarchische Ordnung: So wie der Körper ein Haupt, aber viele Glieder hat, so soll auch die Dienstgemeinschaft hierarchisch organisiert sein. ${ }^{3}$ Der Inbegriff dieser Vorstellung ist die traditionelle Familie, in der der pater familiae selbstverständlich an der Spitze steht und allen andern ihren Platz, ihre Aufgaben und Güter zuweist. Nicht zufällig bilden die diakonischen Anstalten - zum Teil bis heute - diese Struktur ab.

Die besondere Pointe dieser Vorstellung liegt nun darin, dass die jeweils zugeschriebene Rolle sich nicht den Fähigkeiten oder der Entscheidung des Einzelnen verdankt, sondern die jeweils vorfindliche Ordnung als vocatio, als Berufung Gottes, interpretiert wurde. Insofern sind Hierarchien dann auch kein Herrschafts-

\footnotetext{
${ }^{3}$ Noch in der Ethik Bonhoeffers finden sich entsprechende Vorstellungen, wenn dieser formuliert, jede Ethik basiere auf einer „Stabilität der Autoritätsverhältnisse“, sie ,ist nur möglich aufgrund innerer Bejahung und entschlossenen Durchhaltens des Obenseins und des Untenseins“. „Wo es nicht mehr gewagt wird oben zu sein und wo man es nicht mehr ,nötig zu haben glaubt‘ unten zu sein, [...] dort bricht schon das ethische Chaos herein." (Dietrich Bonhoeffer: Ethik. hg. v. Ilse Tödt, Heinz-Eduard Tödt, Ernst Feil, Clifford Green (=DBW 6), München 1992, 378f.)
} 
streben, sondern direkter Ausfluss der göttlichen Ordnung. Dieser - durchaus im guten Sinne - paternalistischen Ordnung folgt sodann auch das Entlohnungssystem: Es orientiert sich ebenfalls nicht an den individuellen Tätigkeiten, sondern an der jeweiligen Position im Organismus. Der Lohn soll ein standesgemäßes Auskommen sichern und gerade nicht die Entlohnung für die caritativ-diakonische Zuwendung zum Nächsten sein. Eben diese Überzeugung ist es, die das besondere Unterscheidungsmerkmal der Diakonie bis heute ausmacht: Diakonisches Hilfehandeln verdankt sich, so die landläufige Überzeugung, keinem Interesse an monetärer Wertschöpfung, sondern es ist vielmehr die Folge bestimmter, nichtmaterieller Werte.

Natürlich sind solche Narrationen idealisiert - aber das ist hier nicht das Thema: Ihren Grad an Konstruiertheit teilen sie mit allen Ursprungsgeschichten, jeder kann dies leicht selbst nachvollziehen, wenn er seine eigene Erzählung, seine eigene Biographie schildert. Entscheidend aber für unsere Fragestellung ist, dass sich die Plausibilität dieser Erzählung einer geschlossenen Weltsicht verdankt. Hier gibt es stabile Orientierungspunkte, die niemandem zur eigenen Disposition stehen. Insbesondere gibt es kaum Möglichkeiten für eine selbstbestimmte Veränderung des sozialen Standes. Vor diesem Hintergrund gewinnt die Vorstellung der Dienstgemeinschaft ihre besondere Plausibilität. Besonders gilt dies natürlich auch für die Gewährung des Selbstbestimmungsrechts nach Art. 137 Abs. 3 WRV. Denn der Gedanke, dass die Religionsgemeinschaften ihre Angelegenheiten selbstständig regeln, basiert letztlich auf der Vorstellung einer stratifizierten Gesellschaft, die sich durch die harmonische Integration dreier, im Wesentlichen selbstständiger Teilbereiche - Kirche, Staat, Familie - verdankt. Der Begriff der Religionsgemeinschaften ist dabei bereits ein Zugeständnis an die beginnende gesellschaftliche Pluralisierung, der im Grunde die innere Systematik der Argumentation der Weimarer Kirchenartikel sprengt, bis in die Gegenwart hinein faktisch jedoch nicht wirksam geworden ist.

Die gesellschaftliche und konzeptionelle Geschlossenheit, mit der die leitende Erzählung der Diakonie bis heute operiert, ist Geschichte - und prägt doch als leitende Erzählung bis heute. An ihre einheitsstiftende Stelle ist heute, wie bereits angedeutet, eine Vielzahl von einzelnen Geschichten und Motivationen getreten, die in den konkreten Praktiken des diakonischen Alltags in zunehmendem Maße miteinander in Konflikt treten. So tritt an die Stelle der traditionellen Vorstellung von einer Berufung heute zunehmend der Gedanke selbstgewählter Tätigkeit. Ebenso erhält der Grundsatz der Entlohnung eine stärkere Beziehung zur konkret ausgeübten Tätigkeit, so dass die individuelle „Wertschöpfung“ einen immer größeren Stellenwert erlangt. Zudem lassen die gesamtgesellschaftlichen Emanzipationsprozesse das Modell einer harmonisch-paternalen Ordnung das im Hintergrund der traditionellen Auffassung von der Dienstgemeinschaft steht, problematisch erscheinen. 
Entscheidend und von großer innerkirchlicher „Sprengkraft“ ist nun, dass diese Veränderungsprozesse nur zum Teil auf gesamtgesellschaftliche und damit der Diakonie gegenüber externe Faktoren zurückzuführen sind. Vielmehr sind sie zumindest zu gleichen Teilen auch durch Entwicklungen und konzeptionelle Inkonzinnitäten bedingt, die das überkommene Modell der Diakonie selbst hervorgebracht hat, bzw. die ihrer eigenen Ursprungserzählung selbst eigentümlich sind - gewissermaßen als Exkurse und Nebenstränge, die sich nicht recht in den dominanten Strang der Handlung einfügen lassen. Ich beschränke mich auf einige exemplarische Problemkonfigurationen:

Die Geschichte der Diakonie ist untrennbar verbunden mit dem Aufstieg des Sozialstaats in der Industriegesellschaft des späten 19. Jahrhunderts. Insofern wird die historische Analyse die organisationale und rechtliche Selbstständigkeit der Diakonie, wie sie immer wieder als Grundlage des „Dritten Weges“ in Anspruch genommen wird, nur als einen selbstvergewissernden Mythos identifizieren können - analog übrigens zur (angeblichen) institutionellen Selbstständigkeit der Kirche, die ihrer Organisationsstruktur nach sich nach wie vor als Abbild der Staatsverwaltung präsentiert. Doch wichtiger als eine solche, der historischen Präzision geschuldeten Kritik ist etwas anderes. Die Verkopplung von staatlichem und diakonischem Handeln, zwischen industriellem Wandel und caritativer Tätigkeit bedeutet zugleich, dass die fundamentalen Veränderungen, die die Industriegesellschaft und mit ihr das Modell des bundesdeutschen Sozialstaats derzeit erfährt, unmittelbar auf die Diakonie zurückwirken. Faktisch ist neben das geistige Kapital der Motivation aus Glauben mittlerweile längst das materielle Kapital staatlicher Umverteilungs- und Solidaritätssysteme getreten, ohne dass dies in die Leitbilddebatten und „großen Erzählungen“ der Diakonie schon genügend eingedrungen wäre.

Eingedrungen ist es allerdings über die allenthalben zu beobachtende Hinwendung zu Managementmethoden in den Führungsebenen der Diakonie. Doch über die - auf Grund veränderter ökonomischer Rahmenbedingungen zweifelsohne notwendige - Professionalisierung der Leitungsebene diakonischer Einrichtungen hinaus gerät leicht aus dem Blick, dass damit ein anderes Leitbild als das narrativ beschworene Organismusideal in die Diakonie Einzug erhält. Denn hier wird das Konzept funktionaler Differenzierung übernommen, das sich keineswegs widerspruchsfrei in das überkommene Ordnungsmodell der Dienstgemeinschaft einfügen lässt. Die Suche der Mitarbeitervertretungen nach besseren Möglichkeiten, die eigenen Interessen nun eben auch im Gegenüber zur „Unternehmensführung“ der Arbeitgeberseite durchzusetzen, ist in diesem Zusammenhang zu sehen.

Der wachsende Konkurrenzdruck und das Diktat der Ökonomie, aber - gleichsam gegenläufig dazu - auch der eigene Erfolg und die damit verbundene Expansion diakonischer Einrichtungen und Tätigkeitsfelder haben dazu geführt, dass aus 
der ursprünglichen Wertegemeinschaft in zunehmendem Maße Dienstleistungsunternehmen geworden sind. ${ }^{4}$ Damit verändert sich jedoch das Verhältnis zwischen Unternehmensführung und den Mitarbeitern nachhaltig. ${ }^{5}$ An die Stelle langfristiger Bindungen und wechselseitiger Verpflichtungen treten nun kurzfristigere Verträge, deren Konditionen jeweils ausgehandelt werden müssen.

In diesen Aushandlungsprozessen treten dabei gerade die Arbeitnehmer - schon im Begriff liegt eine deutliche Verschiebung gegenüber den etablierten Leitmodellen - in zunehmendem Maße selbstbewusst und als Vertreter eigener Interessen auf. Dies lässt sich auf der einen Seite negativ deuten, als ein Niedergang der dem Gedanken von der Dienstgemeinschaft inhärenten Grundüberzeugungen. Doch auch eine positive Interpretation ist möglich, sofern man nämlich dieses Selbstbewusstsein als großen Erfolg für die praktische Umsetzung eines protestantischen Anliegens interpretiert, wonach die Inanspruchnahme von Freiheit auch denjenigen möglich sein soll, die bisher auf Grund der gegebenen Rahmenbedingungen davon ausgeschlossen waren. Zudem treten dabei natülich auch immer stärker die verschiedenen, mitunter widerstreitenden Facetten individueller Glaubensüberzeugungen und - vielleicht noch konfliktträchtiger - die unterschiedlichen Auffassungen in den Fragen der anwendungsorientierten Ethik ins Bewusstsein, was sich in aller Regel an unterschiedlichen Auffassungen über soziale Gerechtigkeit und richtige Entlohnung ablesen lässt.

Die akademische Theologie erweist ihre spezifische Kompetenz für die Gegenwartsprobleme der Diakonie dadurch, dass sie die hermeneutischen Dimensionen der oben exemplarisch genannten Herausforderungen im Rahmen der Überlieferungen der Christentumsgeschichte herausstellt. Dies ist seit jeher ihr „Geschäft" gewesen, denn stets geht es in der Theologie um das Deuten von Geschichten, von kollektiven wie individuellen Erzählungen und Leitvorstellungen. Textauslegung, historisches Bewusstsein und zugleich das Bemühen um normative, bewertende Kriterien sind dafür einschlägig. Zum anderen ist die Theologie in besonderer Weise kompetent dafür, die Grunderzählungen reformatorischen Christentums im Horizont der biblischen Überlieferung und der Christentumsgeschichte als wirkungsgeschichtliche Fortschreibungen zu verstehen und dazu anzuleiten, sie selbst weiterzuschreiben. Um diese Kompetenzen für die Konfliktlösung in diakonischen Aufgaben fruchtbar machen zu können bedarf es jedoch eines Bildungskonzeptes, das pragmatische Leitungsfragen und hermeneutische Deutungsprozesse miteinander zu vermitteln in der Lage ist. Eben diesem An-

\footnotetext{
${ }^{4}$ Vgl. dazu: Thomas Rauschenbach, Christoph Sachße und Thomas Olk: Von der Wertgemeinschaft zum Dienstleistungsunternehmen. Jugend- und Wohlfahrtsverbände im Umbruch, Frankfurt/M. 1995.

${ }^{5}$ Vgl. dazu Heinrich Beyer, Hans G. Nutzinger und Holger Fischer (Hg.): Erwerbsarbeit und Dienstgemeinschaft. Arbeitsbeziehungen in kirchlichen Einrichtungen. Eine empirische Studie, Bochum 1991.
} 
liegen weiß sich der von der Theologischen Fakultät in Göttingen konzipierte Masterstudiengang „Führungskompetenz in theologischer Sicht“ verbunden.

Gemeinsam bilden die hier geschilderten Facetten die Gemengelage, aus der der derzeitige Konflikt um den „Dritten Weg“ erwächst. Seine Schärfe und sein Gewicht bekommt dieser Konflikt eben deshalb, weil er in exemplarischer Weise den Plausibilitätsverlust und auch die internen Widersprüche der leitenden Grunderzählung der Diakonie deutlich werden lässt. Aus diesem Grund ist es auch wenig erfolgversprechend, die gegenwärtig aufgebrochenen Konflikte mit dem Instrumentarium und auf dem Hintergrund der bislang leitenden Paradigmen lösen zu wollen, und das heißt: Eine Lösung anstreben zu wollen, die alle wieder aufs Neue bloß auf die alte Leiterzählung einschwört. Die Pluralisierung auch der Handlungskontexte der Diakonie und die innere Differenzierung diakonischer Tätigkeiten bringt es mit sich, dass Kompromisse geschlossen und zugleich die entsprechenden Leiterzählungen immer wieder weitergeschrieben werden müssen, wie ich dies oben in meinem ersten Abschnitt bereits angesprochen habe. Dabei sage ich bewusst weiterschreiben, denn diese Geschichten müssen sich, soll die Diakonie als Äußerung des Christentums weiterhin identifizierbar bleiben, auf die Grundelemente des Christentums, präziser noch: des reformatorischen Christentums beziehen.

Beides, das Ausloten eines Kompromisses und das Fortschreiben der Leiterzählung, sollte die Aufgabe einer Theologie für die Diakonie sein. Dabei geht es aber nicht nur darum, eine extern konstituierte Theologie einfach zu verinnerlichen und dann im Unternehmen zu vertreten. Vielmehr muss diese theologische Reflexion in der Diakonie selbst geleistet werden. Die akademische Theologie kann dazu Hilfestellungen anbieten und die entsprechenden Reflexionsprozesse begleiten; sie kann sie jedoch nicht substituierend für die Diakonie übernehmen, ohne auf der einen Seite die Selbständigkeit der Diakonie, auf der anderen Seite das Proprium akademischer Theologie zu negieren. 


\section{Diakonisches Handeln als „Dienstleistung“}

Der Schlüssel zu einer solchen problembezogenen Kompromisslösung scheint mir darin zu liegen, sich in guter reformatorischer Sicht um eine Neubestimmung des Verhältnisses von Freiheit und Dienst zu bemühen. ${ }^{6}$ Denn in protestantischer Perspektive bilden beide, Freiheit und Dienst, gerade keine Widersprüche sondern sind eng aufeinander bezogen: „Ein Christenmensch ist ein freier Herr und niemandem Untertan - ein Christenmensch ist ein dienstbarer Knecht und jedermann Untertan." So heißt es ebenso paradigmatisch wie wirkmächtig am Beginn von Luthers Freiheitsschrift.7 Diese Bestimmung ist in der Tradition häufig so ausgelegt worden, dass der Einzelne gerade dann frei ist, wenn er von den eigenen Interessen absieht und sich ganz dem Nächsten zuwendet. Das Bild des ,dienstbaren Knechts“ motiviert dabei jedoch nicht nur dazu, eigene Interessen um des Nächsten willen in den Hintergrund treten zu lassen; die Untertanen-Topik konnte eben auch zu einer Mentalitätsstruktur führen, die mit Recht als „Obrigkeitsgläubigkeit“ des Luthertums immer wieder kritisiert worden ist. Die Mischung aus beidem, aus der Orientierung am Nächsten und der Unterordnung unter die Ideale des christlichen Fürsten, bildet die charakteristische Melange, aus der der paternalistisch geprägte Sozialstaat lutherischer Provenienz entstanden ist. Dabei trägt zur inneren Stabilisierung dieses Konstrukts ganz wesentlich bei, dass die Unterordnung des Einzelnen als Folge des Wissens um die eigene Freiheit kom-muniziert wird: Weil der Christ in der Freiheit des Glaubens steht und gleichzeitig um seine eigene Korrumpierbarkeit als Sünder weiß, ordnet er sich vorgegebenen Institutionen unter, die ihm - ähnlich wie das paradigmatisch für die politische Theorie in Thomas Hobbes' Leviathan formuliert ist - ihrerseits das ihm zukom-mende $\mathrm{Ma} ß$ an denkerischen und materiellen Freiheiten zumessen mit all den geschilderten Problemen, die daraus resultieren. ${ }^{8}$

Statt einer solchen vorrangig auf die Begrenzung individueller Freiheiten ausgerichteten Leitvorstellung könnte es sich anbieten, die Dienst-Metaphorik stärker von einem ökonomischen Sprachgebrauch her zu interpretieren und Diakonie - in Anlehnung an eine Formel von Johannes Degen - als christliche Dienstleistung zu verstehen und damit den Dienstgedanken deutlich von den in der Vergangenheit so prägenden obrigkeitlich-paternalistischen Assoziationen abzuheben. In dieser Perspektive rückt die Orientierung am Einzelnen in den Vordergrund des Interesses, was bislang zumeist überdeckt worden war. Die Orientierung am Einzelnen müsste zunächst deutlich machen, dass die Wahrnehmung des diakonischen Auftrags Sache eines jeden einzelnen Mitarbeiters und jeder einzelnen

${ }^{6}$ Vgl. dazu auch die Überlegungen von Klaus Tanner in diesem Band.

${ }^{7}$ Martin Luther: Von der Freiheit eines Christenmenschen, Luther Deutsch, hg. v. Kurt Aland, Bd. 2, Göttingen 1962, $251 \mathrm{f}$.

${ }^{8}$ Vgl. dazu die ebenso einfühlsame wie prägnante Darstellung von Eberhard Stammler: Protestant sein. Versuch eines Portraits, in: Hans-Wolfgang Heßler (Hg.): Protestanten und ihre Kirche in der Bundesrepublik Deutschland (= Geschichte und Staat Bd. 203-205), München u. a. 1976, 9-26. 
Mitarbeiterin ist und nicht an die Gestaltung der Organisation delegiert werden kann. Zum spezifischen Professionalisierungsprozess muss in der Diakonie möglicherweise auch gestützt durch entsprechende organsationsinterne Weiterbildung - die Ausbildung einer je eigenen Vorstellung vom christlichen Dienst am Nächsten gehören. Diese Zuschreibung würde zwar mit Sicherheit die Rekrutierung entsprechender Arbeitskräfte deutlich erschweren, vielleicht sogar eine deutliche Verkleinerung der Handlungsfelder der Diakonie nach sich ziehen. Jedoch scheint es mir nur auf diesem Wege unter modernen Bedingungen möglich, dem Emanzipationsstreben und der ja durchaus zur protestantischen Identität gehörenden Individualität des Glaubenszeugnisses Genüge leisten zu können und dabei dennoch an einem gemeinsamen Leitbild festhalten zu können. Mit einem biblischen Bild gesprochen: Jeder Einzelne muss als Samariter handeln und sich beständig die Frage nach dem Nächsten stellen, dies kann und darf nicht an die kollektive Identität einer Organisation delegiert werden.

Eine solche Zumessung von Freiheit ist nun aber auch an die Übernahme von Verantwortung gebunden, und zwar auch der Verantwortung für die Organisation - ein Grundzug, der in den notorisch institutionenkritischen Mentalitäten des Protestantismus nur schwach verortet ist. Der Einzelne muss dann, um in der Metaphorik von Lk 10 zu bleiben, sich eben nicht nur Samariter, sondern auch als Wirt verstehen lernen. Nur wenn eine solche Symmetrie gewährleistet ist, ist der Dienstgemeinschaftsgedanke auf Dauer tragfähig. Zugleich bedeutet dies, die im Rahmen einer Organisation immer notwendigen Kompromisse auch jedem Einzelnen in der Alltagstätigkeit zuzumuten und zuzutrauen. Eine solche flache Hierarchie könnte eine nachhaltige Bewährung eines „dritten Wegs“ sein. Sie impliziert jedoch auch, dass - um noch etwas konkreter auf die aktuelle Konfliktlage der künftigen Gehaltsentwicklung einzugehen - die Lohnspreizung innerhalb dieser Organisation nicht besonders groß sein darf. Denn gerade an der Dissonanz zwischen der Betonung der Dienstgemeinschaft auf der einen und einer stärkeren Lohnspreizung auf der anderen Seite entzünden sich ja derzeit die Konflikte um das Tarifrecht. Auch hier wird es darum gehen, auf der Basis von Kompromissen für die spezielle Situation jeder einzelnen Einrichtung oder jedes Werkes Wege zu finden, die die Finanzierbarkeit und die Freiheitsdimension des Gedankens der Dienstgemeinschaft in der Diakonie zu vermitteln vermögen.

Bislang waren nur die Hilfeleistenden im Blick. Über den Dienstleistungsgedanken lässt sich aber auch eine andere Perspektive auf die Hilfebedürftigen einnehmen. Denn wenn man von Dienstleistung spricht, liegt es ja nahe, auch von Kunden und nicht von Hilfsbedürftigen zu sprechen; diese Veränderung der Perspektive bietet nicht nur eine Hintergrundtheorie, die es ermöglicht, auf die speziellen Bedürfnisse des Einzelnen einzugehen, sie definiert zugleich auf der Seite der Dienstleistungsempfänger Anspruchsrechte und Pflichten. Über den Begriff des Kunden könnte es mittelfristig möglicherweise auch gelingen, die Eigenverantwortung der Hilfeempfänger zu stärken - bis hin zu einer stärkeren Eigenbeteiligung dafür, 
dass man von einem Personal betreut wird, das seine Motivation zuvörderst einer Glaubensüberzeugung und nicht dem Gewinnstreben verdankt. Es spricht jedenfalls wenig dafür, dass die staatlich organisierte Solidargemeinschaft in einem religiös immer pluraleren Gemeinwesen auf Dauer bereit sein wird, weltanschauungsspezifische Sonderleistungen - und sei es nur das „Klima“, in dem eine Hilfeleistung erbracht wird - aus allgemeinen Umlagen zu finanzieren, es sei denn, es komme eine allgemein anerkannte Qualitätssteigerung damit zum Ausdruck. Diese Anfrage gilt dabei ganz unabhängig von dem häufig aus Diakoniekreisen zu hörenden Widerspruch, einerseits auf die besondere, eben aus dem christlichen Liebesgedanken resultierenden Motivationen der Mitarbeiter hinzuweisen, im selben Atemzug aber andererseits auch auf die Notwendigkeit einer solidarischen Finanzierung des damit verbundenen höheren Zeitaufwandes zu verweisen. Darüber hinaus dürfte die Glaubwürdigkeit der eigenen Argumentation auch dadurch gewinnen, wenn man dazu bereit ist, gegebenenfalls auch auf Wachstum zu verzichten und diejenigen Einrichtungen abzugeben, in denen sowohl auf der Seite des Personals, als auch auf der Seite der Klienten nur mehr eine Minderheit einer Kirche angehört.

Ich bin überzeugt davon, dass die weitere Geschichte der Diakonie als christliche Dienstleistung am Nächsten davon abhängen wird, dass es gelingt, die Leiterzählung in diesem Sinne weiterzuschreiben. Anknüpfen kann sie dabei übrigens an einem wichtigen, aber häufig vergessenen Vertreter des Sozialen Protestantismus: Theodor Lohmann. ${ }^{9}$ Sein vom liberalprotestantischen Lager um Friedrich Naumann geprägtes Denken zeigt, dass die Tradition des Luthertums keineswegs in den patriarchalen Staatssozialismus Bismarcks münden musste. Lohmann entwarf das Modell einer bürgergesellschaftlichen Diakonie, die von der korporatistischen Unterstützung des einzelnen Hilfsbedürftigen getragen sein sollte. Seine Geschichte zeigt, dass die Orientierung an Freiheit und Eigenverantwortung des Einzelnen durchaus als ein legitimes Erbe des Protestantismus anzusehen ist. Die diakonische Dienstgemeinschaft als Gemeinschaft von gleichberechtigten und gleichverantwortlichen Mitarbeiterinnen und Mitarbeitern wahrzunehmen, sollte daher der erkennbar protestantische Grundzug in allen diakonischen Aktivitäten sein. $\mathrm{Zu}$ dieser Hochschätzung des Einzelnen fügt sich auch die Pluralität unterschiedlicher Konzeptionen evangelischer Aktivitäten in der Wohlfahrtspflege, deren Nebeneinander keine Gefahr, sondern ein Wesensmerkmal für den Protestantismus darstellt und gleichzeitig eine Öffnung der bisherigen, verbandszentrierten Diakonie hin zu einer stärker zivilgesellschaftlich organisierten christlichen Wohlfahrtspflege fördert. Dies alles könnte dann gerade in seiner Angewiesenheit auf einen im Lichte einer gemeinsamen Grundüberzeugung immer wieder auszuhandelnden

\footnotetext{
${ }_{9}$ Vgl. zu Friedrich Lohmann Renate Zitt: Renate Zitt, Zwischen Innerer Mission und staatlicher Sozialpolitik. Der protestantische Sozialreformer Theodor Lohmann (1831-1905). Eine Studie zum sozialen Protestantismus im 19. Jahrhundert, (VDWI, Bd. 10), Heidelberg 1997.
} 
Kompromiss tatsächlich einen „dritten Weg“ in der Organisationsstruktur der Wohlfahrtspflege bilden. 



\section{Hinweise zu den Autoren}

REINER ANSELM, Prof. Dr. theol., mit Schwerpunkt Ethik am Institut für Systematische Theologie der Theologischen Fakultät der Georg-AugustUniversität Göttingen; Leiter des Master-Weiterbildungsstudiengangs „Führungskompetenz in theologischer Sicht“; seit dem WS 2005 Inhaber einer Forschungsprofessur am Zentrum für Religion, Wirtschaft und Politik der Universität Zürich.

Ausgewählte Veröffentlichungen: Streitfall Biomedizin. Urteilsbildung in christlicher Verantwortung (Hg. zs. mit Ulrich H.J.Körtner), Göttingen 2003; Unerfüllter Kinderwunsch. Leitfaden Reproduktionsmedizin für die Praxis (Hg. zs. mit Carl Schirren und Manfred Balkenohl), Köln 2003; Ethische Konstrukte in diakonischen Institutionen (zs. mit Armin Nassehi), in: Michael Schibilsky und Renate Zitt (Hg.): Theologie und Diakonie, Gütersloh 2004, 169-186.

MANFRED FREYERMUTH, Vorsitzender der Mitarbeitervertretung der Diakonischen Heime e.V. Kästorf; Vorsitzender der Arbeitsgemeinschaft der MitarbeiterInnenvertretungen im Diakonischen Werk Hannover und Mitglied der Arbeitsrechtlichen Kommission der EKD.

PETER FÜNDELING, Oberlandeskirchenrat, Mitglied des Landeskirchenamtes der Evangelisch-lutherischen Landeskirche Hannovers.

UlRiCH HAMmer, Prof. Dr. jur., mit Schwerpunkt auf den Lehrgebieten Verfassungs-, Arbeits- und Sozialrecht, Fakultät für Soziale Arbeit und Gesundheit an der Hochschule für angewandte Wissenschaft und Kunst (HAWK); Mitherausgeber der „Zeitschrift für Tarif-, Arbeits- und Sozialrecht des öffentlichen Dienstes“ (ZTR); Redakteur der Zeitschrift „Arbeitsrecht und Kirche“ (AuK); Stv. Aufsichtsratsvorsitzender der „Diakonische Altenhilfe der Region Hildesheim gGmbH“; Mitglied des Kuratoriums des ev. Altenheims „Am Steinberg“, Hildesheim; Mitglied des Kuratoriums des „Annastift“, Hannover; Mitglied der Gesellschafterversammlung der „Diakonische Dienste Hannover gGmbH“.

Ausgewählte Veröffentlichungen: Kirchliches Arbeitsrecht. Ein Handbuch für die arbeitsrechtliche Praxis der Kirchen und ihrer Einrichtungen. Mit Leitfäden MAVO und MVG für Mitarbeitervertretungen in der Katholischen und der Evangelischen Kirche (Hg. unter Mitarbeit von: Bartels, Germer, Heinrich, Scheibe, Völk und Wisznewski), Frankfurt am Main 2002; Trennung von Staat und Kirche, Grundrechte, Loyalitäts- 
pflichten und ACK-Klausel im Mitarbeiterverhältnis, Arbeitsrecht und Kirche (AuK), 2005, Heft 3, 70-74; Mitarbeitervertretung, Dritter Weg und Tarifautonomie. Zugleich eine Anmerkung zu \8 des MVG-Anwendungsgesetzes der Evangelischen Landeskirche Berlin-Brandenburg-Schlesische Oberlausitz, in: Die Mitarbeitervertretung. Zeitschrift für die Praxis der Mitarbeitervertretung in den Einrichtungen der katholischen und evangelischen Kirche (ZMV) 2005, Heft 6, $284-290$.

JAN HeRMELINK, Prof. Dr. theol., mit Schwerpunkt Homiletik, Liturgik und Kybernetik am Institut für Praktische Theologie der Theologischen Fakultät der Georg-August-Universität Göttingen; Leiter des Master-Weiterbildungsstudiengangs „Führungskompetenz in theologischer Sicht“; Mitglied der Landessynode der Evangelisch-lutherischen Landeskirche; Vorsitzender des Wissenschaftlichen Beirates für die IV. Kirchenmitgliedschaftsuntersuchung der EKD.

Ausgewählte Veröffentlichungen: Organisation der christlichen Freiheit. Beispiele, Tendenzen und Programme gegenwärtiger Kirchenreform; in: ThLZ 128 (2003), Sp. 127-138; Wie hat die Kirche Erfolg? Ökonomische, seelsorgliche, systemische und liturgische Überlegungen; in: WzM 56 (2004), 38-54; Die Vielfalt der Mitgliedschaftsverhältnisse und die prekären Chancen der kirchlichen Organisation. Ein praktisch-theologischer Ausblick; in: W. Huber/J. Friedrich/P. Steinacker (Hg.), Kirche in der Vielfalt der Lebensbezüge. Die vierte EKD-Erhebung über Kirchenmitgliedschaft, Gütersloh 2006, 417-435.

HANS-PETER HOPPE, Pastor der Evangelisch-lutherischen Landeskirche Hannovers und Vorstand der Diakonischen Heime in Kästorf e.V.; Initiator des Kästorfer Management-Symposiums.

HANS-RiCHARD ReuTER, Prof. Dr. theol., Direktor des Instituts für Ethik und angrenzende Sozialwissenschaften der Evangelisch-Theologischen Fakultät der Westfälischen Wilhelms-Universität Münster; Mitglied u.a. der Kammer für Öffentliche Verantwortung der EKD sowie der Ethik-Kommission der Ärztekammer Westfalen-Lippe und der Universität Münster.

Ausgewählte Veröffentlichungen: Rechtsethik in theologischer Perspektive, Gütersloh 1996; Religion und Gesellschaft (Hg. mit K. Gabriel), Paderborn 2004; Das Recht der Religionsgemeinschaften in Mittel-, Ost- und Südosteuropa (Hg. mit W. Lienemann), Baden-Baden 2005.

ReINHARD RiCHARDI, Dr. jur., em. o. Professor für Arbeits- und Sozialrecht, Bürgerliches Recht und Handelsrecht an der Universität Regensburg; 
Präsident des Kirchliches Arbeitsgerichtshofs der Deutschen Bischofskonferenz.

Veröffentlichungen aus letater Zeit: Kommentar zum Betriebsverfassungsgesetz, 10. Aufl. 2005; Staudinger-Kommentar zum BGB, Vorbem. vor \611, SS 611 - 615, Neubearbeitung 2005; Arbeitsrecht in der Kirche, München 4. Aufl. 2003.

GÜNTHER SCHANZ, Prof. Dr. rer. pol., Direktor des Instituts für Unternehmensführung der Georg-August-Universität Göttingen.

Letəte Veröffentlichungen: Das individualisierte Unternehmen. Neurobiologische Grundlagen - Konzeptionelle Merkmale - Gestaltungs- und Handlungsfelder, München und Mering 2004; Implizites Wissen. Phänomen und Erfolgsfaktor - Neurobiologische und soziokulturelle Grundlagen Möglichkeiten problembewussten Gestaltens, München und Mering 2006.

STEPHAN SCHLEISSING, Wissenschaftlicher Mitarbeiter am Lehrstuhl für Ethik an der Theologischen Fakultät der Georg-August-Universität Göttingen und wissenschaftlicher Koordinator des Master-Weiterbildungsstudiengangs „Führungskompetenz in theologischer Sicht“; abgeschlossene Dissertation zum Thema „Keine Zeit für den Fortschritt? Geschichtsphilosophie und eschatologisches Denken in der ,technischen Zivilisation “.

Letəte Veröffentlichung: Wahrhaftigkeit und Geschichte. Zum Verhältnis von Ethik und Fortschritt in der Kulturphilosophie Albert Schweitzers, in: Martin Bröking-Bortfeldt/Martin Rothgangel (Hg.): Glaube und Denken (Jahrbuch der Karl-Heim-Gesellschaft, Bd. 17) Frankfurt a. M. u.a. 2004, 215-240.

LOTHAR STEMPIN, Dr. theol., Direktor des Diakonischen Werkes der Ev.-luth. Landeskirche in Braunschweig e. V.; Mitglied des Diakonischen Rates der EKD.

Ausgewäblte Veröffentlichungen: Kooperation und das ekklesiologische Modell - Schritte zu einem Perspektivwechsel im Kirchenverständnis, Hannover 1996; Ordnung als Prozess, Gütersloh 1998; (Hg. von der VELKD, zus. mit Manfred Kießig, Horst Echternach, Hartmut Jetter, unter Mitarbeit von Gerhart Herold): Evangelischer Erwachsenenkatechismus, Gütersloh 2001.

KLaus Tanner, Prof. Dr. theol., mit Schwerpunkt Ethik und Geschichte des neuzeitlichen Protestantismus am Institut für Systematische Theologie der Martin-Luther-Universität Halle-Wittenberg; Direktoriumsmitglied des Interdisziplinären Zentrums Medizin-Ethik-Recht an der Martin-LutherUniversität Halle-Wittenberg; Mitglied der Kammer für Öffentliche 
Verantwortung der EKD; Mitglied der Zentralen Ethikkommission für Stammzellforschung.

Ausgewählte Veröffentlichungen: „Liebe“ im Wandel der Zeiten. Kulturwissenschaftliche Perspektiven (Hg.), Leipzig 2005; Die Macht des Unverfügbaren. Charisma als Gnadengabe in der Thematisierung von Institutionalisierungsprozessen im Christentum, in: Charisma und religiöse Gemeinschaften im Mittelalter. Akten des 3. Internationalen Kongresses des Italienisch-deutschen Zentrums für vergleichende Ordensgeschichte, Hg. von Giancarlo Andenna u.a., Münster 2005, 25-44; Gotteshilfe - Selbsthilfe - Staatshilfe - Bruderhilfe. Beiträge zum sozialen Protestantismus im 19. Jahrhundert (Herbergen der Christenheit; Sonderband 4.) (Hg.), Leipzig 2000 . 